Technical Notes for the Conceptual Design for an Atmospheric Fluidized-Bed Direct Combustion Power Generating Plant

Volume 4

April 1978

Prepared For

U.S. Department of Energy

Assistant Secretary for Energy Technology

Division of Power Systems

Under Contract No. EF-77-C-01-2583 


\section{DISCLAIMER}

This report was prepared as an account of work sponsored by an agency of the United States Government. Neither the United States Government nor any agency Thereof, nor any of their employees, makes any warranty, express or implied, or assumes any legal liability or responsibility for the accuracy, completeness, or usefulness of any information, apparatus, product, or process disclosed, or represents that its use would not infringe privately owned rights. Reference herein to any specific commercial product, process, or service by trade name, trademark, manufacturer, or otherwise does not necessarily constitute or imply its endorsement, recommendation, or favoring by the United States Government or any agency thereof. The views and opinions of authors expressed herein do not necessarily state or reflect those of the United States Government or any agency thereof. 


\section{DISCLAIMER}

Portions of this document may be illegible in electronic image products. Images are produced from the best available original document. 


\title{
Technical Notes for the Conceptual Design for an Atmospheric Fluidized-Bed Direct Combustion Power Generating Plant
}

\author{
Volume 4
}

\section{April 1978}

Prepared By

Stone \& Webster Engineering Corporation

For

\section{U.S. Department of Energy}

Assistant Secretary for Energy Technology

Division of Power Systems

Washington, DC 20545

Under Contract No. EF-77-C-01-2583

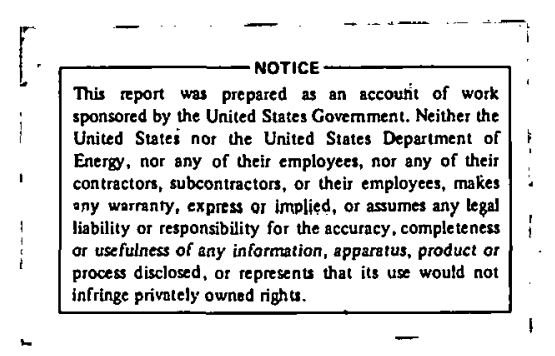




\section{NOTICE}

This report was prepared as an account of work sponsored by the United States Government. Neither the United States nor the United States Department of Energy, nor any of their employees, makes any warranty, express or implied, or assumes any legal liability or responsibility for the accuracy, completeness, or usefulness of any information, apparatus, product, or process disclosed, or represents that its use would not infringe privately owned rights. Reference herein to any spccific commercial product, jrucess, or servlce by trade name, mark, manufacturer, or otherwise, does not necessarily constitute or imply its endorsement, recommendation, or favoring by the United States Government or any agency thereof. The views and opinions of authors expressed herein do not necessarily state or reflect those of the United States Government or any agency thereof. 
TECHNICAL NOTES FOR THE

CONCEPTUAL DESIGN FOR AN ATMOSPHERIC FLUIDIZED-BED

DIRECT COMBUSTION POWER GENERATING PLANT

SUMMARY TABLE OF CONTENTS

Volume 1

Part I - 570 Mwe Base Plant Definition and General

Design Criteria

Part II - AFB state of the Art

Volume 2

Part IIIA- 570 Mwe AFB Plant Definition, Babcock

\& Wilcox Design

Volume 3

Part IIIB- 570 Mwe AFB Plant Definition, Foster Wheeler Design

Volume 4

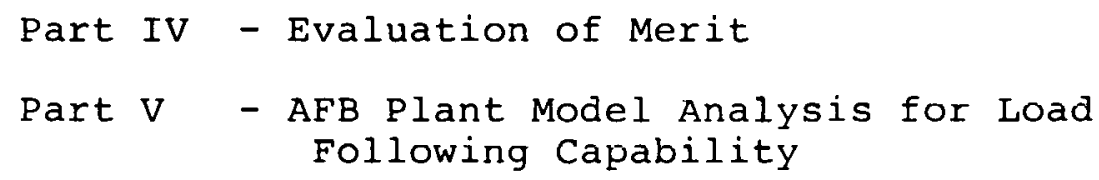




\author{
PART IVA \\ EVALUATION OF MERIT \\ ATMOSPHERIC FLUIDIZED BED BOILER \\ VS. \\ PULVERIZED COAL FIRFD BOILER \\ WITH WLT LIMESTONE FLUE GAS \\ DESULFUR I ZATION
}




\section{objective}

This portion of the report is intended to present a comparison of the conceptual designs of a large (570 MWe) pulverized coal (PC) steam generator equipped with a wet limestone flue gas desulfurization (FGD) system and two equivalent sized atmospheric fluidized bed (AFB) steam generators including balance of plants for electric-power generation. The reader is cautioned that this portion of the report compares a zero generation AFB technology to pulverized coal technology which has been operationally and economically optimized for the past half-century. This comparison is intended to be indicative of whether further development of the AFB concept as a viable alternative to the PC/FGD concept for electric-power generation is merited.

The base plant for this comparison is a 570 MWe PC steam power generating unit. The facility, an even numbered unit extension at an existing site, will be built utilizing a pulverized coal boiler with a wet limestone FGD system. Because the unit is an even numbered extension at an existing site, certain services (such as makeup water demineralizer, auxiliary steam, etc.l are not included, as these systems have been provided with the previous odd numbered unit.

Conceptual designs of two AFB steam generators of equivalent boiler rating to the base plant were developed by Babcock $\&$ Wilcox (B\&W) and the Foster Wheeler Energy Corporation (FWEC) - Conceptual designs of the balance of plants for the three boilers for the generation of electricpower were developed by Stone $\&$ Webster Engineering Corporation (S\&W). As in the base plant, these units are an even numbered extension to an existing site, and certain services (such as makeup water demineralizer, auxiliary steam, etc.) are not included since these have been provided with the previvus idd numbered unit.

\section{Process}

Unlike a conventional pulverized coal fired plant, the AFB fires crushed coal, either -1 in. for FWEC, or $-1 / 4$ in. for BEW. The coal is burned in a bed of limestone which calcines and reacts with sulfur dioxide to form calcium sulfate. Bed material is withdrawn and disposed in a dry state. Some of the solid particles, including unburned coal, elutriate from the bed. The carbon fraction, which is usually the coarser fraction, is collected and returned to the carbon burnup cell or bed. This method of combustion is less efficient than PC firing as represented by boiler efficiencies which range from 85.8 percent for $B \& W$ to 86.4 percent for FWEC vs 87.9 percent for the conventional 
plant. However, it must be understood, these are estimated efficiencies and should not be considered the ultimate achievable boiler efficiency when the technology matures. Several design factors such as limestone calcination and utilization. optimum bed height. optimum superficial gas velocity, and combustion efficiency are important factors which affect boiler efficiency and have yet to be fully confirmed. In addition, the lower boiler efficiency for AFB is mitigated by eliminating the FGD system with the corresponding reduction in auxiliary power and steam requirements.

\section{Layout}

Based on the conceptual designs and arrangements for the conventional plant and those of FWEC and BEW, the PC plant requires less overall plant area. The primary reasons are larger space requirements for material storage and handling. a complex coal feed system, and a complex ash handling system required to collect the higher quantity of fly ash and bed material as well as collection and reinjection of unburned carbon.

\section{Capital Cost}

Itemized plant capital cost breakdown for the base plant and two AFB designs are presented in Parts $I$ and III of this report, respectivcly. Table IVA-1 presents a comparison of the total plant capital cost for the three steam generators including balance of plants for electric-power generation. These figures indicate that the total plant capital cost for the FWEC AFB design is approximately 10 percent less than the base plant, and the $B \& W$ AFB design is approximately 10 percent greater than the base plant. Table IVA-2 presents a comparison of capital costs in $\$ / k w$ for the three plants. The following are areas of major cost differences which are responsible for the differences in total plant capltal cost based on Table IVA-2:

1. The main powerhouse cost for the FWEC unit is approximately 20 percent less than the base plant because of its overall smaller size. The B\&W main powerhouse cost is approximately 17 percent more expensive than FWEC due primarily to the external Carbon Burnup Bed (CBB) vs integral Carbon Burnup Cell (CBC) of FWEC.

2. The boiler equipment cust for the base plant and the FWEC design are similar while the $B \& W$ boiler equipment cost is approximately 56 percent greater than both. This is due to (1) the external CBB design, (2) convection reheat surface vs in-bed 
TABLE: IVA-1

TOTAL PIANT CAPITAL COSTS COMPARISON

APRIL 1982

Base

Total Mat'1. $\$$

Total Iabor. \$

Grand Total. \&

Total Manhours

Net Generation, MWe

$\$ / \mathrm{Kv}$ (Net)
$175,517,000 \quad 136,986,000$

$123,695,000 \quad 134,537,000$

299.212 .000

$321.528,000$

$3,490,000$

$3,542,000$

554

541

569

526
580.6

498
FWEC

$159,595,000$

$109,858,000$

$269,453,000$

$3,042,000$

580.6 
TABIEE IVA - 2

CAPITAL COST COMPARISON

(All figures in $\$ / \mathrm{Nw}$ )

Base $\quad \underline{F E C} \quad \underline{B E W}$

1. Land and Land Rights

2. Yardwork

0.5

0.5

0.5

3. Main Power House

32.9

26.2

30.6

4. Administration Building

5. Miscellaneous Buildings

6. Boiler Equipment (Vendor)

69.3

62.9

108.2

7a. Balance of boiler plant

38

39.8

36.1

7b. Ash Handling

21.2

20.7

8. Fuel Handling and Storage

8.3

15.7

11.6

9. Stack

$3 \cdot y$

3.8

10. Precipitator

17.2

25.4

11. Flue Gas Desulfurizatior.

15.0

0

0

12. Turbinte Generator

37.4

36.6

35.8

13. Balance of Turbine Plant

5.9

5.8

5.8

14. Conditioning and Circulating Water System

14.9

14.8

14.5

15. Water Treatment

0.9

0.9

0.9

16. Waste Treatment

7.4

0

0

17. Accessory EJectrical

22.3

25.2

$25 \cdot 1$

18. Miscellaneous Power Plant Equipment

0.7

0.7

0.7

19. Main Transformers

2.5

2.5

2.4

20. Transmission Lines

Total

$\frac{-}{316.8} \quad \frac{-}{273.0} \quad \frac{-}{326.7}$ 
reheat surface as FWEC design. In-bed reheat surface has a greater heat transfer coefficient. thus requiring less surface area.

3. The ash handling systems for the AFB boilers are approximately 150 percent more expensive than the base plant. This is due primarily to (1) greater solid waste quantities being handled by the ash handling system (2) the AFB ash must be cooled from $1550 \mathrm{deg} F$ to approximately $250 \mathrm{deg} F$ before conveying (3) the AFB ash conveying medium is air, which results in more expensive and sophisticated equipment than the base plant system whose ash conveying medium is water.

4. The fuel handling and storage cost for the AFB designs are more expensive than the base plant. The primary reasons are larger storage requirements and more complex feed systems. The BEW design conveys coal $(-1 / 4$ in.) and limestone together pneumatically to $1: 40$ distributors in the beds. The FWEC design conveys the coal (-1 in.) to the bed via spreader stokers and feeds the limestone by gravity to the beds. The base plant feeds pulverized coal to the boiler pneumatically.

5. The particulate collection system for the base plant consists of an electrostatic precipitator (ESP) - The FWEC system consists of a mechanical collector for carbon-collection and reinjection and a baghouse for particulate collection. This system is comparable in cost to the base plant system. The BEW system utilizes two ESPs, one for carbon collection and reinjection and one for particulate collection. This system is approximately 70 percent more expensive than either the basc plant or FWEC. If the BEW design were to employ mechanical collectors and a baghouse instead of the two ESPs, there would be a $\$ 5$ million savings which would result in a BEW particulate collection system similar in cost to the FWEC and base plant.

6. An FGD system is required for the base plant to satisfy the present Federal EPA New Source Performance standards (NSPS.) The AFB designs do not require an FGD system to satisfy these standards and therefore a $\$ 28.1$ million savings is associated with the AFB units.

7. The base plant requires a waste treatment system for the stabilization and disposal of the scrubber sludge. This system is not required by the $\bar{A} \vec{B}$ 
design and is therefore a $\$ 3.9$ million savings for the APB units.

If it is assumed that there is a 20 percent savings associated with the BEW design employing an integral CBB, in-bed reheat surface, and a baghouse particulate collection system, the BEW capital cost would be comparable to the FWEC design and approximately 10 percent less than the base plant.

\section{operating Costs}

A comparison of the operating costs for the three units is presented on Table IVA-3. These figures include an arbitrary 10 percent increase in AFB power plant operating and maintenance cost to compensate for any uncertainties that may be unaccounted for. These figures indicate that the FWEC operating costs are approximately $2.5 \mathrm{mils} / \mathrm{kw}-\mathrm{hr}$ less than the base plant. The primary reasons for this are: (1) a much lower capital recovery charge resulting from a lower capital investment (2) greater net generation for the FWEC design, 541 Me vs 526 MNe for the base plant. The BEW boiler operating costs are approximately $0.6 \mathrm{mils} / \mathrm{kw}-\mathrm{hr}$ greater than base plant due to the higher capital recovery charge associated with the higher capital investment. As discussed previously in the "capital cost" section, if an integral $\mathrm{CBB}$ were employed along with in-bed reheat surface and $a$ baghouse for the $B \& W$ design, the capital recovery charge for the BEW unit would be reduced by approximately $3.2 \mathrm{mils} / \mathrm{kw}-\mathrm{hr}$. This would result in an operating cost of $36.41 \mathrm{mils} / \mathrm{kw}-\mathrm{hr}$ which is comparable to the FWEC design.

Since the base plant is designed to comply with present EPA New Source Performance Standards (NSPS). the scrubber can be bypassed when down and therefore not affect the boiler operation. Therefore, the 95 percent availability of the FGD system is not detrimental to the operating cost of the base plant. Proposed Federal EPA NSPS for SO2 will prohibit the bypassing of an FGD system except for start-up and shutdown procedurres. This would require a highly available FGD system to satisfactorily operate the plant economically. Based on past industry experiences with FGD systems; numerous operating problems and shutdowns have been experienced. Based on proposed EPA NSPS, these FGD system shutdowns would result in forced boiler shutdowns and consequently decrease the plant capacity factor and increase the plant operating cost. Figure IVA-1 shows the effect. of the operating cost of the base plant with decreasing scrubber availability. Literature indicates that FGD systems to date have operated between 70 and 90 percent availability with the majority within the 80 's. FGD systems have been operated at 95 percent reliability for extended 


\section{TABLE IVA - 3}

\section{OPERATING COST COMPARISON}

(All figures in mills/kw-hr)

\begin{tabular}{|c|c|c|c|}
\hline & Base & BEN & FWEC \\
\hline Capital Recovery (Fixed. Charges) & 15.64 & 15.96 & 13.69 \\
\hline Fuel cost & 17.90 & 17.76 & 18.07 \\
\hline Iimestone Cost & 0.89 & 2.18 & 1.84 \\
\hline \multicolumn{4}{|l|}{ Operation and Maintenance } \\
\hline - Power Generating Plant & 3.14 & $3.28 *$ & $3.36 *$ \\
\hline - FGD Plant & 0.61 & 0 & 0 \\
\hline - sludge stabilization Plant & 0.29 & $\mathbf{0}$ & 0 \\
\hline - Ash \& Sorbent Disposal & 0.16 & 0.11 & 0.10 \\
\hline $\begin{array}{l}\text { - Particulate Emission } \\
\text { Control Equipment }\end{array}$ & $\frac{0.34}{38.97}$ & $\frac{0.32}{39.61}$ & $\frac{0.33}{37.39}$ \\
\hline
\end{tabular}

*Including Arbitrary 10 percent increase in Power Plant O\&M 
lengths of time, but this is a result of numerous operating personnel (approximately 50) and spare scrubbing capacity. Each evening one or more modules must be taken out of service for a complete cleaning to avoid possible pluggage and caking and consequential forced downtime.

Since the proposed EPA NSPS for SO2 prohibit a plant to operate unless the FGD system is available, the effects, of the availability of the scrubber on operating costs, as shown on Figure IVA-1, are significant. Assuming optimistically that a 95 percent scrubber availability can be maintained without numerous experienced personnel for the FGD system, the corrected operating cost for the base plant would be approximately $41 \mathrm{mils} / \mathrm{kw}-\mathrm{hr}$. This figure represents 5 percent forced boiler downtime due to a down FGD system.

Aoourate availability of 502 removal for the AFB designs would require parametric analysis which is not in the scope of work at this time. For purposes of this study, the $\mathrm{SO} 2$ removal availability for the AFB designs is assumed to be equivalent to that of the boiler itself and therefore would not affect the operating costs.

Some operating parameters which may be optimized to decrease the operating costs by improving boiler efficiency are lower superficial gas velocity and deeper beds. Optimization of these two parameters would result in higher combustion efficiencies and lower calcium to sulfur molar ratios and consequently lowering the operating costs for the AFB units.

\section{Environmental Considerations}

The air quality impact associated with the AFB plant is anticipated to be less than the base plant due to the higher exit temperature of the AFB plant stack gases. The higher temperature of the stack gases from the AFB plant would have greater atmospheric dispersion capability and will consequently result in lesser impact to the surrounding environment. The following sections indicate the major emissions associated with the operation of the three units.

\section{Sulfur Dioxide (SO2) Emissions}

Present Federal EPA NSPS emission limitation for 502 is 1.2 lb SO2 per MM Btu heat input. Sulfur dioxide emissions in a conventional PC plant are reduced to Federal emission levels by use of a wet limestone scrubber. In an AFB plant. sulfur dioxide emissions are controlled to required levels without requiring an FGD system by use of sulfur dioxide sorbent such as limestone as bed material. Both the PC plant and the AFB plants were designed to comply with 
present EPA NSPS for SO2. The PC plant is designed to capture sulfur dioxide with a limestone stoichiometry of approximately. 1.2 (i.e.. 20 percent excess limestone.) The $A F B$ plant design requires a limestone stoichiometry in the order of 2.1 to 2.5 . The low calcium utilization is due to (1) elutriation of limestone fines from the bed prior to sulfation and (2) the formation of a barrier of calcium sulfate on the calcined limestone particle thus preventing further reaction between the limestone and sulfur dioxide. The promulgation of the Clean Air Act Amendments of 1977, in August, 1977, requires that the existing NSPS emission limitation for SO2 be revised within one year (August, 1978.) These revisions will includo: (1) a required percentarge reduction in sulfur dioxide emissions (2) a revised weight emission limitation. It is anticipated that in February, 1978 the revised NSPS SO2 will he proposed based on data from DOE. The revised NSPS will require a 90 percent reduction in 502 emissions with a maximum emission limitation of $1.2 \mathrm{lb}$ per million Btu and a minimum of $0.2 \mathrm{lb}$ SO2 per million Btu. Also, the new standards would prohibit the bypassing of the FGD system other than for start-up and shutdown procedures. This would therefore require an FGD system of high availability to satisfactorily operate the plant economically without forced outages due to FGD system downtime. It is anticipated that both the PC plant with a wet 1 imestone scrubber and an AFB plant can be designed to comply with these revised NSPS for SO2. The PC plant can achieve a 90 percent 502 reduction with an increase in FGD system capacity along with an operating staff of approximately 50 personnel to maintain the FGD system at an economically satisfactory availability of 95 percent. The AFB plant can achieve a 90 percent reduction in 502 emissions with the present plant designs by increasing the calcium to sulfur molar ratio to increase so2 capture. other factors which affect 502 capture include depth of bed and superficial gas velocity, both directly related to residence time of the gas in the bed of limestone. These factors would be used to optimize the AFB boiler to assure 502 emiogions which ace in compliance with the revised NSPS while minimizing limestone consumption. The SO2 capture availability for the AFB boilers is assuned to be that of the boiler itself.

\section{Total Suspended Particulate Emissions}

Present federal EPA NSPS emission limitation for ISP is 0.1 lb TSP per million Btu heat input. TSP emissions from both the PC plant and the AFB plant are reduced to comply with federal emission levels by use of either electrostatic precipitator (ESP) or a baghouse. Both the PC plant and the AFB plant were designed to comply with present Federal EPA NSPS for TSP. Based on data from DOE, the proposed NSPS for 


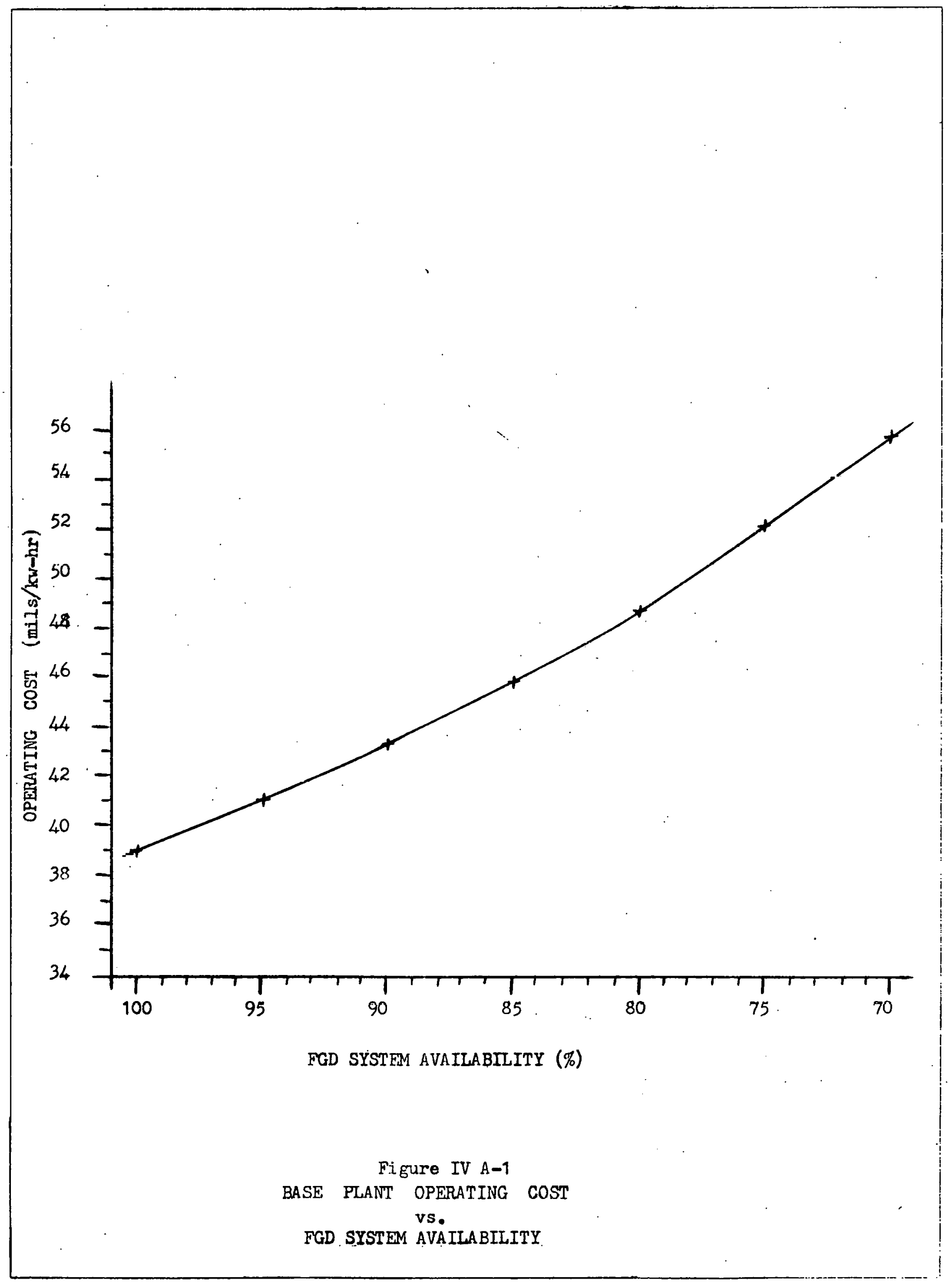


TSP will require a 99 percent reduction in TSP emissions with a maximum emission limitation of $0.03 \mathrm{lb}$ TSP per million Btu. It is anticipated that both the PC plant and AFB plant can be designed to achieve these revised NSPS with TSP with either an ESP or a baghouse. Recent enactment of the Clean Air Act Amendments of 1977 calls for a "trade-off" of air pollution caused by existing sources with the new source in nonattainment areas. This trade-off policy requires a greater than 1 to 1 trade-off of air pollution whose ultimate effect is a reduction in the quantity of pollutant in question. To minimize the economic penalties associated with a trade-off of this kind, it is essential that the new source emit the smallest possible amount of pollutant, therefore minimizing the amount of trade-off required.

For the PC plant with wet limestone scrubber, the ESP can reduce the grain loading of TSP in the flue gas to the ranqe of .007 to .01 grains per $A C F$. The wet limestone scrubber liquor contains 10-15 solids. These solids may be entrained in the flue gas as it passes through the scrubber and possibly. not removed in the mist eliminators. Therefore, the flue gas grain . loading exiting the scrubber could be greater than the inlet grain loading. If this is the case, the scrubber on a PC plant could be the controlling factor with the TSP emissions and not the particulate collection system.

For the. AFB plant with either an ESP or baghouse the TSP outlet grain loading of the flue gas could be significantly below the PC plant with a wet limestone scrubber. Outlet grain loadings of 0.003 grains per ACF can be achieved with a baghouse and consequently emitted from the stack of an AFB plant without possibility of solid reentrainment. From an air pollution viewpoint, the AFB plant has greater potential lor plant siting that the PC plant due to the inherent ability to reduce the TSP emissions lower than the pr plant.

Nitrous Oxide (NOx) Emissions

NOx emissions from the PC plant and AFB plant will comply with present Federal EPA NSPS for NOx of 0.7 ib NOx per million Btu heat input. Predicten NOx emissions from the PC plant are $0.7 \mathrm{lb}$ NOx per million Btu. The AFB plant predicts emissions of NOx in the range of $0.3-0.51 \mathrm{~b}$ NOx per million Btu. Revised NSPS will be promulgated by August, 1978. Based on data from DOE, these revised NSPS for NOx will be $0.6 \mathrm{lb}$ NOx per million Btu. The AFB plant emissions will comply with these revised standards with no modifications. The PC plant will require additional combustion modifications to comply with these revised standards such as staged firing, gas recirculation, or 
modified burner designs, and may consequently require a greater capital investment cost.

\section{Solid Waste}

The major solid waste from the conventional plant consists of FGD sludge, fly ash, and bottom ash. Similarly, for the AFB plant, bed takeoff material and dust collector material represents the major wastes. The most significant difference in the conventional plant waste are largely in a slurry form whereas the AFB plant waste is dry. The PC plant waste will be combined and stabilized and sequentially landfilled. These wastes represent approximately 100,000 lb per hr of dry solids; however, when stabilized, they have approximately 50 percent moisture; thus the waste represents $200,000 \mathrm{ib}$ per $\mathrm{hr}$. The AFB plant solid waste will represent approximately 140,000 $\mathrm{lb}$ per hr of dry solids. Assuming water infiltration is minimized in the landfill operation, the overall disposal area for the solid waste should be somewhat less. Based on results of studies conducted under DOE and EPA contracts, land disposal of solid wastes generated from an AFB boiler will not have adverse environmental effects. In fact, studies have shown the material to be both structurally stable and durable for landfilling. Results of leaching tests have also found the materials feasible for landfilling. In addition, several organizations are actively engaged in developing uses for AFB solid waste in both agricultural and commercial applications which may ultimately decrease waste disposal costs substantially. 


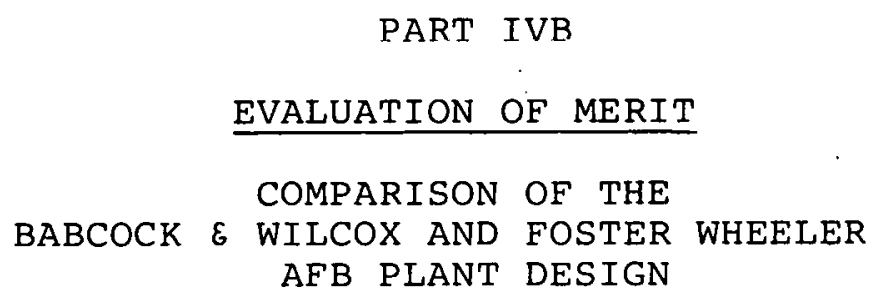


TABLE OF CONTELTS

Page

1.0 objective

IVB-1

2.0 Conclusions. IVB-1

2.1 General

2.2 Technical Feasibility

2.3 Capital and Operating Costs. IVB-1

2.4 Environmental Considerations IVB-1

2.5 Demonstration Plant Recommendations IVB-1

2.6 Features Requiring Additional Development IVB-1

2.7 Boiler Manufacturers * Final Reports $\quad$ IVB-2

2.7.1 Babcock \& Wilcox Final Report - Appendix IIIA-C IVB-2

2.7.1.1 Comments IVB-2

2.7.1.2 Errata $\quad$ IVB-2

2.7.1.3 Revisions IVB-2

2.7.2 Foster Wheeler Final Report - Appendix IIIB-C IVB-2

2.7.2.1 Comments IVB-2

2.7.2.2 Errata $\quad$ IVB-2

2.7.2.3 Revisions IVB-3

3.0 Design Peature Analysis and Comparison IVB-3

3.1 Boiler Design Features $\quad$ IVB-3

3.1.1 Conclusions IVB-3

3.1.2 Once-Through Vs Assisted Circulation IVB-4

3.1.3 Stoker Feed Vs Pneumatic Feed IVB-5

3.1.4 Stacked Vs Condominium Design IVB-6

3.1.5 Superficial Velocity. IVB-6

3.1.6 Grid Pressure Drop $\quad$ IVB-7

3.1.7 Metallurgy

3.1.8 Structural Inteyilíy

3.1.9 Finishing Reheater Surface Location * * IVB-7

3.1.10 Carbon Burn-up Cell Location IVB-8

3.1.11 Economizer Surface $\quad \cdot \quad \cdot \quad$ IVB-8

$\begin{array}{ll}3.2 \text { Coal and Limestone Systems } & \text { IVB-8 }\end{array}$

3.2.1 Coal and Limestone Preparation, Delivery.
and Storage IVB-8

3.2.2 Coal and Limestone Distrimition and Injection IVB-9

3.3 Bed Material Letdown Collection and Disposal
System

3.3.1 Bed Material Letdown Cooler IVB-11

3.3.2 Bed Material Transport to Disposal IVB-12 
Page

3.4 Carbon Ash Collection and Reinjection System

IVB-12

3.5 Fly Ash Collection. Transport, and Disposal

IVB-12

3.6 Combustion Air and Flue Gas Systems

IVB-13

3.6.1 Forced Draft and Induced Draft Fans

IVB- 13

3.6.2 Baghouse Vs Electrostatic Precipitators

IVB-13

3.7 Condensate Polishing System

IVB-14

3.8 Main Steam, Hot and Cold Reheat Turbine Bypass System

3.9 Turbine Generator Design Impact

IVB-14

IVB-15

4.0 Performance Analyses and Comparisons.

IVB-16

4. Boiler Efficiency

IVB-16

4.2 Cycle Impact

4.3 Effect of High Freeboard on Gas-Solid Reactions

IVB-17

IVB-19

4.3.1 Combustion Efficiency

IVB-19

4.3.2 Nitrogen Oxide Production

IVB-20

5.0 Economic Analyses and Comparisons

IVB-23

5.1 Capital Costs

IVB-23

5.1.1. Bases and Assumptions

IVB-23

5.1.2 Boiler and Related Equipment

IVB -23

5.1.3 Balance of Plant

5.1.4 Allowance for Indeterminants

5.1.5 Escalation

5.1.6 Allowance for Funds Used During Construction

IVB -23

IVB-24

IVB-24

IVB-24

5.2 Operating Costs

IVB-24

5.2.1 Bases

5.2.2 Capital Recovery

5.2.3 Fuel Cnsts

5.2.4 Iimestone Costs

5.2.5 Operation and Maintenance Costs

IVB-24

IVB-24

IVD-25

IVB-25

IVB-26

6.U Control systems Analyses and Comparisons

IVB-25

6.1 Introduction

IVB-25

6.2 Boilex Load Control Parameters

IVB-26

6.2.1 Coal Feed

IVB-26

6.2 .2

Bed Temperature

IVB-27

6.2.3 Bed Level

IVB-27

6.2 .4 Bed Slumping

IVB-28 
8.1.1 Sulfur Dioxide Emissions

8.1.2 Oxides of Nitrogen (NOX) Emissions

IVB -34

8.1.3 Total Suspended Particulate (TSP) Emissions

IVB -35

IVB-35

8.2 Solid Wastes

IVB-36

8.3 Conclusions

IVB-36

9.0 Construction Schedule

IVB-37

10.0 Other Analyses and Comparisons

IVB-37 
LIST OF TABLES

Table

IVB-1

IVB-2

IVB-3

IVB-4

IVB-5

IVB-6

IVB-7

\section{Description}

Plant Performance Adjustments

Running Auxiliary Power Comparisons and Adjustments

Comparison and Adjustment of Plant Costs

Boiler Heat Ioss Comparison and Adjustment

Plant Cost Change Comparison

Adjustments to Plant Material Balances, IPH

Adjusted Annual Operating Costs 


\section{IIST OF FIGURES}

Fiqure

Description

4.3 .1

Coal Residence Time

4.3 .2

Nitrogen Oxides in Flue Gas of FBM 


\subsection{OBJECTIVE}

The objective of this part (Part IVB) of the Report is to analyze and compare the boiler and plant designs associated with the Foster Wheeler and Babcock \& wilcox AFB boiler described in Parts IIIB and IIIA of this Report. This document represents a portion of an overall report describing the conceptual designs of two atmospheric fluidized bed boilers and balance of plants for the generation of electric power and the analysis and comparison of these conceptual designs to a conventional pulverized coalfired electric power generation plant equipped with a wet limestone flue gas desulfurization system. Conclusions regarding the various aspects of this effort are presented in this part or Part $V$ of this Report.

\subsection{CONCLUSIONS}

\subsection{General}

After review of the Foster Wheeler (once-through) and the Babcock \& Wilcox (drum type) AFB boiler designs, we conclude that both are viable. It must be remembered that both designs represent zero-generation requiring optimization.

\subsection{Technical Feasibility}

The Foster Wheeler and Babcock 8 wilcox AFB designs are technically feasible, but design optimization is required.

\subsection{Capital and Operating Costs}

The lifetime capital and operating costs for both boilers are essentially comparable.

\subsection{Environmental Considerations}

Both the FWEC and BEW boiler designs reflect compliance with present federal EPA New Source Performance Standards (NSPS) emission limitations for the following:

$$
\begin{aligned}
& \text { 1. } 1.2 \text { 1b SO2 per million Btu } \\
& \text { 2. } 0.7 \text { 1b NOX per million Btu } \\
& \text { 3. } \quad 0.1 \text { 1b TSP per million Btu }
\end{aligned}
$$

\subsection{Demonstration Plant Recommendations}

Review of both boiler designs reveals that both designs should be considered for future demonstration considerations.

\subsection{Peatures Requiring Additional Development}

Review of each boiler design reveals the following areas that need further development: 
1. Superficial Velocity

2. Coal and Iimestone Feed Systems

3. Bed Letdown Cooling/Unburned Combustibles

4. Calcium Utilization

5. Fluid Bed Combustion Controllability

\subsection{Boiler Manufacturers ' Final Reports}

\subsubsection{Babcock \& Wilcox Final Report}

\subsubsection{Comments}

Refer to Radian Corporation letter of January 9, 1978 to Mr. E. C. Trexler of the Department of Energy.

\subsubsection{Errata}

1. Page 1-13. The Solids flow for streams 13 and 14 should read the same as on stream 12 .

2. Pages 6-22 through 6-25. Blowing medium should be air.

3. Pages 6-31 through 6-33, line 15. 077 should read 092.* Pages 6-31 through 6-33, line 16. $1107^{\text {" }}$ should read 122." Pages 4-10 and 4-13, stream 21. $200^{\prime \prime}$ should read $215 . "$

4. Pages 6-39, Iine 4, Natural" should read Massisted."

\subsubsection{Revisions}

There will be no futher revisions made to the Babcock 6 wilcox Report.

\subsubsection{Foster Wheeler Final keport}

\subsubsection{Comments}

See Radian Corporation letter of December 21, 1978, to Mr. E. C. Trexler of the Department of Energy.

\subsubsection{Errata}

1. Page 4 4, line 8, -Seven (7)" should read "Eight (8)

2. Page 4-4, line 3, The word "Gass should read "Gas"

3. Page 5-26. The last sentence, This limestone feed only when the outer segments are nonoperational* should be eliminated.

4. Page 5-38, Figure 5.9. Reference is made on Figure 5.9 to a Figure 5.10 which is not included. 


\subsubsection{Revisions}

There will be no further revisions made to the Foster Wheeler Report.

\subsection{DESIGN FEATURE ANALYSIS AND COMPARISON}

\subsection{Boiler Design Features}

Objective of this section is to assess significant design features of the FWEC and BEW AFB boiler designs. This assessment considers the viability of the design feature and the need for additional testing.

\subsubsection{Conclusions}

\section{General}

The intent of this section is to draw conclusions regarding the design features of the AFB as that design feature impacls the remainder of the plant.

We conclude that the BEW and FWEC AFB offered represents, in general terms, a credible zero-generation definition of a commercial-sized AFB.

In addition, the following general conclusions are drawn regarding the design features of the AFB boilers offered:

1. The coal/limestone distribution and injection system of either manufacturer requires testing:

2. A bed letdown cooler which permits recovering the bed material specific heat is warranted.

\section{Foster Wheeler}

We offer the following conclusions regarding the FWEC AFB boiler design:

1. The ability of the front and rear wall of the beds to transfer their share of the boiler weight to the overhead grid structure has been discussed with FWEC. FWEC was requested to perform a stress analysis on the front and rear wall panels, and it was determined that the existing panels could support the weight of the steam generator, bed material, and fluid but could not support this weight in combination with the maximum upset furnace pressure. The stress within the tubes can be reduced to an acceptable level by increasing the tube diameter to 1.875 in. (1.75 in.) with a wall thickness of $0.262 \mathrm{in}$. $(0.2)$. This would maintain existing tube inside diameter thus not affecting critical pressure 
drop. For the prupose of the study, these changes have a negligible cost increase to the boiler.

2. The once-through design for future commerical plants is not only viable but also probable in a supercritical configuration.

3. While the stoker significantly reduces the complexity of the injection system by reducing the bed area per feed point, testing is required to establish the freeboard combustion, carbon elutriation and sulfur capture associated with this feed method. In addition, FWEC extensions to existing plants will suffer a high ( $\$ / \mathrm{kw}$ ) penalty for an extensive coal handling system addition due to the height of the coal silos required to achieve gravity feed.

\section{Babcock \& Wilcox}

We offer the following general conclusions regarding the BEW AFB boiler design:

1. BEW should take advantage of the high in-bed heat transfer coefficient in the reheater design. The modifications to the turbine bypass system and the SEW imposed boiler trip reheater cooling systems would, in our judgement be minor as compared to the reduction in reheat surface.

2. BEW should make an effort to incorporate the CBC integral with the boiler. The main powerhouse penalty for the external location $(\$ / k w)$ would appear to justify this modification.

3. Feed system and distribution testing is required to prove the concept.

\subsubsection{Once-Through Vs Assisted Circulation}

Both boiler manufacturers were instructed to design an AFB boiler to supply the base plant $2400 / 1000 / 1000$ turbine.

Foster Wheeler chose to design a once-through boiler on the basis that while heat rate oredit associated with supercritical once= through boilers would not be accrued, in their opinion oncethrough design was more representative of the future commercialized AFB market. In addition, FWEC concluded that by undertaking a once-through design over an assisted natural circulation design. the ultimate comercialization of the technology would be better served.

BEW, on the other hand, has stated that with all the complexities of control of an AFB boiler, it was not. warranted at this time to have the complexity of a once-through boiler. 
In our judgement, the position of both vendors is justified. A greater percentage of new fossil power plants are of the supercritical once-through design due to the improved station heat rate. Until the demonstration AFB is built to confirm the control features, we do not believe that a once-through design will be applied.

While there will be little domestic demand for a subcritical once-through boiler, the FWEC work will not be lost since almost all of the subcritical design is applicable to a supercritical design.

We conclude, therefore, that either design is an acceptable definition of an AFB boiler and commercial size.

\subsubsection{Stoker Feed Vs Pneumatic Feed}

The stoker feed and pneumatic feed concepts were chosen by Foster Wheeler and $B E W$ respectively. as the fuel feed systems for the fluidized bed boiler. Our analysis addressed three areas of concern within the bed as affected by these systems:

1. Freeboard Combustion

In the Foster Wheeler design, coal is fed by overbed spreader stokers. Combustion of the fines and heat release will tend to occur in the freeboard area above the beds. Production of fines must be minimized in order that combustion occurs in the bed thereby achieving high heat transfer to the in-bed boiler tubes. Obviously, there will be less freeboard combustion in the underfeed system where fuel is injected below the bed.

2. In-Bed Distribution

The use of the spreader stoker feeder will decrease the number of fuel feed points required as compared to the underfeed system. This is because the spreader stoker feeds the coal into a larger area of the bed than a single pipe in the underfeed pneumatic system. Based on a strict interpretation of existing data, a single feed line will adequately feed $9 \mathrm{sq} \mathrm{ft}$ of bed area whereas a stoker will feed $110 \mathrm{sq} f t$.

3. Bed Carbon Content

The unburned carbon content in the bed is required to be minimized at the bed operating temperature. The coal top size in the FWEC design is -1 in. and $-1 / 4$ in. the BEW design. As a result, burning rate is slower and the bed carbon content is greater in the FWEC design than in the BEK design. 


\subsubsection{Stacked Vs Condominium Design}

In our opinion, either the stacked or condominium designs of FWEC and $B \& W$ are feasible.

However, the stacked FWEC design coupled with their requirement for gravity feed necessitates a high capital cost penalty for a new coal/limestone delivery system $(\$ / k w)$ and a larger powerhouse to enclose the elevated storage bunkers (\$/kw) . The coal/limestone delivery system penalty would only be incuxred on extensions to existing facilities.

The condominium design of B\&W on the other hand has a powerhouse capital cost penalty because it is deeper than the FWEC design. In duditlur, the coal and ilmestone distribution and injection piping and the bed letdown piping on the $B E W$ designs are more complex due to the front-back and bottom bed locations.

The impact of these designs on gas/gas and gas/solid phase reactions is discussed in section 4.3 .

\subsubsection{Superficial Velocity}

Choice of a design superficial velocity must be made very early in the design of the boiler because it affects the boiler bed arrangement, steam circuitry, combustion efficiency, sulfur capture, grid plate design, and dust collection equipment. Wide ranges of gas velocities have been studied, 3 to $15 \mathrm{ft} / \mathrm{sec}$, but no specific guidelines have been established.

The design superficial velocity for the $B E W$ boiler was chosen to be $8 \mathrm{ft} / \mathrm{sec}$ in both the main beds and in the CBB. Foster Wheeler chose $10 \mathrm{ft} / \mathrm{sec}$ in the main beds and $8 \mathrm{ft} / \mathrm{sec}$ in the CBC.

Until more detailed economic optimization evaluations are conducted, which include both capital cost and boiler performance, the choice of an optimum superficial velocity rannot be made.

\subsubsection{Grid Pressure Drop}

One of the largest pressure drops in the FBC system is the grid plate pressure drop. This plate must be designed so that uniform fluidization is obtoinable throughout the entiry range of operating velocities. This is accomplished, based on accepted industry standards, by designing the plate for a pressure differential of approximately 33 percent of the drop across the bed at the lowest operating velocity.

FWEC specified a minimum operating superficial velocity of $5 \mathrm{ft}$ per sec. At this velocity. the slumped bed height will be approximately $12 \mathrm{in}$. and the pressure drop across it close to 17 in. W.C. The minimum recommended grid plate pressure drop for this operating condition, therefore, will be at 5.5 in. W.C. 
(approximately 33 percent of 17 in. W.C. At 24 in. slumped bed height and at the specified design velocity of $10 \mathrm{ft}$ per sec, the pressure drop across the bed will be close to 34 in. W.C. with the developed. grid pressure drop at $(10 / 5)^{2}(5.5)=22$ in. W.C. This figure was specified by FWEC in their report.

BEx, in their report, does not indicate velocity and slumped bed height variations. Their logic diagrams indicate, however, that velocity and bed level will be under control. It is reasonable to assume that the same range of pressure drops as specified by FWEC will be required. Therefore, the same design pressure drops of $22 \mathrm{in.W.C.} \mathrm{for} \mathrm{the} \mathrm{grid} \mathrm{plate} \mathrm{and} 34 \mathrm{in.W.C.} \mathrm{for} \mathrm{the} \mathrm{bed}$ should be applicable to the BEW design.

\subsubsection{Metallurgy}

MBC Air Grid - Stainless steel nozzles on a water-cooled grid are used in the FWEC design. Further development is suggested by FWEC to determine the metallurgy of the air grid. BEW does not address this point. Results from ongoing studies should be used.

Bed Tubes - The materials selected by FWEC have been in accordance with Power Piping standards on the basis of the operating pressures and temperatures in conventional pulverized coal plants.

Corrosion rates exterior to the tubes in the beds may dictate alternate selections. This was beyond the scope of work.

The materials selected by B\&W were also in accordance with the ASME code. No allowance was made to account for possible corrosive effects that could occur in the beds in their design.

\subsubsection{Structural Integrity}

The structural integrity of the FWEC AFB design was subject to question. As stated in 3.1.1. a stress analysis was performed resulting in front and rear wall tube modifications. Because of the result demonstrated by the stress analysis, it can be concluded that the stress can be reduced to an acceptable level.

\subsubsection{Finishing Reheater Surface Location}

FWEC elected to locate finishing reheater surface in the fluid bed to take advantage of the high heat transfer coefficient. While this necessitates a reheater cooling system (see Section 3.8 ), the minimal flow requirements of the once-through design coupled with the FWEC experience with the European bypass (see Sections 3.8 and 3.9) did not make reheater cooling a significant penalty.

B\&W elected not to locate reheat surface in the fluid bed since this would require a cooling system which would complicate the control system. As noted in section 3.8, we conclude that the 
BEW convection pass reheater will require cooling immediately after a boiler trip while the bed carbon inventory is burned out."

If our conclusion is valid, then in addition to the BEW turbine bypass system. S\&W has imposed a boiler trip reheater cooling system that would permit $B E W$ to take advantage of the higher inbed heat transfer coefficient without a significant capital cost penalty.

\section{1. 10 Carbon Burnup Cell (CBC) Location}

FWEC elected to design its AkB boiler with an integral CBC, wereas BEW elected to use an external CBC. In our judgement, either design is feasible: however, the BEW design will result in a significant penalty in our powerhouse cost due to the wider boiler room.

\section{1-11 Economizer Surface}

The B\&W economizer surface utilizes bare tubes and the FWEC economizer surface uses extended surface. Pluggage is not expected in this high dust loading area using extended surface due the dust friability. Abrasion was not considered, however, and FWEC advised that sufficient room to install equivalent bare tube surface exists and costs are minimal should this problem exist.

\subsection{Coal and Iimestone Systems}

\subsubsection{Coal and Limestone Preparation, Delivery, and Storage}

\section{Arrangement}

For both designs, the coal and limestone is transported from the yard stock piles to the in-plant storage bunkers by conventional belt conveyors.

The elevation of the Foster Wheeler boiler and the coal storage bunkers did not permit the use of the existing inclined belt conveyors that run from the yard to the tripper conveyors located above the storage bunkers. New storage bunkers were required to be. located above the highest level of stokers in order to feed them by gravity.

In the BEW arrangement, it was possible to locate the top of the new storage bunkers at the same elevation as that of the existing bunkers. thus allowing the use of the existing inclined belt conveyors that transport to the tripper conveyors from the yard. 


\section{Crushers}

The type of coal crushers selected for preparing the coal and limestone were chosen primarily to provide the boiler with an as nearly as possible uniform top size specified by the boiler manufacturer. (Each boiler manufacturer's requirements for the top size selection will be discussed elsewhere in the analysis.) For both B\&W and Foster Wheeler's design, a minimization of fines production was a requirement. The limestone top size product of approximately 100 percent - 1/8 in. with a minimum production of fines was required by both designs.

The type of limestone crusher chosen was an mimpactor." This type of crusher was chosen because of experience in industry in crushing limestone to similar requirements.

The coal required for the Foster Wheeler design was 100 percent minus $1 \mathrm{in}$. The coal required for the $B \& W$ design was 100 percent minus $1 / 4$ in.

In both cases, the type of crusher chosen was a "cage milln crusher.

The crusher chosen for the BEW design is required to produce a smaller top size. To control top size for a single crusher, the material must remain in the crushing chamber until all of it is reduced. Since the crusher has a closer setting, this results in an increase in fines.

Laboratory tests on a range of coal samples should be tested, but only after it is well established what the relative effect of fines is on boiler performance. These tests will prove or disprove the merits of various types of crushers in the area of quantity of fines produced. If the quantity of fines produced still needs to be reduced, two stage crushers should be considered.

BOth Bø̆W and foster wheeler do not require drying of the coal and limestone in the yard.

The belt conveyors and crusher rates are identical for both manufacturer's designs. $900 \mathrm{tph}$ rates were selected to be compatible with existing conveyor operation and bunkering. Normally. crushing and conveying rates are twice the required feed rates.

\section{2 .2 Coal and Limestone Distribution and Injection}

Coal

The coal feed system chosen by Foster wheeler is an overbed spreader stoker system. This system was chosen as a result of problems that have been encountered with the operation of existing in-bed fluidized bed systems. 
The problems that have been associated with the in-bed feed systems are:

1. Iarge number of feed points
2. Pluggage of pipes
3. Coking in the pipes
4. Erosion

The overbed spreader stoker, by means of a rotary paddle, propels the coal onto the fluid bed. We believe that most of the problems with the in-bed system which were listed will be eliminated with the overbed stoker system. We believe the major problem does not lie in the injection system, the problem is in distributing the coal to the stokers from the bunkers. There are 60 stokers feeding the main beds, 12 per bed level. The current design includes a network of chutes from the bunkers to the stokers. The FWEC coal handling system design needs to be demonstrated to establish if even flow aistribution can be maintained for long pipe distances.

The feed system selected by $B 8 W$ is a pneumatic underbed feed system. This system was chosen on the basis that existing fluidized bed feed systems are in-bed feed. The BEW system incorporates preumatic conveying from the bunkers to the builer. Coal and limestone from the bunker is fed by gravimetric feeders into a common discharge hopper. The mixture is then pneumatically conveyed and dried in transport. There are 25 transport lines; each line is split into 40 streams before injection into the fluid bed boiler. Since pneumatic conveying is a commonly used transport system, our skepticism is in the area of each of coal/limestone lines being split into 40 lines. Problems that were stated above for the in-bed feed systen on the existing fluidized bed system suggests that this system will not provide a reliable, continuous coal/limestone stream to the boiler. We believe that the injection system proposed by $B E W$ needs to be demonstrated.

\section{Iimestone}

The limestone feed system chosen by foster wheeler is an overbed gravity feed to one area of the bed. Foster Wheeler believes this system would promote greatest limestone utilization in a relatively simple system. Foster wheeler has addressed matters such as teed polnt location, elutriatioü, moisture content., limestone sizing and distibution in the bed, reactions in freeboard, and past operating experience in the selection of limestone feed system.

Limestone is fed by rutary valves at the outlet of the limestone bunkers which feed, by gravity, individual lines which run to the rear of each of the main bed side walls. These locations were chosen because the bed letdown extraction points are located at the front wall and thus would provide thorough circulation of bed material and higher limestone utilization. 
The elutriation of limestone fines to the freeboard zone and the amount of reaction with the coal fines in this area is a matter which needs to be demonstrated. Elutriation of unreacted limestone may be a problem in the Foster Wheeler design and must be minimized. We believe that the quantity of the elutriated limestone will be less in the underfeed system proposed by B\&W, since reaction would have a greater potential to occur prior to the time the fines reach the bed surface.

We believe that the moisture content in the limestone may cause problems in transport. Bridging and rat holing may occur in the bunkers and pluggage in the feed pipes.

In the BEW design, the Iimestone is dried in transport: however, hang-ups can still occur in the bunkers.

\subsection{Bed Material Letdown Collection and Disposal System}

\subsubsection{Bed Material Letdown Cooler}

To eliminate the necessity of high temperature material handling equipment, the spent bed material at a temperature of $1550 \mathrm{~F}$ must be cooled. Foster Wheeler proposes to cool the bed material to $250 \mathrm{~F}$ and Babcock 8 Wilcox to $215 \mathrm{~F}$ by the use of a bed material letdown cooler.

Foster Wheeler proposed to use air to cool the bed material using a booster fan which takes suction from the discharge of the forced draft fans. Babcock $\&$ Wilcox proposes to use water-cooled screw conveyors to cool the bed material. Each manufacturer will use rotary seals to control bed material flow through its respective cooler.

The Poster. Wheeler system has advantages in that spent carbon loss ( 6 percent of bed weight) is minimized and sensible heat is recovered. This results in higher boiler efficiency. The BEW system does not minimize spent carbon loss or recover sensible heat, resulting in signiticant heat loss.

However, calculations have shown that with the amount of cooling air specified by Foster Wheeler, the bed material temperature upon leaving the cooler will be greater than when it entered. This is due to the fact that there is additional heat generated upon carbon burnup.

In order for the Foster Wheeler design to function, a greater volume of couling air is required, which requires larger equipment.

Although water-cooled screws conveyors, as BEW has proposed, have no experience in utility size power plants, application of cooling screws in other fields indicate that such a device is technically feasible. Because of the coal size B\&W is feeding. spent carbon loss. (1 percent of bed weight) does not severely 
affect boiler efficiency. Also, sensible heat losses could be minimized by integrating the screw cooling water discharge to the boiler feed system.

In conclusion, both methods of bed letdown cooling require testing to confirm their adequacy. Based on the above, the Foster Wheeler design requires more development than the B\&W.

\subsubsection{Bed Material Transport to Disposal}

The Foster Wheeler and BEW methods of bed letdown disposal are very similar. The bed letdown material is collected in a holding tank. By the use of air lock devices, it is pneumatically conveyed to silos in the waste treatment area. Both systems have the capability to replenish the carbon burnup bed/cell with main bed spent material. BEW, in addition, has the capability to replenish its main beds with main bed spent material, should any one of the main beds be dumped.

Because of the large amounts of bed material removed and the long distances to transport to disposal areas. continuously running large capacity removal systems are required.

\subsection{Carbon Ash Collection and Reinjection System}

The function of the High Carbon Ash and Reinjection System is to collect, transport, and feed the unburned combustible material elutriated from the main bed cells into the carbon burnup cell/bed in order to improve the overall boiler efficiency.

The FWEC Carbon Collection and Reinjection System takes ash collected in the main bed mechanical dust collector and economizer hoppers and pneumatically conveys it to the carbon burnup cell (LBC) .

The B\&W Carbon Collection and Reinjection System takes ash collected in the main bed hot precipitator hoppers to a holding tank and then pneumatically conveys it to the carbon burnup bed (CBB) .

\subsection{P1y Ash Collection, Transport, and Disposal}

The FWEC FIY Ash Collection and Disposal System collects ash from the CBC Mechanical Dust Collector and Fabric Filter Hujpeis and pneumatically conveys it to the silos in the ash waste treatment area. Ash is removed from the hoppers by a vacuum system to a primary collector where it is pneumatically conveyed to the silos.

The B\&W Fly Ash Collection and Disposal System collects ash from the CBC Dust Collector and CBB Hot Precipitator hoppers and pneumatically conveys it to the silos in the ash waste treatment area. Ash is removed from the hoppers by a vacuum system to a 
primary collector where it is pneumatically conveyed to the silos.

Both systems are similar in operation and are commonly used for Fly Ash Removal on other coal-fired plants.

\subsection{Combustion Air and Flue Gas Systems}

\subsubsection{Forced Draft and Induced Draft Fans}

The F.D. fans required by both boiler manufacturers are considerably larger than F.D. fans used on a normal pulverized coal (P.C.) boiler of this size, $570 \mathrm{Mw}$. The larger size fan is necessary due to the higher pressure drop across the grid and through the bed material. The fan manufacturers that $B \& W$ and FWEC have received quotes from presently have fans of this size in operation and have not experienced any difficulties.

Due to the short project duration, no attempt was made to optimize the method of drive for the F.D. fans. Any further studies or project work for the AFB should entail an optimization of the type of driver for the F.D. fans.

The I.D. fans are of a size that are commonly used by utilities and should present no problems in the design of an AFB plant.

\subsubsection{Baghouse Vs Electrostatic Precipitators}

The Foster Wheeler and Babcock 8 Wilcox designs satisfy the present Federal EPA New Source Performance Standards (NSPS) for total suspended particulate (TSP) with a cold baghouse and a hot electrostatic precipitator (ESP). respectively. Based on information from DOE, revised NSPS for TSP of 0.03 lb TSP per million Btu heat input will be proposed in early 1978. The FWEC design would comply with the revised standard without modifications to the baghouse. The B6W design will comply with the revised standards with an approximate 15 percent increase in plate area.

Based on the assumption that grid plate pluggage due to entrained particulate from the APH into the air side will not occur, there appears to be some economic merit to a baghouse over an ESP. The capital costs of a mechanical collector (for the collection of MBC elutriated char and carbon) and a baqhouse (for TSP reductions to meet NSPS) are estimated at approximately 4.9 million dollars less than the two ESPs required by the $B \& W$ design. The pressure drop across the baghouse is inherently higher than the ESPs and would, therefore, require larger induced draft (I.D.) fans, resulting in an increase in their capital costs of approximately $\$ 1 / 4$ million. The capital cost for the baghouse system (including baghouse, mechanical collector, and larger I.D. fans) would be $\$ 4.7$ million lower than that of the original ESP system. The power requirements for the EPSs are much larger than for the baghouse. The net power requirements 
for the baghouse vs the ESPs (including I.D. fan requirements) indicates an approximate $6,700 \mathrm{hp}$ credit for the baghouse system. Fuel and limestone feed rates will be increased in the form of supplemental firing in the CBC due to the lower char and carbon collection efficiency of the mechanical collectors vs the ESP (90 percent versus 99 percent).

In conclusion, the net heat rate for the $B E W$ design would be lowered by approximately $90 \mathrm{Btu} / \mathrm{kw}-\mathrm{hr}$ with a baghouse/mechanical collector particulate collection system.

\subsection{Condensate Polishing System}

The base plant, being a fourth extension of an existing station, did not have a separate makeup water treatment system. However, it does have a full flow powdex condensate polishing system. This system was designed to produce high quality water for return to the boller. Some concern has been raised about the feasibility of a Powdex system to produce satisfactory condensate water quality for a once-through boiler (base plant is drum type). The condensate water quality will depend not only on impurities from the boiler piping etc.. but also from in-leakage of circulating water. The magnitude of the problem, as a result of condensate leaks, depends largely on the quality of circulating water and the condenser integrity. Although we could conceive of conditions where a Powdex system would not be feasible, we do not believe that a Powdex system is generically inadequate for once-through boilers. For a site specific case, a detailed engineering evaluation would be conducted comparing Powdex vs deep bed condensate polishing demineralizers.

\section{8 main Steam, Hot and Cold Reheat Turbine Bypass System}

The Foster Wheeler reheater and finishing superheater in-bed tubes necessitate a main steam to cold and hot reheat to condenser bypass system to ensure a minimum flow of 35 percent MCR flow through the superheater and reheater during start-up. on a boiler trip. the turbine bypass system also ensures superheater and reheater cooling as the residual carbon in the bed is burned out.

The Babcock $\varepsilon$ wilcox superheater in-bed tubes necessitate a main steam direct to condenser bypass system to ensure a minimum flow of 40 percent MCR flow through the superheater during start-up. The reheater located in the convection pass requires a main steam to cold and hot reheat to condenser bypass system to ensure superheater and reheater cooling during a boiler trip as the residual carbon in-bed is burned out.

It can be concluded that due to the AFB concept of having tubes emersed in the bed a turbine bypass systen is required to protect the superheater and reheater both during start-up and boiler trip. It can also be concluded that whether the reheater is in- 
bed tubes or convection pass, a turbine bypass system is required to ensure cooling as the residual carbon in bed is burned out.

Refer to Section 5.2.5 for evaluation of the turbine bypass control systems.

Condenser performance has been evaluated for turbine bypass failure.

\subsection{Turbine Generator Design Impact}

Sizing

Because the steam used for stack gas reheating on the base plant is expanded to the turbine on the AFB plant, this will result in a larger turbine and generator. The larger generation is identified on the heat balances and in Table IVB-1, herein. Increased. cost for the larger turbine generators are identified in Block 12 of Tables IIIA-1 and III.R-1.

\section{Turbine Control}

As noted in section 3.8, a superheat and reheat cooling system is required to prevent tube metal overheating during stant-ups. low loads, and/or trips. While the superheater can be protected by venting excess steam to the condenser as in the B\&W design. protection of the reheat necessitates introduction of steam into the cold reheat with subsequent venting from the hot reheat to the condenser.

In the Foster Wheeler design as described in Section 3.8, control of steam emission to the high pressure (HP) turbine, high pressure bypass (HP bypass), steam emission to the intermediate pressure (IP) turbine, and intermediate/low pressure turbine bypass (LP bypass necessitates that the IP turbine inlet valvescombined reheat valves (CRV) control circuit be modified to balance the IP-IP turbine flow with the FP turbine flow. This bypass system and turbine control circuit is referred to as the European bypass system. Although the experience of General Electric Co. and Westinghouse Electric Corp. with this design feature is limited, both have reviewed the system and have offered turbine generators for plants incorporating this feature. We conclude, therefore, that while additional coordination between Engineering and Design is required of the architect engineer, boiler manufacturer, and turbine generator manufacturer, this design requirement will not create any undue problems.

The BEW design does not require the initial complexity of the pressure control loop since reheater cooling is only postulated on turbine trip and, therefore, the CRV would be closed.

Difference between the two designs from a turbine generator control point of view is not considered significant: 


\subsection{PERFORMANCE ANALYSES AND COMPARISONS \\ 4.1 Boiler Efficiency}

General

The objective of this section is to review the reported boiler efficiencies to ensure that they are on an equivalent basis and to make any adjustments warranted by our evaluation of the design features offered.

The following design features are significant regarding the comparative efficiencies of the AFB boilers:

Calcium Utilization

Unburned Combustibles/Bed Letdown Heat Recovery

Grid Pressure Drop

Mixed Stack Gas Temperature

Calcium Utilization

In Section 5.2 of its final report (Appendix IIIB-B). FWEC states that as a result of using a post-calcination shrinking core model and causing calcination to occur in a $\mathrm{CO} 2$ rich atmosphere, calcium utilization will be approximately twice as high as the test data from Alexandria and Rivesville would indicate. The FWEC position is in our judgement a postulation which requires additional tests to substantiate. In terms of boiler efficiency. however, the lower Ca/S mole ratios result in an increase in boilex efficiency, i.e.. .0028 percent reduction in dry gas loss and a 0.11 percent reduction in net calcination/sulfation loss.

Since the Westinghouse test data would tend to support the Foster Wheeler postulation regarding improved calcination in a $\mathrm{CO} 2$ rich atmosphere, no adjustment has been made in the Foster Wheeler reported boiler efficiency.

\section{Unburned Combustibles}

FWEC has designed on the bas1s of $10 \mathrm{ft}$ per sec full load superficial velocity. whereas $B \& W$ has assumed $8 \mathrm{ft}$ per sec. On the basis of B\&W efforts for TVA after its selection of superficial velocity for this effort, BEW has concluded that $a$ $4 \mathrm{ft}$ per sec superficial velocity is warranted on the basis of carbon and calcium utilization, i.e., residence time for reaction prior to elutriation.

No adjustment in either boiler manufacturer's efficiency has been made for a $4 \mathrm{ft}$ per sec superficial velocity: however, this design basis requires additional review.

However, the relative carbon elutriation can be described by the square of the ratio of superficial velocity, i.e., FWEC unburned combustibles should be $(10 / 8)^{2} \times$ BEN unburned combustibles or 
TABLE IVB-1

PLANT PERFORMANCE ADJUSTMENTS

Load

Reported Gross Generation'. Mw

Reported Auxiliary Power ${ }^{2}$, Mw

Reported Net Output2. Mw

Reported Gross Station Heat Rate ${ }^{2}$, Btu/Kw-Hr

Reported Net Station Heat Rate ${ }^{2}$. $\mathrm{Btu} / \mathrm{KW}-\mathrm{Hr}$

Adjusted Auxiliary Power 3

Adjusted Net Outpur, Mw

Required Boiler Duty, 106, Btu/Hr

Adjusted Boiler EfEiciency`, $x$

Adjusted Heat Input, 106, Btu/Hr

Adjusted Net Station Heat Rate, Btu/Nw-Hr

Vho. $\frac{\text { Babcock \& Wilcox }}{75}$

592.27

592.27

$\underline{75}$

$\underline{50}$

38.64

441.55

292.67

553.63

24.12

16.47

9185

417.43

276.20

9150

9396

9.826

9678

9956

41.48

26.24

17.87

550.79

415.31

274.80

4673

3499

2399

86.23

86.96

87.55

5419

4023

2740

9839

9787

9971

Vwo $\frac{\text { Foster Wheeler }}{75}$

578.32

433.96

288.41

37.16

20.34

11.29

541.16

413.62

277.12

9355

9264

9466

9997

9719

9851

36.75

20.04

11.10

541.57

413.92

277.31

4673

3499

2399

86.11

86.84

87.43

5427

4029

2743

NOTES:

1. Vwo is turbine control valves wide open at 5 percent overpressure.

2. See Heat Balances in Parts IIIA and IIIB.

3. See Table IVB-2.

4. See Table IVB-4: 
2.42 percent. The reported FWEC unburned combustible loss is 2.1 percent. The difference between the 2.42 and 2.1 boiler heat loss is, in our judgement, due to a combination of the size feed to the bed, the method of feed, both of which affect the carbon elutriation, and the bed letdown carbon content.

No attempt has been made to characterize the quantitative effects of each of these variables.

Bed Letdown Heat Recovery

As noted in Section 3.3, the feasibility of the FWEC bed letdown coolers is subject to question. On this basis, we have assumed that the 0.37 percent FWEC has taken over BEW is not warranted without demonstration of the successful operation of the cooler. We have, therefore, in Table IVB-4 deducted this credit.

\section{Grid Pressure Drop}

The BEW design assumes the grid pressure drop of 9 in. H20 at full load. Experience to date indicates that the forced draft fans for $B E W$ would have to have a higher discharge pressure to accommodate the 22 in. W.C. grid pressure drop as discussed in Section 3.1.6. Adjustment in plant auxiliary load and capital costs have been made in Tables IVB-2 and IVB-3. However, higher discharge pressure will increase the heat of compression against the boiler efficiency. This increase in boiler efficiency is shown in Table IVB-4.

\section{Mixed Stack Gas Temperature}

BEW and FWEC assume different mixed stack gas temperatures. This assumption does not alter the turbine design but does alter plant operation. As a result, the FWEC boiler efficiency has been increased in Table IVB-4 to be compatible with the B\&W mixed stack gas temperature.

4.2 Cycle Impact

Once-Through Vs Assisted Circulation

Our inspection of Tables IIIA-6, IIIB-6, and heat balances 12919.02A-HBSK-B1 and 12919.02B-HBSK-B1 shows the following:

BEW (BP) FWEC (HP)

Boiler Circulation Pump Power

Boiler Feed Pump Power (BFP)

Total

$\begin{array}{rc}1,530 & - \\ 13,862 & \frac{16,060}{16,060}\end{array}$

While it had been postulated that the increase in the FWEC boiler feed pump power would be offset by the boiler circulation pump power of $B \& W$, it can be seen that this postulation was incorreot. 
The difference, in our judgment, is due to the higher FWEC net pressure drop across the boiler.

Heat Rejection System

The AFB plant, as previously noted, permits the base plant steam used for stack gas reheating to be expanded through the turbine and thereby increase the plant generation for the same main steam flow. This will, however, result in an increase in the heat rejected to the condenser by approximately 4.2 percent. This requires a larger condenser, cooling tower, and circulating water pump and an increase in the auxiliary power requirements for these components. This small deviation was accounted for by increasing affected flows and the auxiliary power linearly and increasing the cost as noted in section 5 .

In addition, BEW elected not to recover the bed materials specific heat but to reject it to the heat rejection system, thereby increasing the heat rejection system flows and auxiliary power requirements by an additional 0.8 percent.

As noted in Sections 3.3.1 and 4.1, the bed material specific heat recovery credit assumed by FWEC has been eliminated based on our judgment of the ability of the cooler to accomplish its design objective. In the end, both the BEW and FWEC AFB plant heat rejection systems include the base plant stack gas reheating steam and the bed material cooling.

\section{Draft Fan Drives}

Due to the short project duration, no attempt was made to optimize the method of drive for the forced draft or induced draft fan. Subsequent studies should consider driving at least the F.D. fan by turbine to obtain a plant heat rate credit. This conclusion is based on recent utility industry studies which indicate that auxiliary loads of approximately 10,000 BHP can more economically be driven by turbine than by motor. The Engineering and Design complexity of this feature should not be underestimated, however.

\section{Balance of Plant Optimization}

In order to maximize the credibility of the study results, it was decided that no reoptimization of the balance plant components, i.e.. feedwater heaters, turbine end size, heat rejection system, etc.. would be made. In point of fact, fine tuning of the balance of plant would be of questionable value on the basis that the boiler design and performance is concluded to be 0 generation. 
TABLE IVB-2

RUNNING AUXILIARY POWER COMPARISONS AND ADJUSTMENTS 1

(All Figures in Kilowatts)

\section{Plant Load}

FD Fans

ID Fans

PA Fans

TA Fans/ Bed Letdown Cooling Fans

Carb. Reinj. Fans

Fly Ash Transport Blowers

Bed Haterial Transport Blowers

Coal and Limestone Conveyors

Coal and I imestone Crushers

Material Stock-out,Reclaim Equipment

\section{Circulating Water Pumps}

Boiler Circulation Pumps

Cooling Tower MUP Pumps

Cooling Tower Fans

Air Dompressors

Precipitator/Baghouse

Margin for Intermittent Ioads and other Ondefinea Ioads

Reported Running Auxiliary Load 1

Adjustments:

FD Fan

Ambient Air Wet Bulb Grid Pressure Drop

Bed Letdown Specific Heat Cooler Fans

Heat Rejection System

Adjusted Auxiliary Power
Babcock \& Wilcox

\begin{tabular}{rrr} 
VWO2 & $\underline{75}$ & \multicolumn{1}{c}{50} \\
\hline 10769 & 4544 & 1346 \\
4713 & 1989 & 590 \\
1492 & 630 & 174 \\
379 & 160 & 47 \\
189 & 80 & 24 \\
378 & 159 & 47 \\
378 & 159 & 47
\end{tabular}

Included in "margir" below

\begin{tabular}{|c|c|c|c|c|c|}
\hline $\begin{array}{r}3133 \\
1641 \\
1530 \\
207 \\
1443\end{array}$ & $\begin{array}{r}3133 \\
692 \\
1530 \\
155 \\
1082\end{array}$ & $\begin{array}{r}3133 \\
205 \\
1530 \\
104 \\
721\end{array}$ & $\begin{array}{r}3109 \\
1641 \\
- \\
202 \\
1432\end{array}$ & $\begin{array}{r}3109 \\
692 \\
-\quad \\
151 \\
1074\end{array}$ & $\begin{array}{r}3109 \\
205 \\
-\quad \\
101 \\
716\end{array}$ \\
\hline 3357 & 2518 & 1679 & 3357 & 2518 & 1679 \\
\hline
\end{tabular}

$45004500 \quad 4500 \quad$ Included in margin below

$\begin{array}{llllll}3 \frac{3247}{8638} & \frac{2787}{24118} & \frac{2319}{16466} & \frac{3495}{37159} & \frac{2974}{20339} & \frac{2444}{1128}\end{array}$

\begin{tabular}{rrrrrr}
45 & 19 & 6 & - & - & - \\
2800 & 2100 & 1400 & - & - & - \\
$-\quad$ & - & - & $(445)$ & $(334)$ & $(222)$ \\
- & - & - & 40 & 36 & 32 \\
\hline 41483 & $\overline{26237}$ & $\overline{17872}$ & $\frac{36754}{30041}$ & $\frac{.3099}{11099}$
\end{tabular}

Foster wheeler

\begin{tabular}{|c|c|}
\hline VWo 2 & 75 \\
\hline $\begin{array}{r}12204 \\
9340\end{array}$ & $\begin{array}{l}5148 \\
3941\end{array}$ \\
\hline - & \\
\hline $\begin{array}{l}445 \\
189 \\
378 \\
378\end{array}$ & $\begin{array}{r}334 \\
80 \\
159 \\
159\end{array}$ \\
\hline
\end{tabular}

05

101

1679

$\frac{3495}{37159} \quad \frac{2974}{20339} \quad \frac{2444}{11289}$ 
TABLE IVB-3

COMPARLSON AND ALJUSTMENT OF PLANT COSTS

Reported Direc: Costs

Direct Cost Ad justments

Block 7A FD Fans $(+20$ Percent)

Block 6 Bed Lezdown Coolers and Fans Versus Water Coolers

Block 14 Heat Rejection Sy'stem

Adjusted Direc= Costs

Indirects and Distributable

$$
\text { Subtotal }
$$

Allowance for Indeterminates

Subtotal

Escalation

Subtotal

Allowance for Funds Durin: Constraction Total Plant cost

Adjusted Unit Cost, $\$ / \mathrm{KW}$ [ret]

\begin{tabular}{|c|c|c|c|c|c|}
\hline \multicolumn{3}{|c|}{ Babcock \& Wilcox } & \multicolumn{3}{|c|}{ Foster Wheeler } \\
\hline Material & Labor & Total & Material & Labor & Total \\
\hline $118,648,000$ & $68,245,000$ & $186,893,000$ & $97,783,000$ & $53,569,000$ & $151,352,000$ \\
\hline 200,000 & 0 & 200,000 & - & - & - \\
\hline- & - & - & $\mathbf{0}$ & 0 & 0 \\
\hline - & - & - & 18,000 & 9,000 & 27,000 \\
\hline $118,8<8,000$ & $68,245,000$ & $187,093,000$ & $97,801,000$ & $53,578,000$ & $151,379,000$ \\
\hline $16,566,000$ & $10,603,000$ & $27,169,000$ & $16,566,000$ & $10,603,000$ & $27.169,000$ \\
\hline $135,414,000$ & $78,848,000$. & $214,262,000$ & $174,367,000$ & $64,181,000$ & $178.548,000$ \\
\hline $13,501,000$ & 7.845 .000 & $21,386,000$ & $11,437,000$ & $6,418,000$ & $17,855,000$ \\
\hline $148,955,000$ & $86,693,000$ & $235,648,000$ & $125,804,000$ & $69.599,000$ & $196,403,000$ \\
\hline $26,811,000$ & $31,989,000$ & $58,800,000$ & $22,644,000$ & $25,681,000$ & $48,325,000$ \\
\hline $175,766,000$ & $118,682,000$ & $294,348,000$ & $148,448,000$ & $95,280,000$ & $244,728,000$ \\
\hline $24,607,000$ & $16,615,000$ & $41,222,000$ & $20,783,000$ & $13,339,000$ & $34,122,000$ \\
\hline $200,373,000$ & $135.297,000$ & $335,570,000$ & $169,231,000$ & $108,619,000$ & $278,850,000$ \\
\hline & & 609 & & & 515 \\
\hline
\end{tabular}


TABLE IVB-4

BOILER HIAT LOSS COMPARISON AND ADJUSTMENT

(AlI figures in percent)

Babcock \& Wilcox

Fosier wheeler

Load

Vwo

75

$\underline{50}$

vwo 2

$\underline{75}$

Reported Lasses: 3

$$
\begin{gathered}
\text { Dry Gas } \\
\text { Wet Gas } \\
\text { Fuel } \\
\text { Air }
\end{gathered}
$$

Unburned Combustibles

Radiation

Unaccounted and Margin

Calcination/Sulfation

Eed Material Specific Heat

Total Losses

FD Fan Heat of Compression

Over Base Plant

Reported Boiler Efficiency ${ }^{3}$

\section{Adjustments}

zmbient Air Terperature

$$
\begin{aligned}
& \text { Dry Gas } \\
& \text { Wet Gas }
\end{aligned}
$$

Grid Pressure Irop

Bed Naterial Heat

Mixed Stack Gas Temperature

Adjusted Boiler Efficiency Plant

$\begin{array}{lll}5.06 & - & - \\ 5.43 & - & - \\ 0.13 & - & - \\ 1.55 & - & - \\ 0.16 & - & - \\ 1.50 & - & - \\ 0.29 & - & - \\ 0.42 & - & \end{array}$

$\begin{array}{lllll}- & 4.54 & - & - \\ - & 5.42 & - & - \\ - & 0.11 & - & - \\ - & 2.10 & - & - \\ - & 0.17 & - & - \\ - & 1.50 & - & - \\ - & 0.18 & - & - \\ - & 0.05 & - & -\end{array}$

$(0.38) \quad(0.45)$

$\begin{array}{llllll}85.84 & 86.5 & 87.16 & 86.38 & 87.11 & 87.70\end{array}$

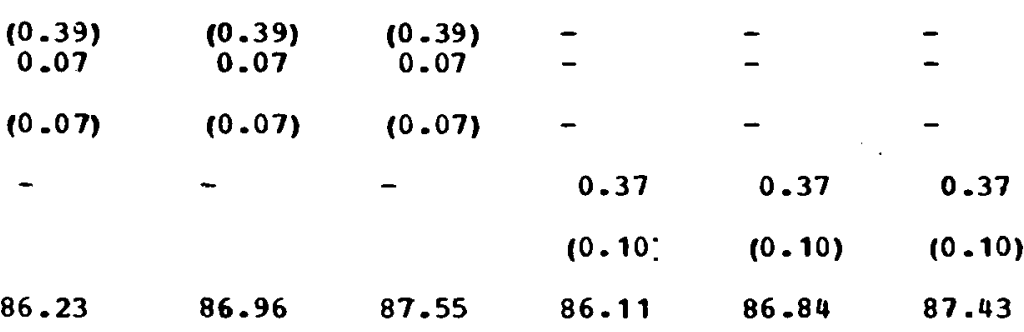




\section{Reheater Drop}

As in any utility plant, reheater pressure drop is critical to plant performance. Because of BEWs use of convection reheat surface, the greater surface has resulted in a lower reheater drop. which thereby increases the IP-LP turbine power generation. The location of reheater surface is a trade-off between surface area and pressure drop.

\subsection{Effect of High Freeboard on Gas-Solid Reactions}

One characteristic of both the Babcock $\varepsilon$ wilcox and Foster Wheeler conceptual designs is the high freeboard specified. The high freeboard along with the length of hot flue provides additional time for freeboard reactions to go to completion. This aspect of the process has not been demonstrated in test units to date since existing test units have small freeboard heights and, therefore, limited hot flue gas residence time. The two areas where this could be important are with respect to combustion efficiency and NOX emissions.

\subsubsection{Combustion Efficiency}

Combustion will occur in the freeboard as long as the gas temperature exceeds about $800 \mathrm{~F}$. The effects of this combustion compared to test unit performance are expected to be as follows:

1. Reduced hydrocarbons evolution

2. Reduced CO evolution

3. Reduced fly ash production

4. Lower fly ash carbon content

5. Increased sulfur emissions

The existing experimental data which form the basis for the Rivesville MPB design and the two currently proposed conceptual designs are from test units with hot gas residence times of a fraction of a sccond. The Babcock 8 Wilcox design leads to hot gas residence times of 2-3 sec, whereas the Foster wheeler design would yield a range of hot gas residence times of about 1.5 sec for the top bed to nearly $6 \mathrm{sec}$ for the bottom bed.

The characteristics of the $f l_{y}$ ash produced may be significantly changed. The residence time of fly ash particles in the combustion region will be determined by their size. The smallest particles, those below 100 microns, will travel at velocities near the gas velocity due to their low terminal (falling) velocities. The larger particles will travel at a velocity equal to the gas velocity minus their terminal velocity. Thus. the largest of these particles will travel very slowly upwards until they burn to a smaller size and gradually pick up speed.

Figure IVB-1 shows predicted results from the Alexandria FBM. The smallest particies completely burn out in their small residence time. The largest particles remain in the bed. An 
intermediate size range of about 150 to 400 microns is calculated to be in the hot gas portion of the FBM for less time than the particle burnout time. This prediction shows good agreement with the carbon content of the fly ash actually found in the FBM.

Extension of this calculation method to the longer hot gas residence times, expected in large scale units, yields the result that $f l y$ ash production will be decreased and $f l y$ ash carbon content will be lower. Furthermore, the sulfur emitted in freeboard combustion will be inefficiently captured due to the low sorbent concentration.

One of the results of the early FBM studies was that carbon monoxide emission was a significant combustion efficiency problem. Hydrocarbon emission was also a problem when the fuel distribution was not adequate. It is expected that the longer hot gas residence time expected in large scale units will yleld more complete combustion of these species. Thus, freeboard combustion may compensate for a large part of this type of emission due to fuel maldistribution if the coal feeders do not operate properly. This increased hot gas reslaence time may. therefore, allow overbed feeders to be used in large scale units. whereas they could not be used in smaller units.

\subsubsection{Nitrogen Oxide Production}

Early experience with the FBM indicated that nitrogen oxides were destroyed in the freeboard. This is illustrated by the data shown in Figure IVB-2. This can be anticipated from thermodynamic calculations of the following reaction:

$$
2 \mathrm{NO} \leqslant \mathrm{N} 2+02
$$

This reaction equilibrium constant at bed operating temperatures predicts a nitrogen oxide equilibrium concentration of about $50 \mathrm{ppm}$. It is expected that the above reaction proceeds during the hot flue gas residence time yielding reduced levels of nitrogen oxides. The conceptual designs proposed by both manufacturers would, therefore, be expected to produce lower Nox emissions than are shown by current test unit results. 


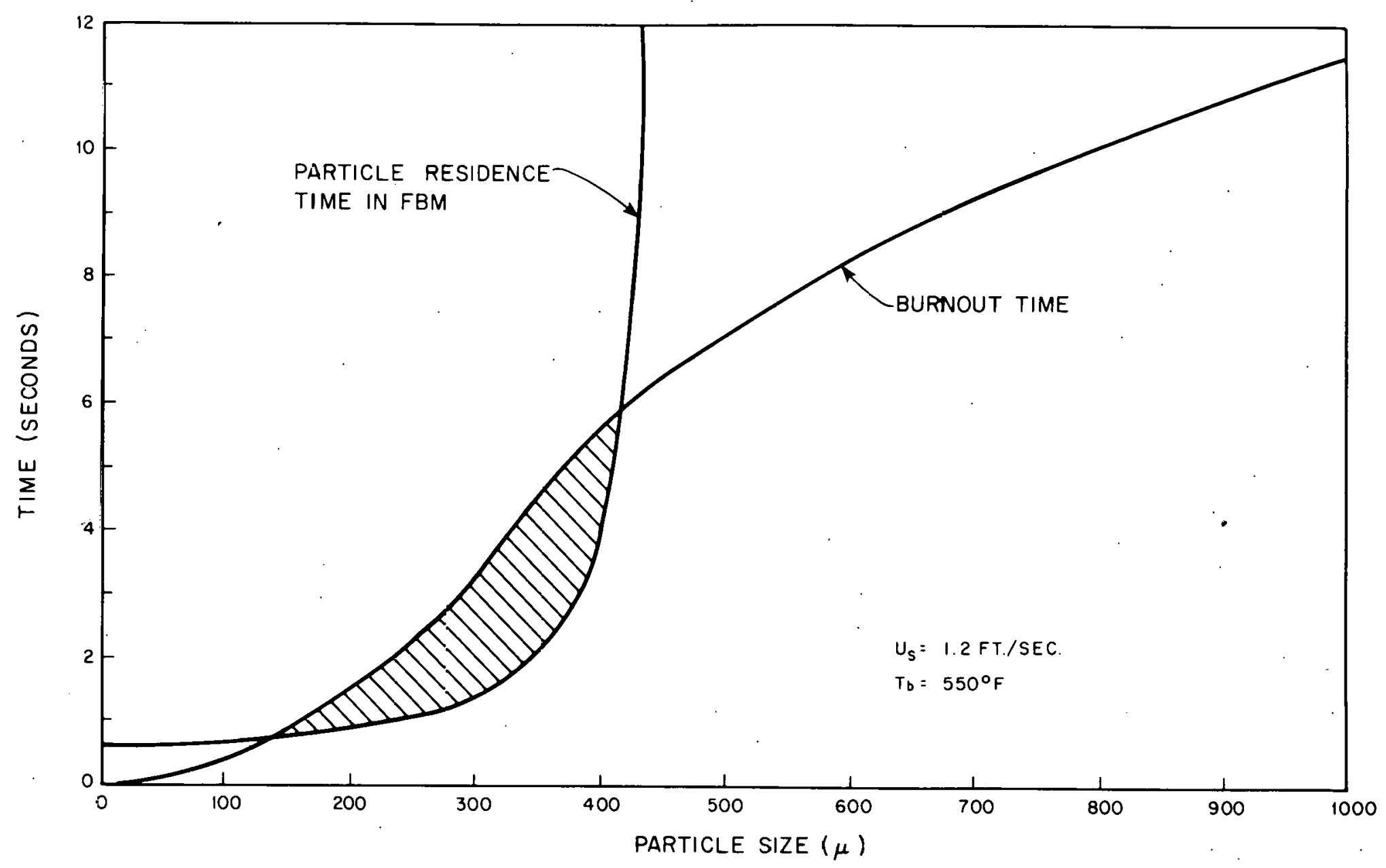

FIGURE IVB-1

COAL RESIDENCE TIME AND BURNOUT TIME VERSUS PARTICLE SIZE 


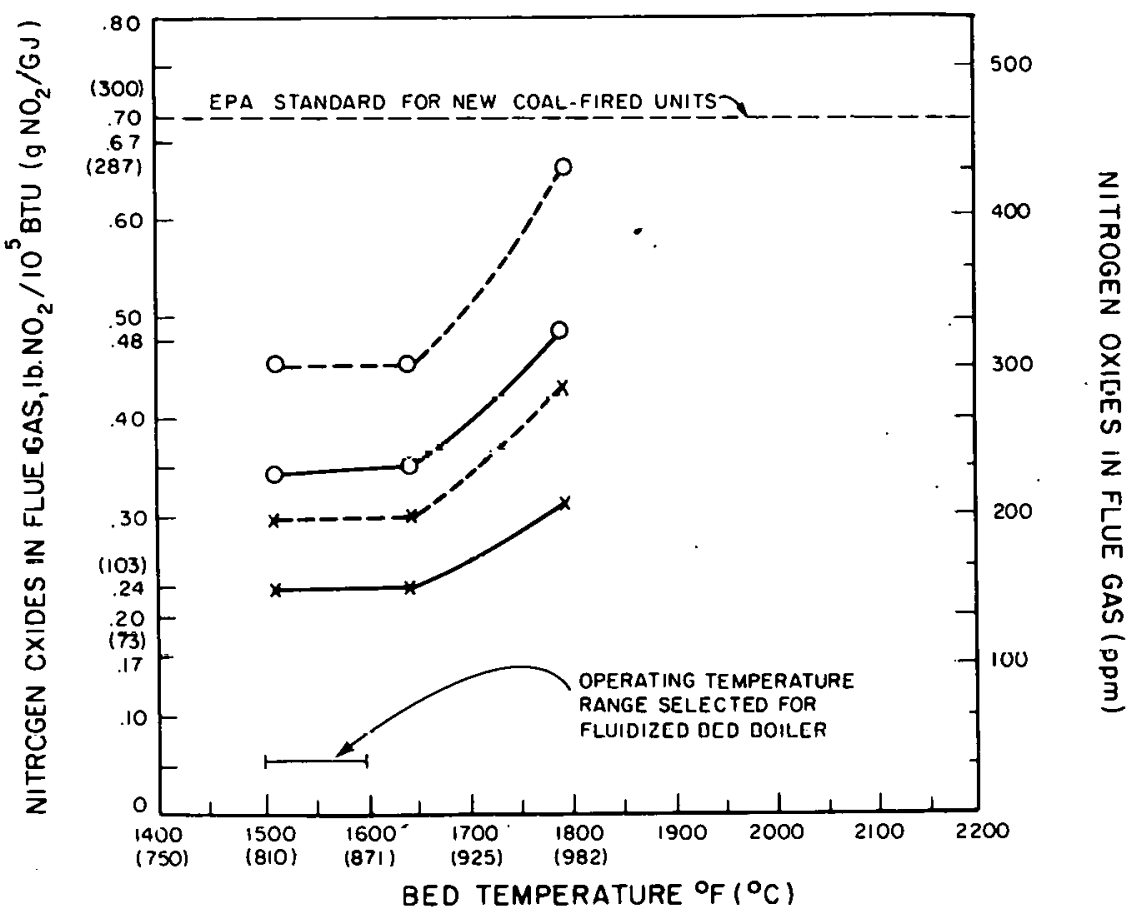

KEY

$X \quad N=1.49 \%$ NITROGEN IN FUEL-MOISTURE

AND ASH FREE BASIS

○. $\quad N=2.02 \%$ NITROGEN IN FUEL-MOISTURE

AND ASH FREE BASIS

FORMED IN COMBUSTION ZONE

EMITTED FROM STACK

FIGURE DB-2

NITROGEN OXIDES IN FLUE GAS OF FBM 


\section{5:0 ECONOMIC ANALYSES AND COMPARISONS}

\subsection{Capital Costs}

\subsubsection{Bases and Assumptions}

The capital cost pricing for the AFB plant consists of the base plant pricing with additions and deletions noted in Tables IIIA-2 and IIIB-2. This alternate pricing was developed in one of the following manners as noted on Table $1 \mathrm{VB}^{-5}$ and as identified in subsequent sections:

Deletion of base plant price Adjustment of base plant price using the 0.8 power Replacement of base plant price with vendor supplied pricing

\subsubsection{Boiler and Related Equipment}

The price for equipment for the conventional boiler manufacturers scope of supply was developed in a manner consistent with the boiler manufacturers' current offerings for conventional equipment. In addition, the pricing assumed that the technology had been demonstrated and, therefore, no margin above that currently used on pulverized coal technology was included for the unknowns of the AFB technology.

While the pricing basis for the AFB boiler was developed on a proprietary basis by both manufacturers, in our judgment, the reported pricing represents the boiler manufacturers' best estimate based on the engineering and design detail permitted by project schedules.

It should be noted that the pricing included in the boiler manufacturers' final report are October, 1977, prices. These data were deescalated by the factors noted in Table I-2 to January. 1976, to permit comparison with the base plant pricing.

\subsubsection{Balance of Plant}

In general, the balance of plant adjustments were made by deletion of nonapplicable components or specific cost adjustment based. on percent change and capacity from base plant raised to the 0.8 power.

The adjustments from the base plant for draft fans, ductwork, and air pollution control equipment were generated by the boiler manufacturers. Boiler manufacturers" price for these commnents does not lñclude a markup.

The adjustment in turbine generator pricing was developed using then available manufacturer's price book with a 0.71 handbook multiplier. 
The heat rejection system cost adjustment was based on a 5 percent increase in capacity which is equivalent to a 4 percent increase in cost.

Increase in boiler feed pump and start-up boiler feed pump pricing was based on a manufacturer's estimate.

The coal handling and preparation equipment costs were submitted by conveyor and crusher manufacturers. The cost for the new crusher house structure was prepared using the base plant costs.

The bed material transport and fly ash transport to disposal system costs were developed in conjunction with material manufacturer.

\subsubsection{Allowance for Indeterminants}

The allowance for indeterminants in both AFB capital cost estimates is 10 percent of the total direct, and distributable costs. This is consistent with the base plant estimate.

5.1.5 Escalation

In both AFB estimates, a compound escalation of 3.25 percent per year for material and 7.25 percent per year for labor was applied to the total January, 1976, costs through July, 1980. This is consistent with the base plant estimate.

\subsubsection{Allowance for Funds Used During Construction}

A simple 8 percent per year allowance was included in both AFB capital cost estimates from July, 1980, to April, 1982, to account for funds used during construction. This is consistent with the base plant estimate.

\subsection{Operating Costs}

\subsubsection{Bases}

Operating costs have been developed for the AFB designs using the net station output and a capacity factor of 63.74 percent as noted in Table I-2. These costs are segregated into the rollowing categories:

Capital recovery (fixed charges)

Fuel costs

Limestone costs

Operating and maintenance costs

5.2 .2 Capital Recovery (Fixed charges)

The capital recovery portion of the operating costs were developed by multiplying the 1982 plant costs by the fixed charge rate $(15.35$ percent) and dividing by the levelized annual station 
PLANT COST CHANGE COMPARISON (All Figures in Millions of Dollars)

\begin{tabular}{|c|c|c|c|}
\hline Block & Description & BEW Change & FWEC Chazge \\
\hline $\mathbf{1}$ & Land & $N / I$ & $N / I$ \\
\hline 2 & Yard Work & $\mathrm{N} / \mathrm{C}$ & $\mathrm{N} / \mathrm{C}$ \\
\hline 3 & Main Powerhouse & 4.081 & $(3.099)$ \\
\hline 6 & Boiler by Bölex Mfr. & 22.001 & $(1.040)$ \\
\hline 7. & Boiler Feed Pump and Drive & $(0.040)$ & 0.113 \\
\hline 7 & Turbine Bypass/Reheater Cooling & 0.523 & 0.470 \\
\hline 7 & FD and ID Fans, Drives, and Ducts & $(1,800,003)$ & $(1,322,833)$ \\
\hline 7 & Start-up Boiler Feed Pump & 0.897 & 0.793 \\
\hline 7 & Flash-Tank and Chemical Feed & $n / C$ & $(0.064)$ \\
\hline 7 & Ash and Bed Material Transport & 7.119 & 7.119 \\
\hline 8 & Conveyors, Crushers, and Crusher House & 3.718 & 6.283 \\
\hline 8 & Coal Bunkers & 0.680 & 0.413 \\
\hline 8 & Bunker/Boiler Piping, Gates, etc. & 0.372 & 0.172 \\
\hline 9 & Stack & $(0.173)$ & $(0.173)$ \\
\hline 10 & Precipitator/Baghouse & 3.919 & 0.432 \\
\hline 10 & Structural Steel and Foundations & 2.249 & 0.974 \\
\hline 11 & Flue Gas Desalfurization & $(28.093)$ & $(28.093)$ \\
\hline 12 & Turbine Generator & 0.150. & 0.150 \\
\hline 13. & Component Cooling water & 0.114 & $\mathbf{N} / \mathrm{C}$ \\
\hline 14 & Condenser & 0.056 & 0.056 \\
\hline 14 & Circulating Water and Pumps & 0.030 & 0.025 \\
\hline 14 & Cooling Tower & 0.120 & 0.098 \\
\hline 15 & Water Treatment & $\mathrm{N} / \mathrm{C}$ & $\mathrm{N} / \mathrm{C}$ \\
\hline 16 & Sludge Stabilization & $(3.884)$ & $(3.884)$ \\
\hline 17 & Station Service Transformer & 0.535 & 0.535 \\
\hline
\end{tabular}


Block
Description

Switchgear and FGD

Substations anc MCC

Bus Duct and Cables

Instrumentation and Control

Miscellaneous Equipment

Main Transform $\equiv x$

Transmission Lines

Total

Notes: N/C - No change

$N / I=N o t$ included
FWEC Change

$(0.162)$

(0.136)

0.210

0.141

0.275

0.267

2.674

0.293

$\mathrm{N} / \mathrm{C}$

$\mathrm{N} / \mathrm{C}$

$\mathrm{N} / \mathrm{C}$

N/I

$\mathbf{N} / \mathbf{C}$

14.723

$-20.813$ 
output. This is consistent with the methodology used for the base plant.

\subsubsection{Fuel Costs}

Lifetime fuel costs for each AFB plant were computed using the annual coal used (tons per year) at a fuel cost of $\$ 21.25$ per ton (1982) at a 7 percent annual fuel cost escalation. This cost was then levelized using a present worth discount rate of 10.5 percent for each year. The total lifetime fuel cost was then multiplied by the capital recovery factor and then divided by the levelized annual station output (.6374 $\mathrm{x}$ VWo net output). Refer to Tables IIIA-3 and IIIB-3 for annual fuel operating costs. This above procedure was performed again using the adjusted coal feed rates noted on Table IVB-6, and the adjusted annual fuel operating costs are noted on Table IVB-7.

\section{2 .4 Iimestone Costs}

Lifetime limestone costs for each AFB plant were computed using the annual limestone used (tons per year) at a limestone cost of $\$ 12.75$ per ton (1982) at a 5.5 percent annual cost escalation. This cost was then levelized using a present worth discount rate of 10.5 percent for each year. The total lifetime limestone cost was then multiplied by the capital recovery factor and then divided by the levelized annual station output $1.6374 \times$ vwo net output) - Refer to Tables IIIA-3 and IIIB-3 for annual limestone operating costs. This above procedure was performed again using the adjusted limestone feed rates noted on Table IVB-6, and adjusted annual limestone operating costs are noted on Table IVB-7.

\subsubsection{Operation and Maintenance Costs}

The operating and maintenance costs for the base plant were reduced by the FGD operation and maintenance cost noted in Appendix I-D. This operating cost was then assumed to be equivalent to a pulverized coal-fired plant without FGD. This cost was then arbitrarily increased to 10 percent for both the FWEC and BEW AFB plants. The results in O\&M cost was then adjusted by ratio BWO plant output for that manufacturer as compared to the base plant.

\subsection{CONTROL SYSTEMS ANALYSES AND COMPARISONS}

\subsection{Introduction}

Since, at this time, there is neither predictive data from a mathematical model nor experimental data from an operating FBC utilizing the design features of $B W$ and FWEC, it is not possible to critically evaluate the effectiveness of the proposed control systems for the respective boiler designs beyond pointing out differences and areas of concern. The objective of this control system evaluation/comparison will be to identify areas of 
uncertainty and differences between the BEW and FWEC controls and to raise questions about the respective control systems. Since a control system does not have to be finalized until late in design, any control system can incorporate recommended changes based on results from computer models and experimental data.

\subsection{Boiler Load Control Parameters}

\subsubsection{Coal Feed}

Both vendors utilize modulation of coal feed for load turndown for each segment/compartment. Because of the larger coal size, the response time to change the bed temperature for the FWEC design would be longer than for the BEW design. The FWEC coalfeed controls would have to include a corrective control action to inhibit excessive over- or underfiring while at the same tine providing adequate unit responsiveness to load demand.

There is also an additional delay in the FWEC design introduced by the time required to change the stoker feeder speed. However, this delay is not expected to be significant.

Items that would need further clarification, as the design progresses for the respective AFB boilers, are:

1. A recommendation for the start-up and shutdown of the bed compartment sequence for meeting load demands for BEW design

2. The lucidtiun of Qlgltal permissives for tripping and hold points for start-up and shutdown in the FWEC boiler control logic

3. How FWEC would incorporate a Btu correction for coal into their combustion controls

BEW presents a clearer logic picture of how the furnace firing rate demand is split between the boiling bed surface demand and the superheater bed surface demand. B\&W also shows how both of these error signals are scaled in sensitivity by the number of compartments in service. 
ADUUSTMENTS TO PLANT MATERIAL BALANCES, TPH

(AII Figures in Tons Per Hour)

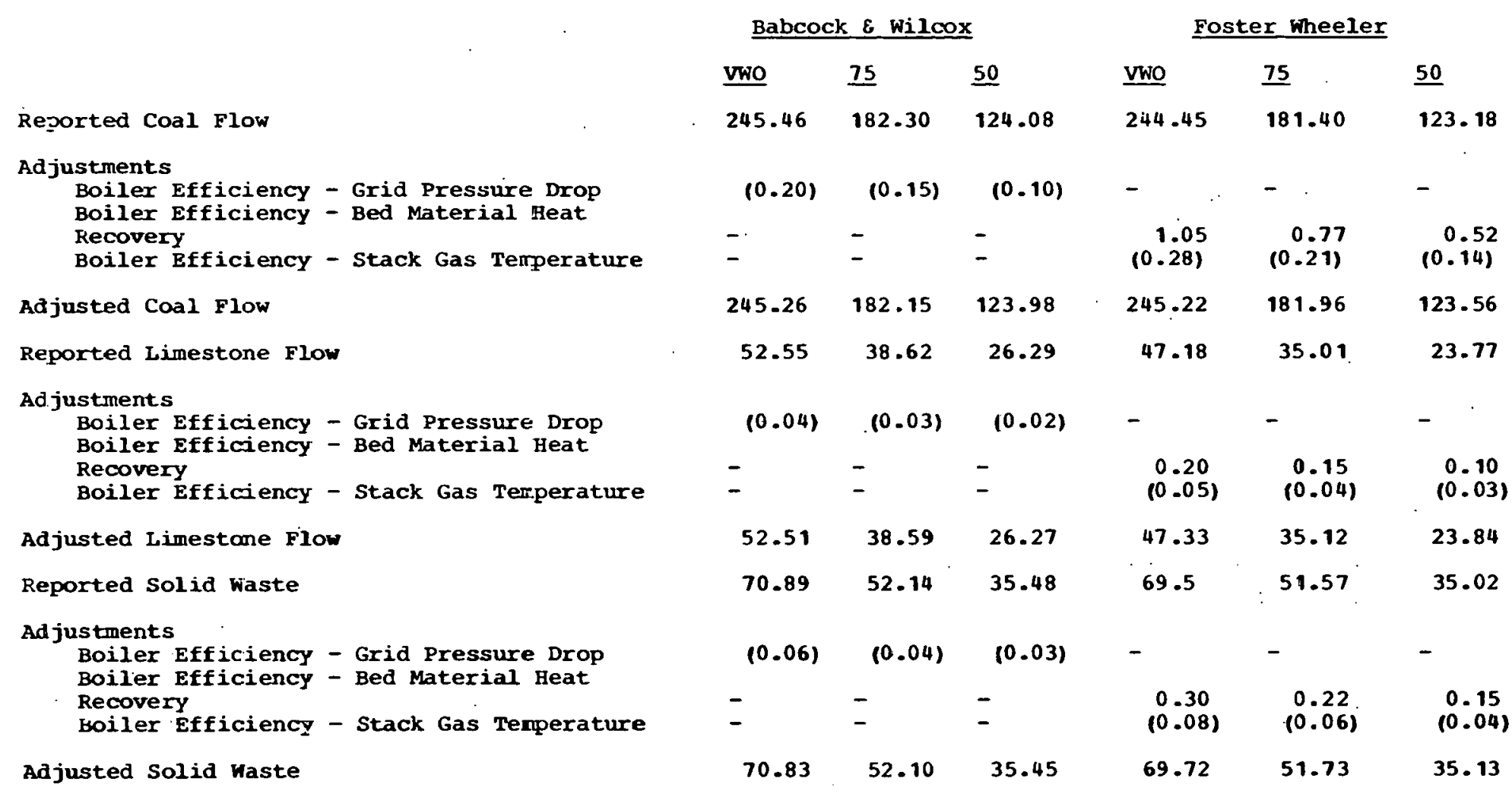


TABLE I $\sqrt{ }-T$

ADJUSTED ANNUAL OPERATING COSTS, MILLS/KW-HR

Foster Wheeler Babcock \& Wilcox

Fuel

18.16
1.81

17.75
1.95

Limestone

Page 1 of 1 


\section{2 .2 Bed Temperature}

The problems of utilizing bed temperature as a control variable are not insurmountable but would require experimental testing to solve the following problems:

1. Bed material temperature measurement location - Since the bed material temperature varies throughout the bed, the location of temperature measurement devices should be determined to give a representative bed mateirial temperature. The bed temperature monitors would simultaneously have to provide signals to prevent any local hot-spot temperature from exceeding the limits as required for safe operation.

2. Because of the slow response of bed temperature, a degree of undershoot and overshoot of coal and air in excess of a conventional pulverized coal-boiler would be required to adjust the bed temperature, since the bed mass is large and the rate of temperature change would be slow.

3. Since the calcium utilization curve demands more limestone at bed temperatures both higher and lower than 1500-1600 F. the calcination heat losses would increase at bed temperatures above and below this range. These calcination heat losses would tend to inhibit a steady state bed temperature higher or lower than the 1500-1600 F range since the additional limestone would cause the bed temperature to drop on the low side of $1550 \mathrm{~F}$ and inhibit bed temperature above $1550 \mathrm{~F}$. The calcination heat losses would further decrease boiler efficiency.

\section{2 .3 Bed Level}

Bed level does not seem to be a controllable variable for load turndown for the following reasons:

1. The horizontal configuration of bed tubes in the BEW and FWEC designs does not provide wide range of bed material height vs steam generation rate to make effective use of a level signal.

2. The effects of exposing bed tubes due to level modulation are not clearly known; nverheating of lower submerged tubes may occur.

3. Since the actual bed level is continuously changing due to violent bubble eruptions throughout the bed surface an accurate measurement of the bed material level would not be a meaningful measurement. 
4. Air modulation to change bed level would adversely effect combustion efficiency because coal combustion could not respond as quickly.

5. Dtilizing the bed letdown system to change the bed level would be slow and inefficient because of the large volume of bed material required to adjust the bed material height.

It is our judgement that at this time it is premature to postulate a bed level control for load turndown with the two designs presented.

However, the alternative to varying the bed level would be to maintain a constant bed level. This means that optimum air/fuel ratio cannot be maintained for all loads since the undergrid secondary air dampers would be positioned to maintain a constant bed material expansion height as the coal feed rate is changed.

\subsubsection{Bed Slumping}

Bed slumping to achieve load modulation offers the most favorable degree of load turndown capability for the BEW and FWEC designs, however, areas of concern are as follows:

Due to overbed or freeboard combustion, excessive temperatures may result at the surface of the slumped section causing high temperature problems (ash fusion, clinkering, etc.). This would be continuous problem for the BEW design since the center start-up section is always slumped during normal operation. Bed slumping to achieve turndown may require some minor air/fuel modulation of the remaining oegment3/compartments as a segment is slumped. This can be achieved.

slumping a bed on a turbine trip may cause problems since a burnout of residual carbon is required. If this residual carbon is burned out at the minimum fiuidizing velocity, a reducing atmosphere could possibly be expected to form within the bed. It is not known whether this reducing zone will cause problems during the coal burnout time. If a higher minimum fluidizing velocity is required to avoid any reducing zone problems, the resulting steam generation rate may cause the safety valves to lift.

\subsubsection{Turbine Bypass}

A turbine bypass sytem is required by the AFB boiler to maintain minimum steam flows at low loads for in-bed cooling and for minimum steam flow for bed cooling after a turbine trip. This means the AFB boiler can never be fired at less than 4035 percent MCR. The bypass system will require control loops to ensure: 
1. Balanced flows between the HP and IP/IP turbines on a start-up and shutdown

2. Minimum flow of steam/water through fired beds on a turbine trip

3. Simultaneous control of:

For the FWEC design:

4 HP bypass valves and 4 IP/LP bypass valves

For the BEW design:

3 HP bypass valves for start-up and shutdown

4 reheater cooling inlet control valves and 4 reheater cooling outlet control valves for a turbine trip condition

However, the advautayes of a bypass ayotan are as follows:

1. Smooth warming of the main steam line preventing thermal shocks and stresses.

2. Capability of matching main steam and reheat steam temperature before rolling the turbine.

3. Faster hot restarts since the boiler can be kept on hot standby -

4. Load rejection without the necessity of tripping the boiler.

\subsection{Combustion Controls}

\subsubsection{Main Bed Combustion Controls}

Because of the BEW pneumatic underfeed coal system, additional controls are required for the primary and tempering air fans and dampers. It is essential that these controls operate properly to ensure continuous supply of dry coal. FWEC needs no similar system because they utilize overbed stoker feeders that have no requirement for drying.

Although no logic is shown, FWEC utilizes a constant pressure control for the F.D. fan discharge. No mention is made of any interlocks. BEW programs forced draft fan discharge pressure with the boilex load demand to minimize undergrid damper modulation on a change of load. Interlocks with safety features are also incorporated.

BEW incorporates an oxygen trim in the combustion air control. within the limits of fluidizing velocity. FWEC does not mention any oxygen trim. The usefulness of an oxygen trim is doubtful 
since the airflow has to be held constant to maintain proper fluidizing velocity. Both designs cross-limit fuel and air modulation to avoid a reducing atmosphere. Both designs provide close control over the I.D. fan dampers. BEW allows the operator to bias the $I$.D. dampers to achieve balance of gas flow between the two fans.

The differences in I.D. and F.D. fan control are not significant and either design is adequate.

Both vendors provide implosion protection for a main fuel trip. It is not clear how a fuel trip on a fluid bed boiler would cause implosion problems, however, these controls can be easily altered. FWEC provides additional implosion protection by controlling the I.D. fan discharge damper if the I.D. fan inlet damper fails open. BEW shows more clearly than FweC how the start-up and shutdown interlocks are incorporated in the analog control system.

BEW utilizes a fuel demand signal for a bed level set point. The problems of utilizing a bed level to attain turndown is described in Section 6.2.3.

\subsection{2 $\mathrm{CBB} / \mathrm{CBC}$ Combustion Control}

The BEW design for the CBB firing rate demand incorporates a feed forward signal from the boiler load demand. This allows the CBB to adjust the char feed in anticipation of a change in bed temperature: whereas the operation of the FWEC CBC is designer to burn the char as it is produced with the use of supplemental coal feed to maintain CBC bed temperature as required. FWEC does not provide any anticipatory feed forward signal for load changes.

Since the B\&W design includes a char feed tank, there is always an available storage of char which is used to meet temperature changes. In comparison with FWEC, the BEW CBB operation would require less supplemental coal and associated limestone feed to maintain the CBB temperature.

\subsection{Bed Material Control}

BEW does not try to trim limestone feed with the so2 measurements but allows the operator to make changes in the sorbent flow ratio. FWEC utilizes a three-element limestone feed control that incorporates an SO2 trim. It is not clear as to why SO2 measuring devices should be utilized to provide an 502 signal for the analog limestone feed control. It might be desirable to incorporate a workable automatic so2 trim in the limestone feed controls: however, in our judgement, it is adequate to utilize an operator adjustable so2 trim.

FWEC shows a differential pressure arrangement to determine bed level for the bed letdown devices. BEW does not indicate how a measurement of bed level would be achieved. The BEW limestone 
feed and ash rotary seal speed control does not seem to allow for a constant inventory of limestone with a limestone input/output matching 100p. FWEC matches the limestone feed and bed letdown with an adjustment for bed level. The following items are questionable with the BEW bed material controls:

1. Why the bed temperature is supposed to affect the ash rotary seal speed.

2. Why an increase in bed temperature increases the coal/limestone feed and decreases the bed letdown.

3. Why the limestone feed and the bed letdown have been decoupled.

4. Why a bed level error has to be sensed before the limestone feed is affected.

\subsection{General}

Because of the inventory of water contained within the B\&W boiler and because of the assisted circulation, it is likely that a loss of feedwater will not cause tubes to overheat. Because of the once-through design, it is necessary to investigate further whether the FWEC boiler can sustain a loss of feedwater and maintain sufficient tube cooling during the required coal burnout time.

Tube leaks in a drum type boiler would be comparatively easier to detect than in a once-through design. The water chemistry requirements within a once-through boiler are so strict that small leaks cannot be detected by sudden changes in the boiler water chemistry as is the case with a drum type boiler. While small leaks would not pose a problem within submerged bed tubes, large leaks could cause the limestone to react with the water to form harmful cementious compounds. Neither boiler manufacturer at this time, has a suitable method for detecting and correcting larye tube leaks.

The BEW boiler control logic shows a turbine control based on throttle pressure error. This means that the turbine-generator output will only be varied after the boiler pressure has been adjusted by a change in the firing rate for the load. With this design, megawatt response is relatively slow since the faster responding presaure control loop does not allow the turbine to borrow energy stored in the boiler during transients.

The FWEC boiler control logic, however, allows the boiler and turbine to respond to load changes simultaneously. This coordinated control is a more conventional, faster responding control system than the controls proposed by BEW.

The question arises as to why B6W imposes a relatively less responsive system on their boiler-turbine controls. 


\subsection{Conclusions}

As was stated earlier, it is not possible to pass judgement on the validity of the control systems presented. However, the effort has been a worthwhile and necessary step toward evolving an effective AFB boiler control system.

It is obvious from the approaches of the two manufacturers that the knowledge of the fluid bed process is limited for this application. The next logical step would be to simulate the control systems to determine the suitability of each design.

With the development of the open 1oop, S\&W AFB system model, Part $v$ of this report, the control strategies for parameters such as bed height and temperature, proper handling of the dynamic effects on the boiler such as coal particle burnup $t$ ime; coordinated unit load control, etc.., may be confirmed or modified by applying the proposed control concepts to the model. Thus, the suitability of the once-through unit controls and those of the drum boiler concept, with appropriate model modifications, could be confirmed or recommendations developed for appropriate changes. The systems would be evaluated for normal load range operation, start-up, and fast transients such as load rejections or plant trips. It is recommended that the AFB model work be extended to include these further checks on the control system design.

\subsection{ELECTRICAL SYSTEMS ANALYSIS AND COMPARISON}

\section{1 General}

The auxiliary station service systems for the $B E W$ and FWEC AFB plants are similar in size and arrangement. tach system consists of one main and one reserve statiun service transformer with three voltage levels for feeding major loads: $13.8 \mathrm{kv}, 4.16 \mathrm{kv}$. and $480 \mathrm{v}$. Load tap changers are provided for the auxiliary station service transformers to improve voltage regulation at the $480 v$ level.

The factors leading to the design of the station service system arrangement and the major differences between the BEW and FWEC systems are discussed below.

\subsection{Technical Fuasibility}

Several alternative arrangements for the station service systems were considered, including changes in the number of transformers and switchgear buses, and different voltage levels. The final design was chosen based on economic and technical factors. Although not the only possible arrangement, the final design incorporates the best combination of economic and technical factors of all systems studied. 


\subsubsection{Motor Starting Considerations}

The major problem posed by both the B\&W and FWEC AFB plants is the starting of the large motors for the F.D. and I.D. fans. A motor during starting draws a large current which in turn causes a drop in voltage. It is desirable to maintain a minimum of 80 percent of full load motor terminal voltage to minimize voltage fluctuations in the rest of the system. Multispeed motors and variable speed drives cause less voltage drop but are technically unproven and economically unfeasible for such large motors.

The FWEC motors are larger than the B\&W motors and accordingly present more of a problem. A study of the station service system indicated that the large motors in the FWEC plant would have to be rated at $13.2 \mathrm{kv}$ for satisfactory starting performance.

For the BEW plant, it is technically feasible to use $6.6 \mathrm{kv}$ motors which are less expensive than $13.2 \mathrm{kv}$ motors. However, starting performance is marginal, and this arrangement was rejected for other reasons detailed in sections 7.2 .3 and 7.2 .4 .

There are no motor starting problems with the $4 \mathrm{kv}$ motors in either the BEW or FWEC plants. Load tap changers are provided for the auxiliary station service transformers to improve valtage regulation at the $480 \mathrm{v}$ level. The load tap changers could be eliminated if the $480 \mathrm{v}$ substations were fed directly from the $13.8 \mathrm{kv}$ switchgear bus, but this would entail additional expense in the switchgear bus and substation transformers. The decision to use the load tap changers was based on economics.

\subsubsection{Auxiliary Station Service Load}

The expected station service electrical load for BEW is approximately 1 percent higher than for the FWEC plant. Detailed figures are presented elsewhere in this report. Although the totals for both plants are similar, the FWEC plant has a greater $13.8 \mathrm{kv}$ load, and BEW has a greater $4 \mathrm{kv}$ and $480 \mathrm{v}$ load. These differences are reflected primarily in equipment sizes and capital costs for the two plants.

\subsubsection{Equipment Sizes and Ratings}

The impedances of the unit and reserve station-service transformers are selected to allow 80 percent starting of all motors without exceeding the short circuit withstand capability of the medium voltage switchgear. The $13.8 \mathrm{kv}$ switchgear used in both plants is 750 kva class. In order to use $6.9 \mathrm{kv}$ switchgear for the BEW plant, the load would have to be divided among more switchgear buses and more transformer secondaries to accommodate the lower short circuit withstand capability of this switchgear.

There are a greater number of $4.16 \mathrm{kv}$ breakers for the BEW plant because of the larger $4 \mathrm{kv}$ motor load, and there are more 480 
unit substations, primarily because of the large precipitator load.

7.2.4 Capital and Operating costs

Capital and operating costs are detailed elsewhere in this report. Differences in capital costs for the electrical systems of the two plants arise because of additional cable and $4.16 \mathrm{kv}$ switchgear required for the BEW plant. Operating costs should be approximately the same for the two plants because the total station-service loads are about the same.

\subsection{ENVIRONMENTAL ANALYSES AND COMPARISONS}

8.1 Air Quality

\subsubsection{Sulfur Dioxide Emissions}

'the sultur dloxide (SO2) emissions, predicted by both manufacturers, reflect compliance with present Federal EPA New Source Performance Standards (NSPS) emission limitations for SO2 of 1.2 1b SO2 per million Btu. Predicted SO2 emissions from the BEW and FWEC designed boilers are 1.2 and $1.16 \mathrm{lb}$ SO2 per million Btu, respectively- For purposes of this evaluation, both so2 emission rates are considered equivalent at $1.21 \mathrm{~b}$ so2 per million Btu. Achievement of compliance 502 emission rates require a calcium-to-sulfur $(\mathrm{Ca} / \mathrm{s})$ molar ratio of 2.5 and 2.1 for BEW and FWEC, respectively.

Promulgation of the clean Air Act Ammendments of 1977, in August 1977, proposed that the existing NSPS emission limitations for $\mathrm{SO2}$ be revised within one year (August 1978). These revisions will include: (1) a required percentaye reduction in sulfur dioxide emissions and (2) a revised weight emission limitation. It is anticipated that in February, 1978, the revised NSPS for 502 will be proposed. These revised NSPS will require a 90 percent reduction in $\mathrm{SO} 2$ emissions with a maximum emission limitation of $1.2 \mathrm{lb}$ SO2 per million Btu and a minimum of $0.2 \mathrm{lb}$ SO2 per million Btu.

It is the opinion of both manufacturers that achievement of a 90 percent reduction in SO2 emissions is possible with present designs and would require a CA/S molar ratio of approximately 3.9 with existing operating parameters. An increase of Ca/S molar ratio would also generate a larger quantity of solid waste.

Both manufacturers have designed their boilers to attain 1.2 ib SO2 per million Btu. It is believed that an AFB boiler designed for 90 percent reduction in SO2 emissions may employ operating parameters different from present design to minimize the high limestone consumption needed with present operating parameters. This area of concern requires additional study with subsequent testing and evaluation. 


\subsubsection{Oxides of Nitrogen (NOx) Emissions}

The boiler manufacturers have designed their boilers to meet New Source Performance standards (NSPS) emission limitations for NOx of $0.7 \mathrm{Ib}$ NOx per million Btu. BEW and FWEC have predicted the Nox emissions from their boilers to be approximately 0.5 and 0.3 Ib NOx per million Btu, respectively. Since both boilers have similar operating parameters (i.e., bed height, superficial gas velocity, excess air and temperaturel and are firing the same fuel, it would be expected that these emissions should not reflect this great a discrepancy between the two designs. It is our opinion that these emissions differ due to the use of different models utilized in predicting the Nox emissions from their respective boilers. It is, therefore, believed that neither predicted emission is incorrect, but that they reflect the range of NOx emissions (.3-.5 Ib NOx/MMBtu) that can be expected from the operation of a 570 Mw AFB boiler.

Promulgation of the clean Air Act Amendments of 1977, in August 1977, proposed that revised NSPS emission limitations for Nox be promulgated within one year (August 1978). A proposed revised NOX NSPS emission limitation of $0.6 \mathrm{lb}$ NOX per million Btu is anticipated in February 1978 and is expected to be promulgated by August 1978. It is expected that the proposed revised NOx NSPS emission limitations of $0.6 \mathrm{lb}$ NOx per million Btu would be satisfied by both designs.

\subsubsection{Total Suspended Particulate (TSP) Emissions}

The present Federal EPA New Source Performance standards (NSPS) emission limitation for TSP is 0.1 lb TSP per million Btu. Both manufacturers have designed their systems to attain 0.06 ib TSP per million Btu, which was specified by stone $\varepsilon$ Webster, and is in compliance with NSPS. TSP emission rates are achieved by use of two hot electrostatic precipitators (ESP) for the BEW design and mechanical collectors and a baghouse for the FWEC design. Promulgation of the Clean Air Act Amendents of 1977, in August 1977, requires a revision of NSPS emission limitations for TSP within one year (August, 1978). It is anticipated that a revised TSP NSPS emission limitation of $0.03 \mathrm{lb}$ TSP per million Btu will be proposed by February 1978. This revised NSPS particulate emission limitation can be achieved by the baghouse as currently designed by FWEC. The B6W hot ESP's will require an increase in size (plate area) by approximately 15 percent to satisfy the revised TSP NSPS emission limitation.

At this time, there is some disagreement in the industry as to whether (1) hot ESPs can be designed to effectively collect both high carbon content material and high calcium material and. (2) with the use of a cold baghouse, will. high particulate loadings in the air heater cause entrainment of particulate matter in the primary air stream and subsequent pluggage of the air alstributor plate. 
It is recommended that a test program be initiated to characterize particulate emissions from AFB boilers to establish the most cost effective method for complying with paticulate requirements from both environmental and process viewpoints.

\subsection{Solid Wastes}

Solid wastes from the AFB plant include bed material and elutriated material collected in the particulate collection system. Both of these wastes consist of calcium sulfate, calcium oxide, fly ash, bottom ash, and other inert materials. The quantities of solid waste from the AFB plant designs are approximately $140,000 \mathrm{lb}$ per hour for the BEW design and 125,000 1b per hour for the FWEC design. The discrepancy in the quantity of solid waste generated for the two designs is due to higher CA/S molar ratio predicted for the B\&W design (2.5 vs 2. 1).

Conceptually, the AFB solid wastes from both designs would be pneumatically conveyed to silos and subsequently trucked to the landfill area being worked. Both designs would use the 120 acre solid waste disposal area with a total required landfill height of approximately 38 and $34 \mathrm{ft}$ for the BEW and Foster Wheeler designs, respectively.

Based on the results of studies conducted under DOE and EPA contracts for AFB solid waste disposal. land disposal of solid wastes generated from an AFB boiler will not have adverse environmental effects. In fact, studies have shown the material to be both structurally stable and durable for landfilling. Results of leaching tests have also found the material feasible for landfilling.

Revisions of NSPS (as discussed in Section 8.1.1, Sulfur Dioxide Emissions) will require greater amounts of limestone and inherently greater quantities of solid wastes. This area of concern requires additional study with subsequent testing and evaluation to minimize limestone consumption and solid waste generation.

\subsection{Conclusions}

The following are the environmental design criteria that were set by Stone $\varepsilon$ Webster at the start of this project:

$\begin{array}{ll}\text { Pollutant } & \text { Maximum Emission Rate } \\ \text { SO2 } & 1.2 \text { lb per MM Btu } \\ \text { NOX } & 0.7 \text { lb per MM Btu } \\ \text { TSP } & 0.06 \text { 1b per MM Btu }\end{array}$

For purposes of this evaluation, both the BEW and FWEC designs have predicted meeting the above design criteria. It is also expected that both manufacturers" designs would satisfy 
anticipated revised NSPS with minor particulate control equipment modifications. The quantity of solid wastes generated by the BEW design is slightly greater than the FWEC design due to a higher calcium-to-sulfur molar ratio caused by lower limestone utilization. Iand disposal of solid wastes generated from an AFB boiler will not have adverse environmental effects. In fact, studies have shown the material to be both structurally stable and durable in landfilling.

In summary, both designs satisfy the environmental design criteria set by $\mathbf{S} \boldsymbol{E}$.

\subsection{CONSTRUCTION SCHEDULE}

The Babcock $\&$ Wilcox AFB construction schedule is comparable to a conventional pulverized coal plant construction schedule. A Foster Wheeler construction schedule was not received. Since no contradictory information has been indicated, we assume the Foster theeler AFB construction schedule is also comparable.

10.0 OTHER ANALYSES AND COMPARISONS 


\section{PART V}

\section{ATMOSPHERIC FLUIDIZED BED \\ PLANT MODEI ANALYSIS \\ FOR \\ LOAD-FOLLOWING CAPABILITY}




\section{ABSTRACT}

The load-following capability of a once-through subcritical Atmospheric Fluidized Bed Boiler is analyzed. Digital computer simulation predictions of the plant's response to open loop step changes in firing rate, feedwater flow, governor valve, unit load demand, etc, are made. The predicted response of throttle pressure, steam temperature, unit load, etc, are compared to the response of a conventional coal-fired, once-through, subcritical unit. The load-following capability is assessed through this qualitative comparison. Additional model response predictions are also presented for which. no test data are presently available. 
TABLE OF CONTENTS

Section

Description

Page

1.0

1. 1

1.2

INTRODUCTION

General

objective

1

1

2.0

DESCRIPTION OF THE ATMOSPHERIC FLOIDIZED BED POWER PLANT

3.0

3.1

RESULTS

AFB Steady State-Lodd Conditions

AFB Open Loop Response for Comparison with

3.2 PC Unit

3.2 .1

3.2 .2

3.2 .3

Step In Combustion Rate

Step In Feedwater Flow

Step In Throttle Valve Position

Step In Unit Load

3.2 .4

CONCIUSIONS

9

4.0

RECOMMENDATIONS

10

6.0

REFERENCES

APPE'NDICES

Appendix VA: Description of Mathematical Model

Appendix VR: Computer Program and Detailed Results 


\section{LIST OF FIGURES}

Pigure

No.

\section{1.}

2.

3.

4.

5.

6.

7.

A1.
Once-Through Atmospheric Fluidized Bed Boiler

water. Steam, and Gas Path Schematic

Water, Steam, and Gas Path Temperatures

Open Loop Response Comparisons At $100 \%$ Load Step In Combustion Rate

Step In Feedwater Flow

Step In Throttle Valve position

Step In Unit Load

Appendix

Overall AFB Model Solution Diagram 


\subsection{INTRODUCTION}

\section{1 General}

There has been a very rapid increase in the size of power systems during the decades of the fifties and sixties, and it is still growing today- If the present trend continues, one can foresee that in the seventies and eighties the power companies will experience an even greater increase in the total peak MW demand. Due to the higher cost of coal, oil, and natural gas total energy consumption will not increase as fast since the price of electric energy will tend to increase. The gap between the daily base load and the daily peak MW load demand will increase. This increase in the magnitude of cycling load demand would necessitate the need for more responsive fossil units.

Furthermore, in the next decade, as more nuclear units with their low incremental operating cost are put into service, the burden of following minute-to-minute load demands will be placed heavily on fossil-fired units.

The Atmospheric Pluidized Bed (AFB) with the ability to burn more abundant high sulfur coal, and with a useful byproduct, may provide such load-following capability with minimum environmental impact. The questions remaining are:

a. What plant and control system configurations should be employed?

b. Will its load-following ability be adequate?

This study addresses the second question for a particular plant configuration as explained in the following objective:

\section{2 objective}

The objective of this effort is to predict the open 100p response characteristics of the Foster Wheeler Energy corporation Atmospheric Fluidized Bed (AFB) plant to step changes in controlled variables for comparison with typical results for a conventional pulverized coal-fired, once-through, utility unit to ascertain the AFB load-following capabilities. 


\subsection{DESCRIPTION OF THE ATMOSPHERIC FLUIDIZED BED PLANT}

The $570 \mathrm{Mw}$ AFB plant is briefly described in this section to provide a background for the load-following capability study. The AFB plant consists of:

a. One Foster wheeler designed subcritical, once-through AFB steam generator, and

b. The associated balance of plant equipment for power generation.

Figure 1 shows the arrangement of the various elements that would comprise the AFB steam generator. The AFB steam generator consists of tive main bed cells (MBC) stacked vertically over one another and a single carbon burnup cell (CBC) which is located to the rear of the MBC stack. Heat transfer surfaces in MBCs are arranged for boiling, superheat, and reheat duty.

Figure 2 shows the simplified water, steam, and air-gas schematic for the AFB steam power plant. Combustion air requirements of the AFB steam generator are furnished by two forced draft (F.D.) fans. Combustion air is preheated through the air preheaters before being introduced to the MBCs and the CBC compartmented plenums beneath each cell. Airflow to each compartment is regulated by individual dampers. Gaseous combustion products from each cell passes through the cell freeboard and the common gas column before being directed over the convection reheater and the primary superheater arranged in the heat recovery area (HRA).

Gas flow through the HRA is biased by means of automatic reheat termerature control dampers. Gases leaving the dampers pass over an extended surface economizer and are cooled prior to entering the dust collector trains. Finally, the gases are discharged to the stack via the regenerative air heaters, baghouse collector, and the induced draft (I.D.) fan.

Feedwater enters the steam generator through the HRA extended surface economizer (LCON1). The feedwater then passes through convection economizer (ECON2) above the CBC bed, and through the CBC in-bed heating surtace (BCON3). The teedwater then passes through the $C B C$ walls to the $M B C$ in-bed steam generating surfaces. Transition from water to steam-water mixture occurs within $M B C$ bed $B B 2$. The steam/water mixture leaving BB2 then passes through the steam generator enclosure in the following order: front wall (FW). sidewalls (SW), rear wall (RW), gas pass (GP). heat recovery area (HRA), and roof (ROOF). Transition from a two-phase mixture to superheated steam occurs in the $R W$ pass at full-load conditions.

From the ROOF outlet, superheated steam passes through integral separators which are required during start-up and for low load operation to separate the steam and the water. After passing through the separator. the superheated steam passes through the convection superheater (PRI) in the HRA and then passes through 


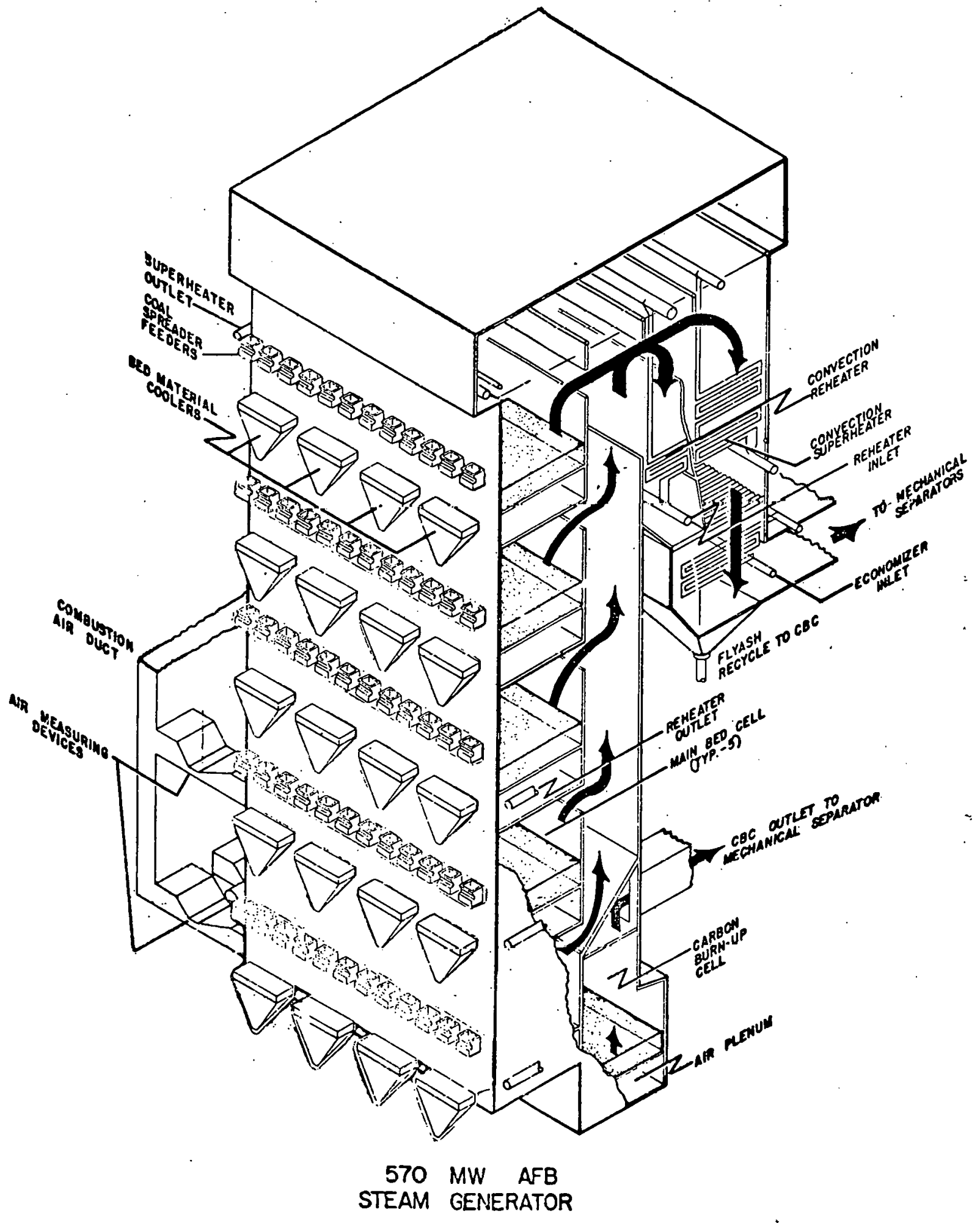

FIGURE I

ONCE THROUGH ATMOSPHERIC FLUIDIZED BED BOILER 

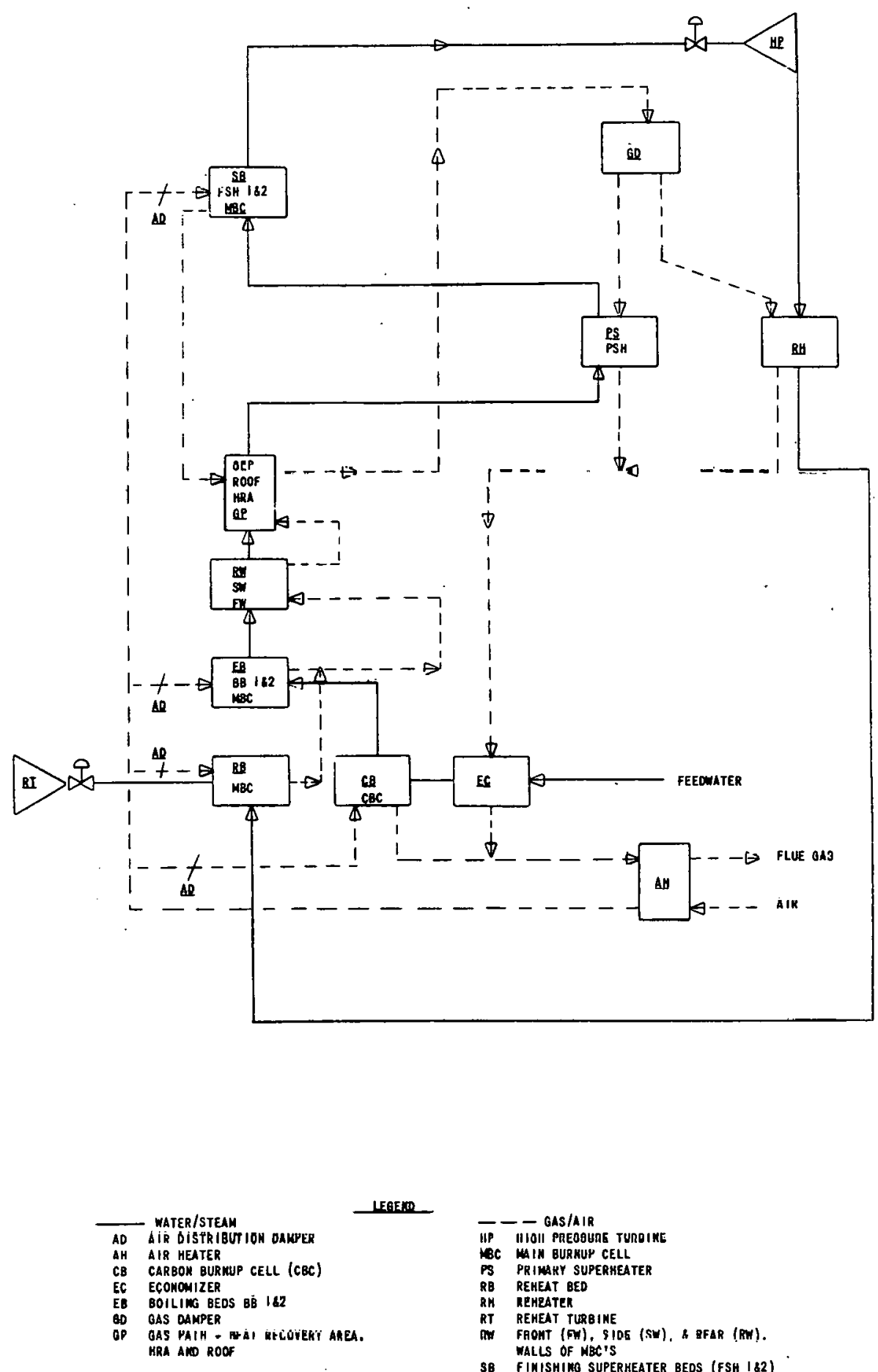

FIGURE 2

WATER-STEAM AND AIR-GAS PATH SCHEMATIC 
the horizontal MBC bed superheating surfaces (FSH1 and FSH2). Feedwater sprays provide control of final steam temperature by desuperheating the superheated steam.

Steam flow leaving the steam generator superheater outlet enters the HP turbine and is regulated by the turbine governor valves. The exhaust from the HP turbine passes through the convection reheater surface in the gas pass before entering the horizontal in-bed MBC reheater surface. The reheated steam then flows through IP/LP turbine.

Figure 3 shows:

a. The water-steam temperature gradient through the boiler system.

b. Corresponding gas path tcmperatures.

c. Typical above bed combustion temperature profile, and

d. Relative directions of gas flow to water-steam flow.

This provides a visual perspective for understanding the relationship of the temperature differential with the heat transfer. 


\subsection{RESULTS}

The results section of this report includes the following main points of interest:

Included is a brief discussion of the accuracy of the model relative to reproducing the steady-state conditions.

Comparisons are made of the difference in response between the AFB boiler and the conventional coal-fired boiler for step changes of 5 percent. The results are presented in graphical form for visual comparison and discussion.

Appendix VA gives a general description of the mathematical model used in this study.

The computer program and nomenclature are included in Appendix VB. Also, the dynamic response of other variables are presented in graphical form providing additional system details.

\subsection{AFB Steady-State Load Conditions}

The AFB model was developed on the basis of manufacturer's design data. The program was run for an equivalent of 36 minutes of plant operation to demonstrate the accuracy of initial steadystate conditions. The steady-state values at the end of 36 minutes were within one-half of 1 percent of the initial starting values. The model was initialized at these stabilized conditions for all step response runs. Running an additional equivalent plant operation time of 36 minutes produced deviations of less than one-tenth of a percent, demonstrating an acceptable starting steady-state condition.

A printout of steady-state results is given in Appendix VB. Also presented is the Computer Program Nomenclature which defines all computer program parameter names and their design values at 100 percent load.

\subsection{AFB Open Loop Response for Comparison with PC Plant}

The following presents responses to steps in major controlled variables for main steam and reheat temperature, main stcam and turbine first stagc pressuru, and unit. load. The results compare the $570 \mathrm{MW}$ AFB boiler with a $200 \mathrm{MW}$ subcritical pulverized coalfired unit. Response data for megawatts were not available for the conventional plant.

Comparisons are yiven for 5 percent steps in firing rate, feedwater flow, throttle valve position, and unit load. For individual steps, the other two variables were held constant except for the step in unit load in which all three input variables were stepped at once. Larger steps would require 


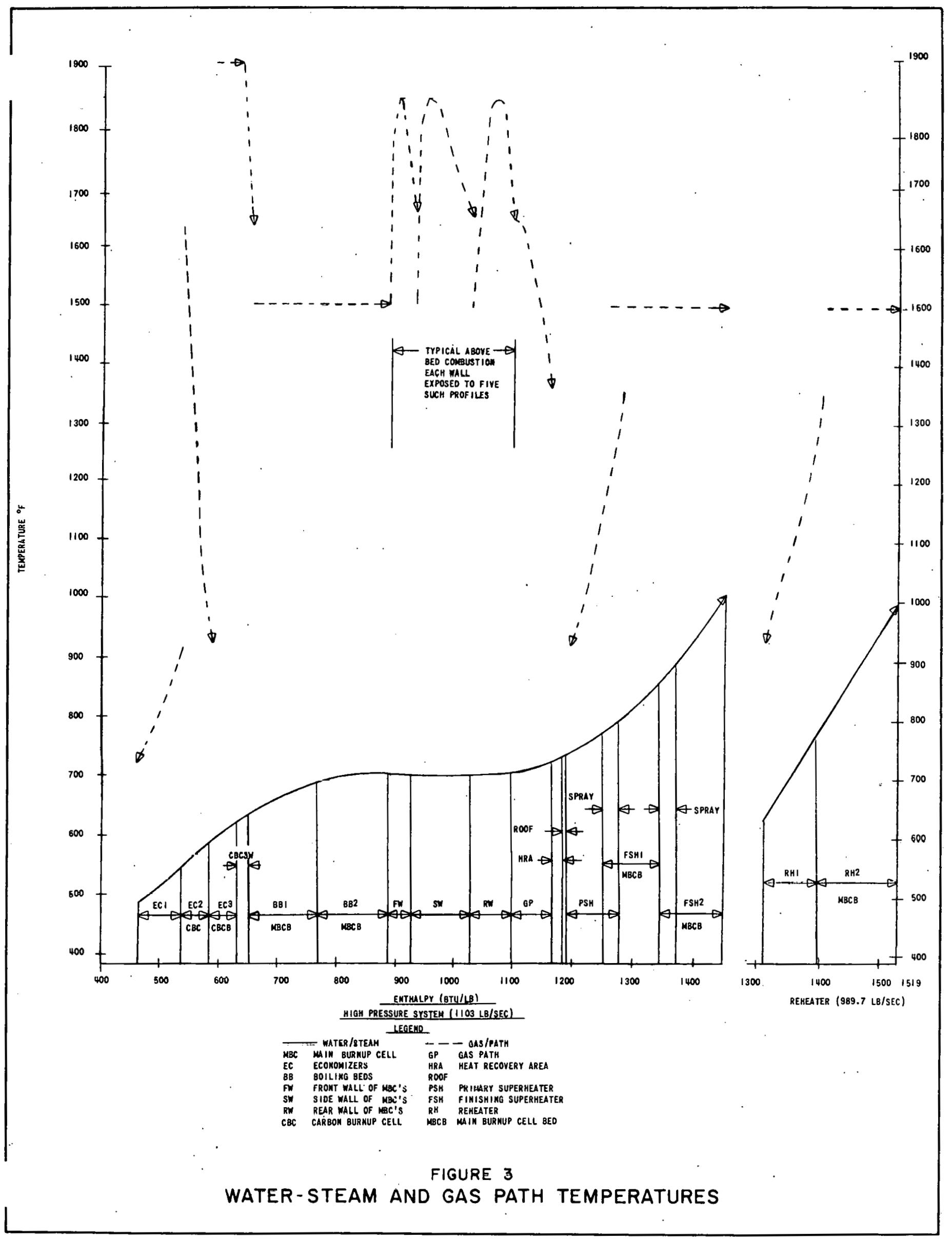


slumping of individual beds and the model is not currently set up to simulate this phenomenon.

\subsubsection{Step in Combustion Rate}

Figure 4 shows a step change in the firing rate at 100 percent load. Coal, air, limestone, and spent bed material were all increased 5 percent. Feedwater flow and throttle valve position were held constant.

The results show initial decreases in all AFB model variables for approximately 2 minutes while the conventional plant variables hold or increase over this period of time. AFB main steam pressure crosses zero in 4 minutes while reheat and main steam temperatures take 4 and 8 minutes, respectively, to increase above zero. For the conventional unit, main steam and first stage pressure respond immediately, whereas reheat and main steam temperature begin to respond within 1 to 2 minutes. The above times appear to indicate the difference in dead time between the two units. Plant variables for both units are essentially at their now steady-stale conditions in approximately 36 minutes.

The initial decrease in AFB steam temperatures, pressures, and unit load results from the step in airflow before the combustion process releases its energy. The boiler design incorporates a holdup of 6 percent carbon in the beds. This is about 8.6 minutes of full load coal flow. The combustion process was assumed to be exponential with a time constant of 1.7 minutes; thus effectively delaying the energy release due to the combustion of the coal.

During the initial 20 minutes, reheat and main steam temperatures for the conventional subcritical unit are more responsive to firing rate increases, thus providing for quicker megawatt response.

The combustion process, including the combustion burnup time, should be examined more closely because of its influence on temperature response which directly affects the unit load response.

The inherent lag in temperature response of the AFB will lead to problems in unit control. Dead time requires control with low gain. long reset time, and the addition of derivative action. Dynamic feed-forward compensation is also required.

Load-following units move at a 2 to 5 percent per minute ramp rate in response to dispatcher request for power. The AFB wula require considerable over and underfiring to meet this response time with subsequent adverse effects on metal temperatures and unit thermal stress.

The AFB is roughly three times the megawatt rating of the conventional unit. It is anticipated that unit size has a 
secondary effect on unit response time. However, this assumption should be pursued further as some data indicate that response time increases with size. Under the limited scope of this study. this point could not be pursued further.

Indicated AFB power is slightly higher than expected with the 5 percent step in firing rate. This may be attributed to the simple turbine megawatt calculation used in the model. Also, feedwater flow and temperature were held constant for the AFB while the feedwater temperature increases in the actual unit. Final values for reheat and main steam temperature are slightly higher for the AFB. In general, AFB temperatures and pressures are in agreement with the conventional unit data except for the slower initial response of the AFB.

\subsubsection{Step In Feedwater Flow}

Figure 5 shows response of the AFB unit to a 5 percent step increase in teedwater flnw while holding feedwater temperature constant. Here a quicker response is observed in main steam and reheat temperatures. Note that feedwater flow increases over a period of about 3 minutes for the conventional boiler while it increases instantaneously for the AFB boiler. First stage and throttle pressures responses are similar. The AFB response shows a final megawatt offset of about -2.7 percent. This would not occur in a real plant as increased flow through the turbines would raise extraction pressures. thus increasing feedwater temperature which eventually would increase megawatts.

Main steam temperature increases about 1 percent initially. This is due to rise in main steam pressure cuased by the step increase in feedwater flow, i.e.. isenthalpic compression process. As cooling takes over, temperatures are reduced as expected.

First stage and throttle pressure comparisons between the $\mathrm{AFB}$ and conventional unit are in good agreement once allowances are made for the 3 minute ramp in feedwater flow in the latter.

Dead time in main steam and reheat temperature is greater in the conventional plant than in the AFB model. This is associated with lumped parameter models which could be modified for future studies. Also, the response time of temperature sensor clcments is not simulated in the AFB model. Incorporating either or both of the above factors in the model would tend to result in a slower response.

In general, the temperature decays due to an increase in feedwater flow are faster for the AFB, indicating possibly less thermal storage in this unit, i.e.., a more compact boiler. The AFB temperature decay is several minutes quicker than the conventional plant when adjustments are made for the initial difference in Ilow, i.e., ramp vs step increase. The net effect is less integrated megawatts (energy) from the AFB feedwater step than for the conventional unit. 


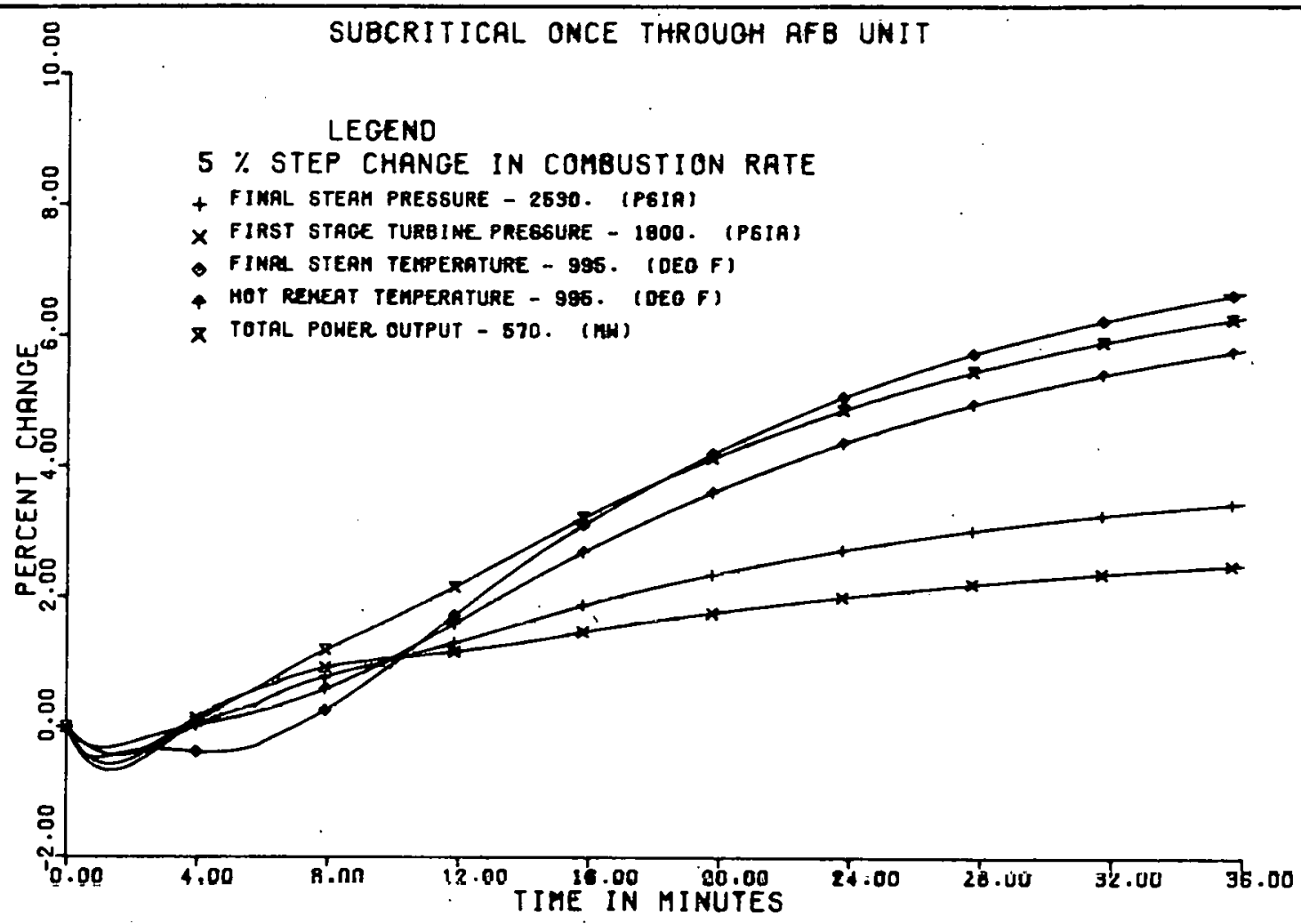

BALTIMORE GAS AND ELECTRIC CHARLES P. CRANE STATION SUBCRITICAL ONCE THROUGH CORL FIRED UNIT

$$
\text { (UP-6 } 191 \text { MW UNIT) }
$$

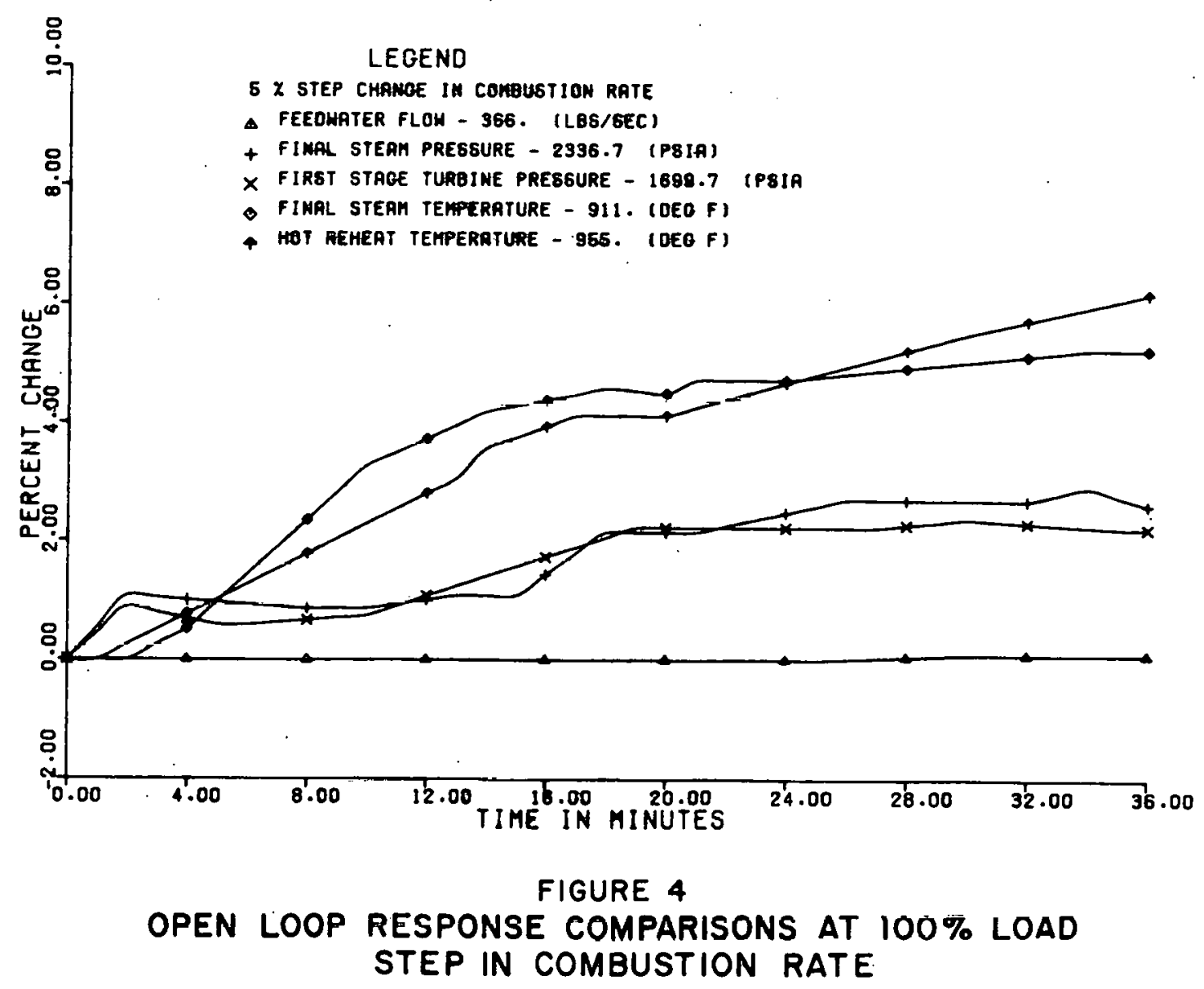




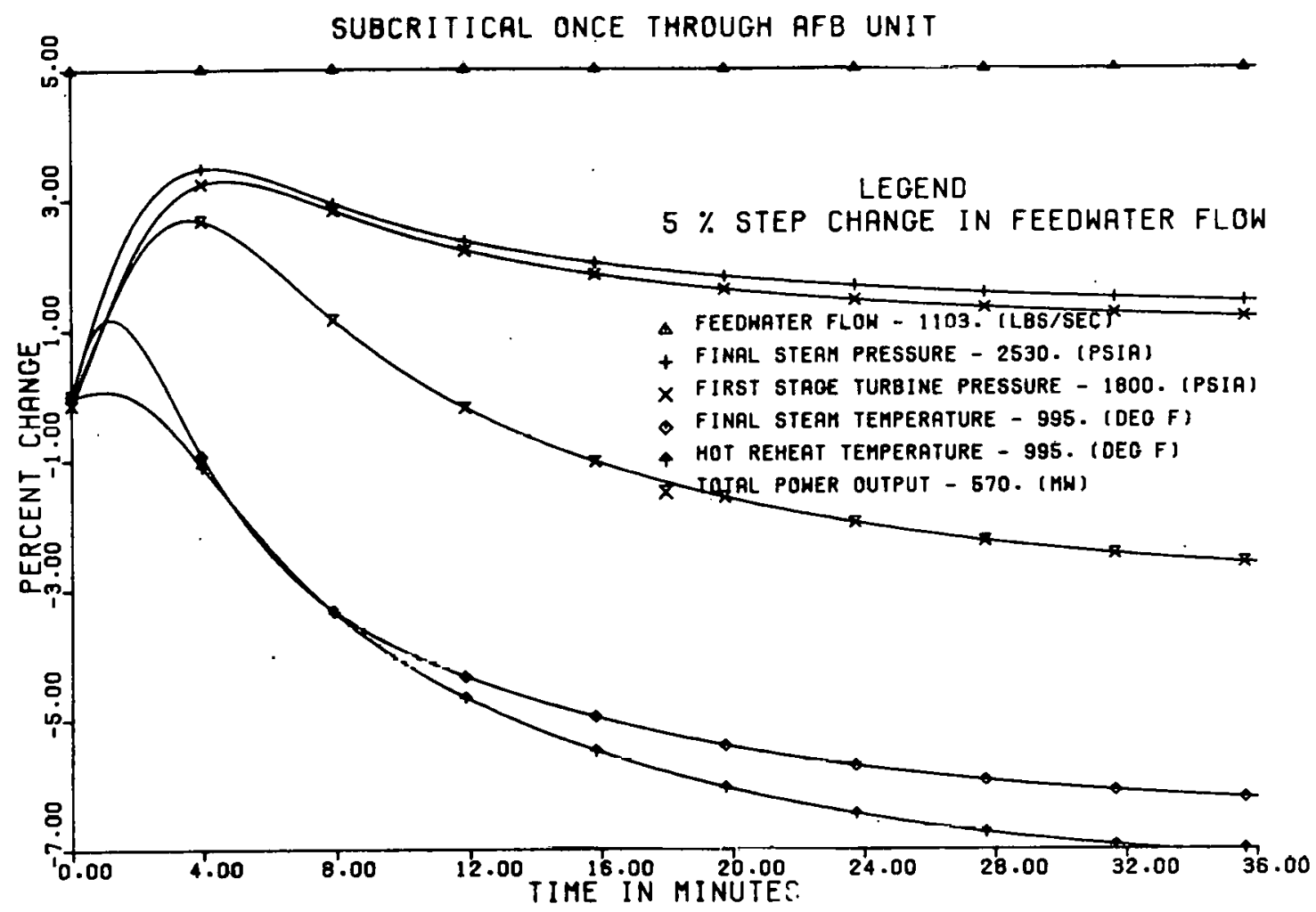

BALTIMORE GAS AND ELECTRIC CHARLES P. CRANE STATION

SUBCRITICAL ONCE THROUGH COAL FIRED UNIT

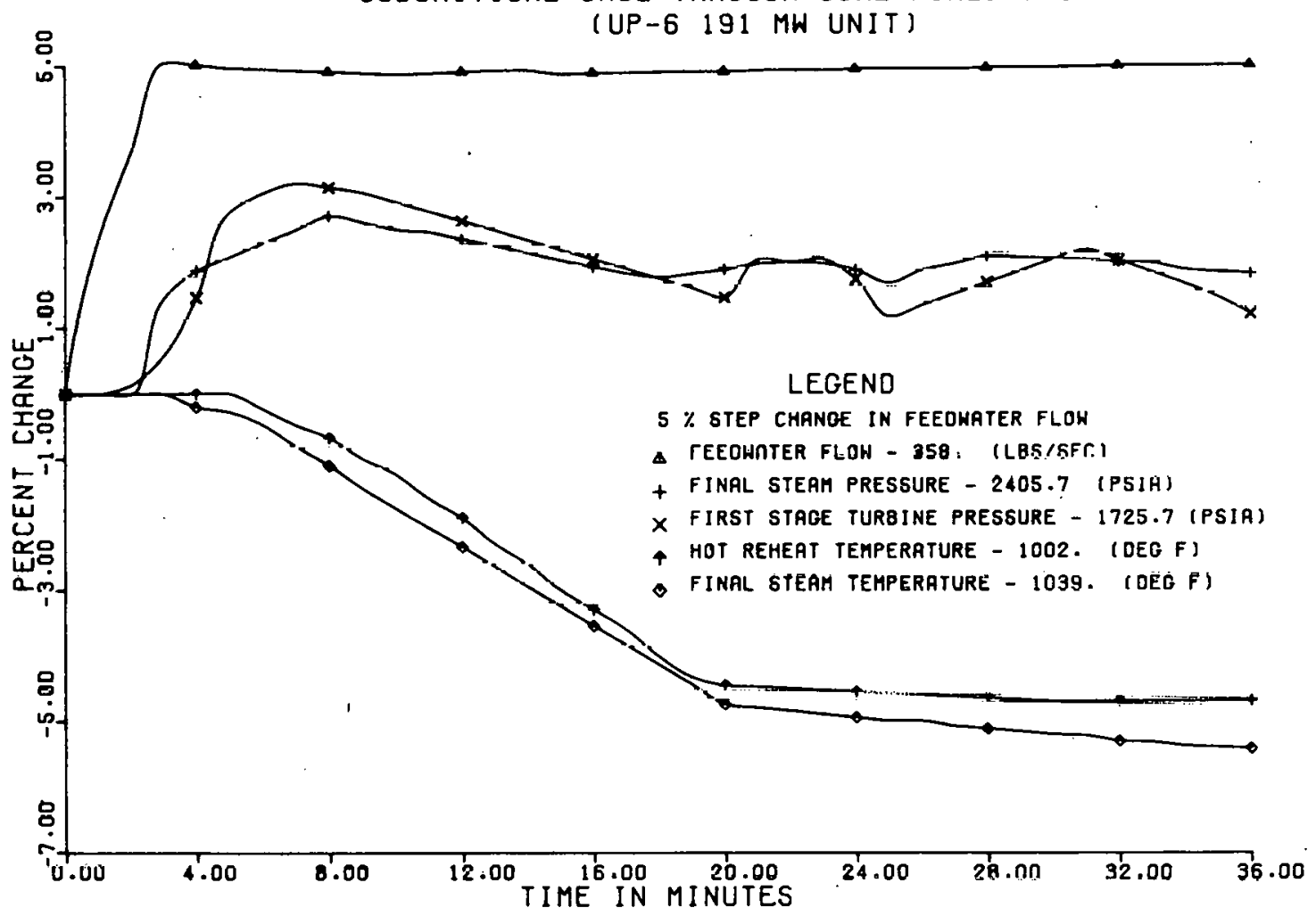

FIGURE 5

OPEN LOOP RESPONSE COMPARISONS AT $100 \%$ LOAD STEP IN FEEDWATER FLOW 
Because the AFB thermal response to firing rate is slower and its response to water flow quicker, more dynamic compensation would be necessary to obtain the desired degree of control for following load demand ramps.

\subsubsection{Step in Throttle Valve Position}

Fiyure 6 shows the response of the AFB and conventional subcritical unit to a 5 percent step increase in throttle valve position with other variables held constant. However, for the conventional plant, an additional upset in feedwater flow is induced.

Main steam pressures are in good agreement once allowances are made for the feedwater upset:

First stage pressure response for the AFB model is offset by 3 percent from that of the conventional unit data. This is attributed to the rather simple correlation used to estimate this varlable value within the model. All other variables were in good agreement. The apparent difference in first stage pressure is only an offset. The transient shape and magnitude is in agreement with data.

Final hot reheat and main steam temperatures for the conventional boiler do not show the magnitude of upset when compared to the AFB model. Main steam temperature increases while reheat temperature decreases indicating a change in heat absorption within the boiler. This could be due to close coupling of the steam and gas in the primary superheater causing a redistribution of energy due to reduced throttle pressure. The megawatts are only slightly changed as would be expected since input energy is unchanged.

The AFB unit shows temporary negative excursions for both main steam and reheat steam temeprature during the first 4 minutes. These are attributed to temporary expansion cooling of main steam on depressurization. This temporary effect also propagates into the reheater. This trend is not apparent for the conventional unit data which may be due to slow response time of the temperature measurement devices.

The ability to increase first stage pressure (steam flow) with opening of the throttle valves is an indication of a unit's initial responsiveness to load demand. The conventional unit is capable of maintaining first stage pressure positive for about 12 minutes with approximately constant throttle and reheat temperatures; and megawatts are supported for this period of time. The AFi, however, supports megawatts for about 3 minutes and appears to have less fluid storage from which to draw initial turbine energy. Thus, the megawatt response of the conventional unit appears to be better for the initial 12-minute time frame. 


\subsubsection{Step In Unit Load}

Figure 7 shows the unit load response of both units brought about by simultaneous 5 percent steps in the three main control variables.

As a first approximation, the respective response variables for the step change in unit load for the conventional unit were derived by adding their magnitudes for the individual responses.

The megawatt response for the conventional unit was not available from the field data: however, first stage pressure corrected for main steam and reheat temperature can be used as an indication of expected megawatts. Based on the above, it is estimated that the conventional unit reaches its new megawatt steady-state value in approximatply $R$ to 12. minutes. By comparison, the AFB shows megawatts increasing gradually for approximately 36 minutes.

Both main steam and reheat temperature of the AFB unit are lower than for the conventional unit following the unit load step. The AFB does not support load as readily as the conventional unit due to its lagging thermal response caused by the delayed coal combustion rate. 


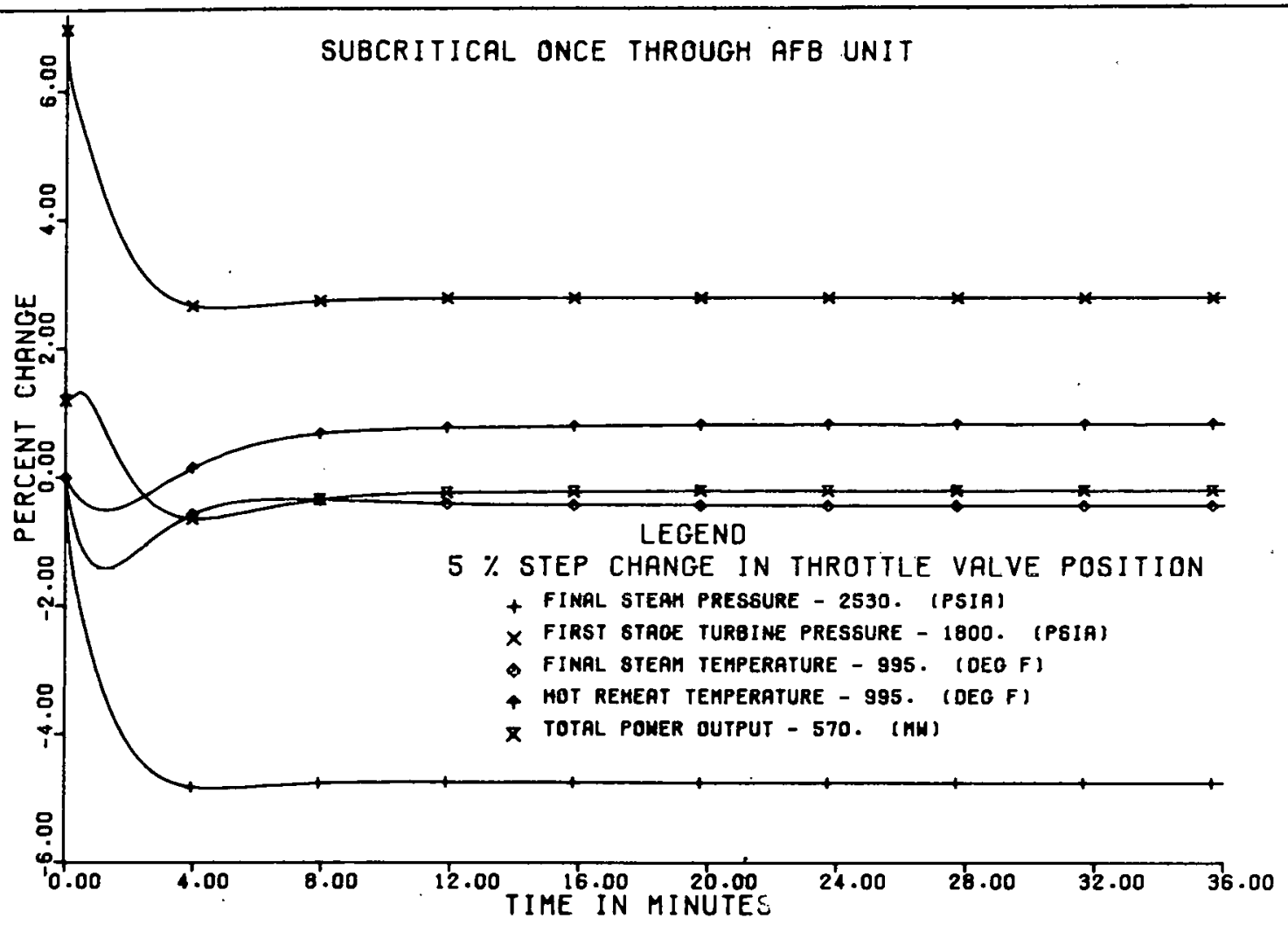

BALTIMORE GAS AND ELECTRIC CHARLES P. CRANE STATION

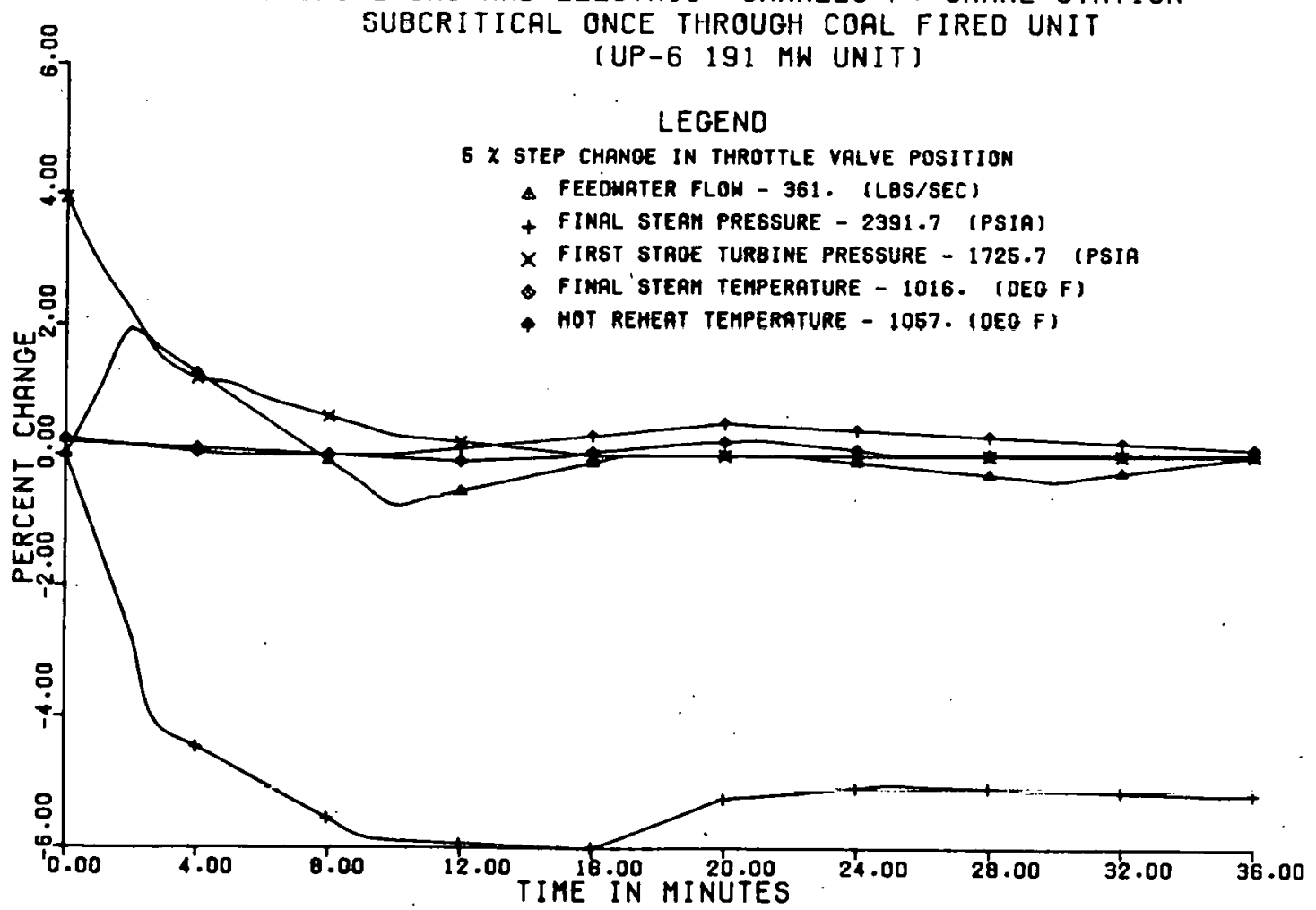

FIGURE 6

OPEN LOOP RESPONSE COMPARISONS AT 100\% LOAD

STEP IN THROTTLE VALVE POSITION 


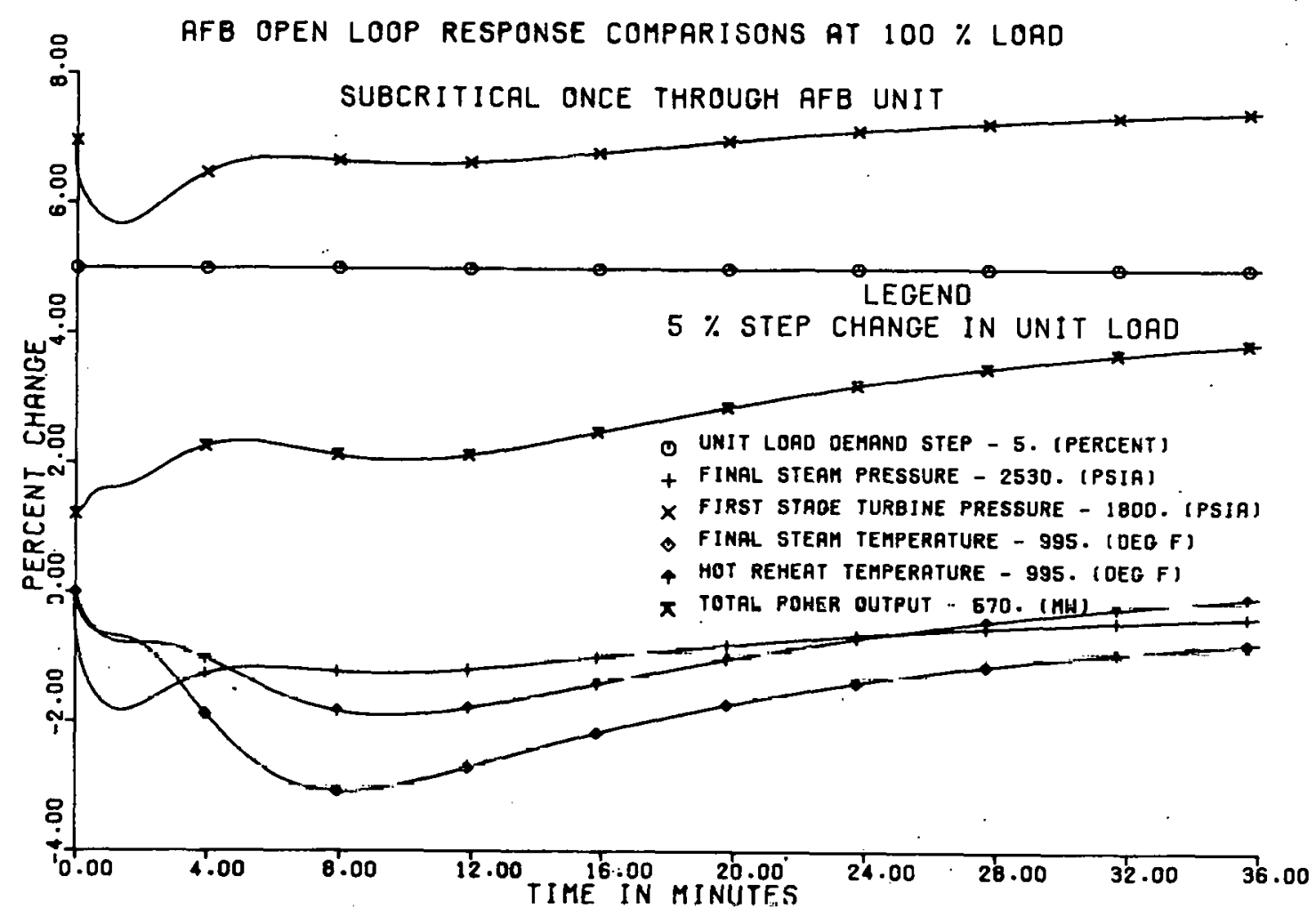

BALTIMORE GAS AND ELECTRIC CHARLES P. CRANE STATION SUBCRITICAL ONCE THROUGH CORL FIRED UNIT

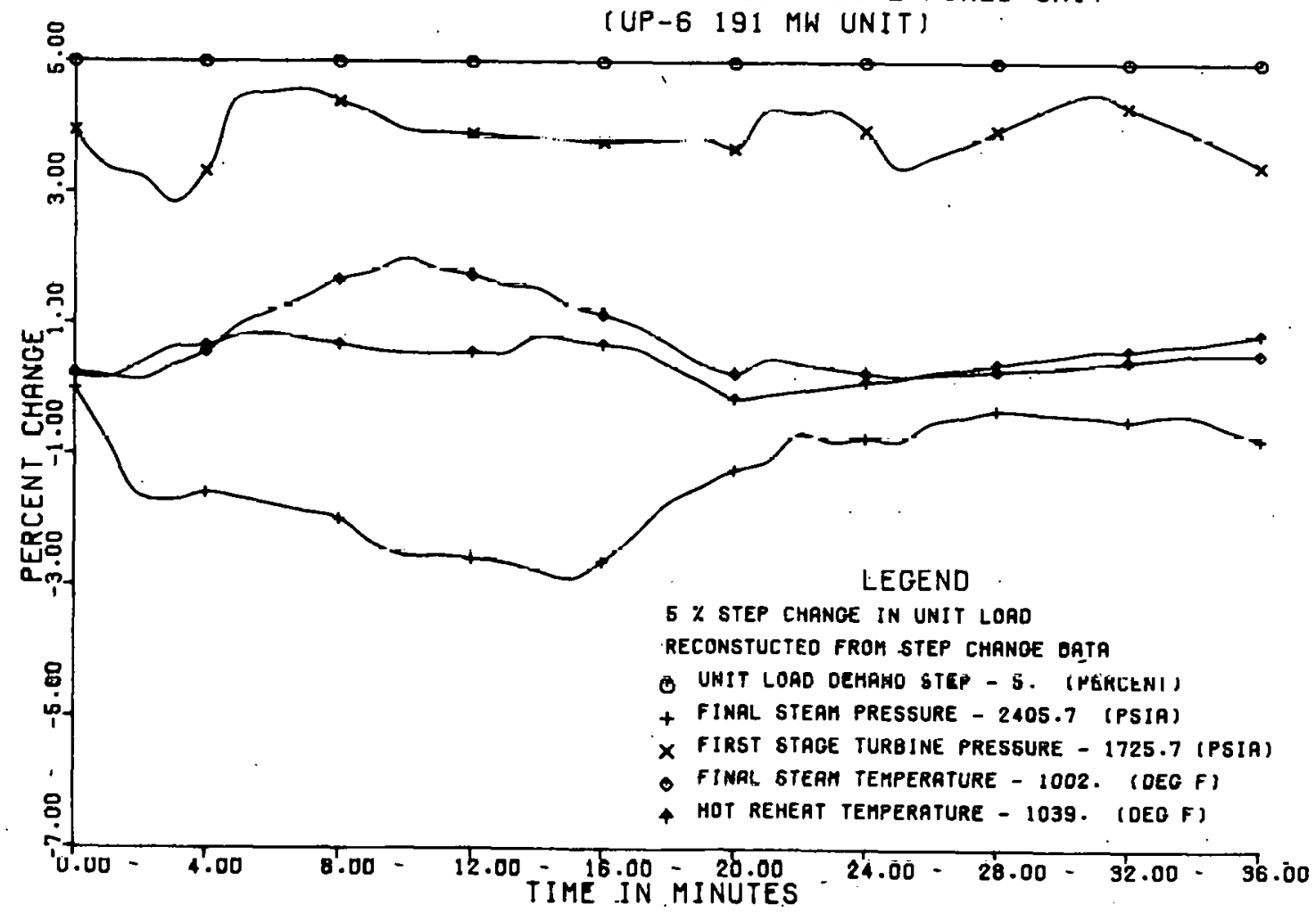

FIGURE 7

OPEN LOOP RESPONSE COMPARISONS AT 100\% LOAD STEP IN UNIT LOAD 


\subsection{CONCLUSIONS}

1. The AFB unit represented by this design is not as responsive as a conventional 200 megawatt coal-fired subcritical unit. Assuming unit size does not influence dynamic performance this AFB would not perform as well as the subcritical unit to which it was compared.

2. The AFB unit has more dead time in its initial response which is attributed to coal burnup time and thermal storage. This would require under and overfiring of the unit to meet the 2 to 5 percent per minute load ramp rate desirable for load following application.

3. Considerable under or overfiring required for load following could lead to excessive metal temperature excursions with subsequent thermal stress failures reducing the units availability.

\subsection{RECOMMENDATIONS}

1. The influence of unit size on thermal responsiveness should be further investigated.

2. The burning process within the model should be refined to predict the consequences of slumping of individual beds on the units dynamic response.

3. The influence of coal burnup time on plant load response should be studied, i.e.. curves of different burnup time vs unit load response.

4. The coal burnup time needs to be better correlated with independent variables such as excess air, bed temperature, average particle size, etc, and confirmed with actual test data.

5. With several minor model modification, the proposed control scheme included in the boiler design document could be added to the simulation and checked for adequacy and performance and modifications proposed where necessary.

6. The units response to 2 to 5 percent per minute ramp rates should be studied to further investigate ways of improving unit response.

7. The results in this report should be reviewed to determine whether alternate boiler design configurations or modifications would result in improved boiler response.

8. The response of this unit should be compared to the response of the alternate drum boiler type AFB design. 
9. Modifications should be made to this model to assist in evaluating results of experimental operations and their control systems performance. That is, steady-state correlations of bed dynamics, heat transfer, etc, would be checked not only for steady-state prediction accuracy and sensitivity, but also their ability to adequately represent dynamic conditions. 


\subsection{REFERENCES}

1. Adams, J.. et al, Mathematical Modeling of Once-Through Boiler Dynamics, IEEE Trans on Power Apparatus and Systems, February 1965

2. Babcock and Wilcox Company, "Steam/Its Generation and Use," 1972

3. Botterill, J.. miluid-Bed Heat Transfer," Academic Press, San Francisco, 1975

4. Foster Wheeler Energy Corporation, "Conceptual Design for an Atmospheric Fluidized Bed Steam Generator," Report 2-43-3075. November 1977

5. Kunii, D.. Levenspiel, 0., mluidization Engineering," Krieger Publishing Company, 1977

6. Louis, J. F.. "Quarterly Technical Progress Report (No. 1) tor Period May 1, through July 31, 19\%," MIT Energy Lab, ERDA Contract E (49-18) 2295, August 1976

7. Muira, K.. "Comparison of the Dynamic Characteristics of Natural Circulation Boilers and of Once-Through Boilers," Hitachi Review Vol. 16, No: 5, Date Unknown

8. Perry, H., Chilton, C., "Chemical Engineers Handbook," McGraw Hill. 1973

9. Ray, A. et al, Mathematical Modeling and Digital Simulation of the MERC Component Test and Integration unit,n MITRE Technical Report 3447. May 1977

10. Woo, R... Dynamic Response of a Supercritical Power Plant," Instrumentation Technology, July 1969

11. Zenz, F. A.. Othmer, D. F.. Fluidization and Fluid Particle Systems, Reinhold Chemical Engineering Series, 1960

12. Kwatny, H.G. et al, Nonlinear Model of a Reheat BoilerTurbine Generator System," Philadelphia Electric Company Research Division Report No. E-196, September 1970

13. Strom, S.S. et al, mreliminary Evaluation of Atmospheric Pressure Fluidized Bed Combustion Applied to Electric Utility Large Steam Generators, EPRI No. RP412-1, February 1976

14. Adams, J., et al, Dynamic Testing of a Once-Through BoilerTurbine and Control System, Personal communication-R.W. Perry, Baltimore Gas and Electric Company. 
APPENDIX V-A

DESCRIPTION OF MATHEMATICAL MODEL 
Description of Mathematical Model

The Foster Wheeler Once-Through Atmospheric Bed Boiler is shown in Figure 1. A schematic of the plant component models is shown in Figure Al with the flow of information internal to the computer program. Parameters, definitions, and values at full load are given with the computer program on Appendix B. Equations were developed to represent time dependent conservation laws for mass, momentum, and energy balances. A list of general assumptions is given in Table $I$.

Typical energy and mass balances are listed below for steam. metal, water, gas, and air.

Steam Energy Balances

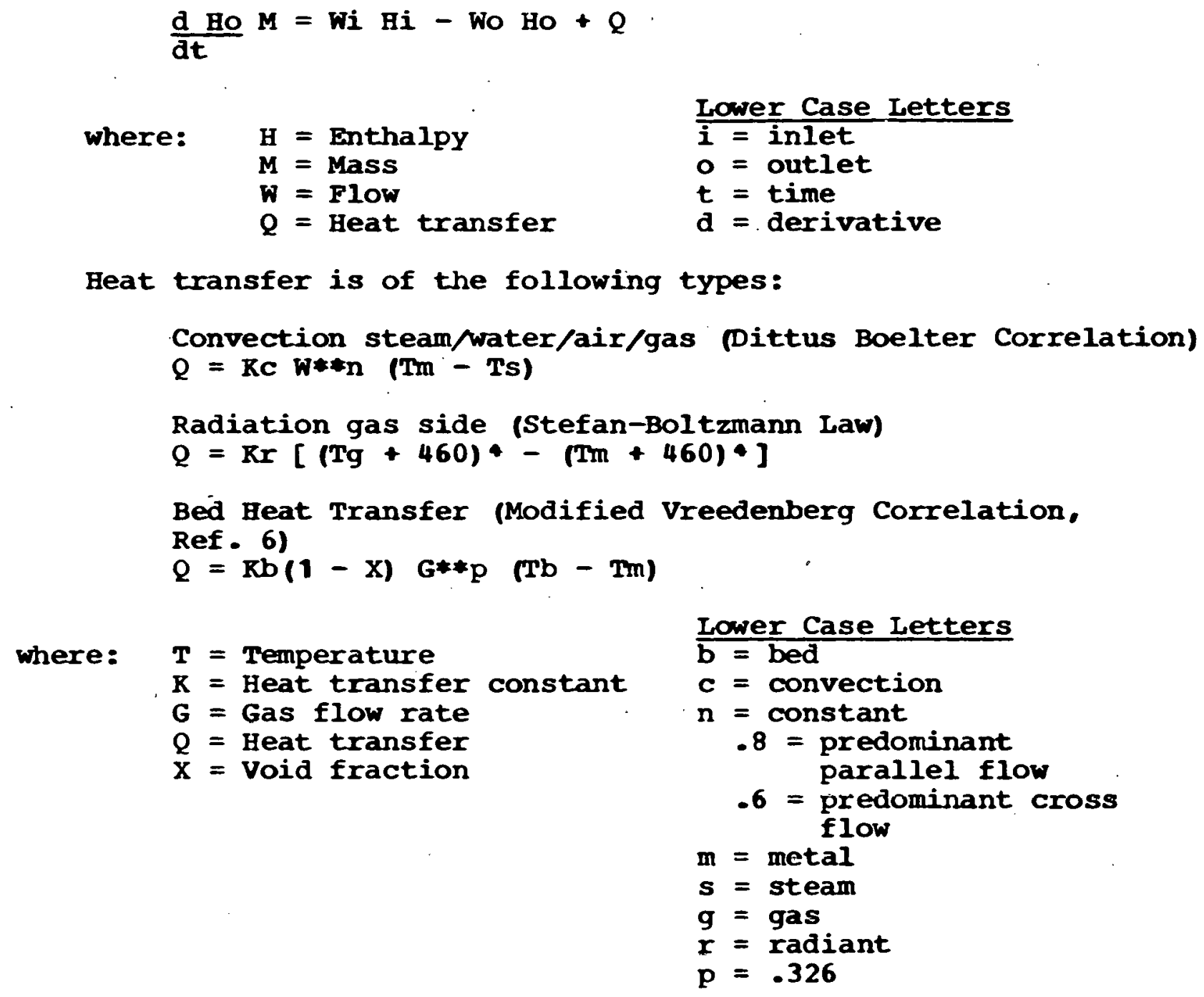

$\frac{\mathrm{d} \text { HO }}{\mathrm{dt}} \mathrm{M}=$ Wi Hi - Wo Ho $+Q$ 
Tube Metal Energy Balance

$$
\begin{aligned}
& \frac{d m_{m}}{d t}=(Q i-Q 0) / C M \\
& \text { where: } \quad \begin{array}{l}
C=\text { Specific heat } \\
M=\text { Mass of metal }
\end{array}
\end{aligned}
$$

Properties

For Gas and Air

$$
\boldsymbol{P}=\mathrm{KKI}
$$

For Steam

$$
\begin{aligned}
& P=f(H, R) \text { Bivariate curve fits to } 1967 \text { ASME Steam } \\
& \text { Table Properties } \\
& \mathbf{T}=\mathbf{f}(\mathbf{H}, \mathbf{R}) \\
& \text { where: } \quad K=\text { Gas constant } \\
& \mathbf{P}=\text { Presbure } \\
& \mathbf{R}=\text { Density } \\
& \text { H = Enthalpy } \\
& T \text { = Temperature }
\end{aligned}
$$

Gas flow is determined from a mass balance assuming constant holdup of material.

$$
\begin{aligned}
& \mathbf{G}=\mathbf{I}+\mathbf{A}+\mathbf{F}-\mathbf{B} \\
& \text { where: } \quad \begin{aligned}
\mathbf{I} & =\text { Iimestone flow } \\
\mathbf{A} & =\text { AIr flow } \\
\mathbf{F} & =\text { Fuel flow } \\
\mathbf{B} & =\text { Spent bed material } \\
\mathbf{G} & =\text { Gas and elutriated solids }
\end{aligned}
\end{aligned}
$$

Bed Energy Balance

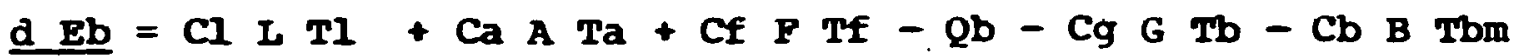

$$
\begin{aligned}
& \text { dt } \\
& \text { where: } \quad T=\text { Temperatures } \\
& E \text { = Internal energy } \\
& C=\text { Specific heat } \\
& Q=\text { Heat flow }
\end{aligned}
$$




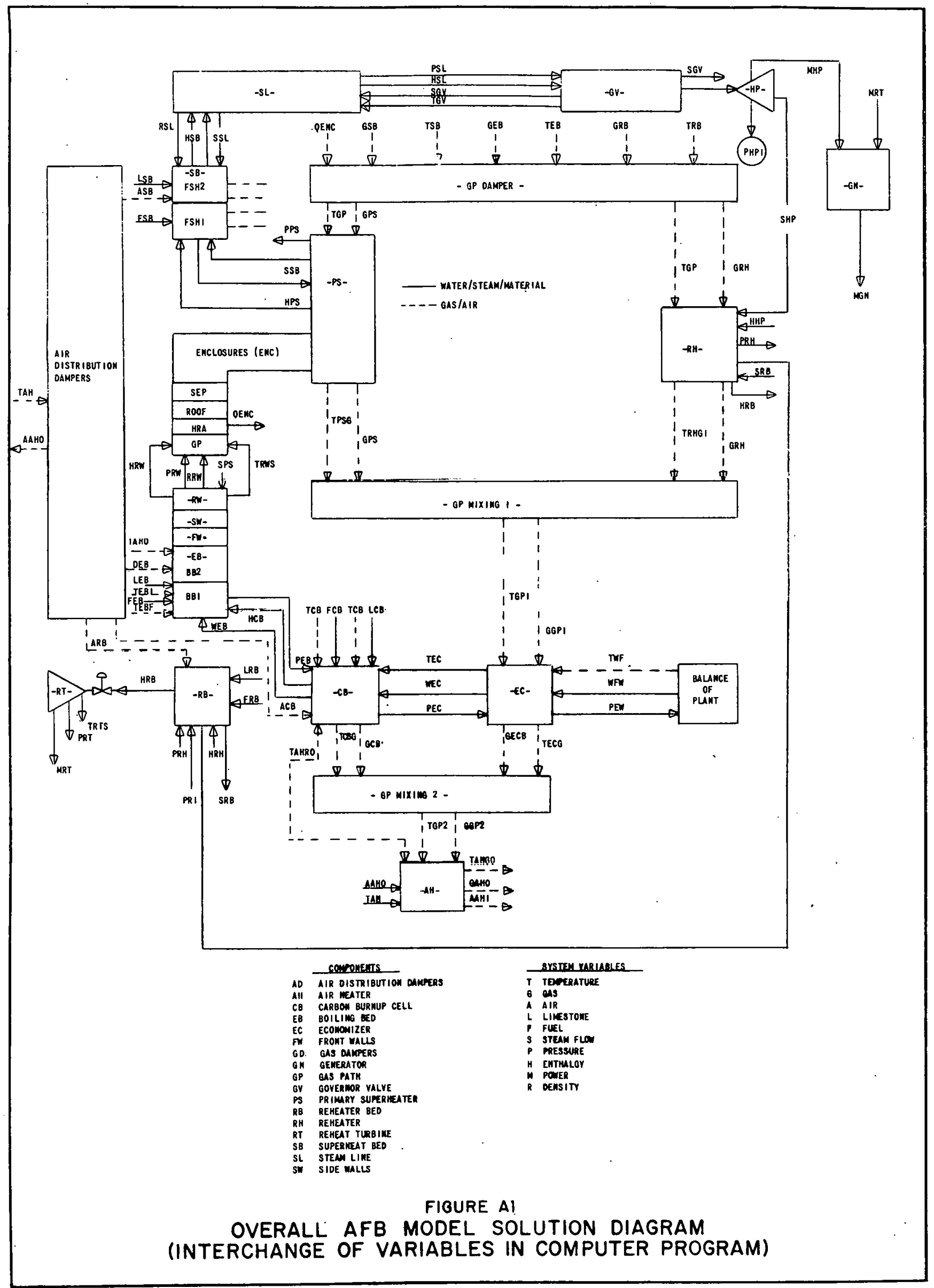


Bed or Gas Temperature

$$
\begin{aligned}
\mathrm{Tb}= & \frac{E b}{\mathrm{MbCb}} \\
& \text { where: } \quad M=\text { Mass of bed material }
\end{aligned}
$$

Bed Height (Based on System Geometry)

$$
\begin{aligned}
\mathrm{H}=(\mathrm{Vt}+\mathrm{M} / \mathrm{R}) & /(1-\mathrm{X}) \mathrm{A} \\
\text { where: } \quad \mathrm{H} & =\text { Bed height } \\
\mathbf{V} t & =\text { Tube volume } \\
\mathrm{R} & =\text { Density of bed material } \\
M & =\text { Mass of bed } \\
\mathrm{X} & =\text { Void fraction } \\
\mathrm{A} & =\text { Flow area }
\end{aligned}
$$

Bed Void Fraction (Levá Correlation, Ref. B)

$$
\begin{aligned}
& X=\left(R G^{2}(N t+M / R) / R g M \text { A) } P\right. \\
& \text { where: } \quad K=\text { Correlation constant } \\
& \mathbf{G}=\text { Gas flow } \\
& \text { Rg = Gas density } \\
& P=.333 \\
& \text { Rest are given above }
\end{aligned}
$$

Gas Side Energy Balances

$$
\begin{aligned}
& \frac{d T_{0}}{d t}=\left(C p G\left(T i-T_{O}\right)-Q\right) / C v M \\
& \text { where: } \quad C=\text { Specific heat } \\
& \mathbf{Q}=\text { Heat transfer } \\
& \text { M = Máss } \\
& \mathbf{T}=\text { Temperature } \\
& \text { Lower Case Letters } \\
& i=\text { inlet } \\
& 0 \text { = outlet } \\
& p=\text { constant piessure } \\
& \boldsymbol{v}=\text { constant volume }
\end{aligned}
$$

Pressure Drop

$$
\begin{aligned}
& P i-P O=K \text { ABS (W) } W / R \\
& \text { where: } \quad W=\text { Water/steam/gas/air flow } \\
& \mathrm{R}=\text { Density of fluid } \\
& \mathbf{P}=\text { Pressure } \\
& \mathrm{K}=\text { Correlation constant } \\
& \text { ABS = Absolute valve }
\end{aligned}
$$


Heat Release From Coal

$$
\begin{aligned}
& \frac{d Q}{d t}=((1-k) \quad F-Q) / T \\
& \text { where: } \quad \begin{aligned}
Q & =\text { Heat release } \\
R & =\text { Fraction not burned } \\
\mathbf{F} & =\text { Coal flow rate } \\
H & =\text { Heating valve of coal } \\
T & =\text { Average burn time }
\end{aligned}
\end{aligned}
$$

Coal Burn Time (based on 6 percent bed carbon content)

$$
\text { where: } \quad \begin{aligned}
& T=0.06 \mathrm{M} / 5 \mathrm{~F} \\
& \mathbf{M}=\text { Total bed material weight } \\
& \mathbf{F}=\text { Coal flow } \\
& \mathbf{T}=\text { Average burn time } \\
& \mathbf{5}=\text { Five time constant process assumed }
\end{aligned}
$$




\section{TABIE I}

ASSUMPTIONS

1. Only radial heat conduction occurs.

2. Bed heat transfer may be represented by the modified Vreedenberg Correlation.

3. Average Bed Void Fraction may be represented by the Leva Correlation.

4. Average carbon particle burning time is proportional to the coal residence time.

5. All energy and mass balances are based on lumped average exit conditions.

6. Steam properties may be represented by bivariate fits.

7. Gas side pressure is atmospheric.

8. Gas side density is dependent only on temperature.

9. Heat transfer is based on arithmetic average temperatures.

10. Economizer and boiling bed water, steam, and metal are assumed at a mixed mean temperature because of the high water/steam heat transfer, while separate gas, metal, and water/steam dynamic energy balances are used for the remainder of the system components.

11. Material balance on limestone, coal, and spent bed is maintained keeping material inventory constant.

12. The inertia of boiler gas, air, steam, and water is negligible and changes in flow are due to storage capacity and point-to-point piping steady-state static friction-head losses.

13. Contribution of pressure-volume work to steam energy balances is negligible.

14. Conduction and convection heat transfer may be represented by a constant times a flow dependent term nultiplied by temperature difference.

15. Flue gas and air properties are represented by average gas law equations. '

16. Gas and elutriated solids travel together through gas path. 
17. Total bed pressure drop is equal to bed mass divided by flow area.

18. HP turbine extraction is a constant fraction of governor valve flow.

19. Pressure drops due to density gradient, static heads are neglected.

20. Feedwater flow is constant unless stepped to obtain the system response.

21. Air and gas flows are instantaneous.

22. Main steam spray flow can be neglected. 


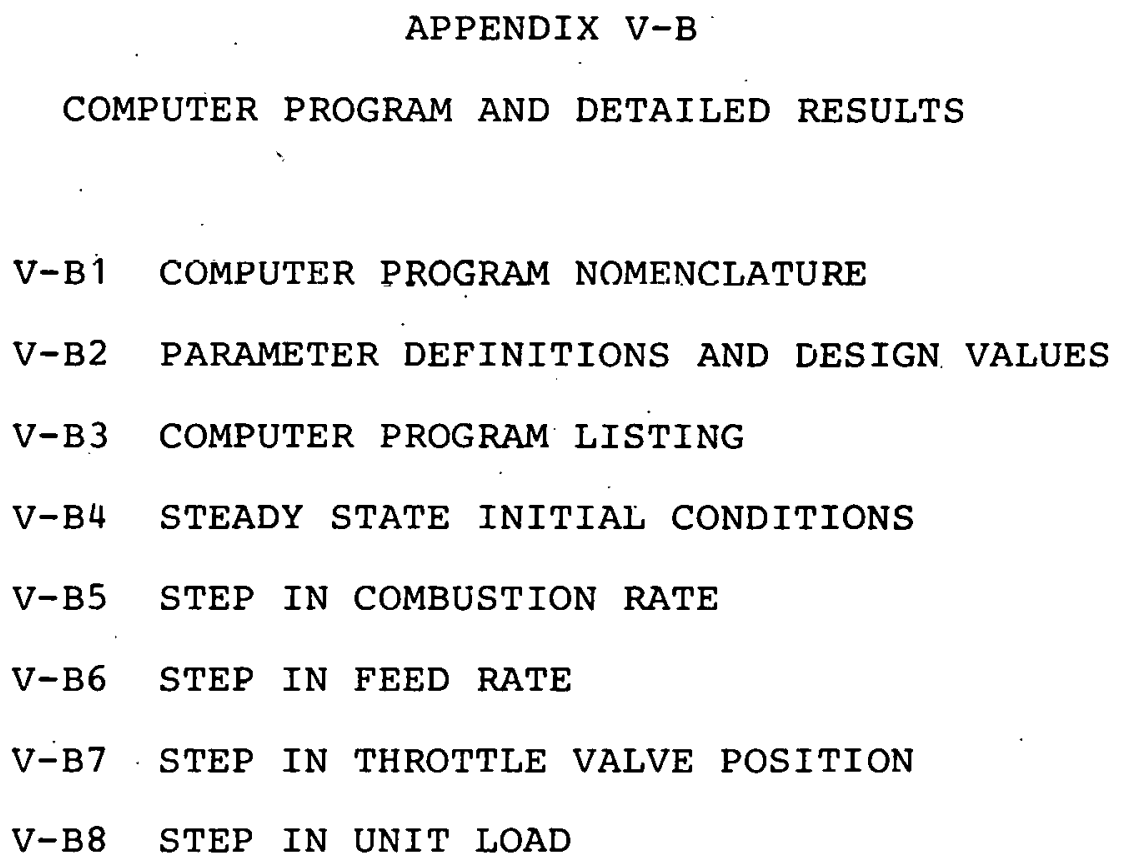




\section{APPENDIX V-B1}

COMPUTER PROGRAM NÓMENCLATURE

The nomenclature employed in development of the AFB Computer program is presented in this section. 
THIS PAGE

\section{WAS INTENTIONALLY LEFT BLANK}


COMPUTER PROGRAM NOMENCLATURE'

COMPUTER VARIABLE FIRST AND FOURTH LETTER DESIGNATIONS

FOR PARAMETER IDENTIFICATION

First or Fourth Letter

for System Parameter

Identi-

fication

Paraneter

Airflow/Area

Spent Bed Material

Elutriated Solids

Derivative

Energy

Coal Flow

Gas Flow

Enthalpy

Initial Condition

Constant

Limestone Flow/Length

weight/Electrical Power

Pressure

Heat Flow

Density

Steam Flow

Temperature

Volume

Water Flow

Void Fraction
Dimensions

$1 \mathrm{~b} / \mathrm{sec}$ or sq $\mathrm{ft}$

$1 \mathrm{~b} / \mathrm{sec}$

$1 \mathrm{~b} / \mathrm{sec}$

-

Btu

$1 \mathrm{~b} / \mathrm{sec}$

$1 \mathrm{~b} / \mathrm{sec}$

Btu/1b

-

$1 \mathrm{~b} / \mathrm{sec}$ or $\mathrm{ft}$

$\mathrm{Ib}$ or $\mathrm{Mw}$

$1 \mathrm{~b} / \mathrm{sq}$ in. $\mathrm{Btu} / \mathrm{sec}$

$1 \mathrm{~b} / \mathrm{cu} \mathrm{ft}$

$1 \mathrm{~b} / \mathrm{sec}$

oF

cu ft

$1 \mathrm{~b} / \mathrm{sec}$

decimal 


\begin{abstract}
COMPUTER PROGRAM NOMENCLATURE (CON 'T) COMPUTER VARIABIE SECOND AND THIRD LETTER DESIGNATIONS FOR COMPONENT IDENTIFICATION
\end{abstract}

Identi-

fication

$\begin{array}{ll}\text { AD } & \text { Air Distribution Dampers } \\ \text { AH } & \text { Air Heater } \\ \text { EF } & \text { Bed Material Feeder (Limestone) } \\ \text { BS } & \text { Spent Bed Material Handling } \\ \text { CB } & \text { Carbon Burnup Bed } \\ \text { CD } & \text { Main Steam Condenser } \\ \text { EB } & \text { Boiling (Evaporator) Bed } \\ \text { EC } & \text { Economizer in Gas Path } \\ \text { EN } & \text { Enclosures } \\ \text { FF } & \text { Fuel Feeder } \\ \text { FW } & \text { Main Feedwater } \\ \text { GD } & \text { Gas Distribution Dampers } \\ \text { GP } & \text { Gas Path } \\ \text { GV } & \text { Governor Valve } \\ \text { GN } & \text { Electrical Generator } \\ \text { HP } & \text { High Pressure Turbine } \\ \text { PS } & \text { Primary Superheater } \\ \text { RB } & \text { Reheat Bed } \\ \text { RH } & \text { Keheat in Gas Path } \\ \text { RT } & \text { Reheat Turbine } \\ \text { RW } & \text { Frnnt. Side and Rear Walls of Main } \\ & \text { Burnup Cells } \\ \text { SB } & \text { Finishing Superheater Beds } \\ \text { SL } & \text { Main Steam Line } \\ \text { UN } & \text { Universal Constant }\end{array}$




\subsection{REFERENCES}

Adains, J.. et.al Mathematical Modeling of once-Through Boiler Dynamics ${ }^{\circ}$ IEEE Trans on Power Apparatus and Systems, February 1965

Babcock and Wilcox Company, 1972 "Steam/Its Generation and Usen Batherill, J.. "Fluid-Bed Heat Transfer" Academic Press, San Francisco, 1975

Foster-Wheeler Energy Corporation, mConceptual Design for an Atmospheric Fluidized Bed Steam Generator", Report 2-43-3075, November 1977

Kunii, D.. Levenspiel, O.. "Fluidization Engineering" Rrieger Publishing Company, 1977

Louis, J. F., wuarterly Technical Progress Report (No. 1) for Period May 1, through July 31, 1976 MIT Energy Lab ERDA Contract E (49-18) 2295, August 1976

Muira, K.. "Comparison of the Dynamic Characteristics of Natural Circulation Boilers and of Once-Through Boilers" Hitachi Review Vol. 16. No. 5, Date Unknown

Perry, H.. Chilton, C.. "Chemical Engineers Handbook" McGraw Hill, 1973

Woo, R., "Dynamic Response of a Supercritical Power Plant" Instrumentation Technology, July 1969

Zeny, F. A., Othmer, D. F., Fluidization and Fluid Particle Systems" Reinhold Chemical Engineering Series, 1960 
THIS PAGE

\section{WAS INTENTIONALLY LEFT BLANK}




\section{APPENDIX V-B2 \\ PARAMETER DEFINITIONS AND DESIGN VALUES}

This section lists each of the parameters used in the AFB computer program in alphabetical order. The parameter definitions, steady state values and units are included in the parameter list. 
THIS PAGE

\section{WAS INTENTIONALLY \\ LEFT BLANK}




\begin{tabular}{|c|c|c|c|}
\hline AAH & AIR HEATER AVERAGE AIR FLOW RATE & 1379.4 & (LBS/SEC) \\
\hline AAHI & AIR HEATER INLET AIR FLOW RATE & 1465.4 & (LBS/SEC) \\
\hline AAHO & AIR HEATER OUTLET AIR FLOW RATE & 1293.3 & (LBS/SEC) \\
\hline AAL & AIR LEAKAGE IN AIR HEATER & 172.13 & (LBS/SEC) \\
\hline ACB & AIR FLOW TO CSC & 145.06 & (LBS/SEC) \\
\hline$A C B I$ & IHITIAL AIR FLOH TO CBC & 145.06 & (LBS/SEC) \\
\hline AEB & AIR FLOW INTO THE EVAPORATOR BEDS & 403.76 & (LBS/SEC) \\
\hline AEBI & IHITIAL FLOH INTO THE EVAPORATOR BEDS & 483.76 & (LBS/SEC) \\
\hline AGV & TURBINE EFFECTIVE AREA (STATIC) & 40.047 & $(S Q I N)$ \\
\hline AGVF & TUREIHE EFFECTIVE AREA (DYNAIIIC) & 40.047 & (SQ IH) \\
\hline$A R B$ & AIR FLOW INTO REHEAT GED & 241.85 & (LBS/SEC) \\
\hline AFBI & INITIAL AIR FLON INTO REHEAT BED & 241.85 & (LBS/SEC) \\
\hline$\Delta R T$ & LOW PRESSURE TURBIHE GOVERNOR VALVE AREA & 182.71 & $(S Q-I N)$ \\
\hline ASB & AIR FLOW INTO THE SUPERHEATER BEDS & 483.76 & (LBS/SEC) \\
\hline ASEI & INITIAL FLOW INTO THE SURPEHEATER SEDS & 483.76 & (LGS/SEC) \\
\hline BCB & SPENT HAIN BED WATERIAL RECYCLED TO CBC & 3.796 & (LBS/SEC) \\
\hline BEB & SPENT BED HATERIAL REHOVED & 7.518 & (LBS/SEC) \\
\hline BEBI & INITIAL SFENT BED MATERIAL REMOVED & 7.518 & (LBS/SEC) \\
\hline BRB & SPENT HATERIAL REHOVAL & 3.759 & (LBS/SEC) \\
\hline GRBI & INITIAL SPENT METERIAL REHOVED & 3.790 & (LBS/SEC) \\
\hline BSB & SPENT BED HATERIAL REHOVED & 7.518 & (LBS/SEC) \\
\hline BSEI & IHITIAL HATERIAL REIIOVED & 7.518 & (LBS/SEC) \\
\hline DXEBHF & RATE OF CHANGE OF LIQUIO GOUNDARY & 0.0 & $(L B S / S E C)$ \\
\hline DXEBHS & RATE OF CHAHGE OF BOILING BOUNDARY & 0.0 & (LES/SEC) \\
\hline ECR & ENERGY CONATENT OF CEC HATERIAL & $85.3632 \mathrm{E} 06$ & (BTU) \\
\hline ECEG & EIHERGY IH CBC CELL GAS & 30836 . & (BTU) \\
\hline ECBH & ENERGY CONTENT OF METAL AHO HATER & $9.90380 E 07$ & (BTU) \\
\hline EEBG & ENERGY IH GAS SPACE GAS & 307960 & (BTU) \\
\hline EEBH & ENERGY IN BOILING BEDS,FW,SW,RW OF BEDS & $1.1912 E+08$ & (BTU) \\
\hline EEBT & ENERGY COIITENT OF EVAPORATOR BEDS & $1.9534 E+08$ & (BTU) \\
\hline
\end{tabular}




\begin{tabular}{|c|c|c|c|}
\hline ERBG & ENERGY CONTENT OF GAS IN GAS SPACE & 153963. & (BTU) \\
\hline ERBS & ENERGY IN STEAHI IN REHEAT BED & $2.2516 E+06$ & (BTU) \\
\hline ERET & ENERGY IN REHEATER BED MATERIAL & $9.7667 E+07$ & (BTU) \\
\hline ESST & ENERGY COHTENT OF BED & $1.9534 E+08$ & (BTU) \\
\hline FCB & ELUTRIATED COAL AND SOLIDS COLLECTED FOR CBC & 24.4 & (LBS/SEC) \\
\hline гCBI & INITIAL COAL AHD SOLIOS COLLECTED FOR CBC & 24.4 & (LBS/SEC) \\
\hline FEB & COAL FLOH INTO EVAPORATOR BEDS & 54.32 & (LBS/SEC) \\
\hline FEBI & INITIAL COAL FLOH INTO EVAPORATOR BEDS & 54.32 & (LES/SEC) \\
\hline FRB & COAL FLOH INTO RB & 27.16 & (LDSi3CC) \\
\hline FPיפ & IMITIAL GOAL CI RH THTA DEHENT B̈̈L & 47.10 & (LE $3 ; 3 E C)$ \\
\hline FSB & COAL FLOH IHTO SUHERHEATER GEDS & 54.32 & (LES/SEC) \\
\hline FSBI & INITIAL COAL FLONA INTO SUPERHEATER GEDS & 54.32 & (LBS/SEC) \\
\hline GAH & AIR HEATER AVERAGE FLOW RATE & 1567. & (LBS/SEC) \\
\hline GAHOO & AIR HEATER OUTLET GAS FI DH RATE & 1653.6 & (LBS/SEC) \\
\hline GCB & GAS FLOW RATE FROH CARBON BURIIUP CELL & 172.44 & (LBS/SEC) \\
\hline GCEC & GAS FLOW PATE FROII CSC TO ECOHOHIIZER & 128.0 & (LBS/SEC) \\
\hline GEB & GAS FLOW OUT OF EVAPOPATOR BEDS & 541.04 & (LBS/SEC) \\
\hline GEC & ECOHOHIZER GAS FLOH RATE & 1352.6 & (LBS/SEC) \\
\hline GGP & GAS FLOH RATE FPOII HRA GAS PATH & 1352.6 & (LBS/SEC) \\
\hline GEP1 & GAS FLOW RATE ARFOUIID ECCHOIIIZER & 1352.64 & (LES/SEC) \\
\hline GSP2 & AIR HEATER IIILET GAS FLOH RATE & 1.48 .4 .4 & (LBS/SES) \\
\hline GCP 155 & STEADY GTATE AIR HEATER INLET GAS FLUW RATE & 2352.6 & (LBS/SEC) \\
\hline GP̈S & GAS PATH FLOH TO PPIMARY SUPERHEATER & 903.2 & (LES/SEC) \\
\hline GPSSS & STEADY STATE HASS FLOW RATE IH GAS MIXTURE I & 901.73 & $(L B S / S E C)$ \\
\hline GRB & GAS FLOW RATE FROH THE REHEAT BED & 270.52 & (LBS/SEC) \\
\hline GRH & GAS MASS FLOH RATE THROUEH REHEATER & 450.43 & (LBS/SEC) \\
\hline GRHSS & STEADY STATE GAS WASS FI OH THFOUGH PEHEATER & 450.43 & (LBS'SEC) \\
\hline G5B & GAS FLONN RATE FROH TWO SUPERHEATER BEOS & 541.05 & (LES/SEC) \\
\hline HCD & CCNDENSER ENTHALPY AT 2 (PSIA) & 1050. & (BTU/LEHI) \\
\hline HEBDIF & EVAPORATOR GED. INLLET ENATHALPY DIFFERENTIAL & 442.27 & (BTU/LBII) \\
\hline
\end{tabular}




\begin{tabular}{|c|c|c|c|}
\hline HEBI & EVAPORATOR BEO INLET ENTHALPY & 652 . & (BTU/LBH) \\
\hline HEBS & ENTHALPY OF STEAM LEAVING REAR WALL & 1095. & (BTU/LBH) \\
\hline HEBSI & INITIAL ENITHALPY OF STEAM LEAVING REAR WALL & 1095.0 & (BTU/LBH) \\
\hline HEBST & ENTHALPY OF STEAN LEAVING REAR WALL & 1093.3 & (BTU/LBH) \\
\hline HEBWS & SATURATED LIQUID ENTHALPY & 786.25 & (BTU/LBH) \\
\hline HEEISSO & ENTHALPY OF VAPORIZATION & 251.75 & (BTU/LCBH) \\
\hline HEC & GAS PATH ECONOIIIZER DISCHARGE ENTHALPY & 537. & (BTU/LBII) \\
\hline HGPS & ENTHALPY OF GAS PATH STEAH & 1190. & (BTU/LGH) \\
\hline HIGPI & INITIAL ENTHALPY OF GAS PATH STEAM & 1190. & (BȚ/LEH). \\
\hline HHP & HIGH PRESSURE TURBIIIE INLET STEAII ENTHALPY & 1456. & (BTU/LBH) \\
\hline HPS & PRIHAPY SUPERHEATER OUTLET STEAIA ENTHALPY & 1255: & (BTU/LEH) \\
\hline HPS & PRIMARPY SUPERHEATERS OISCHARGE ENTHALPY & 1258 & (BTU/LEH) \\
\hline HPSI & INITIAL PRIMARY SUPERHEATER DISCHARGE ENTHALP & Y1258. & (BTU/LEH) \\
\hline HÉ & REHEAT BED OUILEI ENIHALHY & 1519. & (BTUILEH) \\
\hline HFH & REHEATER BED INLET ENTHALPY & 1391.0 & (BTU/LBH) \\
\hline HP.HI & IHITIAL REHEATER GED INNLET ENTHALPY & 1391.0 & (BTU/LEH) \\
\hline HRHS & REHEATER STEAH OUTLET ENTHALPY & 1308. & (BTU/LEH) \\
\hline HRHSPW & REHEATER SFRAY WATER ENTHALPY & 350 & (BTUALEH) \\
\hline HRT & ENTHALPY OF STENII IN REHEAT TURBINE & 1519. & (BTU/LBH) \\
\hline HRTI & IHITIAL ENTHALPY OF STEAH IN REHEAT TURBIHE & 1519. & (BTU/LGH) \\
\hline $\mathrm{HRW}$ & EINTHALPY OF STEAII LEAVING REAR WALL & 1093. & (BTU/LBH) \\
\hline HSB & FIHISHIHG SUPERHEATER DISCHARGE ENTHALPY & 1456. & (BTU/LBH) \\
\hline HSL & STEAH LIHE OUTLET ENTHALPY & 1456. & (BTU/LBH) \\
\hline HSLI & INITIAL STEAH LIHE OUTLET ENTHALPY & 1456. & (BTU/LBH) \\
\hline IPRPEB & INITIAL REHEAT EED PRESSURE & 550.7 & (PSIA) \\
\hline IPGPS & IHITIAL GAS PATH STEAMH OEISITY & $6.00 \mathrm{U} 5$ & (LESICU PT) \\
\hline IRGPSI & IHITIAL GAS PATH IHILET STENH DEMSITY & 5.0 & ( LES/CU FT) \\
\hline IRGS & INITIAL GAS PATH INLET STEAH OEHSITY & 5.2455 & (LBS/CU FT) \\
\hline IRPSI & IHITIAL PRIHARY SUPERHEATER STEAH DENSITY & 5.0 & (LBS/CU FT) \\
\hline IRRBS & IHITIAL REHEAT BED STEAH DENSITY & .64906 & (LBS/CU FT) \\
\hline
\end{tabular}




\begin{tabular}{|c|c|c|c|}
\hline IRRH & INITIAL REHEATER STEAM DENSITY & .81529 & (LBS/CU FT) \\
\hline IRRHI & INITIAL OF INITIAL REHEATER STEAM DENSITY & .8 & (LBS/CU FT) \\
\hline IRRT & INITIAL REHEAT TURBITE STEAM DENSITY & .64906 & (LBS/CU FT) \\
\hline IRRTI & $\begin{array}{l}\text { INITIAL OF INITIAL REHEAT TURBIME STEAH } \\
\text { DENSITY }\end{array}$ & 8.7247 & (LBS/CU FT) \\
\hline IF.RW & IPITIAL REAR WALL STEAN DENSITY & 4.283 & (LBS/CU FT) \\
\hline IRSB & INITIAL FINISHING SUPERHEATER STEAH DENSITY & 3.3206 & (LBS/CU FT) \\
\hline IRSL & INITIAL STEAH LINE DENSITY & 3.33 & (LBS/CU FT) \\
\hline IPSLI & INITIAL OF INITIAL STEAH LINE DENSITY & 3.33 & (LBS/CU FT) \\
\hline $\mathrm{KAH}$ & AIR HEATER LEAKAGE FRACTION & .13310 & $-\cdots--\cdots$ \\
\hline KAHII & AIR HEATER TUBE METAL MASS & $3.62 E+05$ & (LBII) \\
\hline KAHAHT & AIR HEATER AIR HEAT TRANSFER PARAMETER & 9.1301 & (BTU/DEG F-SEC) \\
\hline KAHGHT & AIR KEATER GAS HEAT TRAISSFER PARALETER & 9.2314 & (BTU/DEG F-SEC) \\
\hline KAHGSH & AIR HEATER GAS SPECIFIC HEAT & .32090 & $(B T U / L B-F)$ \\
\hline KAHTA & AIR HEATER IHTERHEDIATE AIR VARIABLE & 1676.1 & $------n$ \\
\hline КАНTG & AIR HEATER INTEPIIEDIATE GAS VARIAGLE & 2174.4 & $--\ldots-n$ \\
\hline KCBAR & EIIPTY BED FLOW AREA & 1200 & $(S Q F T)$ \\
\hline KCBEC2 & CONVECTION HEAT TRANSFER CONSTANT & 3.1932 & $------\cdots$ \\
\hline KCBF & ELUTRIATED CARBON FROI.1 CBC & 0.1 & ------- \\
\hline K'CEGCB & HEAT TRANSFER CONSTANT . & 25.77 & $-\cdots---n$ \\
\hline KCEGHIR & RADIATON HEAT TRANSFER COHSTANT & $6.0447 \mathrm{E}-10$ & $---n---$ \\
\hline KCEX & COEFFICIENT BASED ON DESIGH DATA & $2.9917 E-02$ & -------- \\
\hline KDAIIP & HEAT RECOVERY AREA GAS FLOW DAIIPER & .333333 & $--n-m-n-m$ \\
\hline KEGAR & EHIPTY BED CROSS SECTIONAL FLOH AREA & 1320 & (SQ FT) \\
\hline KEEF & CAREON CARRY OVER & .10 & $----n---$ \\
\hline KEEGBT & BED HEAT TRAIISFER COEFFICIENT & 104.95 & (BTU/SEC) \\
\hline KEBGWR & RADIANT HEAT TRANSFER COEFFICIENT ABOVE HALL & $3.38 \varepsilon-09$ & (BTU/SEC) \\
\hline KEEHER & EVARORATOR BLO IHILLICIT LOOR CRROR CRITLRIA & .01 & $-\ldots-n-\infty-\infty$ \\
\hline KEEHV & HEATIIIG VALUE OF COAL & 11000 & (BTU/LBH). \\
\hline KEBRHV & EOILING BEDS AFID FW,SH, AND RH FLUID VOLUIIE & 2994 . & $(C U F T)$ \\
\hline KEBSH & SPECIFIC HEAT OF WALLS & .12 & $(B T U / L B-F)$ \\
\hline
\end{tabular}




\begin{tabular}{|c|c|c|c|}
\hline KEBX & VOID FRACTION CORRELATION CONSTANT & $1.0351 E-02$ & $--\cdots-n---$ \\
\hline KECG & GAS TO METAL HEAT TRANSFER PARAHETER & 502.79 & (BTU/SEC-F) \\
\hline RECH & ECONOHIZER TUBE METAL MASS & 290150. & (LBS) \\
\hline KECVW & VOLUHE OF WATER IN ECONOHIIZER & 591.65 & (CU FT) \\
\hline KECW & METAL TO WATER HEAT TRANSFER PARAIIETER & 6141.42 & $----n--$ \\
\hline KEF & OVERRALL TURBINE EFFICIENCY & .85676 & $----\infty----\infty$ \\
\hline RGP & NEWTON RAPHSON DENSITY GAIN & .85676 & ---------- \\
\hline KGPGVT & GAS PATH GAS VOLUIIE & 175140 . & (CU FT) \\
\hline RGPM & GAS PATH,ROOF AND $1 / 2$ HRA METAL MASS & 845720 & (CU FT) \\
\hline KGPHS & METAL TO STEAM HEAT TRANSFER PARAHETER & 8402.3 & (BTU/SEC-F) \\
\hline KGPRAD & GAS PATH RADIATION COEFFICINET & $1.2086 E-08$ & IBTU/SEC DEG R** \\
\hline KGPVT & STEAN VOLUHA IN GAS PATH ENCLOSURE WALLS & 2809 & $(\mathrm{CU} F \mathrm{FT})$ \\
\hline KGVI & FRICTION DROP FOR FIRST SSTAGE PRESSURE & 849870 . & IPSIA-SEC **2/LBM \\
\hline KGPZGV & GAS VOLUHE OF GAS PATH 2 & 41040 & (CU FT) \\
\hline RHPFR & HIGH PRESSURE TURBINE EXHAUST FRICTION LOSS & $1.7423 E-05$ & IPSIA-SEC *\#2/LBH \\
\hline KHPS & RATIO OF REHEAT STEAM TO MAIN STEAH & .897 & --------- \\
\hline KHPSFR & HIGH PRESSURE TURBINE EXHAUST FLOW FRACTION & .8973 & $-\infty------\infty$ \\
\hline KPS & NEWTON RAPHSON DENSITY GAIN & .8973 & -------- \\
\hline KPSCV & PRIHARY SURPERHEATER NODE COHIPRESSIBILITY VOL & -5443. & (CU FT) \\
\hline KPSGH & $\begin{array}{l}\text { DITTUS BOELTER COEFFICIENT FOR CONVECTION } \\
\text { HEAT TRANSFER }\end{array}$ & 270.47 & ---------- \\
\hline KPSH & PRIHARY SUPERHEATER TUBE METAL MASS & 798510.4 & (LBH) \\
\hline KPSHG & GAS PATH GAS MASS & 867.09 & (LBH) \\
\hline KPSHS & HETAL TO STEAH HEAT TRANSFER COEFFICIENT & 438.54 & (BTU/SEC-F) \\
\hline KPSV & GAS PATH GAS VOLUUHE & 39600 & $(C U F T)$ \\
\hline KPSVT & PRIMARY SUPERHEATFR STEAHY VOLUHE & $\varepsilon 608.94$ & (CU FT) \\
\hline KRBAR & EHPTY BED CROSS SECTIONAL FLOW AREA & 1320. & (SO FT) \\
\hline KRBF & CARBON CARRYOVER & .1 & 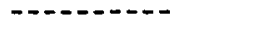 \\
\hline KRBGWR & RADIANT HEAT TRANSFER GAS CONSTANT. & $1.6922 E-09$ & $-\cdots---n$ \\
\hline KRBM & ENERGY CONTENT OF IHMERSED. TUBES & 33460 . & (BTU/LB) \\
\hline
\end{tabular}




\begin{tabular}{|c|c|c|c|}
\hline KRBQBT & HEAT TRANSFER CONSTANT & 112.86 & --------2 \\
\hline KRBQTS I & HEAT TRANSFER EQUATION-COEFFICIENT & 8.2552 & ------ \\
\hline KRBV & HALF OF REHEATER STEAM LINE VOLUME & 5333. & (CU FT) \\
\hline KRBX & COEFFICIENT BASEO ON DESIGN DATA & $1.0351 E-02$ & 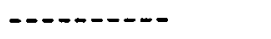 \\
\hline KRH & NEWTON RAPHSON GAS FOR REHEATER & .1 & -------- \\
\hline KRT & NEWTON RAPHSON GAS FOR REHEAT TURBINE & .1 &.------- \\
\hline KRHFR & FRICTION DROP CONSTANT & $2.0075 E-05$ & (PSIA-SEC $* 2 / L B M$ \\
\hline KRHGM & GAS TO METAL HEAT TRANSFER COEFFICIENT & 416.94 & (BTU/LBH-F) \\
\hline KRHM & REHEATER METAL MASS & 456518.4 & (LBS) \\
\hline KRHMS & METAL TO STEAN HEAT TRANSFER & 713.78 & (BTU/SEC-F) \\
\hline KRHV & HALF OF REHEATER STEAM VOLUME & 39600 & $(C U \cdot F T)$ \\
\hline KRHVT & REHEATER STEAM VOLUHE & 2753.61 & (CU FT) \\
\hline KRWFR & LINE FRICTION FROH RW TO PRIMARY SUPERHEATER & $7.9355 E-04$ & (PSIA-SEC**2/LBH \\
\hline KSBAR & EMAPTY BED CROSS SECTIONAL AREA & 1320 . & (SQ FT) \\
\hline KSBF & CARBON CARRYOVER & 0.1 & $-\cdots----\infty$ \\
\hline KSBGBT & HEAT TRANSFER CONSTANT & 164.70 & --------- \\
\hline KSBGSV & CONSTANT VOLUHE SPECIFIC HEAT & 0.2 & $(B T U / L B \quad D E G \quad F)$ \\
\hline KSBGWR & HEAT TRANSFER CONSTANT & $3.3843 E-09$ & ---------- \\
\hline KSBHV & HEATIING VALUE OF COAL & 11000 & (BTU/LB) \\
\hline KSBM & ENERGY CONTENT OF METAL IN SUUPERHEATER BEDS & 44403. & (BTUIOEO F) \\
\hline KSBQTS & HEAT TRANSFER EQUATION COFFECIENT & 9.022 & ------- \\
\hline KSBVOL & TOTAL STEAM VN̄l IME & 1972. & (CU FT) \\
\hline KSBQX & VOID FRACILUUN CORRELATYOHA EAPASIAAHI & $1.0351 E=02$ & $-\infty+\infty=\pi=-=-$ \\
\hline KSHFR & LINE FRICTION DROP FROH PS TO GOVERMOR VALVE & $7.2527 E-04$ & $-----\cdots$ \\
\hline KSL & NEWTON RAPHSON GAIN FOR STEAH LINE & .1 & -------- \\
\hline KSLM & STEAH LINE METAL MASS & 362378 . & $($ LBH $)$. \\
\hline KSLMQ & STEAH LINE HEAT TRANSFER PARAMETER & 451.05 & $(B T U / S E C-F)$ \\
\hline KSLVT & TOTAL STEAH LINE AND FSH VOLUHE & 4747.72 & $(\mathrm{CU} F T)$ \\
\hline KT & SPECIFIC HEAT RATIO & 1.2567 & $+\cdots,+-----$ \\
\hline KUNASH & AIR SPECIFIC HEAT AT COHSTANT PRESSURE & .28 & (BTU/LB-F) \\
\hline
\end{tabular}




\begin{tabular}{|c|c|c|c|}
\hline KUNBSH & SPECIFIC HEAT OF BED SPENT MATERIAL & .27 & ( BTU/LB-F.) \\
\hline KUNAFHV & HEATING VALUE OF COAL & 11000 & (BTU/LB-F) \\
\hline KUNFSH & SPECFIC HEAT OF COAL & .25 & (BTU/LB-F) \\
\hline KUPGGP & UNIVERSAL CONSTANT FOR GAS PATH & 39.7 & - \\
\hline KUNGC & UHIVERSAL GAS CONSTANT & 1545.0 & (FT-LB/MOLE F) \\
\hline KUNGSH & GAS SPECIFIC HEAT AT COHSTANT PRESSURE & .27 & (BTU/LB-F) \\
\hline KUNGSV & GAS SPECIFIC HEAT AT CONSTANT VOLUHE & .2 & $(B T U / L B-F)$ \\
\hline KUitGSI & SPECIFIC HEAT OF GAS IN GAS PASS 1 & .3057 & (BTU/LBH-F) \\
\hline KUNLSH & LIHESTONE SPECIFIC HEAT & .65 & (BTU/LB F) \\
\hline KUN! ISH & SPECIFIC HEAT OF METAL & .12 & $(B T U / L B \quad F)$ \\
\hline KUNPG & BOILIHG BED GAS COHSTANT & 39.7 & (CU FT/IN SQ-R) \\
\hline RUUHSBG & SUPERHEAT BED GAS CONSTANT & 39.7 & (CU FT/SQ IN) \\
\hline KUUNSSH & SPECIFIC HEAT OF STEALI & .39982 & $(B T U / O E G-F)$ \\
\hline MUNHEII & GRCCIFIC HEAT Ü WAIEK & 1.386 & $(B T U / L B-F)$ \\
\hline KVECG & GAS PATH 1 VOLUHE & 216180 & $(C U F T)$ \\
\hline LEB & LIIIESTOHE FLOW IHTO EVAPORATOR BEDS & 10.48 & (LBS/SEC) \\
\hline LEBI & IHITIAL LIMESTOHE FLOH INTO EVAPORATOR BEDS & 10.48 & (LES/SEC) \\
\hline LRB & LIMESTOHE FLOW INTU REHEAT BED & 5.24 & (LBS/SEC) \\
\hline LRBI & INITIAL LIMESTOHE FLOW INTO REHEAT BEO & 5.24 & (LBS/SEC) \\
\hline LSB & LIMESTOHE FLOH INTO SUPERHEATER BEDS & 10.48 & (LES/SEC). \\
\hline LSBI & INITIAL LIMESTONE FLOW INTO SUPERHEATER BEDS & 10.48 & (LES/SEC) \\
\hline HCB & HASS OF HATERIAL IN CBC & 224640 . & (LBS) \\
\hline HCBG & HASS OF GAS IN CBC CELL & 214. & (LBS) \\
\hline HCBH & MASS OF TUBES IN CBC BED, WALLS AND GAS SPACE & 438324 & (LBS) \\
\hline HCEW & IIASS OF WÁTER IN CBC SYSTEM & 76994. & (L8S) \\
\hline HEB & MASS OF HATEPIAL IN BED & 466752.0 & (LBS) \\
\hline HEC & MASS OF MATERIAL IN ECONOHIIZER BED & 29582 & (LES) \\
\hline HEBG & WEIGHT OF GAS IN EVAPORATOR GAS SPACE & 938.9 & (LBS) \\
\hline IEESH & METAL HASS IN BOILING EEOS AFT WAILLS & 698950. & (LES) \\
\hline HEBW & HASS OF HATER AHD STEAM IH BOILIHG BEDS & 55941. & (LBS) \\
\hline
\end{tabular}




\begin{tabular}{|c|c|c|c|}
\hline MGN & TOTAL POWER OUTPUT IN. PERCENT & 570. & $(\mathrm{HW})$ \\
\hline MGNSS & TOTAL POHER OUTPUT STEADY STATE & 570. & $(M W)$ \\
\hline HGP & GAS HASS IN GAS PASS & 3834.9 & (LBM) \\
\hline MGPI & MASS OF GAS IN GAS PASS 1 & 6202.4 & (LBH) \\
\hline MGPS & STEAH MASS IN GAS PATH ENCLOSURE WALLS & 6202.4 & (LBH) \\
\hline HGP2 & IASS OF GAS PATH & 1380.8 & (LEH) \\
\hline IHP & POWER OUTPUT OF HIGH PRESSURE TURBINE & $1.493 E+08$ & (1.WW ) \\
\hline MPS & PRIMARY SUUPERHEATER STEAH MASS & 13729. & (LBH) \\
\hline HAB & HOSS OF HATERTTAL IN BEO & 233376 & (LB) \\
\hline HRBO & llASS OF GAS & 469.4 & (LBH) \\
\hline HIRES & MASS OF STEAH & 1618.7 & (LB!1) \\
\hline H.RH & REHEATER STEAH MASS & 2250 & (LBH) \\
\hline IIRHG & HASS OF REHEATER GAS & 32352 . & (LBH) \\
\hline 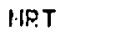 & POWER OUTPUT LOW PRESSURE TURBINE & $4.1649 \varepsilon+08$ & ( $(A \cdot 1)$ \\
\hline $1.15 B$ & MASS OF MATERIAL IN SUPERHEAT BED & 466752 . & (LBH) \\
\hline HSBG & MASS OF GAS IN GOTH FSH GAS SPACES & 938.9 & (LEN) \\
\hline MSBO & HASS OF STEAH & 8468.2 & (LB!U) \\
\hline 1.1SL & STEAH LINE ANO FSH STEAH MASS & 15765 . & (LEH) \\
\hline PATM & ATHOSPHERIC PRESSURE & 14.7 & (LBS/SQ IN) \\
\hline PGPI & GAS PATH INITIALIZATION PRESSUE & 2717. & (PSIA) \\
\hline PGUN & gOVERHOR VALVE nOHINAL VALUE & 2534.7 & (PSIA) \\
\hline Plivss & GOVERTHOR VALVE SS PRESSI:RF & 2534.7 & (PSIA) \\
\hline PHP & TURBIHE EXHAUST̈ PRESSURE & 590.7 & (PSIA) \\
\hline PHPSS & TURBINE EXHAUST PRESSURE STEADY STATE & 590.7 & (PSIA) \\
\hline PHP 1 & FIRST STAGE PRESSUPE & 598.13 & (PSIA) \\
\hline PHP1SS & TIRST STAGE PRFSSURE STEADY STATE & 598.13 & (PSIA) \\
\hline PPS & FSH INLET PRESSURE & 2740.7 & (PSIA) \\
\hline PPSI & INITIAL FINAL SUPEHEATER INLET PRESSURE & 2740.7 & (PSIA) \\
\hline PRB & REHEAT BED PRESSURE & 550.7 & (PSIA) \\
\hline$P R H$ & OUTLET REHEAT PRESSURE & 564.7 & $(P S I A)$ \\
\hline
\end{tabular}




\begin{tabular}{|c|c|c|c|}
\hline PRT & REHEAT TURBINE THROTTLE PRESSURE & 550.7 & (PSIA) \\
\hline PRTI & INITIAL REHEAT TURBINE THROTTLE PRESSURE & 550.7 & (PSIA) \\
\hline PRTN & NORHALIZER REHEAT TURBINE. THROTTLE PRESSURE & 550.7 & (PSIA) \\
\hline PRTSS & STEADY STATE REHEAT TURBIHE THPOTTLE PRESSURE & E 550.7 & (PSIA) \\
\hline PRW & REAR WALL OUTLET STEAH PRESSURE & 2900. & (PSIA) \\
\hline PSL & PRESSURE AT GOVERNOOR VALVE & 2534.7 & (PSIA) \\
\hline PSLI & INITIAL PRESSURE AT GOVERTIOR VALVE & 2534.7 & (PSIA) \\
\hline QAHA & CONUECIION HEAT TRATSFER FROII TUEE TO AIR & $2.09 E+05$ & (BTU/SEC) \\
\hline QAHG & COHVECTION HEAT TRANSFER FROH GAS TO TUBES & $2.09 E+05$ & (BTU/SEC) \\
\hline QCB & HEAT RELEASE IN CARBON BURHUP CELL & 129780 & (BTUISEC) \\
\hline QCEEC2 & HEAT TRAISSFE TO ECONONHIZER 2 TUBES & 50738 . & (BTU/SEC) \\
\hline QCEGHE & REAT TRANSFER TO WATER IN CEC & 69489 . & (BTU/SEC) \\
\hline QCBGHR & RADIATION FROH GAS SPACE TO WALLS & 18751 . & (BTU/SEC) \\
\hline QCBT & HEAT TRANSFER TO CBC BED TUBES (ECONOHIZER-3) & 157098 & (BTU/SEC) \\
\hline QEB & COAL EHERGY RELEASE & 537760.8 & (OTU/SEC) \\
\hline QEEGLR & TOTAL REAT FLOH FROH BOILIHG BEDS TO STEAII & 90446. & (BTU/SEC) \\
\hline QEBT. & TOTAL HEAT FLOW FROH BOILIITG BEDS TO STEAIM & 262514 & (BTU/SEC) \\
\hline QEBTB & TOTAL HEAT FROH BONOILING BEDS, FW,SH AHT RN & 488629.0 & (BTU/SEC) \\
\hline QECC & COHVECTION HEAT FLOW FROH FLUE GAS TO ECON. & 84125 . & (BTU/SEC) \\
\hline QECI & HEAT FLOH FROH TUGE HALLS TO HATER IN ECON. & 84076 & (GTU/SEC) \\
\hline QEN & $\begin{array}{l}\text { RADIATIVE HEAT TRANSFER PARAIIETER } \\
\text { GAS TO METAL }\end{array}$ & 104780 . & (BTU/SEC) \\
\hline QGPHIS & HEAT TRANSFER ENERGY METAL TO STEAH & 104560. & (BTU/SEC) \\
\hline UPSA & HEAT TRANSFER ENIERGY (GAS TO HETAL) & 74196. & (BTU/SEC) \\
\hline QPSIIA & REAT TRAMSFER HETAL TO STEAM & 75004 & (BTU/SEC) \\
\hline QRB & ENERGY RELEASE OF COAL IN REHEATER CELL & 268880 & (BTU/SEC) \\
\hline QREGHR & TOTAL HEAT FLOH FROH REHEAT BEDS TO STEAHI & 45223. & (BTU/SEC) \\
\hline QRET & HEAT TRANSFER FROH BED TO IMHERSED TUBES & 106730 & (BTU/SEC) \\
\hline QRETS & METAL TO STEAH HEAT FLOW & 126681. & (BTU/SEC) \\
\hline QSB & ERERGY RELEASE OF COAL IN SUPERHEATER BED & 537760 . & (BTU/SEC) \\
\hline QSBGLIR & RADIANT HEAT TRANSFER TO FW,SH, AND RW OF FSH & 90058. & (BTU/SEC) \\
\hline
\end{tabular}




\begin{tabular}{|c|c|c|c|}
\hline QSBT & HEAT TRANSFER IN SUPERHEAT BED & 218780 & (BTU/SEC) \\
\hline QSBTS & HEAT TRAYISFER FROI SUPERHEAT BEDS TO STEAM & 126681. & (BTU/SEC) \\
\hline QSLA & STEAM LINE GAS TO METAL HEAT TRANSFER & 0.0 & (BTU/SEC) \\
\hline QSLMA & STEAH LINE HETAL TO STEAH HEAT TRANSFER & 17.494 & (BTU/SEC) \\
\hline RCBG & CBC BED GAS DENSITY & .016822 & (LBS/CU FT) \\
\hline RCEH & BED DETSSITY & 160. & (LBS/CU FT) \\
\hline REEG & BOILING BED GAS DENSITY & .01976 & (LBS/CU FT) \\
\hline REEH HEB & DENSITY OF LIMESTONE AND COAL & 158.4 & (LBS/CU FT) \\
\hline RECW & DEHSITY OF FEEEOHATËR AT ECOONOHIIZER OUTLET & 50 . & (LBS/CU FT) \\
\hline RGP & GOS PATH GAS DENSITY & .0219 & (LBS/CU FT) \\
\hline RGPS & GAS PATH STEAH DENSITY & 6.0774 & (LBS/CU FT) \\
\hline RGP 1 & DENSITY OF GAS IN NO. 1 MIXING VOLUHAE & .0288 & (LES/CU FT) \\
\hline RGP2 & DENSITY OF GAS PATH II & .0336 & (LBS/C.U FT) \\
\hline RPS & PRIIIARY SURPEHEATER STEAH DENSITY & 5.2623 & (LES/CU FT) \\
\hline RRBB & REHEAT BED EXIT STEAII DEFISITY & .64907 & (LBS/CU FT) \\
\hline RREG & GAS DENSITY & .01976 & (LBS/CU FT) \\
\hline RPQBII & DEHSITY OF REHEAT BED MATERIAL & 158.4 & (LBS/CU FT) \\
\hline RRE.WEB & DENSITY OF LIMESTONE AND COAL & 158.4 & (LBS/CU FT) \\
\hline RRBS & DENSITY OF STEAN IN REHEATER BEO TUBES & .64906 & (LES/CU FT) \\
\hline RRH & OUTLET REHEAT STEAH OENSITY & .81528 & (LBS/CU FT) \\
\hline RRT & REHEAT TURBINE THROTTLE DENSITY & .65040 & (LBS/CU FT) \\
\hline RRA & REAR WALL STEAII DENSITY & 8.7410 & (LBS/CU FT) \\
\hline RSB & STEAH DËHSITY & 4.1671 & (LBS/CU FT) \\
\hline RSBG & SUPERHEAT GED GAS DENSITY & .01976 & (LBS/CU FT) \\
\hline RSBO & SUPERHEAT BED EXIT STEAH DENSITY & 3.5289 & (LBS/CU FT) \\
\hline RSSI.UEB & DENSITY OF LIMESTONE ARX COAL & 158.4 & (LBS/CU FT) \\
\hline RSL & STEAH LIHE AHD FINÄSHITHG S̄UPERHEATER DENSITY & 3.3261 & (LBS/CU FT) \\
\hline SEB & STEAH FLOW OUT OF EVAPORATOR & 1103. & (LBS/SEC) \\
\hline SSV & GOVERNOR VOLVE STFAH FI NW & 1103. & (I B.S/SFC. ) \\
\hline SHP & HIGH PRESSURE TURBINE DISCHARGE FLOW & 989.7 & (LBS/SEC) \\
\hline
\end{tabular}




\begin{tabular}{|c|c|c|c|}
\hline SPS & PRIMARY SUPERHEATER STEAH FLOW & 1203. & (LBS/SEC) \\
\hline SSPSS & STEAH MASS FLOW AT $100 \%$ LOAD & 1103. & (LBS/SEC) \\
\hline SRB & STEAM FLOW THRU IMMIERSED BED TUBES & 989.7 & (LBS/SEC) \\
\hline SRH & REHEATER STEAH FLOW & 989.73 & (LBS/SEC) \\
\hline SRHSS & INITIAL REHEATER STEAH FLOW & 1103. & (LBS/SEC) \\
\hline SRT & REHEAT TURBINE FLOW & 989.7 & (LBS/SEC) \\
\hline SRH & STEAII FLOW OUT OF REAR WALL ENCLOSURE & 1103. & (LES/SEC) \\
\hline SRWSS & STEAOY STATE STEAH FLOW OUT OF RW EHCLOSURE & 1103. & (LBS/SEC) \\
\hline SSS & FINISHIRIG SUPERHEATER STEAH FLOH & 1103. & (LBS/SEC) \\
\hline SSBSS & STEADY STATE FIPISHING SUPERHEATER STEAH FLOW & 1103 & (LES/SEC) \\
\hline SSL & STEAI! LINE HASS FLOIY (SSESS) & 1103. & (LBS/SEC) \\
\hline TAH & AIR HEATER IMLET AIR TEMPERATURE & 96.00 & (DEG F) \\
\hline TAHA & AIR HEATER AVERAGE AIR TEIIPERATURE & 367.42 & (DEG F) \\
\hline TARG & AIR HEATER AVERAGE GAS TEIIPERATURE & 501.89 & (DEG F) \\
\hline TAHAO & AIR HEATER OUTLET AIR TEMPERATURE & 638.84 & $(D E G \quad F)$ \\
\hline TAHGO & AIR HEATER OUTLET GAS TEMIPERATURE & 283.64 & $(D E G F)$ \\
\hline TAHM & AIR HEATER TUBE METAL TEMPERATURE & 438.1 & (DEG F) \\
\hline TAHO & AIR INLET TEHIPERATURE & 639.0 & (DEG F) \\
\hline TCB & CBC BED TEHIPERATURE & 1900. & (DEG F) \\
\hline TCBF & AVERAGE COAL PARTICLE BURIIUP TIYE & 59.52 & (SECS) \\
\hline TCBG & OUTLET TEMIPERATURE OF CAREON EURNIUP CELL & 720 . & $(D E G F)$ \\
\hline TCBGA & AVERAGE GAS TEIIPERATURE IN ECONOHIZER 2 & 1310. & (DEG F) \\
\hline TCBSBI & TEIIPERATURE OF ENTERIIIG SPENT BED MATERIAL & 250. & $(D E G \quad F)$ \\
\hline TCBGPI & CAREOII BED EXIT GAS TEMIPERATURE & 720 . & (DEG F) \\
\hline TCЗSPY & PERCENT CHANGE EXIT GAS TEMPERATURE & 0.0 & (PERCENT) \\
\hline TCBI & CARBON BURIIUP BED GAS TEMPERATURE & 1900. & $(D E G F)$ \\
\hline TCBW & WATER TEIIPERATURE LEAVING CBCSIY & 623.3 & (DEG F) \\
\hline TCEWI & WATER TEIIFERATURE LEAVING CBCSW & 623.3 & (DEG F) \\
\hline TCEHY & PERCENT CHANGE CEC EXIT WATER TEHPERATUE & 0.0 & (PEPCENAT) \\
\hline TCBY & PERCENT CHANGE IN CBC TEIIPERATURE & & (PERCENT) \\
\hline
\end{tabular}




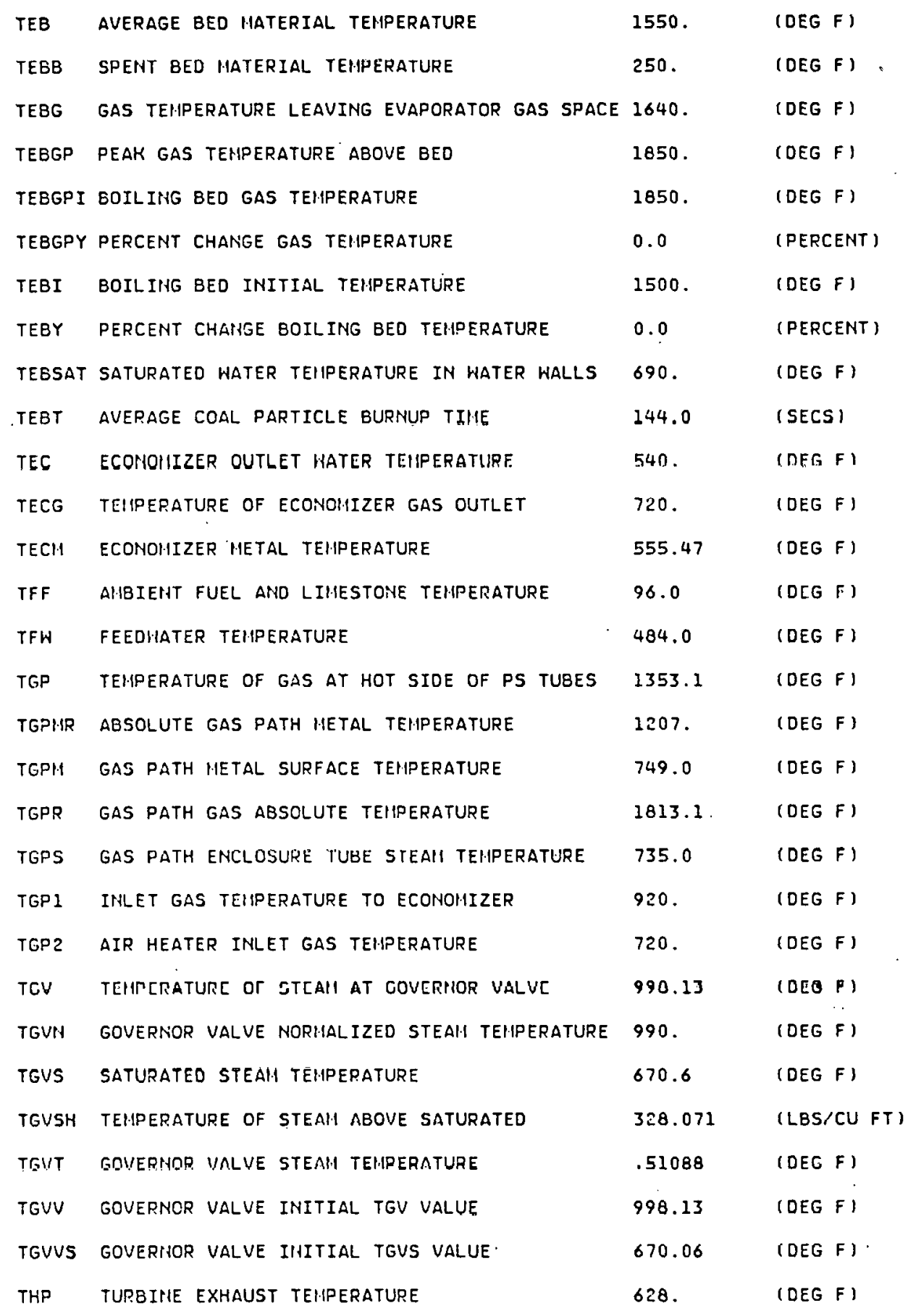




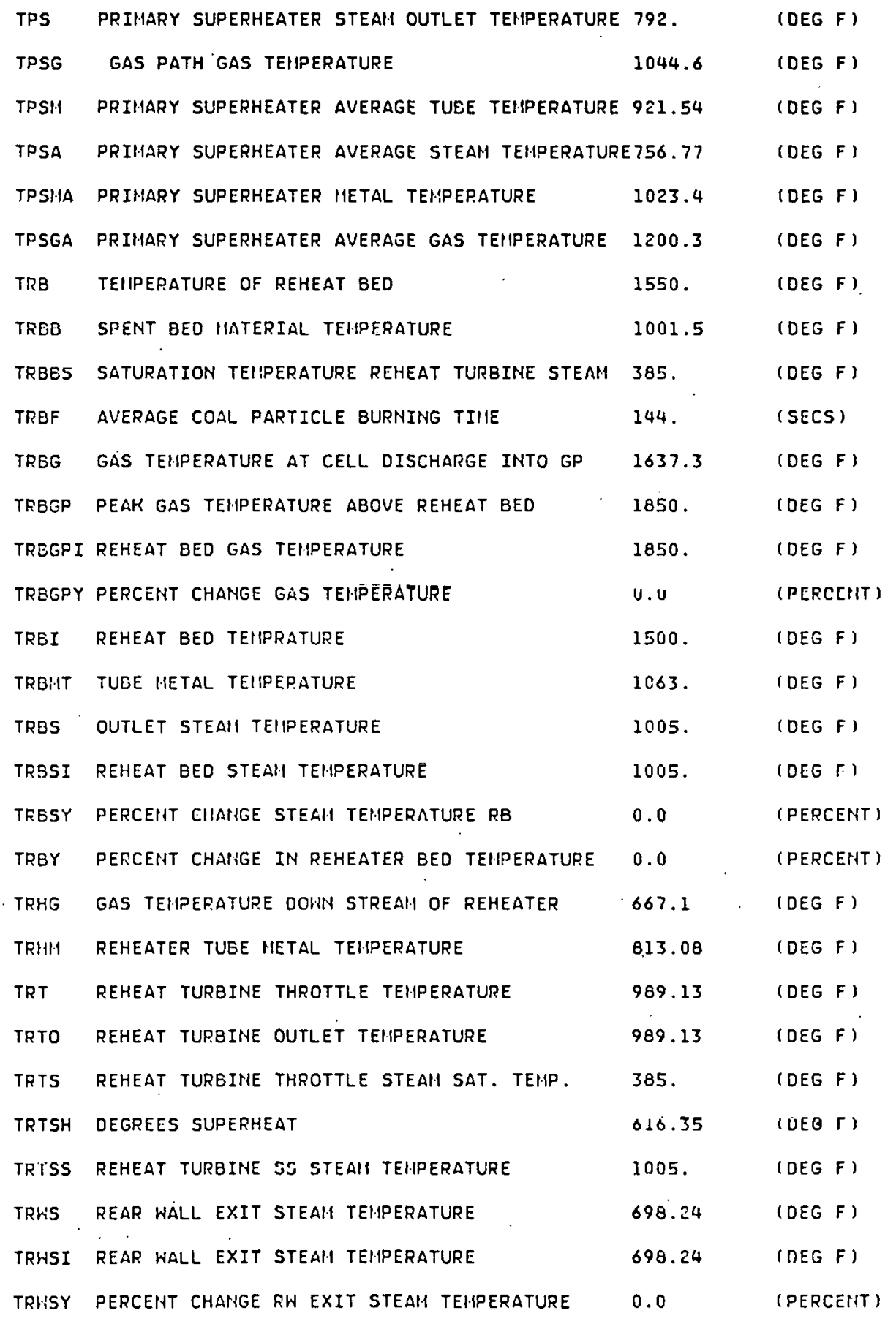




\begin{tabular}{|c|c|c|c|}
\hline TSB & AVERAGE BED HATERIAL TEMPERATURE & 1550. & (DEG F) \\
\hline TSEB & SPENT BED MATERIAL TEMPERATURE & 250. & (DEG F) \\
\hline TSBF & AVERAGE COAL PARTICLE BURNUP TIHE & 244. & (SECS) \\
\hline TSEG & FSH BED CELL EXIT GAS TEHPERATURE & 1640 . & $(D E G F)$ \\
\hline TSBGP & PEAK GAS TEMPERATURE ABOVE FSH BEDS & 1850 . & $(D E G F)$ \\
\hline TSBGPI & SUPERHEAT BED GAS TEIIPERATURE & 1850 & $(D E G F)$ \\
\hline TSEGPY & PERCENT CHANGE IN SUPERHEAT.BED GAS TEMP. & 0.0 & (PERCENT) \\
\hline TSS!HT & METAL TEMPEFATURE IN SUPERHEATER BEDS & 1094.1 & $(D E G F)$ \\
\hline TSBS & TEISPERATURE FOR BED STEAN & 1005 & (DEG F) \\
\hline TSBSI & IMITIAL TEHPERATURE FROH BED TO STEAH & 1005 & $(D E G F)$ \\
\hline TSBSY & PERCENT CHANGE FROII BED TO STEAIM & 0.0 & (PERCEIIT) \\
\hline TSSY & PERCENT CHAHGE IN SUPERHEAT BED TEMPERATRE & 0.0 & (PERCENT) \\
\hline TSLM & STEAM LIHE METAL TEMPERATURE & 998.13 & (DEG F) \\
\hline TUNTA & AIR STEP TIIIE & 5. & (SECS) \\
\hline TURITB & BED MATERIAL STEP TIME & 5. & (SECS) \\
\hline TUNTE & ELUTRIATED SOLIDS STEP TIME & 5. & (SECS) \\
\hline TUHTF & FUEL STEP TIME & 5. & (SECS) \\
\hline TUNTGV & GOVERNOR VALVE STEP TIME & 5. & (SECS) \\
\hline TUNTL & LIMIESTUHE STEP TIME & 5. & (SECS) \\
\hline TUITH & FEEDHATER STEP TIHE & 5. & (SECS) \\
\hline VRaS & TOTAL REHEAT BED STEAH VOLUHE & $\$ 494$. & $(C U F T)$ \\
\hline MCB & WATER FLOH TO COILIMG DEOG & iius. & $(1, B S / S E C)$ \\
\hline WEB & WATER FLOW INTO EVAPORATOR & 1103. & $(L B S / S E C)$ \\
\hline WEBA & WATER FLON IN BOILING BED & 1103. & (LBS/SEC) \\
\hline HEBW & WATER FLOW IN SOILING BED & 1103. & (LBS/SEC) \\
\hline WEBINS & TWO PHASE FLON IN EVAPORATOR BED & 1103. & (LES/SEC) \\
\hline WEC & MASS FLOW RATE AT ECONOHIZER OUTLET & 1103 & $($ LES/SEC ) \\
\hline HECI & WATER FLOH IN BOILING BED & 1103. & (LES/SEC) \\
\hline WECSS & WATER FLOW & 1103. & (LBS/SEC) \\
\hline WFW & FEEDHATER MASS FLOW RATE (WFWSS) & 1103. & (LBS/SEC) \\
\hline
\end{tabular}




\begin{tabular}{|c|c|c|c|}
\hline WFWSS & WATER FLOW & 1103 & (LBS/SEC) \\
\hline WRHSP & REHEAT SPRAY WATER FLOW RATE & 0 . & (LBS/SEC) \\
\hline$X C B$ & CBC CELL VOIO FRACTION & .6743 & $----\cdots---$ \\
\hline $\mathrm{XCBH}$ & BED HEIGHT. & 4. & $(F T)$ \\
\hline XEB & FLUIOIZED BED VOID FRACTION & .6262 & --------- \\
\hline XEBH & HEIGHT OF FLUIDIZED BED & 4. & (FT) \\
\hline XEGSF & $\begin{array}{l}\text { BOILIHG BED INLET TO RW OUTLET } \\
\text { SUPERHEATED STEAH FRACTION }\end{array}$ & .122 & $----n-n-n$ \\
\hline XEBWF & $\begin{array}{l}\text { BOILIFIG BED INLET TO REAR WALL OUTLET } \\
\text { WATER FRACTION }\end{array}$ & 0.303 & -------- \\
\hline XEVWF I & $\begin{array}{l}\text { INITIAL BOILING BED INLET TO REAR WALL } \\
\text { OUTLET WATER FRACTION }\end{array}$ & 0.573 & -------- \\
\hline XEBWSPF & BOILING BED TO RN THO PHASE FLOW FRACTION & .56194 & 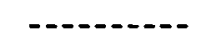 \\
\hline XEBHSI & RATE Or CHANGE MF TWN PHASE FLOW FRACTION & 0 & ------- \\
\hline XRB & BED VOID FRACTION & .6262 & -------- \\
\hline XRBH & HEIGHT OF FLUIDIZEO REHEATER BED & .4 & (FT) \\
\hline XsB & SUPERHEAT BED FLUIDIZED VOIO FRACTION & .6262 & $----n$ \\
\hline XSBH & HEIGHT OF FLUIOIZED BEO & 4. & (FT) \\
\hline XUNGV & GOVERNOR VALVE STROKE FRACTION & 1. & 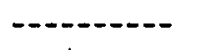 \\
\hline XUNA & AIR HEATER STROKE FRACTION & 1. & $-\cdots-1-\cdot-$ \\
\hline XUNB & BED SPENT MATERIAL FRACTION & 1. & $\cdots-\cdots-\cdots$ \\
\hline XUNE & ELUTRIATED SOLIDS STROKE FRACTION & 1. & ------- \\
\hline XUNF & FUEL STROKE FRACTION & 1. & 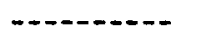 \\
\hline XUNL & LIMESTONE STROKE FRACTION & 2. & ------ \\
\hline XUTAW & FEEDWATER STROKE FRACTION & 1. & -------- \\
\hline
\end{tabular}


THIS PAGE

WAS INTENTIONALLY

\section{LEFT BLANK}




\section{APPENDIX V-B3 \\ COMPUTER PROGRAM LISTING}

This section presents the AFB computer program listing. The language employed is IBM's Continuous system Modeling Program (CSMP). 
THIS PAGE

\section{WAS INTENTIONALLY \\ LEFT BLANK}


\&STORAGE H(20),V(20),RV(20),HHRH(20), VRH(20), RVRH( 20$), \ldots$

* TEMPP(20),PRES(20), TEMPH (20),PRERH(20)

*TABLE H(1) $=1000,, H(2)=1095,, H(3)=1282,, H(4)=1372, H(5)=1456 \ldots, \ldots$

* $\quad H(6)=1600, V(1)=.3, V(2)=.2, V(3)=.14, V(4)=.1, \ldots$

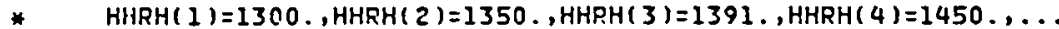

* HHRH ( 5$)=1519$, , HHRH $(6)=1550$, HHRH $(7)=1600$, HHRH $(8)=1650, \ldots$

* $\operatorname{VRH}(1)=4 ., \operatorname{VRH}(2)=2, \operatorname{VRH}(3)=.1, \operatorname{VRH}(4)=.8, \operatorname{VRH}(5)=.6$

FIXED IBUG 1, IBUG2, IBUG3, IBUG $4, I, J, K, L$

**

*****************************************************************

* SATURATION TEMPERATUPES AS A FUNCTION OF P.RESSURE

* FUINCTION TEISPS = (SAT. FRESSURE, SAT. TEI!PERATURES )

*******************************************************************

***

FUNCTION TEMPS $=(1,101.74),(2,126.07),(3,141.47), \ldots$

$(10,, 193.21),(1000,, 544.58),(1500,596.50),(2000,635.80), \ldots$

$(2200,649.45),(2400,662.11),(2600,673.91),(2800,684.96), \ldots$

$(2900,690.0),(3000,695.33),(3200,705.08)$

$* *$

**********************************************************************

* * SATURATIOH ENTHALPY'S AS A FU:ICTION OF SAT. PRESSURES

** FLNICTION HSATL = (SAT. PRESSURE, SAT. ENTHALPY)

*********x************************************************************

$* *$

FURYCTICN HSATL $=(1000,542.6),(1500 ., 611.7),(2000,672.1), \ldots$

$(2200 ., 695.5),(2400 ., 719.0),(2600 ., 744.5),(2800 ., 770.7), \ldots$

$(3000 ., 801.8),(3200 ., 875.5)$

$* *$

**********************************************************************

* EVAPCRATION EHTHALPY'S AS a FUITCTION OF SAT. PRESSURE

* FIJPICTION HSATDF (SAT.PRESSURE, EVAR. ENTTHALPY)

**********************************************************************

FUNCTIOH HSATDF $=(1000,0650.4),(1500,, 558.4),(2000,, 466.2), \ldots$

$(2200 ., 426.7),(2400 \ldots, 384.8),(2600,337.5),(2800 ., 285.1), \ldots$

$(3000,218.4),(3200,56.10)$

$* *$

$* * * * * * * * * * * * * * * * * * * * * * * * * * * * * * * * * * * * * * * * * * * * * * * * * * * * * * * * * * * * * * * * * * * *$ * SUPERHEAT REgION TElTFERATURES AS a FUNCTION OF ENTHALPY AND DENSITY * * FUITCTICN*TEIP, ENTHALPY $=$ (DENSITY, TEIIPERATURE)

************************************************************************

***

FUHCTIÖN TEHP, $1000=(1 ., 430.844),(2.5,520.871),(3.33,551.555), \ldots$

$(5, .596 .133),(7.143,635.961),(10 ., 673.141)$ 
FUNCTION TEMP, $1095=(1 ., 444.702),(2.5,539.672),(3.33,572.000), \ldots$ $(5 ., 619.117),(7.143,661.094),(10,, 728.889)$

FUNCTION TEHP, $1282=(1 ., 581.957),(2.5,682.034),(3.33,725.135), \ldots$ $(5 ., 795.082),(7.143,865.870),(10, .911 .779)$

FUNCTION TEH!P, $1372=(1 ., 742.299),(2.5,823.385),(3.33,860.629), \ldots$ $(5 ., 923.501),(7.143,981.735),(10 ., 1013.377)$

FUNCTION TEHP, $1456=(1 ., 899.225),(2.5,966.172),(3.33,998.495), \ldots$ $(5 ., 1054.845),(7.143,1098.326),(10 ., 1122.553)$

FUNCTICN TEHP, $1600=(1 ., 1166.925),(2.5,1218.765),(3.33,1244.958), \ldots$ $(5 ., 1288.463),(7.143,1314.316),(10 ., 1330.160)$

**

*********************************************************************** ** SUPERHEAT REGION PRESSURES AS A FUNCTION OF ENTHALPY AND DENSITY ** FUNCTION PRESS, ENTHALPY = (DENSITY, TEMPERATURE) ***********************************************************************1

$* *$

FUNCTION PRESS, $1000=(1 ., 346.812),(2.5,818.654),(3.33,1058.859), \ldots$ $(5,1499.784),(7.143,2002.973),(10,2586.738)$

FUNCTION PRESS, $1095=(1, .400 .466),(2.5,959,196),(3.33,1246.134), \ldots$ $(5, .1775 .806),(7.143,2385.155),(10 ., 3315.097)$

FUNCTICN FRESS, $1282=(1,550.030),(2.5,1380.425),(3.33,1833.668), \ldots$ $(5 ., 2733.001),(7.143,3950.000),(10 ., 5600,000)$ -

FUNCTION PRESS, $1372=(1 ., 668.509),(2.5,1655.341),(3.33,2199.180), \ldots$ $(5 ., 3279.593),(7.143,5250.000),(10 ., 6700.000)$

FUNCTICN PRESS, $1456=(1,771.661),(2.5,1912.240),(3.33,2541.857), \ldots$ $(5 ., 3795.191),(7.143,5450.000),(10,, 7750.000)$

FUNCTICN PRESS, $1600=(1 ., 941.899),(2.5,2344.465),(3.33,3121.385), \ldots$ $(5 ., 4680.000),(7.143,6790.000),(10 ., 9600.000)$

**

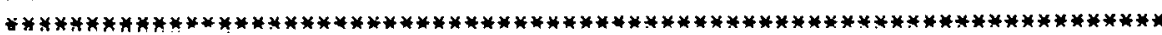
* SUPERHEAT REgICN TEIPERATURES AS a FUNCTION OF ENIHALPY ANU DESITi * FOR THE REHEATERS

* FUIICTION TEIIPRH, ENTHALPY=(DENSITY, TEMPERATURE)

**

FUNCTION TEMPRH, $1300=(.25,549.200),(.5,572.110),(1,612.9591, \ldots$ $(1.25,631.718),(1.667,659.854),(2 ., 680.684)$

FUNCTION TEMFRH, $1350=(.25,649.437),(.5,668.086),(1,, 142.1032), \ldots$ $(1.25,718.425),(1.667,743.231),(2 ., 761.787)$

FUNCTION TEIIFRH, $1391=(.25,731.503),(.5,747.685),(1 ., 777.324), \ldots$ $(1.25,792.160),(1.667,814.538),(2 . ; 031.436)$

FUNCTINN TFIIPRH, $1450=(.25,848,589),(.5,062.192),(1,000.003), \ldots$ $(1.25,900.236),(1.667,919.774),(2 ., 934.678)$

FUNCIIUN TEI!PR̈H, 1519=(.25,903.41L1,(.1,794.898),(1.,2016.927),... $(1.25,1027.472),(1.667,1044.472),(2 ., 1057.551)$

FUNCTION TE:IFRH, $1550=(.25,1043.142),(.5,1053.899),(1,1074.571), \ldots$ $(1.25,1084.505),(1.667,1100.572),(2 ., 1112.971)$

FUNCTION TEMPRH, $1600=(.25,1138.342),(.5,1148.086),(1, .1166 .925), \ldots$ $(1.25,1176.013),(1.667,1190.778),(2,, 1202.220)$

FUNCTION TELIPRH, $1650=(.25,1232.127),(.5,1241.045),(1, .1258 .351), \ldots$ $(1.25,1266.729),(1.667,1280.390),(2 ., 1291.016)$

*

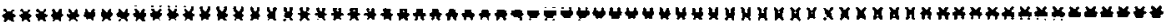
* SUPERHEAT REGION PRESSURES AS A FUNCTION OF ENTHALPY AND DENSITY * FOR THE REHEATERS * FUIRCIION PRESRH, ENTHALPY = (OENSITY, FRESSURE)

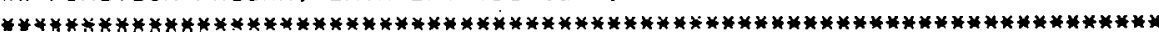
**

FUNCTION PRESRH, $1300=(.25,146.233),(.5,291.583),(1 ., 580.122), \ldots$ $(1.25,724.713),(1.667,962.368),(2 ., 1152.734)$ 


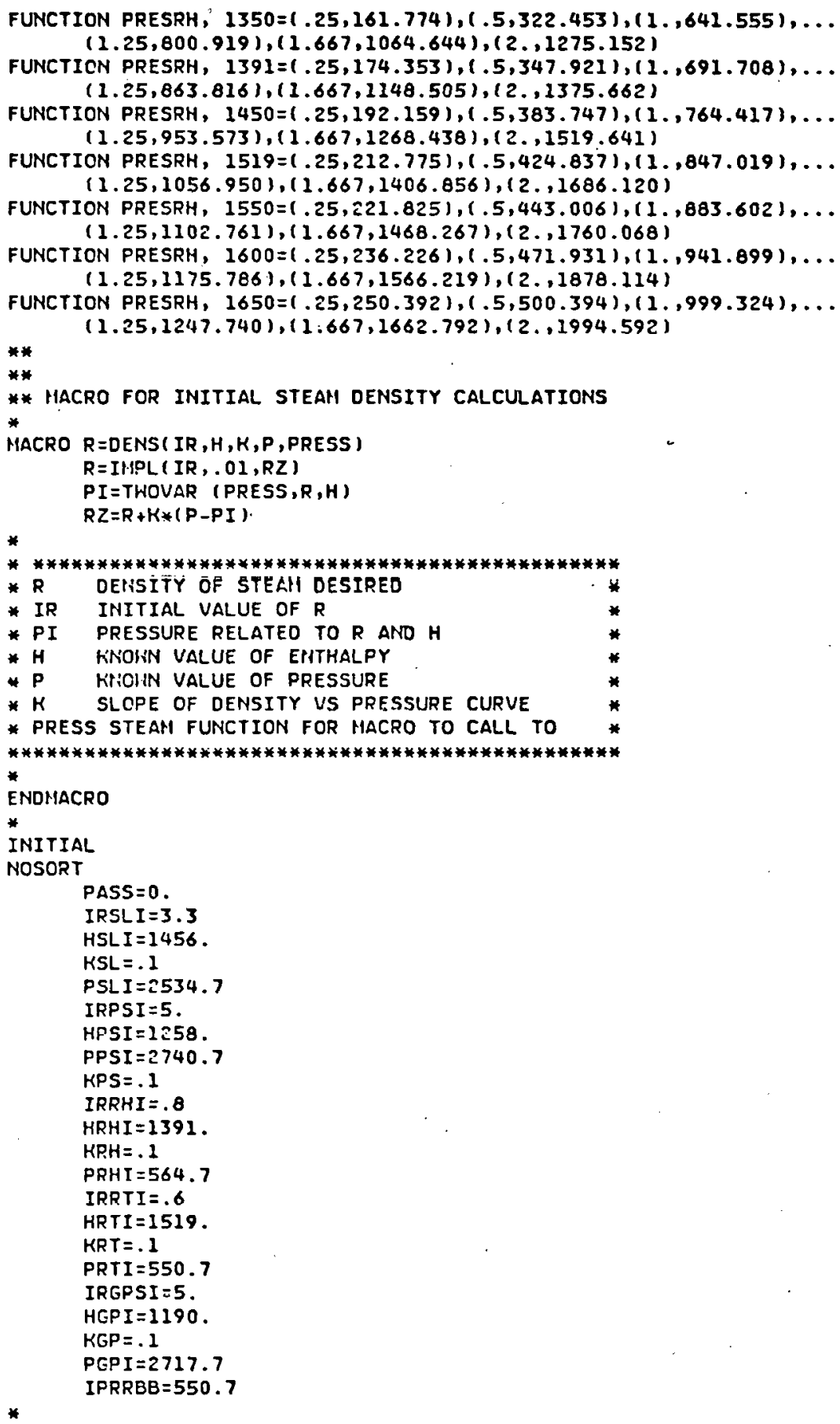




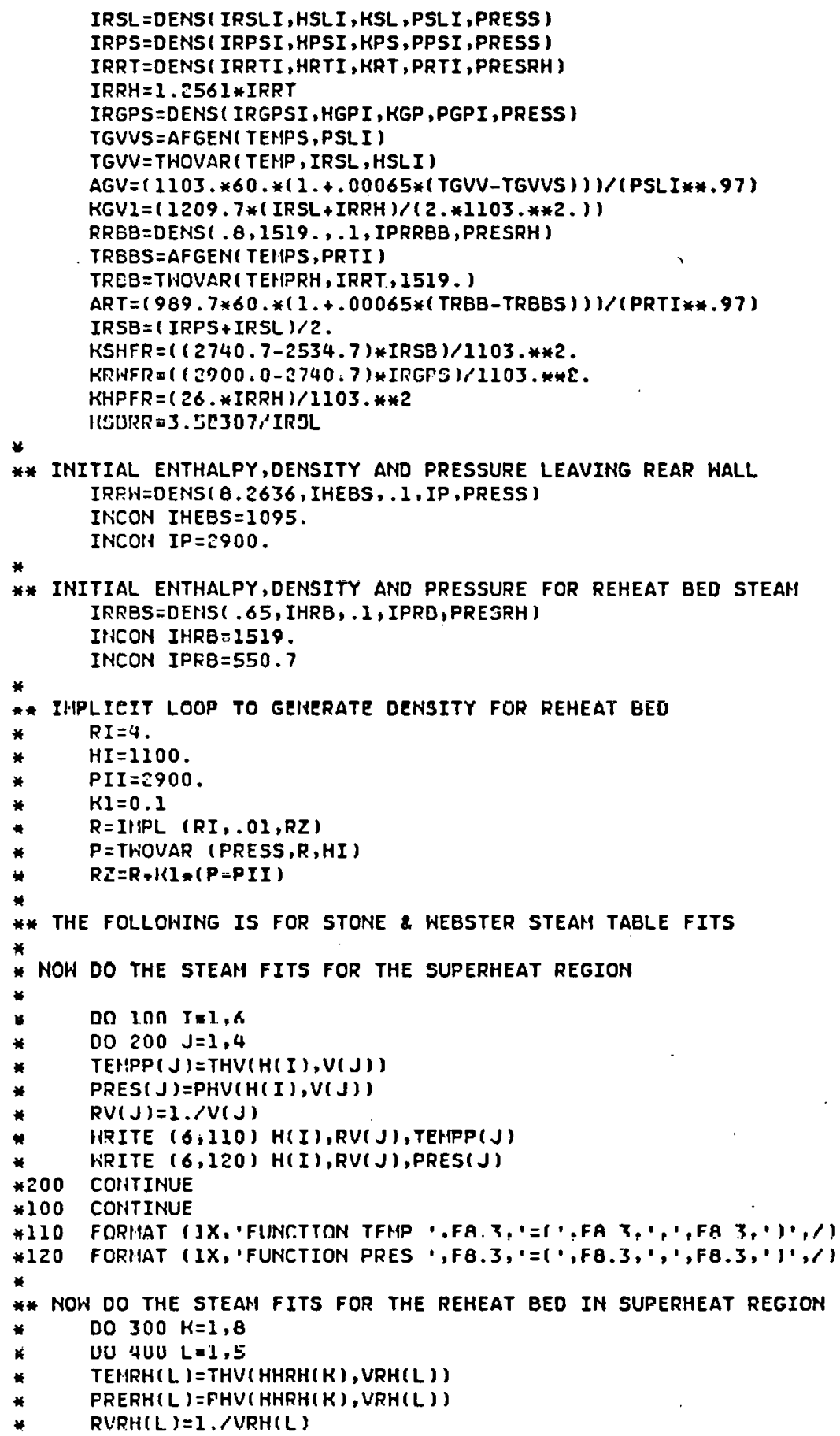




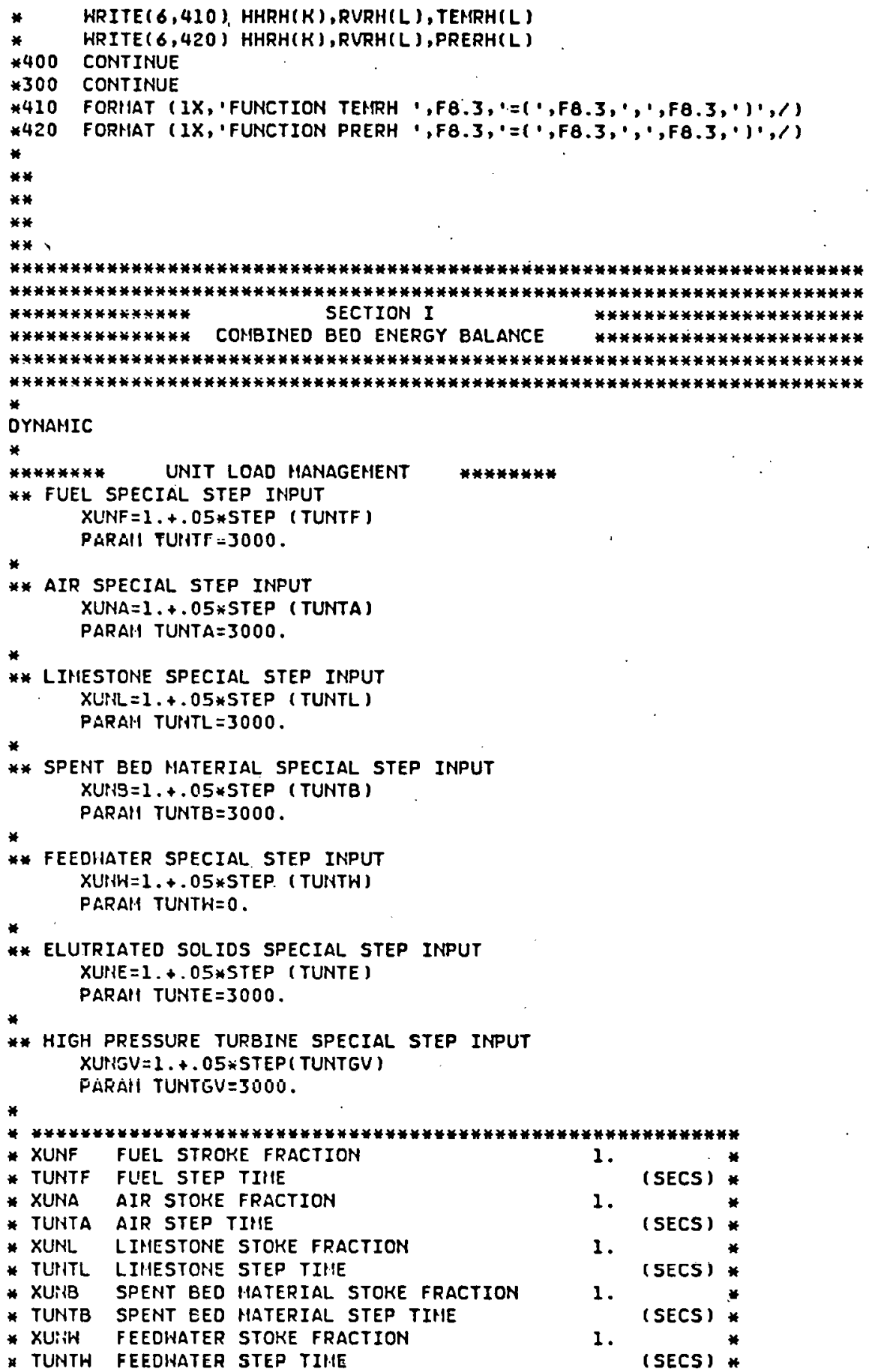

1. (SECS)
1. (SECS)
1. (SECS)
1. (SECS)
1. (SECS)*




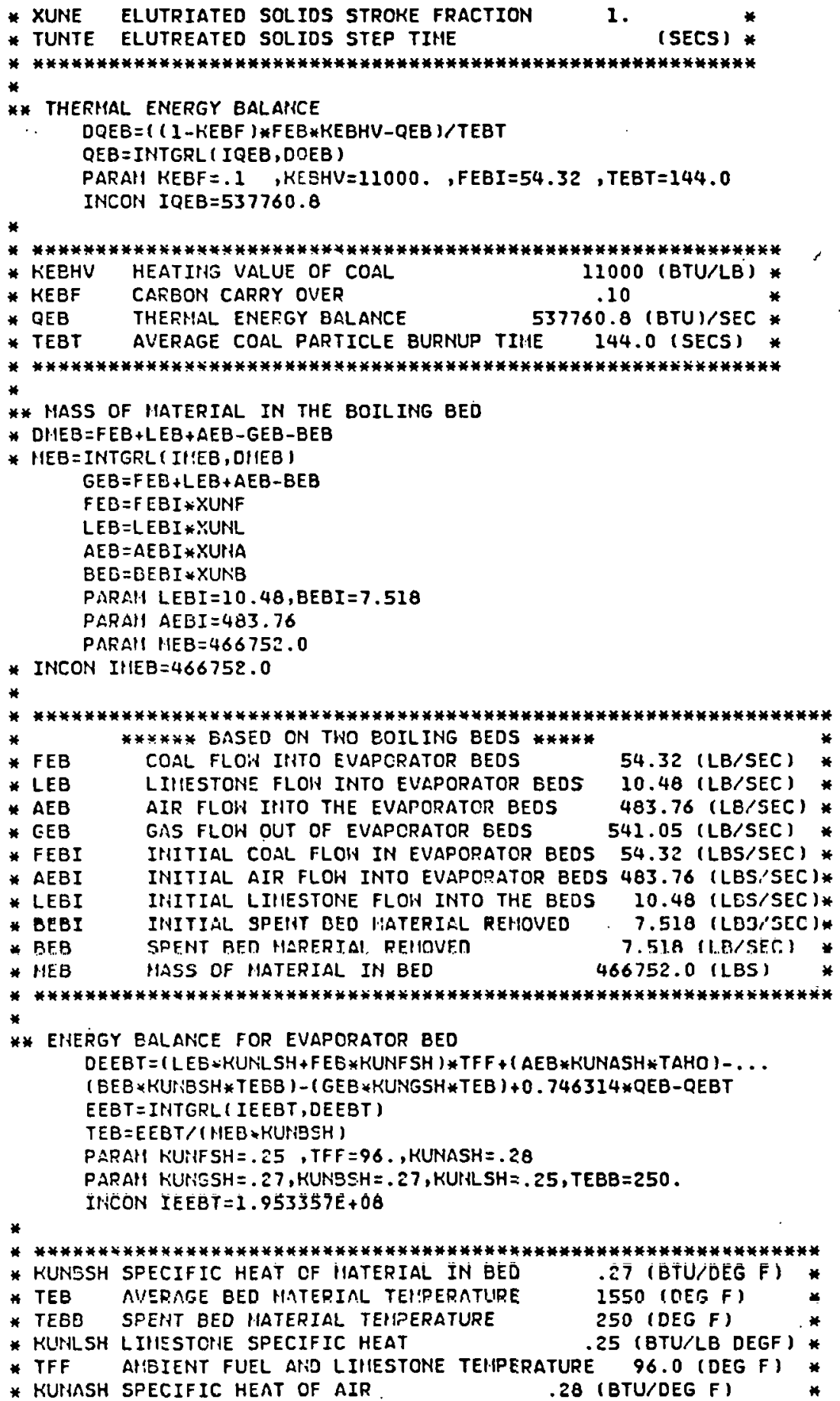




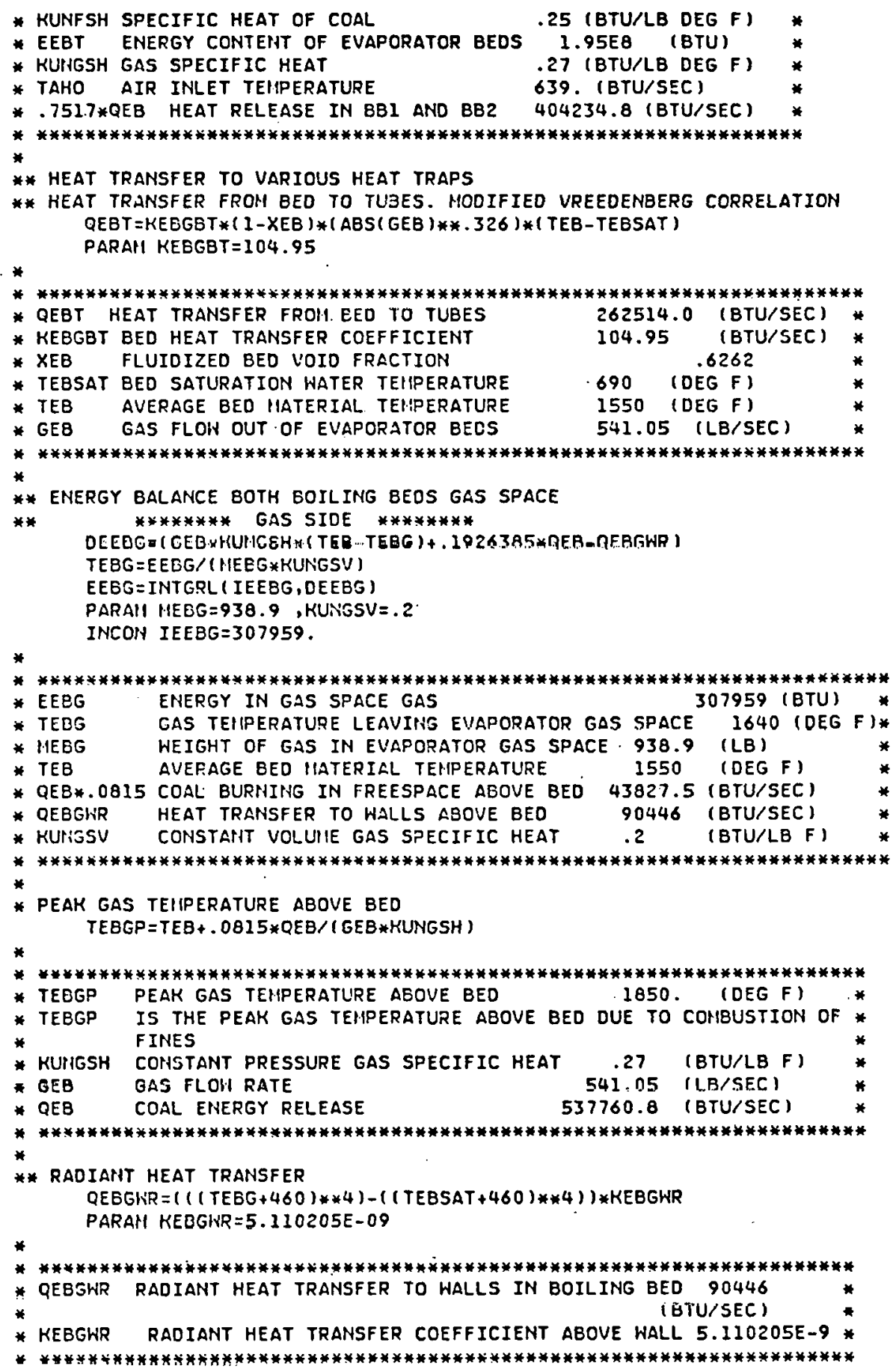




\section{*}

* energy balance to boiling bed halls

$Q E B T B=Q E B T+Q E B G H R+Q R B G H R+Q S B G I V$

DEEBI $=$ ( HEG*HEBI -SEB*HEBS +QEBTB )

EEBH = INTGRL ( IEEBH, DEEBII)

INCON IEEBM $=119.119 \mathrm{E} 06$

*

* boil ing bed and rear hall flows are the same SEB $=$ WEB

* BOILING bed hater floh equals that of CBC HEB $=$ HCB

* ********************************************************************1 * EEBM ENERGY IN BOILING BEDS,FRONT, SIDE \& REAR WALLS OF BECS

* Qébit total heat flon fron boIling Beds to steal 262514 (BTU/SEC) *

* QRBghr total heat fLOH FROH REHEAT BEDS TO STFAN 4573$\}$ (RTII/GFr) *

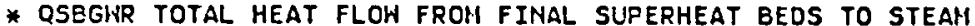

$*$

* QEBGHR TOTAL HEAT FLOW FPOH BOILING BEDS TO

* HEBI EVAPORATOR BED IHIET ENTHALPY 652 (BTU/LB)

* heb - hater flow INTO eVAPorator

* seb steall flow out of evaporator

* aebtr total heat fron boilifig beds, fh, sh aNd R

* WEC MASS FLOH RATE AT ECONOHIZER OUTLET ENTHALPY OF STEAH LEAVING REAR WALL 1103 (LE/SEC) RH $488,629.0$

1103. (LBS/SEC)

1095. (BTU/LBII)

********************************************************************

* ***************************************************************

* hater steali side horizontal tubes Fh, Sh \& RH energy balance

* BED enClosures

* FH FFOHT IHALL

* SH Sideg halls

* rh rear halls

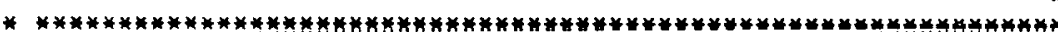

* evaporator beo enthalpy balatice

HEBS = IMPL I HEBSI, KEBHER, HEBST

PRW = TWOVAR (FRESS, KKH, HEBS )

TEBSAT = AFEEN(TEIPS,PRW)

HEBST = (EEBII-HEGI $*$ *TEGSAT*KEBSWM $) / M E B W$

MKIYEHEBS

TRHS = THOVAR ( TEH!P, RRW,HRW )

PARAH HEBH $=698953, \mathrm{KEBSH}=.12, \mathrm{HIEBW}=55941$.

PARAM HEBSI $=1095$, KEBHER $=.01$

*

* $* * * * * * * * * * * * * * * * * * * * * * * * * * * * * * * * * * * * * * * * * * * * * * * * * * * * * * * * * * * * * * * *$

* prW pRessure at Rear hall discharge 2900 (PSIa)

* hebr hetal hass associated hith gotling beds and halls

* HeBs eidThalp't üf sieari leaving rear wall

* hPh enthalpy of steaHi leaving rear hall

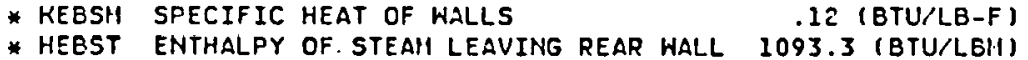

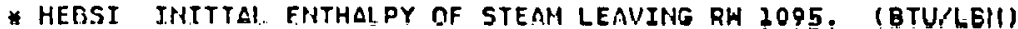

* KEEitié eVAPCRATOR Bed IHIPLICIT LOOP ERROR. .01

* CRITERIa

* tebsat saturated hater ter.p. in hater halls 690. (deg f) * 


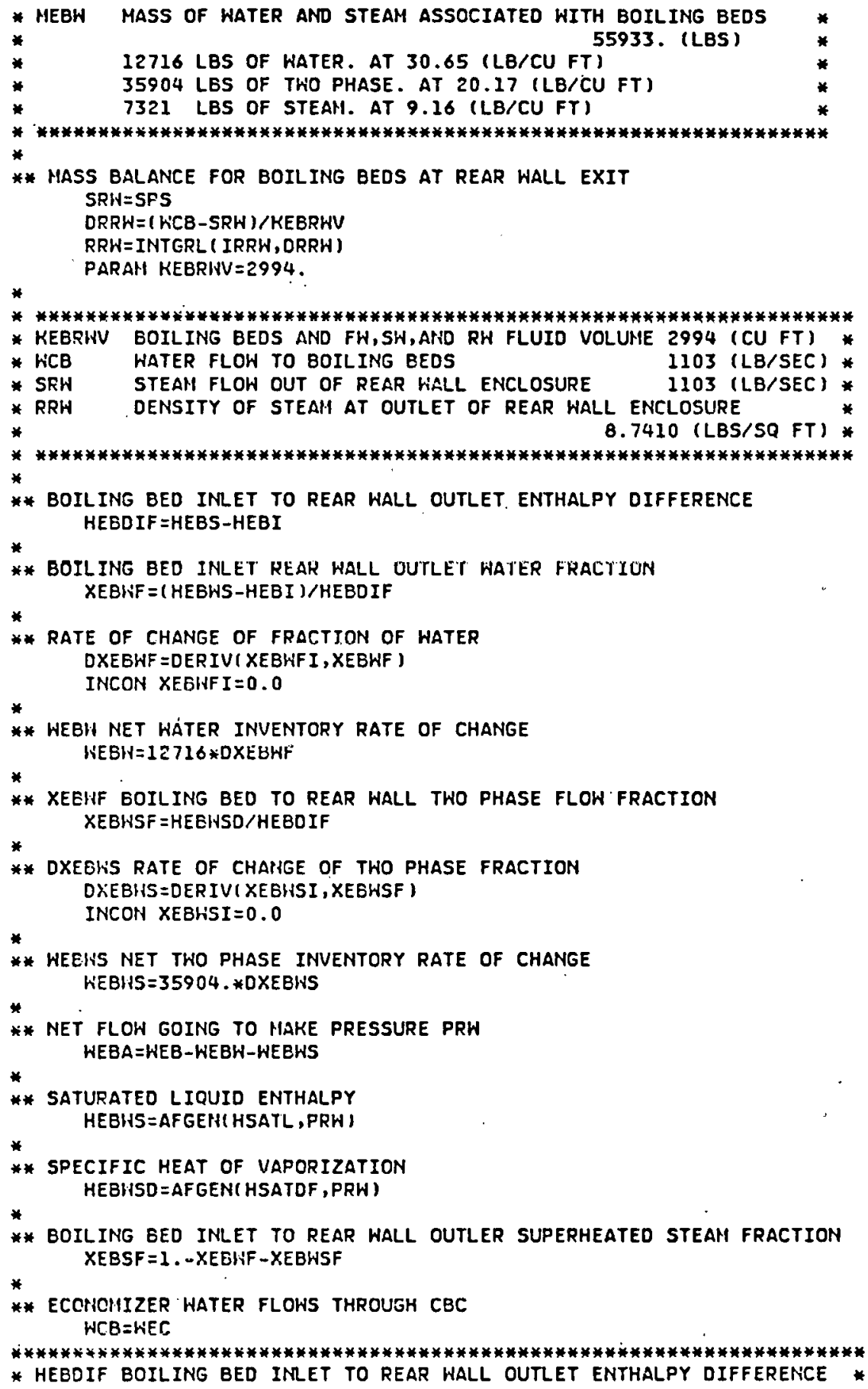




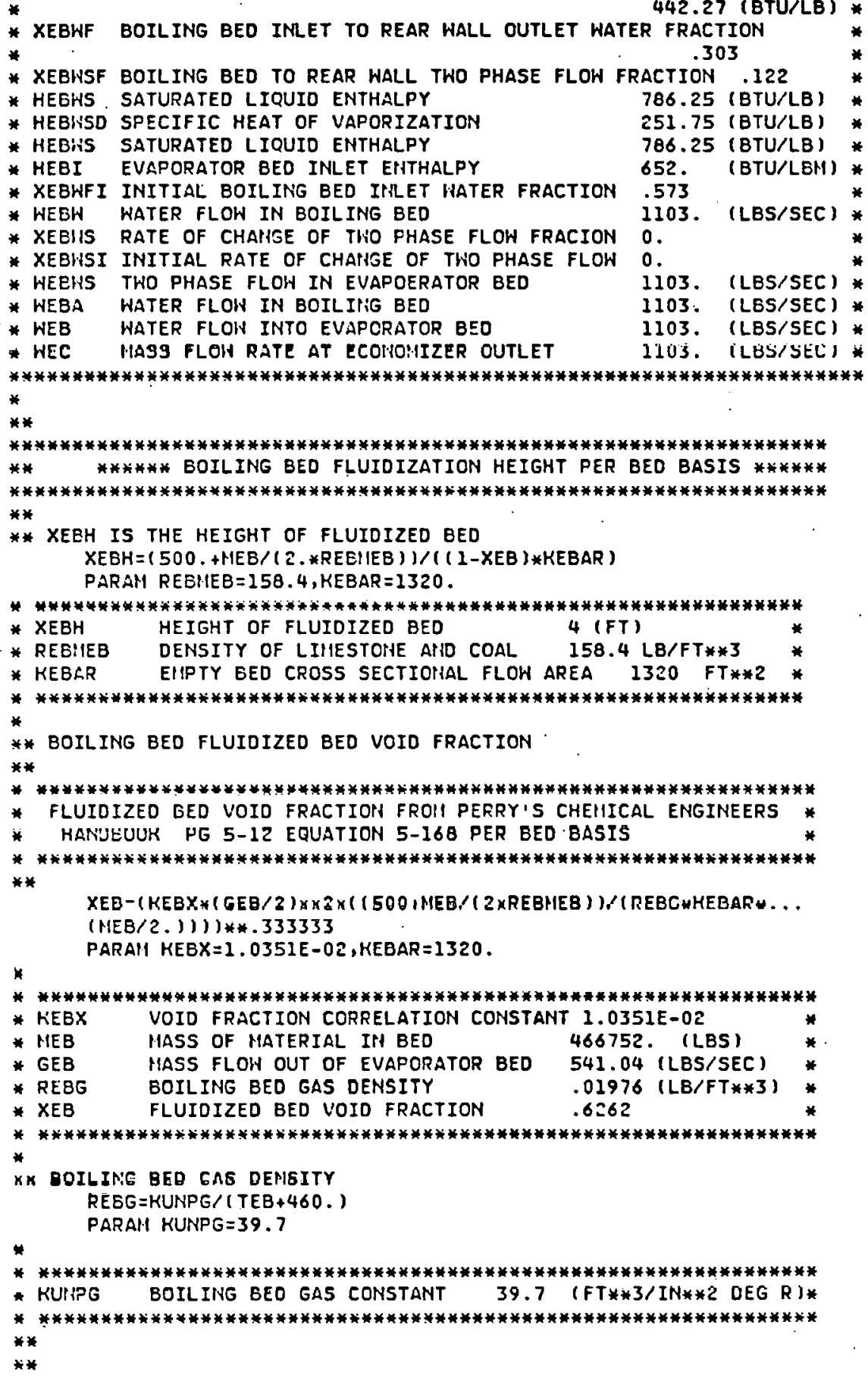




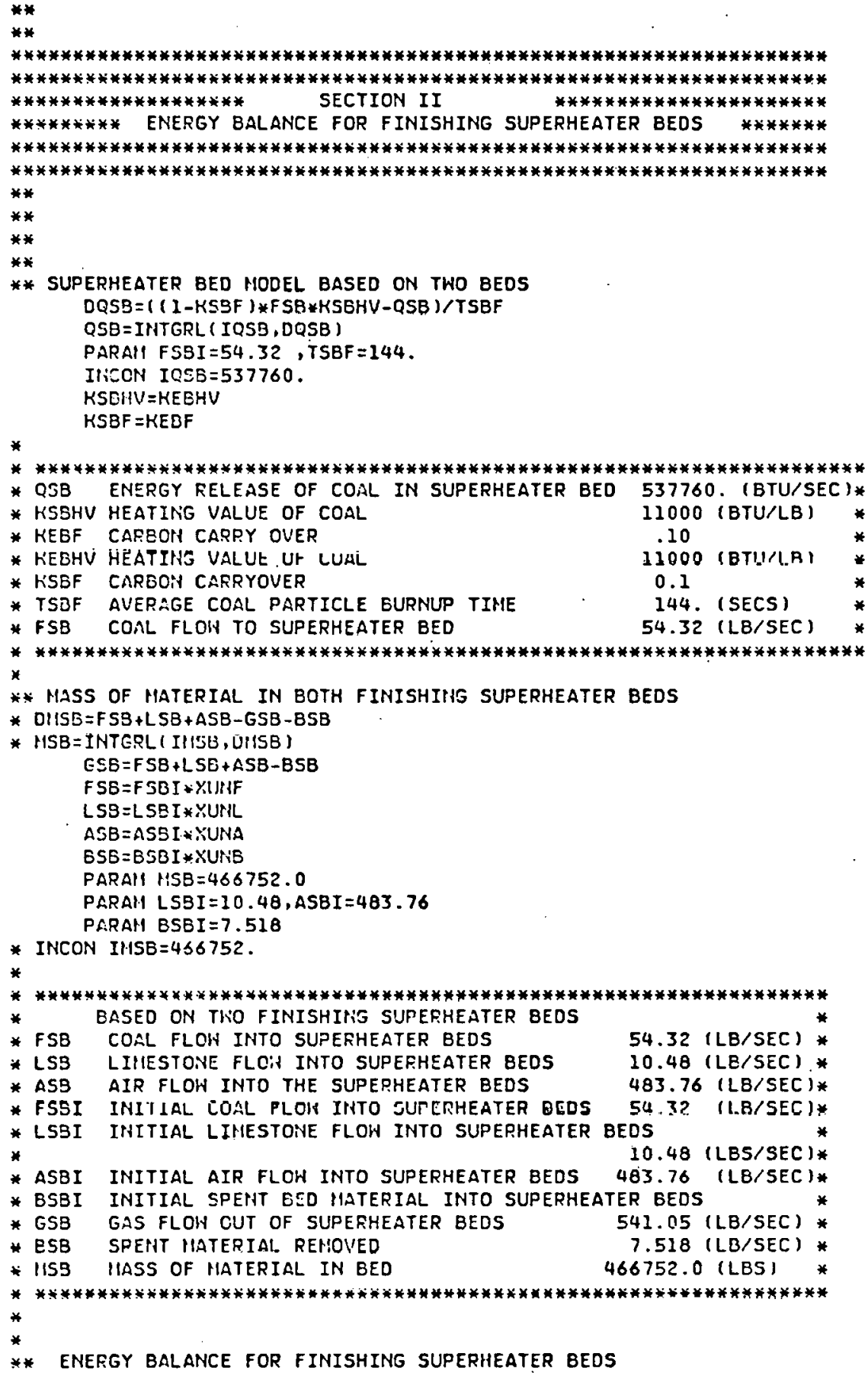




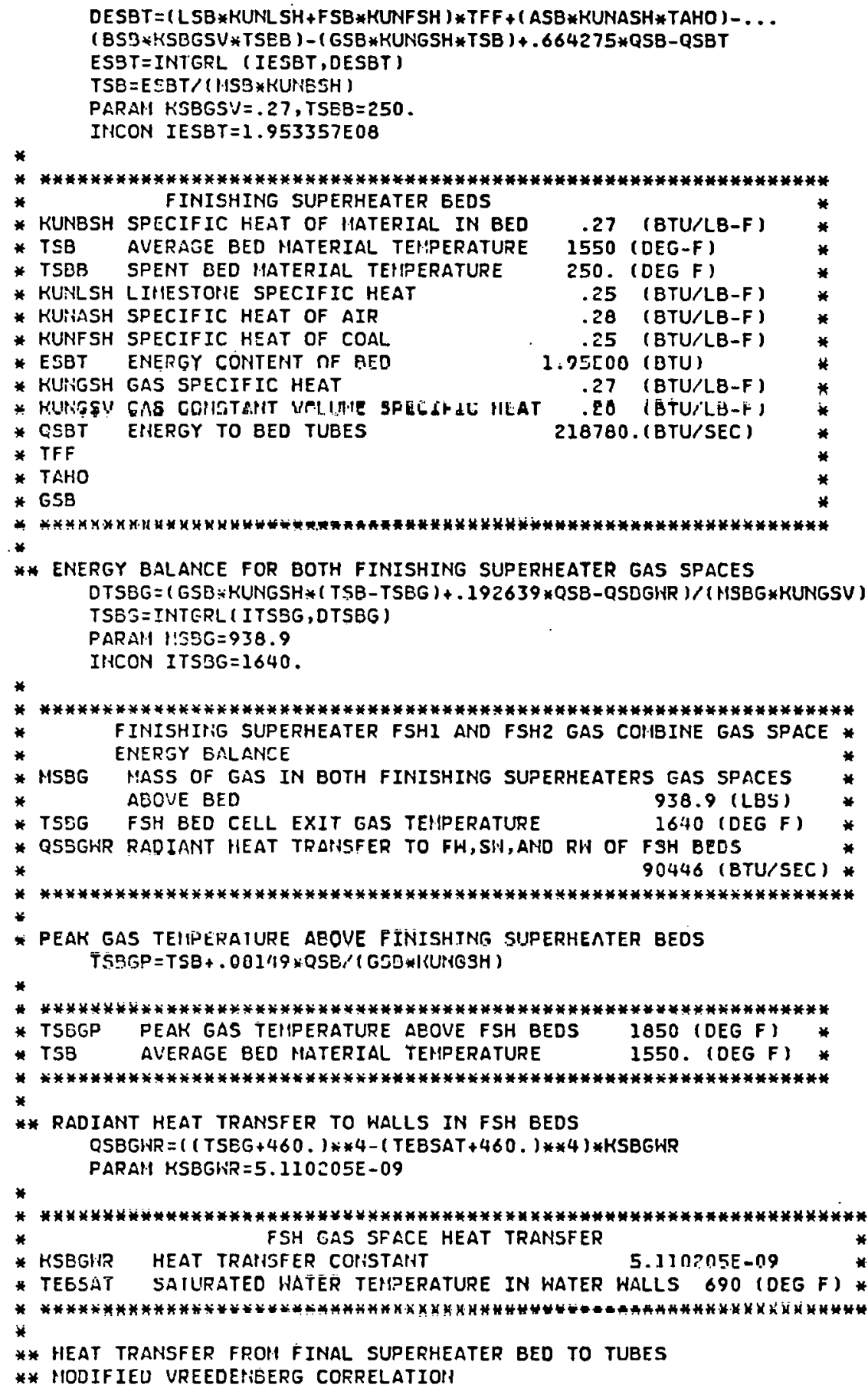


QSBT $=K S B G B T *(1-X S B) *(A B S($ GSB $) * .326) *(T S B-T S B M T)$

PARAM KSEGBT $=164.699$

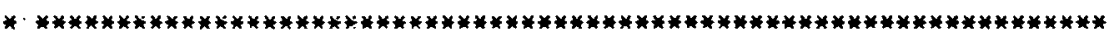

FIIISHIITG SUPERHEATER

* GSB

* XSB

* TSB

* TSBNT FITISHIYGFER FROII BED TO TUBE METAL GAS MASS FLOI THRU BED FLUIDIZED BED VOID FRACTION AVERAGE BED TEIIPERATURE

* KSBGBT hEAT TRANSFER CONSTANT 218394 (BTU/SEC) * 541.07 (LB/SEC) * 0.6262 1550 (DEG F) * 1094.1 (DEG F) *

* ******************************************************************

* HeAt StORAge IN SUPERHEater bed tube Metal OTSB!IT = ( QSBT-QSBTS $) /$ KSBH TSEIIT = INTGRL (ITSEHT, OTSBHT )

IRCON ITSEMT $=1094.1$

PARAII KSEl $=44403$.

*

* HEAT TRAHSFER FROM STEAM TO SUPERHEAT BED QSBTS =KSEQTS*ABS(SSB)**.8*(TSSH $1 T-T S S S)$ PARAH KSSGTS $=9.021995$ TSBS = THOVAR (TENP, RSBO, HSB) $R S E O=K S B R R \approx R S L$

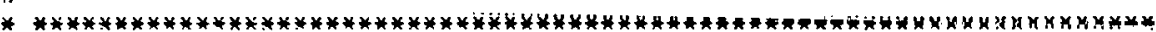

* KSE!I ENEFGY CONTEHT OF l.AETAL IN SUPERHEATER BEDS 44403 (BTU/DEG F)* * QSBTS HEAT TRANSFER FROII SUPEPHEAT EEDS TO STEAH. 218394.(BTU/SEC)*

* KSSTTS HEAT TRANSFER EqUATION COEFFICIENT 9.022

* SS9 FINISHIHG SUPERHEATER STEAH FLOH 1103.

* taAnsfer pife heIGHT

* RSBo bed cutlet deisity

* kssrr ratio of bed outlet to steah line derisity

* headers neight

* specific heat of hetal

* total height

* tSbitt metal teliperature in superheater beds 1094.1 (DEg F)

* TSES TEIPERATURE fOR Bed STEAMI 1005. (DEg F)

* $* * * * * * * * * * * * * * * * * * * * * * * * * * * * * * * * * * * * * * * * * * * * * * * * * * * * * * * * * * * * * * * * * * * * *$

* heat storage IN STEAlf IN FiHISHING SUPERHEATER Beds PIPING DHSB $=($ SPS $* H P S-S S B * H S B+Q S B T S) / 11560$

HSB $=$ IHTTGL (IHSB, DHSB)

IHCON IHSB $=1456$.

PARAII HPS $=1202$.

*

再******************************************************************

* SPS PPIIIARY SUPERHEATER STEAlI FLON 1103 (LB/SEC)

* SSB FINISHIIIG SUPEFHEATER STEAl FLOW 1103 (LB/SEC)

* HPS FRIIIARY SUPERHEATEKS OISCHARGE ERTHALPY 1282 (BTU,LB)

* HSB FINISHIPG SUPEFHEATER DISCHARge ENTHALPY 1456 (BTU,LB)

* Qsgts heat floh to steall

* eriesgy content of steali

* Voluile of steali in tuses

* VOluH. OF trailsfer pipes

* Voluite of heade?s

* hssvol total steali volupe

* average delisity

* SPECIFIC HEAT OF STEAH

* fSh itllet pRessure

218394 (BTU/SEC)

886 ( CU FT)

7.451 (BTU/DEG F)

708 (CU FT)

378 (CU FT)

1972 (CU FT)

4.1671 (LB/(FT**3))

0.8196 (BTU/DEG F)

2740.7 (PSIA) 


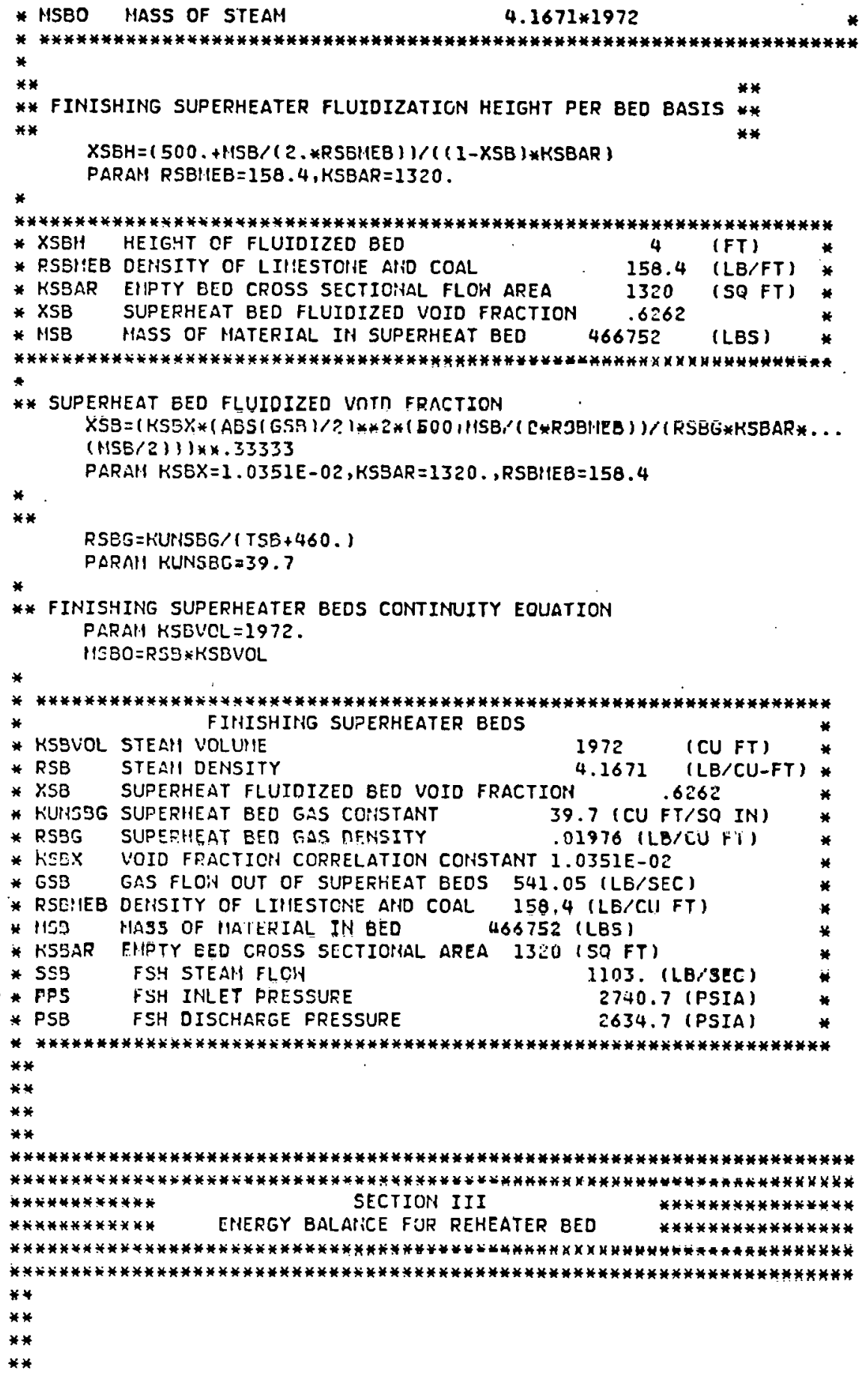




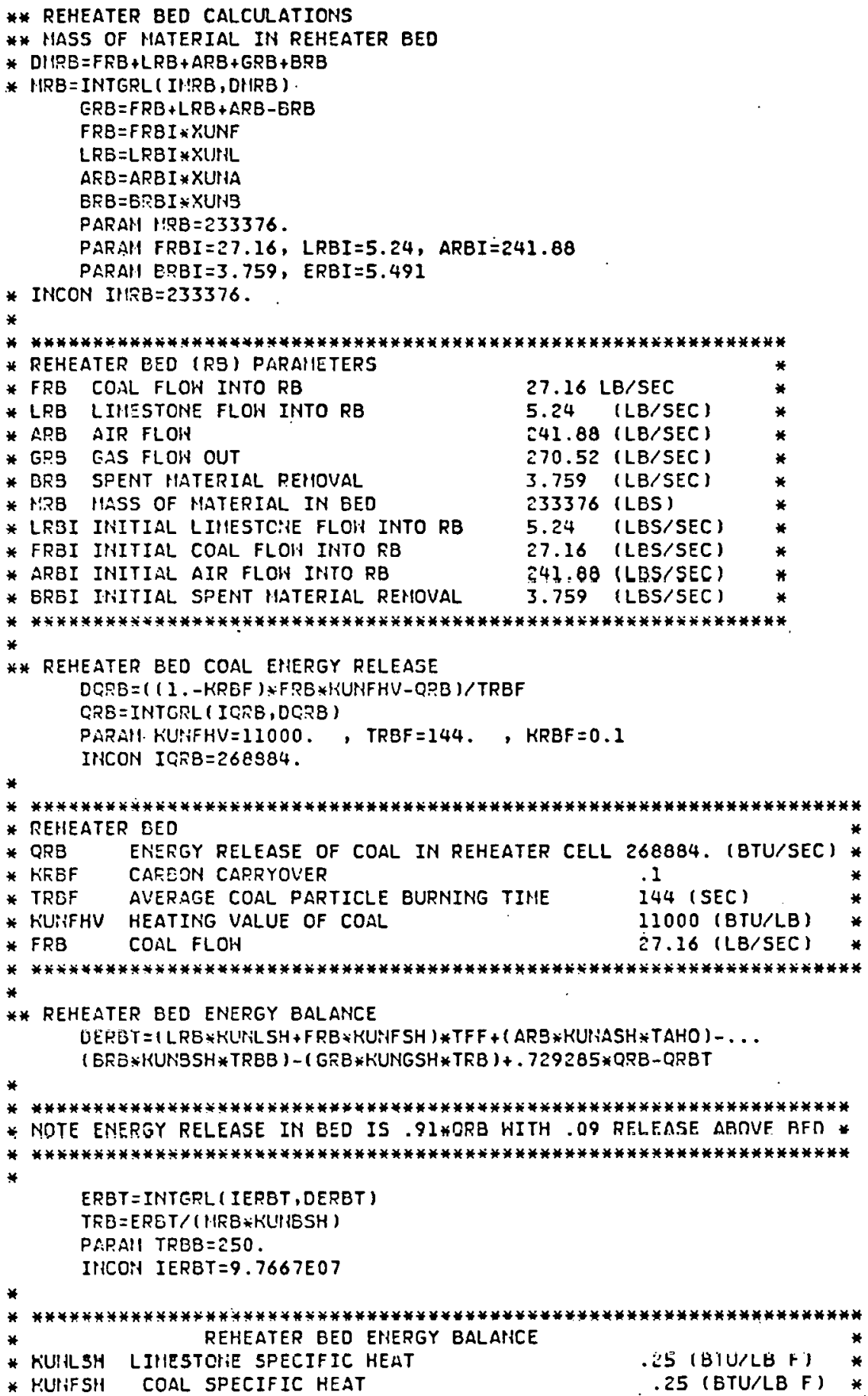




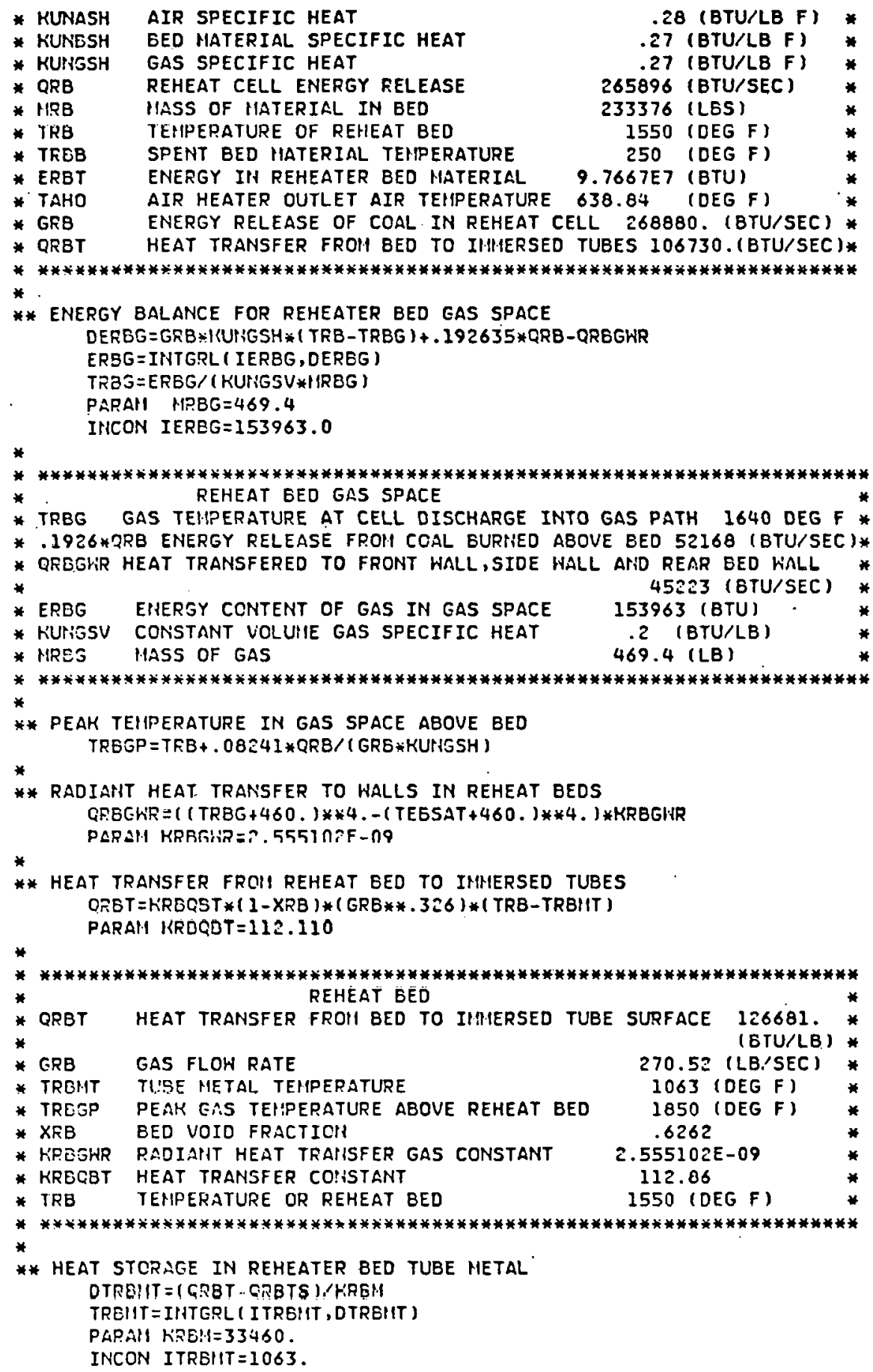




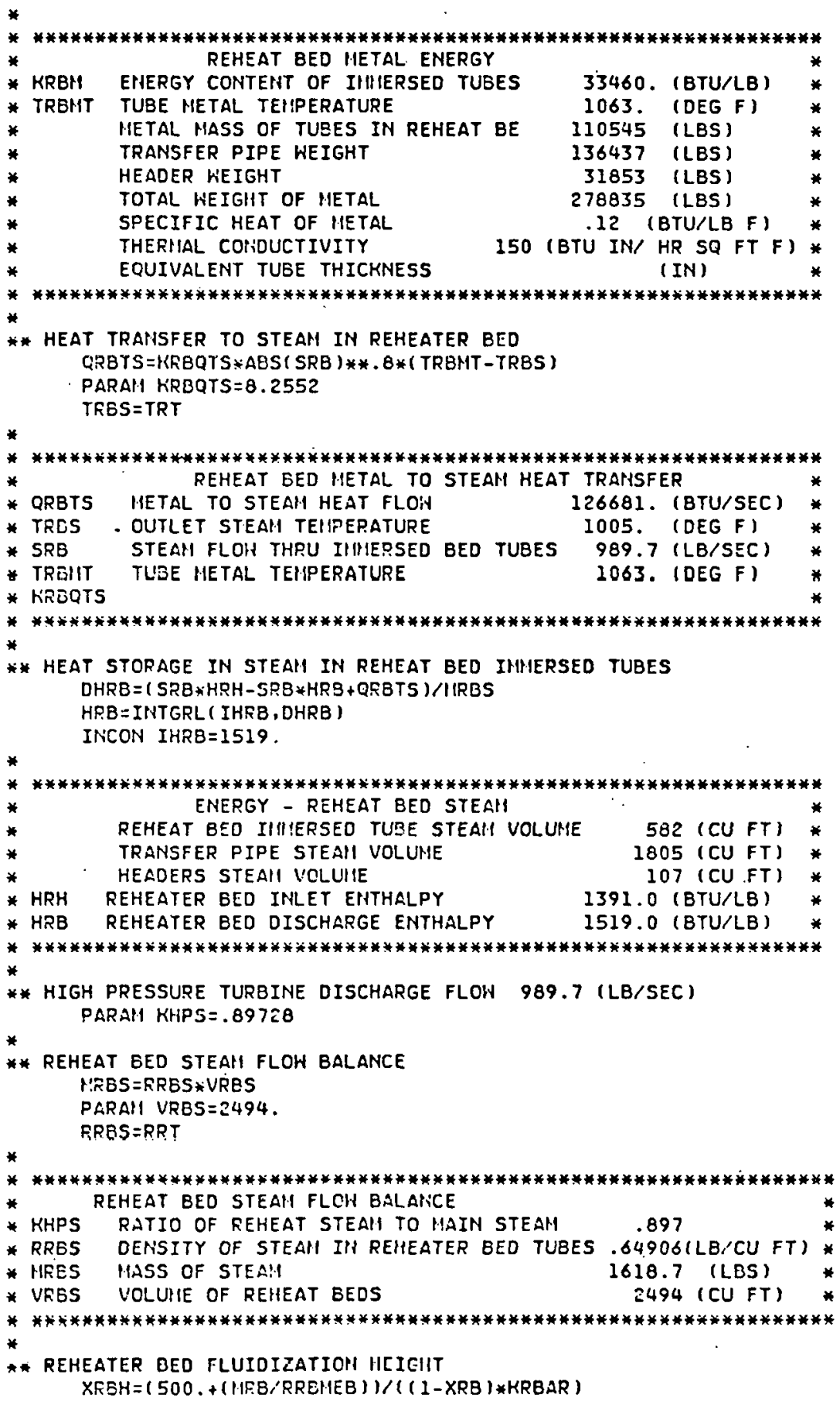


PARAM RRBMEB $=158.4$, KRBAR $=1320$.

*

* ***********************************************************

* XRBH HEIGHT OF FLUIDIZED REHEATER BED

* RRBIIEB DENSITY OF LIIIESTONE AISD COAL 158.4 (LB/CU FT) *

* kPBAR elipty bed cross sectional floh area 1320 (SQ FT) *

* IIPB

* XRB

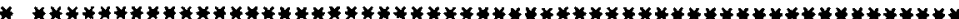

*

* Fluidized ReHEATER BED VOID FRACTION

$X R B=(K R B X * A B S(G R B) * * 2 *(500 .+(N R B / R R B H)) /(R R B G * H R B * K R B A R)) * .3333$

PARAM KRBX $=1.0351 E-02, R R B I 1=158,4, K R B A R=1320$.

*

* $* * * * * * * * * * * * * * * * * * * * * * * * * * * * * * * * * * * * * * * * * * * * * * * * * * * * * * * * * * *$

* GPB gas flow. RATE fROH tHe REHEAT BED 270.52 (LB/SEC)*

* KRBX

* FRGG

COEFFICIENT BASED ON DESIGN DATA $1.0351 E-02$

* KFENR

GAS DENSITY 01976 (LB/CU FT)

* RRE:I DEHSITY OF REHEAT BED MATERIAL 158.4 (LB/CU FT) *

* TRB TEI!PERATURE OF REHEAT GED 1500 (DEG F)

* ***********************************************************

* REHEATER BED GAS DENSITY

RREG = KUNPG $/($ TRB +460.)

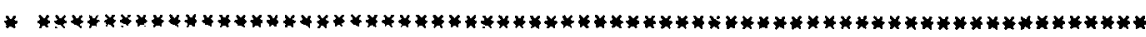

* Kulipg gas lah constaht assumilig atmospheric pressURe

*

* trg terperature of Reheat bed 1550 (DEg F)

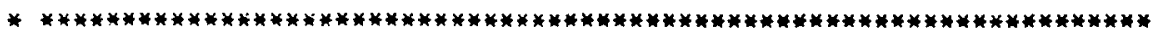

$* *$

***

$* *$

$* *$

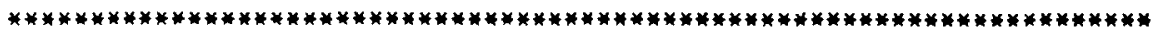
$* * * * * * * * * * * * * * * * * * * * * * * * * * * * * * * * * * * * * * * * * * * * * * * * * * * * * * * * * * * * * * * * * * * * * *$ $*_{* * * * * * * * * *}$ SECTICN IV $* * * * * * * * * * *$ HASS BALANCE FOR CARSOPI BURNUP CELL $*^{*} * * * * * * * * * * * * * *$ *************************************************************************

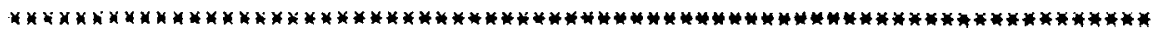
$H *$

**

$* *$

$* *$

* hlass balarice for carbon burnup cell

* DI!CB $=F C B+B C B+A C B-G C B$

* HCB = IHITGRL ( IHICB, DIICB ) $A C B=A C B I * Y$ UTHA $G C B=F C B+B C B+A C B$

PARAII $A C B I=145.06$

INCON IIICB $=224640$.

*

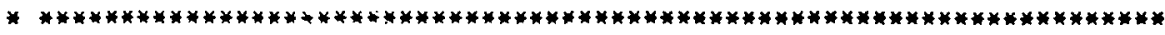
* CAFBCN BUPIIUP CELL

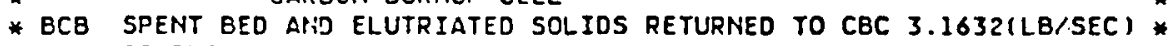

* CER SPLIOS ELUTRIATED FROII CEC

* acb reheat ailo air elohier air to cBC

* gCB gas âto solios flow out of cBC

* hicb llass of bed 


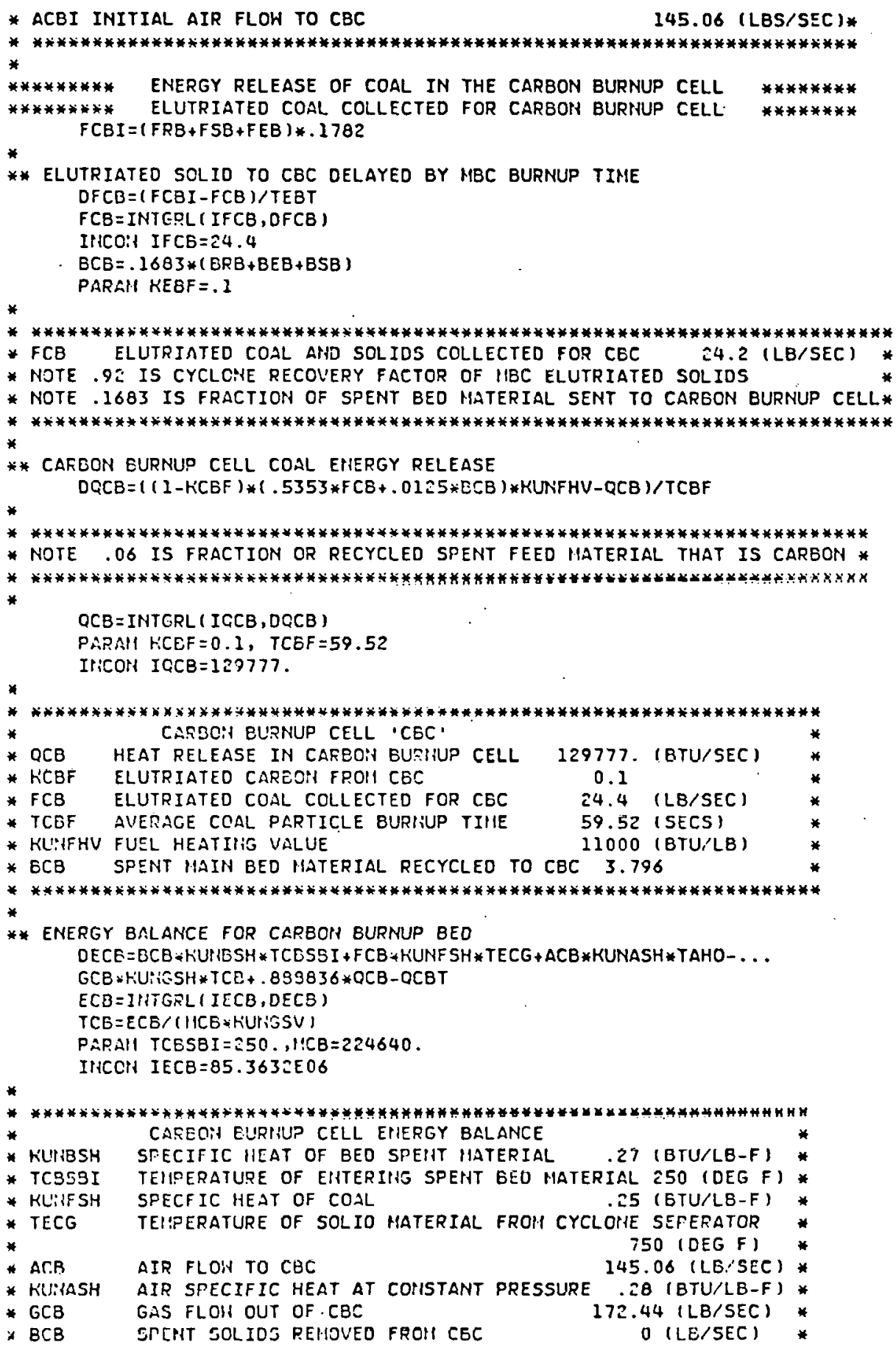




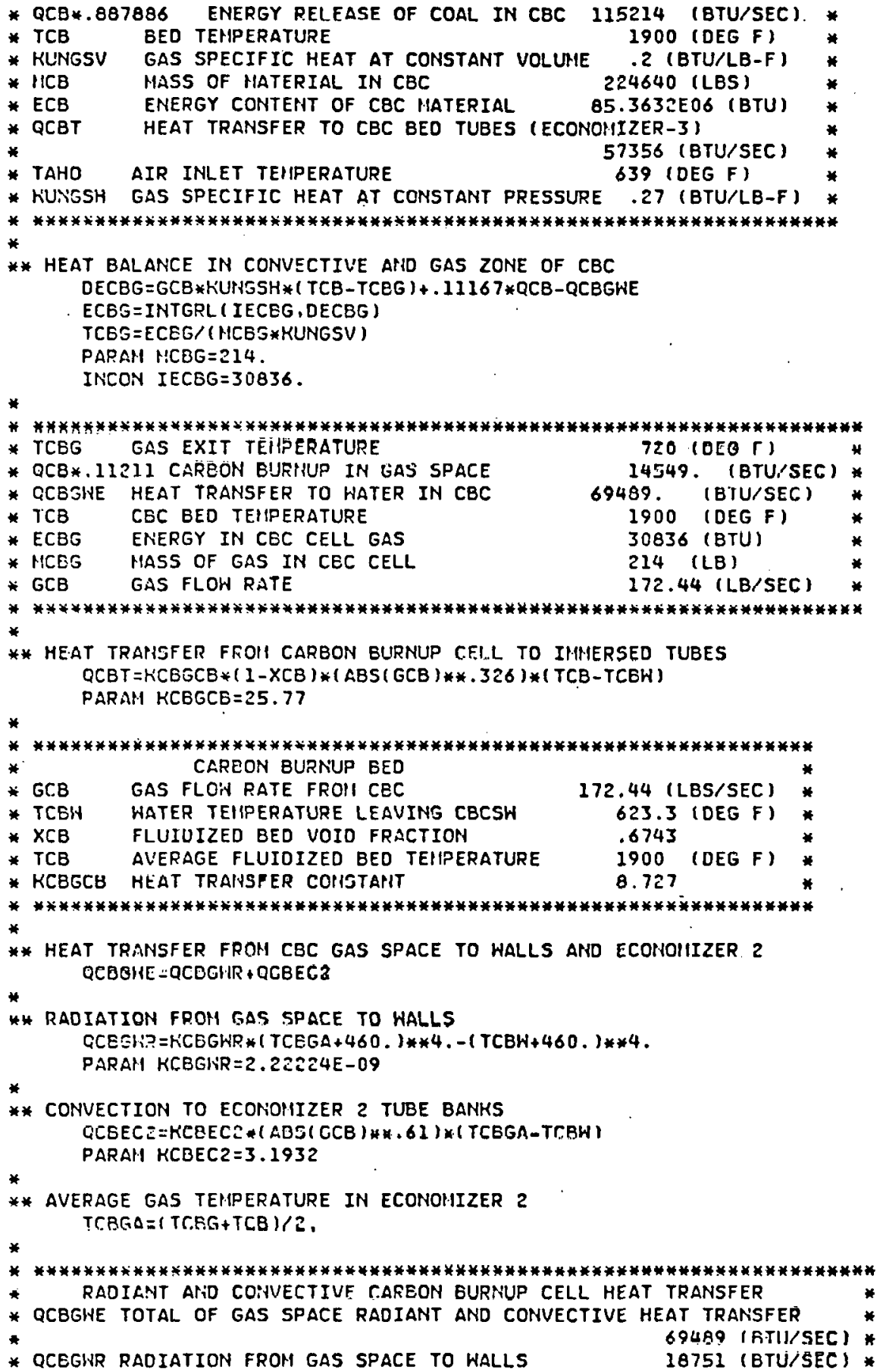




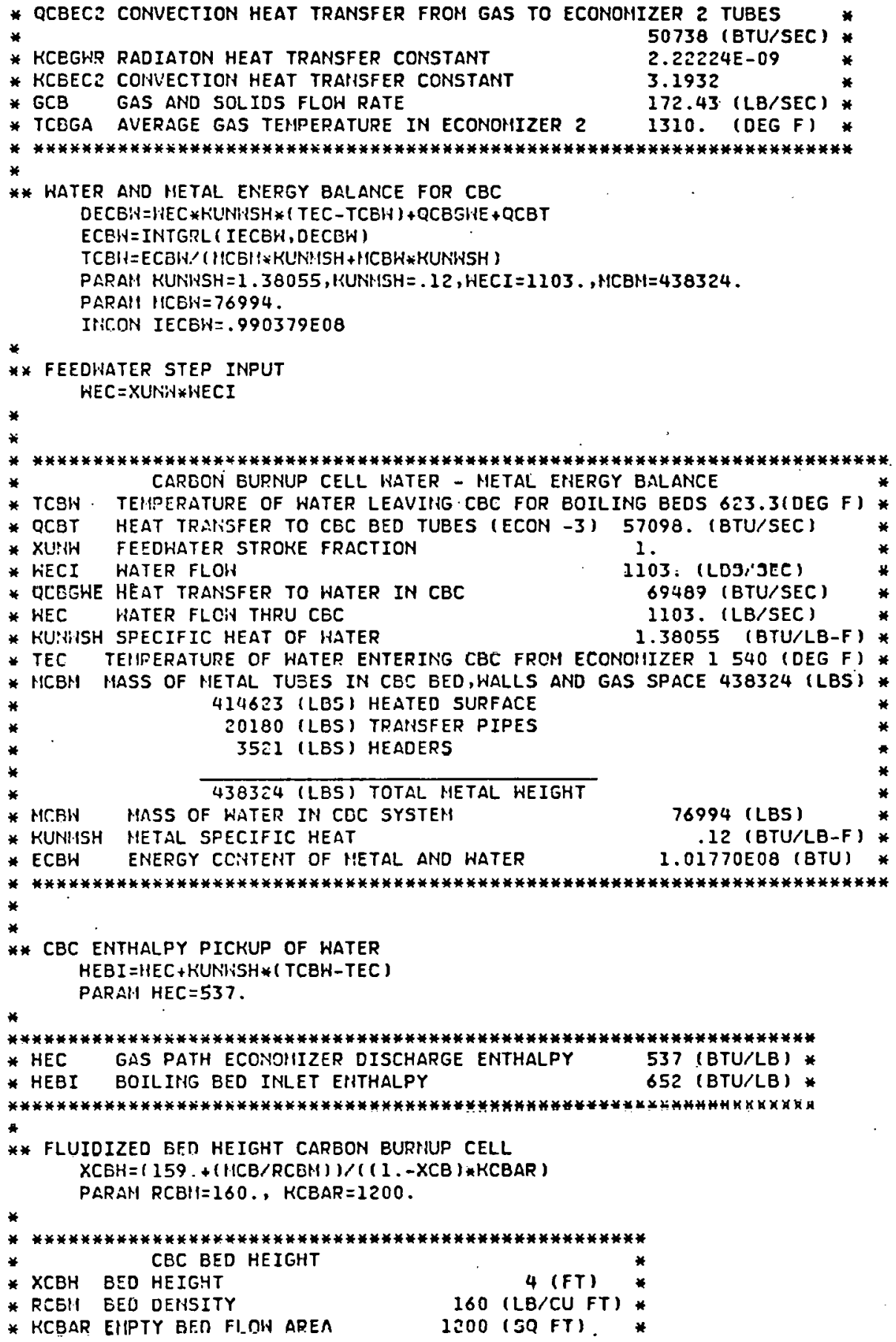




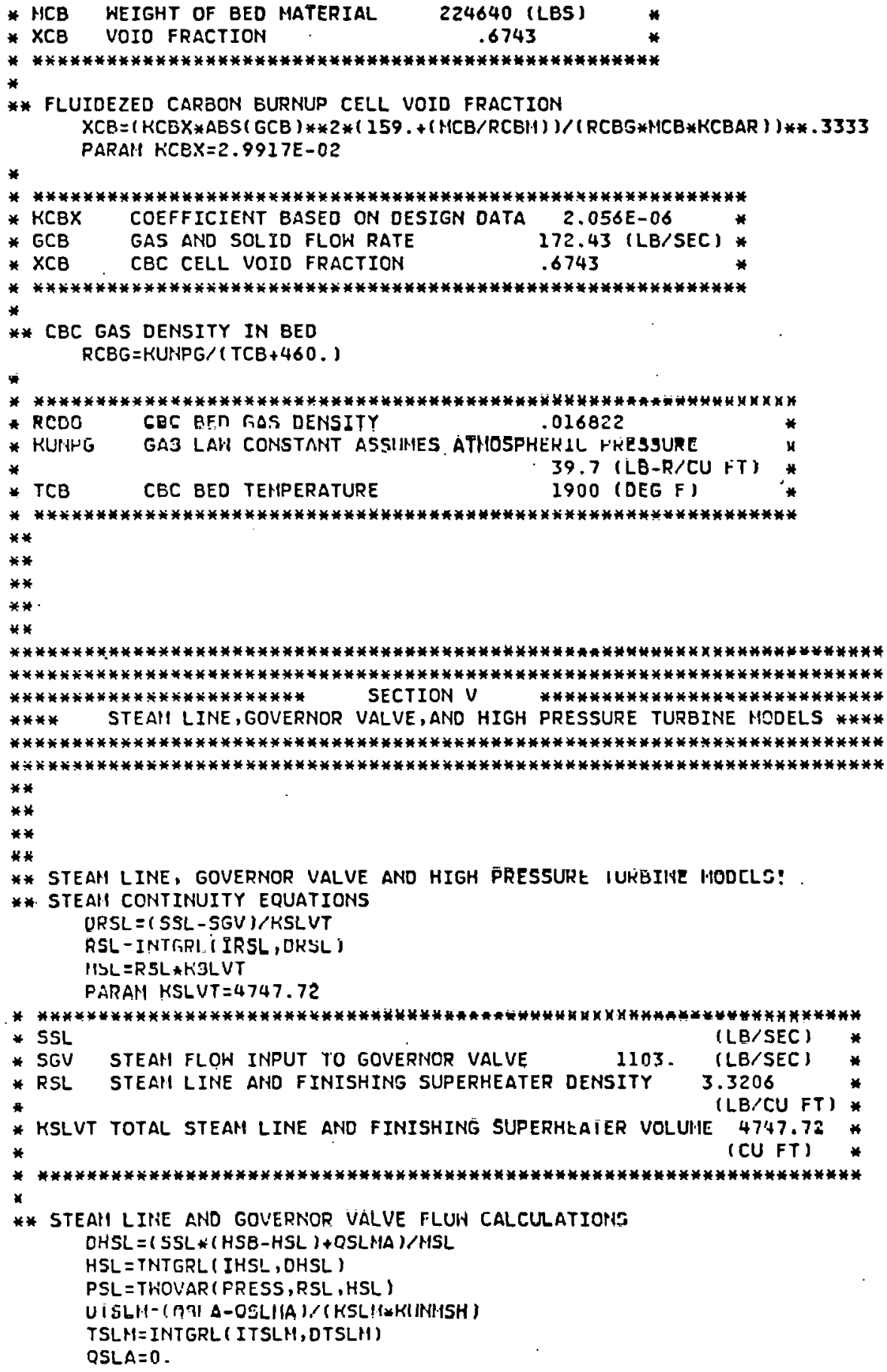


QSLHA $=K S L H Q * A B S(S S B / S S B S S) * .8 *(T S L M-T G V)$

PARAN SSBSS $=1103$, KSLM $=362378$, KSLMQ $=451.05$

IPICON IHSL $=1456$.

IPICON ITSLH $=998.13$

* insulated steam line and governor valve entahlpy

** aNo PRESSURE CalCULATIONS

* ********************************************************************

* SSL STEAM LINE MASS FLOH (SSBSS) 1103. (LEII/SEC)

* HSL STEAH LINE OUTLET eHTHALPy 1456. (BTU/Lih)

* HSB FINISHING SUPERHEATER OUTLET ENTHALPY 1456. (BTU/LBM)

* hSlm stear line metal mass

* TSLM Steali line hetal teliperature 1005 . (Deg F)

* QSLHIA STEAll LINE MeTal to STEaH HEat TRANSFER I7. 484 (BTU/SEC) *

* qsla steali line gas to metal heat transfer 0. (bTu/sec) *

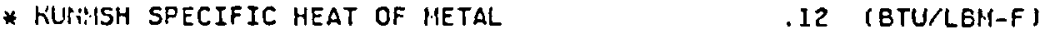

* kSLliq STEahl line heat transfer paraneter 451.05 (BTU/SEC-F)

* SSSSS STEADY STATE fINISHING SUPERHEat STEAH FlOW 1103 . (LBS/SEC) *

* SSB FINISHING SUPERHEAT STEAN FLOH 1103 . (LBS/SEC) *

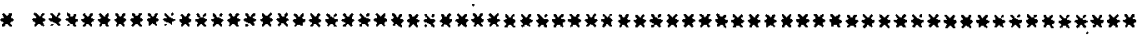

** high pressure tURBine governor Valve teMperature and stean flow

TGV = THOVAR (TEYP, RSL, HSL)

TGUS = AFGEN (TEMPS, PSL)

TGI, $6 \mathrm{H}=$ (TCV - TCVS)

SGV $=\therefore G V F * P S L * .97 /(60 . *(1 .+.00065 * T G V S H))$

$A G V F=A G V * X U R I G V$

*

蓜*****************************************************************

* TGV TEHPERATURE OF STEAII AT GOVERHOR VALVE

* tgus satupated Steall teliferature 670.6 (DEg F) *

* tgVSh ter!perature of steall above saturated 328.071 (LB/CU FT) *

* ngV tURBIIIE eFFEctive area

* sgV steali flow ilfput to goverpior valve

* psl pressure at govertior valve

* AGVF TURSIHE EFFECTIVE AREA (STATIC)

* xUNGV governor VAlVE stroke fraction

40.047 (SQ IN)*

1103 . (LBS/SEC) *

2534.7 (PSIA)

40.047 (SQ IN) *

*******************************************************************

* ReHEATER steAll outlet density aND pressure

$P R H=P R T+K R H F R * A B S(S R H) * S R H$

$R R H=1.2561 * R R T$

PARAII KRHFR $=2.0075 E-05$

*********************************************************************

* KRHFR FRICTICN DROP CCNSTANT 2.0075E-05 (PSIA-SEC**2/LBH CU.FT)*

* RRH OUTLET REHEAT STEAH DEISITY . B1528 (LB/CU FT) *

* prt reheat tuRbirle thpottle pressure

* ERII REIILAT bTEall FloH

* rRt reheat turbine throttle density

* PRH OUtlet ReHEAT PRESSURE

989.73 (LBES/SÉC) *

.65040 (LB/CU FT) *

* *******************************************************************

$*$

** HIGH PRESSURE TURBIME EXHAUST STATES

$P H P=$ KHPFR $* A B S(S H P) * S H P I R R H+P R H$

$T H P=(T G V+460) *.(F H P / P S L) *((K T-1.) / K T)-460$.

$H H P=H S L-K U I N S S H *(T G V-T H P)$

PHP I =PHP +KGVI *ABS ( SGV) $* S G V /(R R H+R S L) / 2$

PARAll KT $=1.2567$, KUTSSH $=.39982$ 


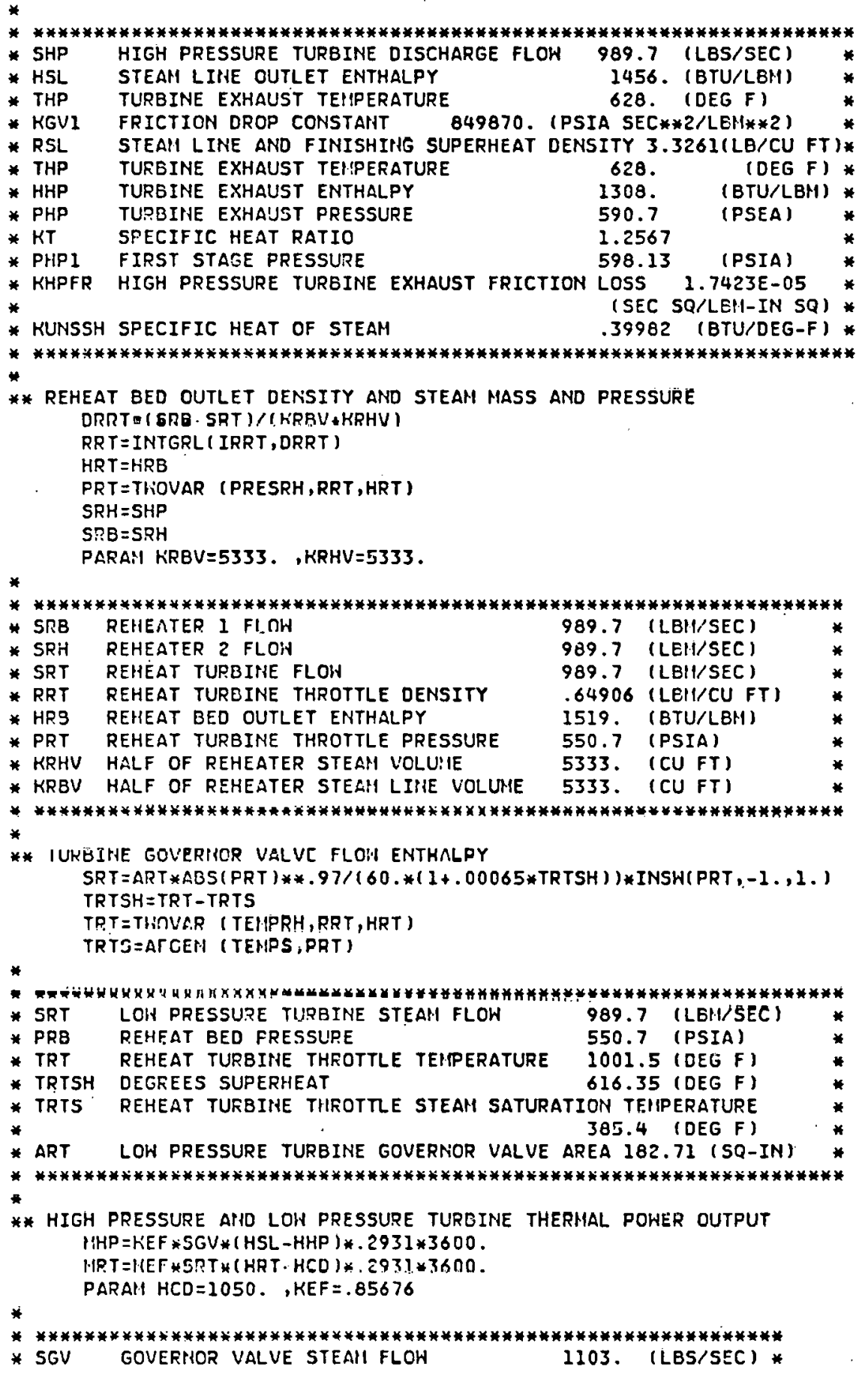




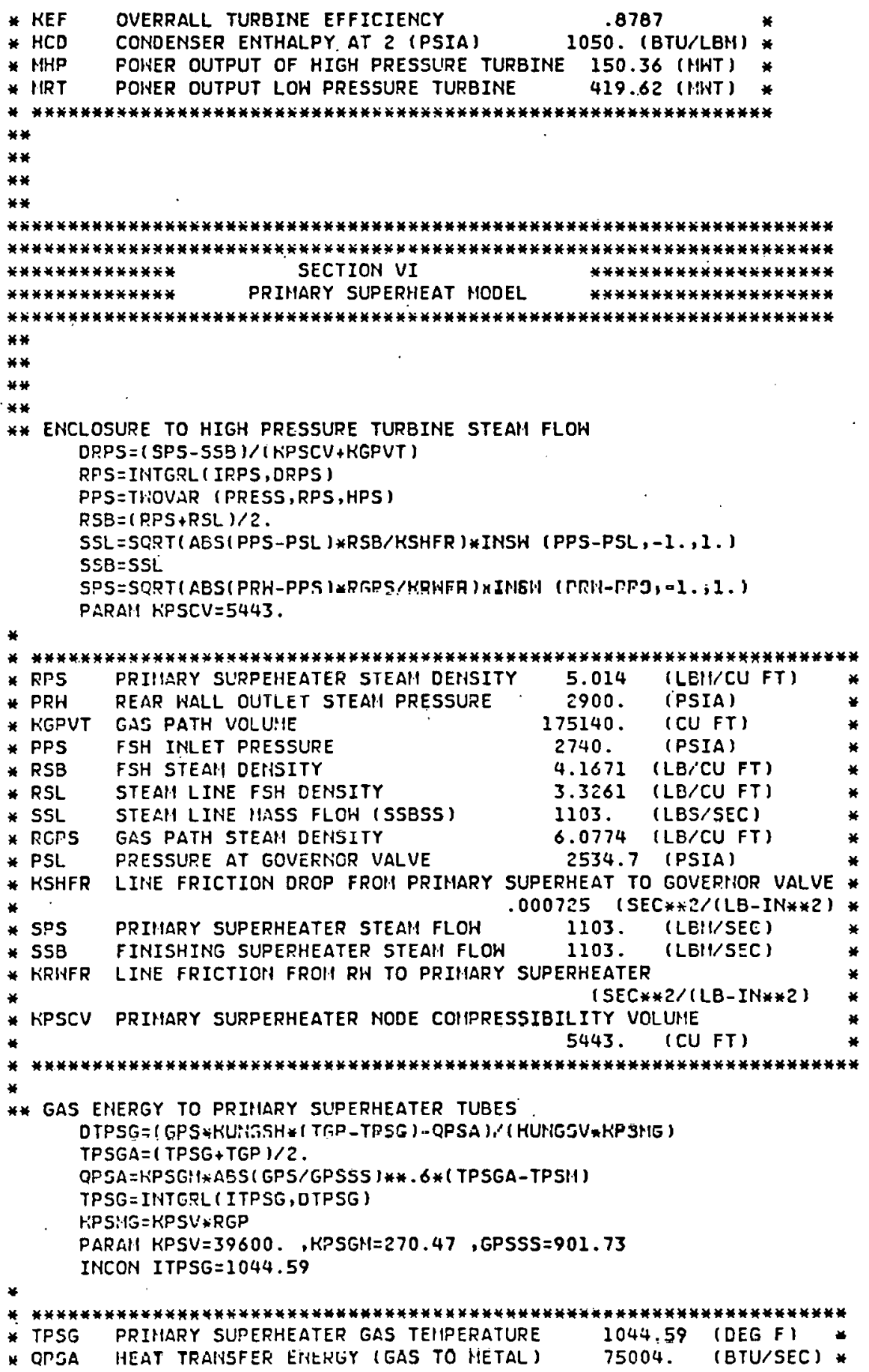




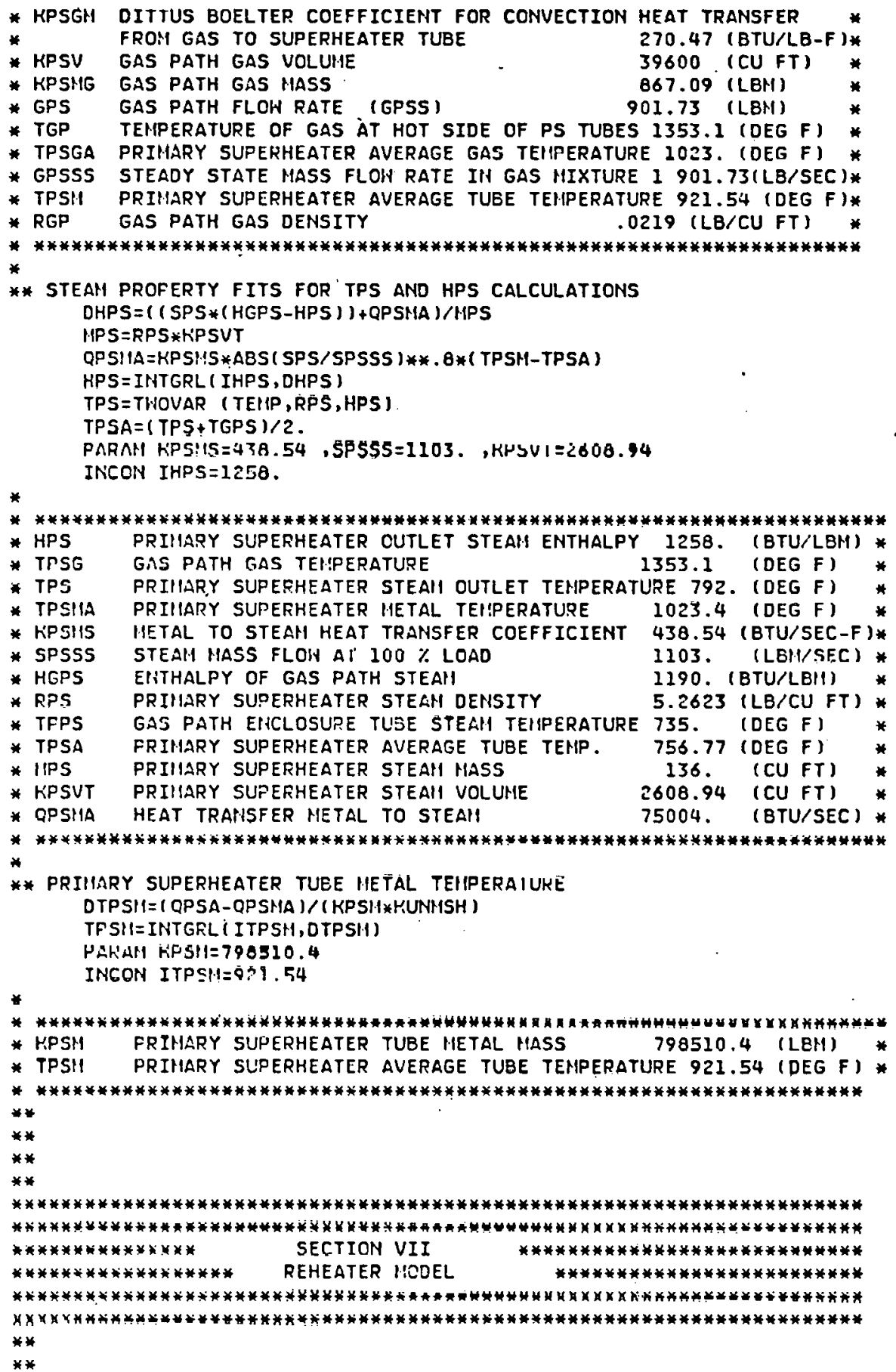




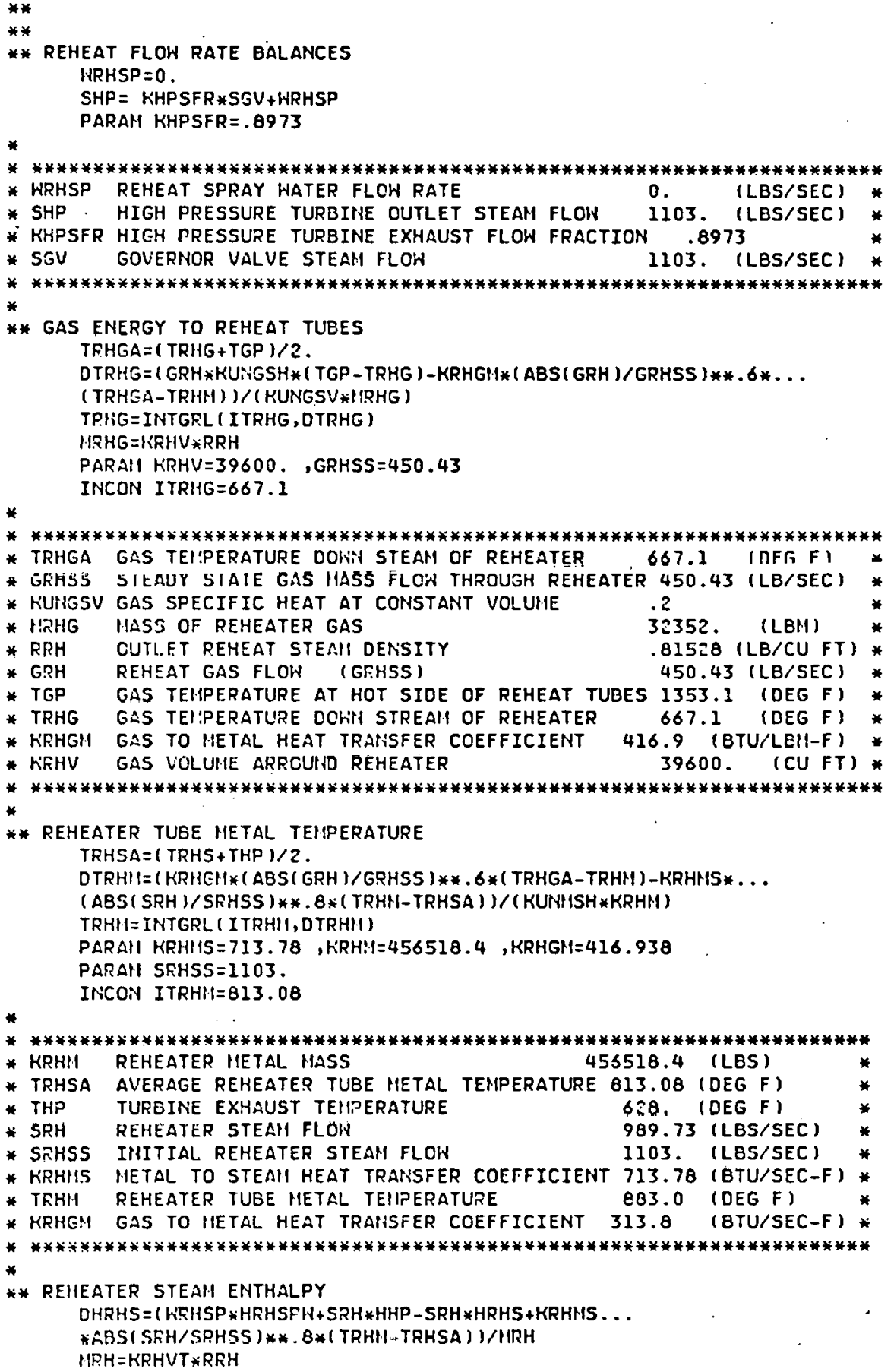




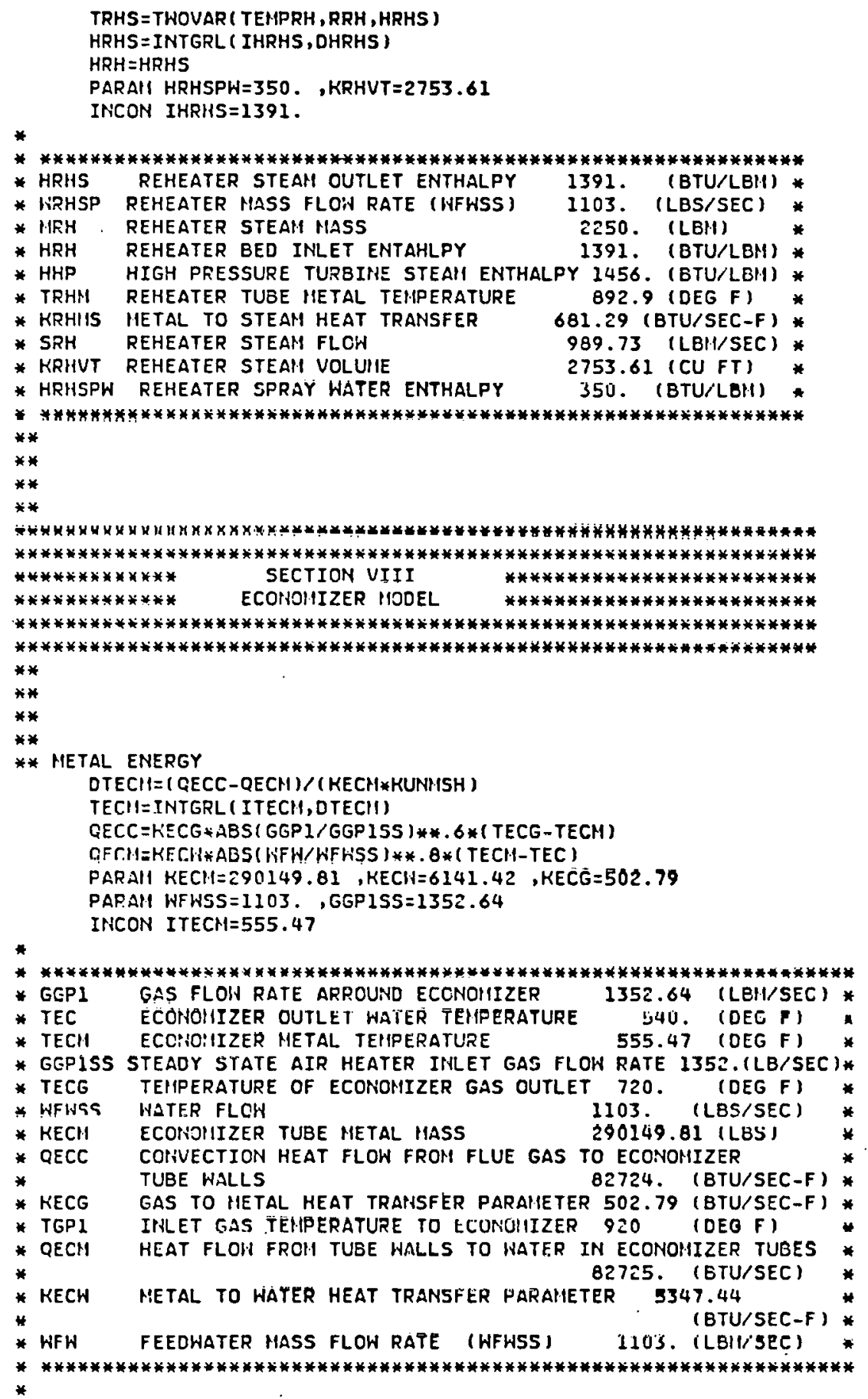


MEC $=$ KECUH*RECW

HFW=HFHSS $*$ XUNWH

HECSS = HFHSS

PARA11 KECI'H $=591.65, R E C W=50$.

* **********************************************************************

* RECH DENSITY OF FEEDINATER AT ECOHOHIIZER OUTLET 50. (LEH/CU FT).*

* HFH hass floin RATE OF FEEDHATER

* hec hass floir rate at ecciloilizer outlet

* KeCUH VCluite of hater IN ECOHOMIZER

* hec. hass of haterial in bed

* wiHss hater floir

* XUtir fEeDhater sTROKE fRACTION

* HeCSS hater FLOW

1103. (LES)

1103 . (LES)

526.8 (CU FT)

466752 . (LBS)

1103. (LBS.'SEC)

1103. (LBS/SFC) .

* $* * * * * * * * * * * * * * * * * * * * * * * * * * * * * * * * * * * * * * * * * * * * * * * * * * * * * * * * * * * * * * * * * * * * * * * *$

** teliperatuRe aND PRESSURE OF ecolHOHIZER OUTLET hater

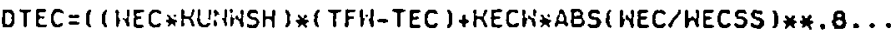

* (TECH-TEC) )/(IEC *HUHWISH)

TEC $=$ ITITGRL ( ITEC,DTEC)

PAPAII TFII $=484$.

IriCON ITEC $=540$

$*$

* $* * * * * * * * * * * * * * * * * * * * * * * * * * * * * * * * * * * * * * * * * * * * * * * * * * * * * * * * * * * *$

* TEC TEIIFERATURE OF ECOHIDIIIZER OUTI FT WNTER 5!I (DLO F)*

" KECII IIETLL IU IIATER HEAT TRAHSFER PARAIIETER 6141.42 *

* TFH FEEDHATER FLOIN 484. IDEG F) *

* $* * * * * * * * * * * * * * * * * * * * * * * * * * * * * * * * * * * * * * * * * * * * * * * * * * * * * * * * * *$

* TEI?PERATUPE OF ECCiOCHIIZER gas fLOW

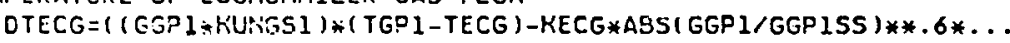

(TECG - TECH) /(1:GP I*KU:IGS')

$1: S P 1=R G P 1 \rightarrow H V I E C G$

TECG $=$ IPUTERL ( ITECG, DTECG )

PARGH KVECG $=216180$, GGP1SS $=1352.64$, KUNGS $1=.3057$

IRICON ITECG $=720$.

* ****************************************************************

* HECG GAS PATH I VOLUI!E

216180. (CUFT)

GAS FLOIY RATE AFPOUEN ECOHOHITZER

* kUissi specific heat of gas path Hix. I

1352.64 (LES/SEC)

.3057 (ETU/LB-F)*

.3057 (ETU/(B-F)*

* gGPISS STEADY STATE aIR heATER itllet gas

* floh Rate

* TECH

ECOYOIIIZER HETAL TEIIPERATURE

* TECE

TEIOOEPATURE OF ECOIIOIIIZER GAS OUTLET

555.47 (DEG F)

* TGP 1

TEIIPERATUSE OF GAS IN GAS MIXTURE I

920 . (DEG F)

* MGP1

MASS FLOW RATE OF GAS IN GAS MIXTURE 1 (GTOISS)

1352.64 (LB/SEC) *

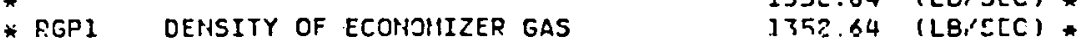

\#

$* *$

**

$* *$

$*$

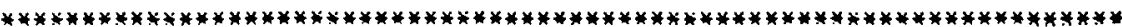

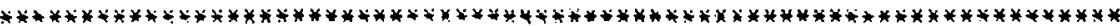

*

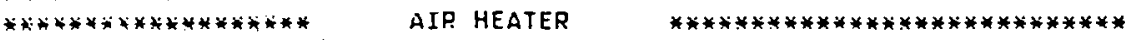

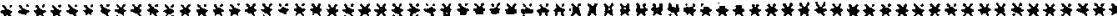

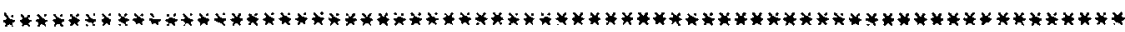




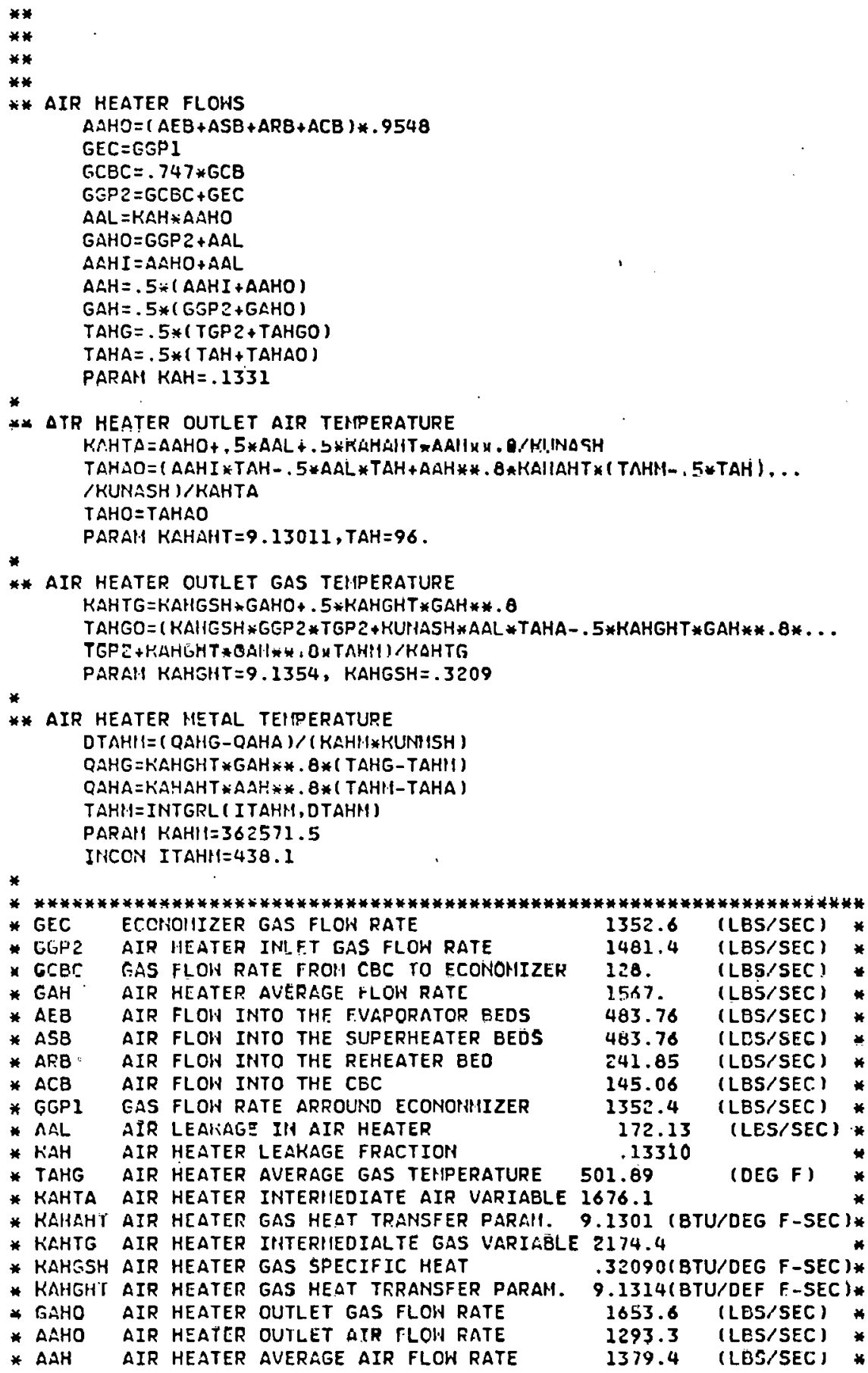




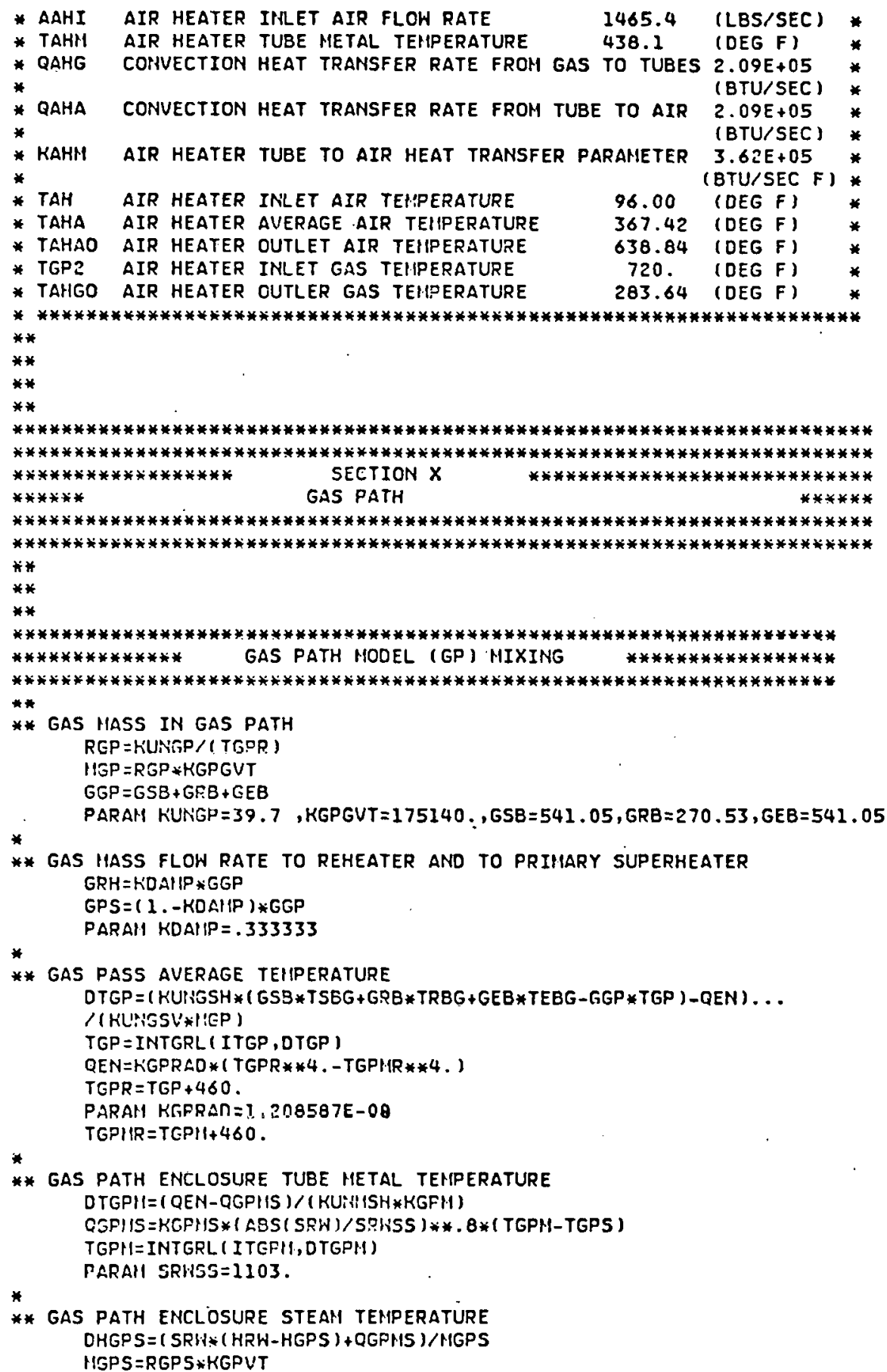


HGPS = INTGRL ( IHGPS, OHGPS )

TGPS = TWOVAR (TEIIP, RGPS, HGPS)

RGPS $=.2343 * R R H+.7657 *$ RPS

PARAII KGPHS $=8402.29, K G P H=845720.1$

PARAII KGPVT $=2809 ., T S B G=1640 ., T R B G=1640 ., T E B G=1640$.

INCON ITGP $=1353.1$, ITGPM $=749$. , IHGPS $=1190$.

* *************************************************1

*

* TGP

gas PATH aVERAGE GaS TEHPERATURE

GAS PATH GAS DENSITY

* hgp gas mass

* GGP

GAS PATH MASS FLOW RATE

* kDailp heat recovery area gas flow dartper

* GRH

GAS PATH TO REHEATER

* hurgp uitiversal constaht for gas path

* kgPRad gas path radiation coefficient

* tGPIIR

ABSOLUTE GAS PATH IIETAL TEHPERAIUKE

- TRFII

ABSOLUTE GAS PATH IIETAL TEIIPERAIUKE

* QCPIIS

* SRH

HEAT TRANSFFR ENERGY HETAL TO STEAYI

STEAHI FLON OTU OF REAR HALL ENCLOSURE

1353.1 (DEG F) (IBH/CU FT)

.0219 (LGH/CU FT) *

3834.9 (LBH)

1352.64

.333333

450.43

39.7

(LB/SEC)

(LBH/SEC)

-08 (BTU/SEC DEG R**4)*

1207 . (DEG F)

749.0 (DEG F)

104560 IATU,

* HCPS

* HPW

STEADY STATE STEAM FLOH OUT OF RH ENICLOSU

( LBS/SEC)

ENTHALFY OF GAS PATH STEAI

(BTU/LBII)

* RGPS GAS PATH STEAM DENSITY

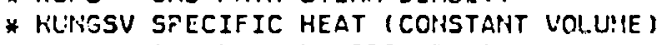

* GPS

* GSB

* TSS

GAS PATH TO PRIILRY SUPERHEATER

GAS FLOH RATE FRO!. THO SUPERHEATER BEDS

GAS TEHPERATURE AT SUPERHEATER GEDS

1093.

(BTU/LEH)

6.0774 (LBS/CU FT)

2.4

903.21 (LBII/SEC) *

* GRB

* GEB

GAS FLOW RATE FROII THE REHEAT BED

544.06 (LE/SEC)

155.0

(CEG F)

GAS FI. OH RATE FROH THO EVAPORATIYIG BEDS 541.05

(LBS/SEC)

RADIATIVE HEAT TRANSFER PARAIETER GAS TÓ METAL

104785

* TGPM

* TGPR

* rigPli

GAS PATH METAL SURFACE TEIIPERATURE

GAS PATH GAS ABSOLUTE TEI?PERATURE

GAS PATH,ROOF AND 1/2 HFA HETAL MASS

(BTU/SEC-F)*

* KGFIIS

(DEG F

* TGRS

HETAL TO STEAII HEAT TRAHSFER PARAIIETER 5373.6

* Hisps

STEAH HASS IN GAS PATH EHICLOSURE WHLLS

* higvt steali volutie iH gas path eticlosure halls

2809. (CU FT)

(CU FT)

*

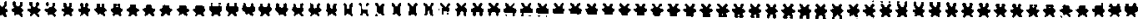

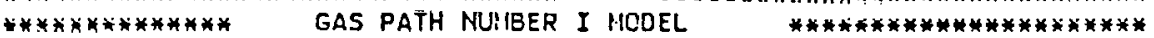

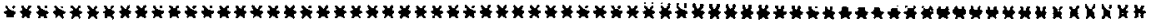

* gas mass in numeer l hixing voluhe RGPI =KUPIGP/( TGP $1+460$.)

$G \mathrm{GP}^{2}=\mathrm{GRH}+\mathrm{GPS}$

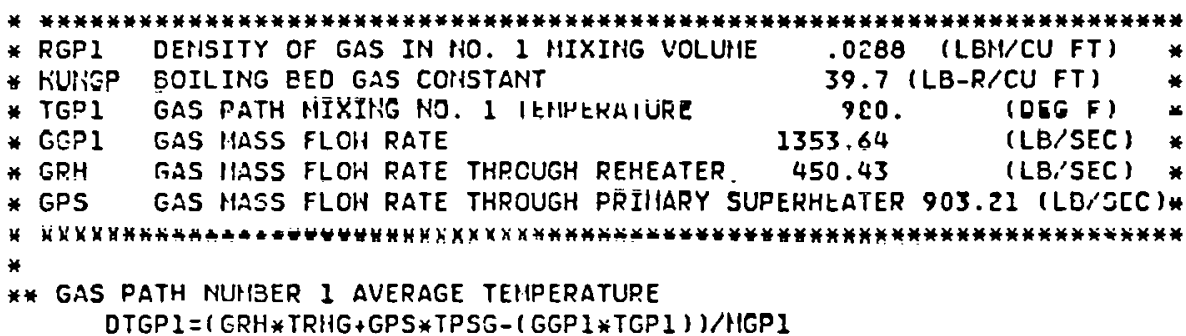

DTGPI $=($ GRH $*$ TRIHG +GPS *TPSG - (GGP $1 * T G P \perp)) / H I G P I$ 
TGP I = INTGRL ( ITGP1, DTGPI)

INCON ITGPI $=920$.

***********************************************************************

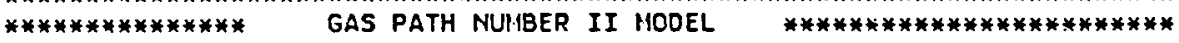
*************************************************************************1

*

* GAS MASS IN NUPISER II MIXING VOLUHIE

RGP $2=K U N G P /(T G P 2+460$. )

MGP $2=R G P 2 * K G P 2 G \mathrm{~V}$

** gas path average teitPerature

DTGP $2=($ GCEC * TCBG + GEC *TECG-GGP $2 *$ TGP2 $) /$ MGP 2

TGP Z = INTGRL ( ITGP 2, DTGP 2 )

PARAN KGP ZGV $=41040$.

* INCON ITGP $2=720$.

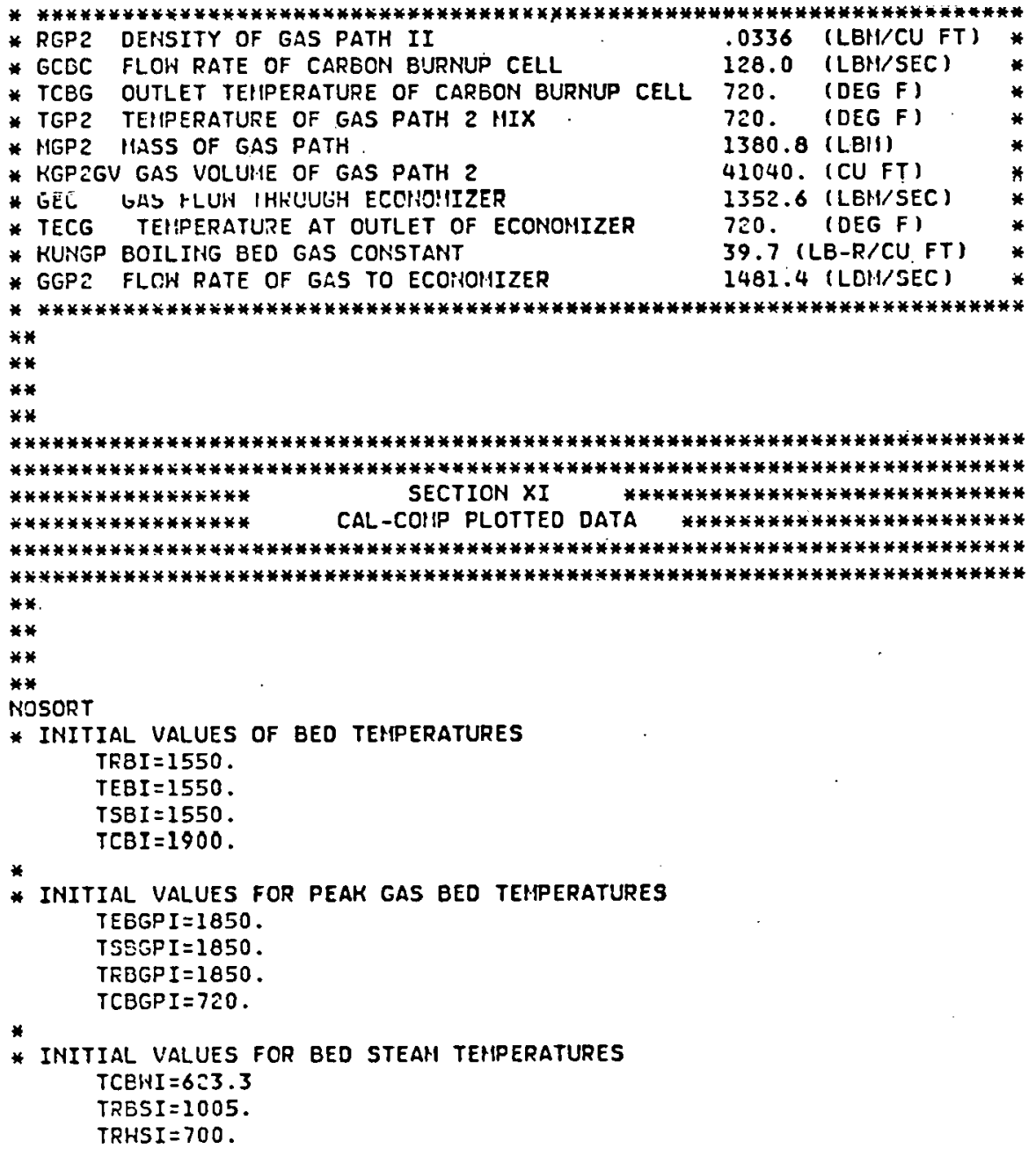


TSBSI $=1005$.

$*$

* Deternine the percent change in Bed temperatures

$T R B Y=(T R B / T R B I) * 100,-100$.

$T E B Y=(T E B / T E B I) * 100,-100$.

$T S B Y=(T S B / T S B I) * 100 .-100$.

$T C B Y=(T C B / T C B I) * 100,-100$

* now determine the percent change in peak gas bed temperatures TEBGPY $=($ TEBGP/TEBGPI $) * 100 .-100$.

TSBGPY $=($ TSBGP/TSEGPI $) * 100 .-100$.

TREGPY $=($ TREGP/TREGPI $) * 100 .-100$.

* TCBGPY $=($ TCEG $/$ TCBGPI $) * 100 .-100$.

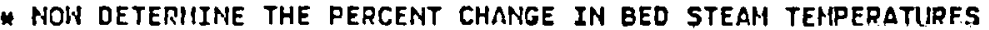

TCBWY $=($ TCBW/TCBWI $) * 100 .-100$.

TRBS'

TRLST $=($ TRHS TRHSI )*100.-100.

TSBSY $=($ TSBS/TSBSI $) * 100,-100$.

* now convert time fron seconds to minutes and write data on to a

* disk file data set nale 'Rlo.datal'

*

* if(reep.ne. I ) GO TO 999

* IFITIIIE.LE.O) TPRIN $=0$.

* IF(TIME.LT.TPRIN) GO TO 999

* TIIIEII=TIIIE/60.

* h'RITE(25,606) TIY!EH, TEBY, TSBY, TRBY, TCBY

*606 FORIIAT $(3 \%, \mathrm{FB} .3,4 \mathrm{FB} .3)$

TPRIN=TPRIN+12.

*999 CONTINUE

$*$

$* *$

* initial values for cal-coilp plotted data

PGUSS $=2534.7$

TEVIV $=990.0$

PRTSS $=550.7$

PHP 155 $=1800.0$

HENSS $=570, E+06$

TRTSS $=1005$.

PHPISS $=-100, *(1,-$ HHH $1 /$ HHHISS)

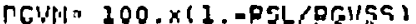

TGVT $=-100 . *(1 .-T G V / T G V N)$

PRTH $=-100 *(1,-$ FRT/PRTSS $)$

TRTO $=-100 . *(1 .-$ TRT/TRTSS $)$

IIGN $=-100 * *(1 .-(1: R T+1: H P) /$ IIGNSS

* HOW IILREIIEIT TIML TRO:I gLCOHIDS TO MIINUTES AMD HRITE DATA ONTO DISK

IF (KEEP. NE. 1$)$ GO TO 999

IF (TIIIE. LE. O)TPRIN $=0$

IF (TIHE.LT.TPRIN) GO TO 999

TIIIEH $=T I H I E / 60$.

HRITE $(\approx 5,606)$ TIMEN, PGVN, PRTN, TGUT, TR TO, MGN

606 FOFILTI3X,F8.3,5F8.3)

TRRIYISTPRINI12.5

999 COHTIRHE

** NUM:BER OF DEBUGS

PARAII IEUGI $=4$., IBUG2 $=3$, IBUG $3=3$, , IBUG $4=3$. 


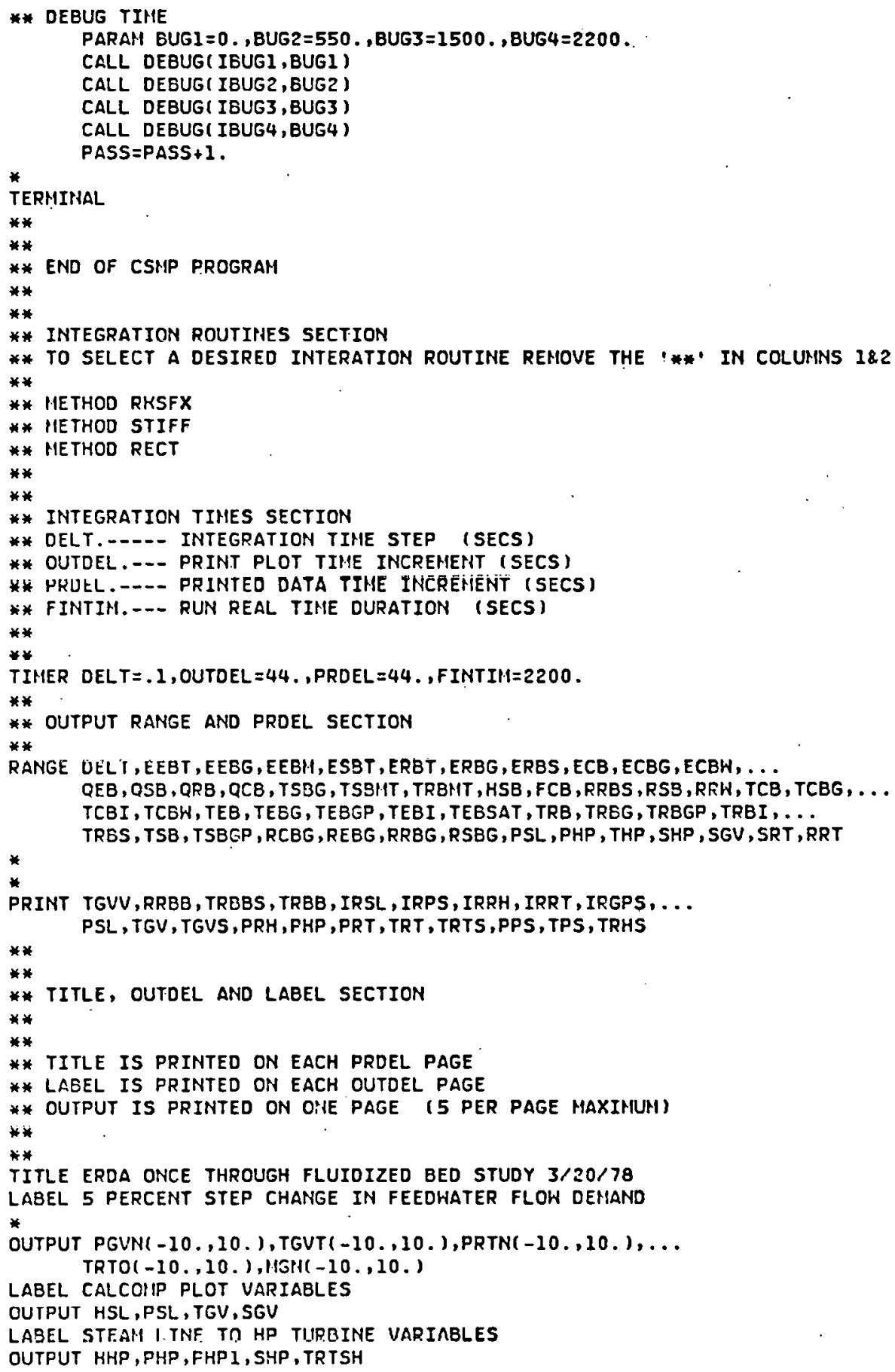




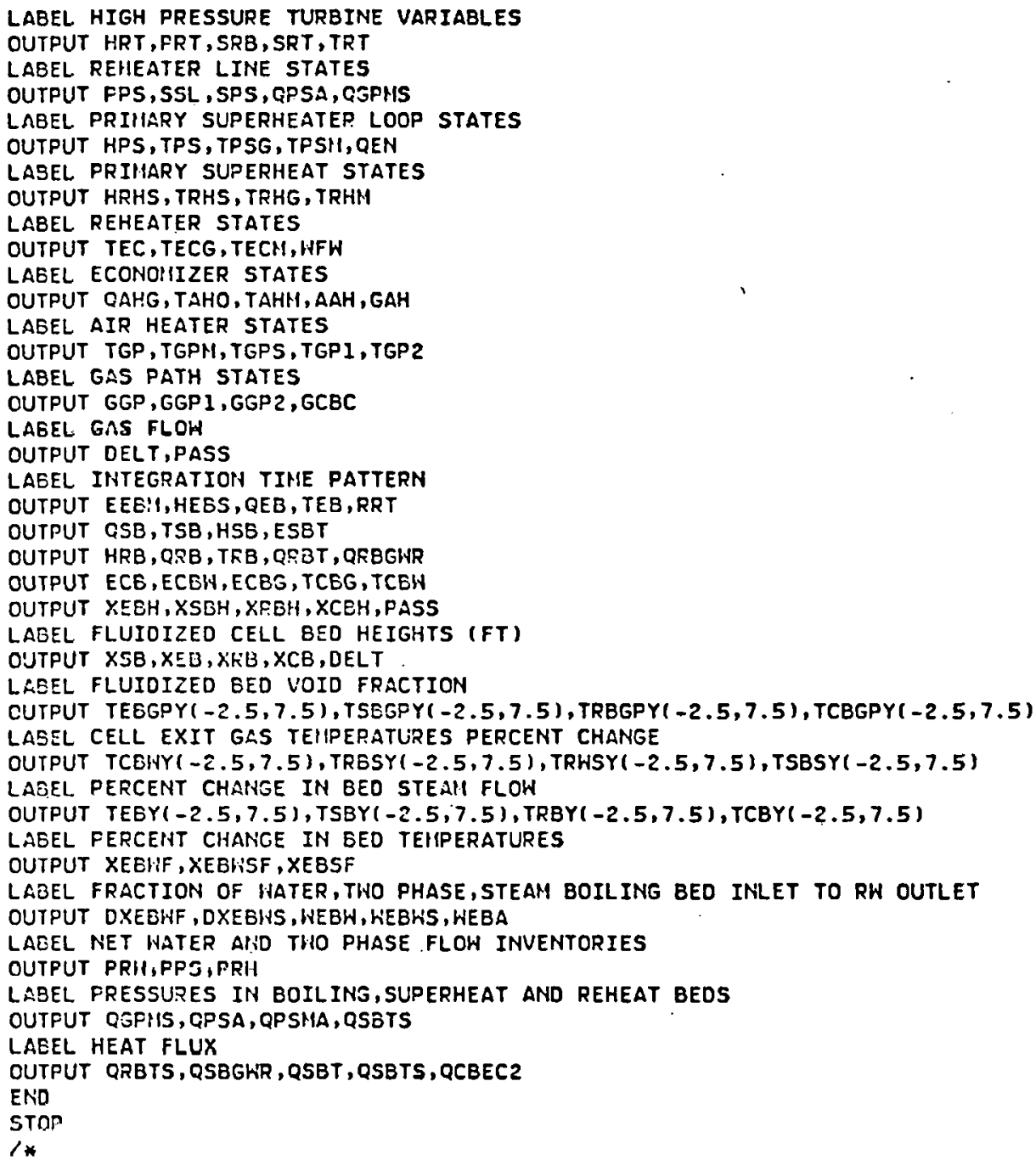


APPENDIX V-B4

STEADY STATE INITIAL CONDITIONS

This section presents all of the steady state computer program parameter values. The variables include input parameters, integrator variables and output variables. 


\section{THIS PAGE}

\section{WAS INTENTIONALLY \\ LEFT BLANK}




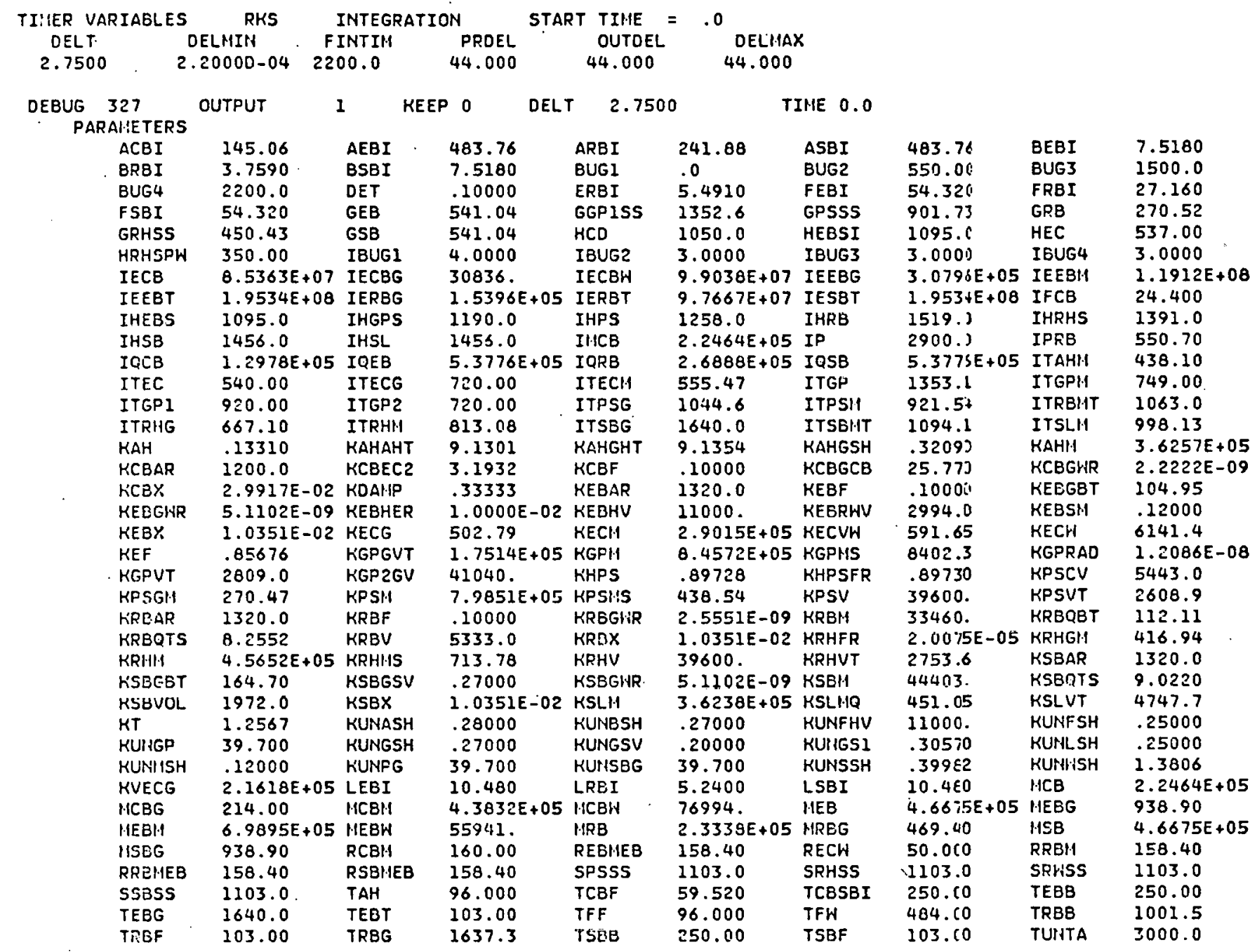




\begin{tabular}{|c|c|c|c|c|c|c|c|c|c|}
\hline TUNTB & 3000.0 & TUNTE & 3000.0 & TUNTF & 3000.0 & TUNTGV & 3000.11 & TUNTL & 3000.0 \\
\hline TURATIN & 3000.0 & VRBS & 2494.0 & WECI & 1103.0 & WFHSS & 1103.11 & XEBWFI & .0 \\
\hline
\end{tabular}

INTEGRATOR VARIABLES

\begin{tabular}{|c|c|c|c|c|c|c|c|c|}
\hline LOCATION & OUTP & & DERIVA & VES & INITIAL & CONDITIONS & ERROR & RATIO \\
\hline 1 & QEB & $5.3776 E+05$ & DQEB & $7.7670 E-02$ & 221022 & $5.3776 E+05$ & .0 & \\
\hline 2 & EEBT & $1.9533 E+08$ & DEEBT & -6.2500 & 221024 & $1.9533 E+08$ & .0 & \\
\hline 3 & EEBG & $3.0795 E+05$ & DEEBG & 1.7500 & $Z 21026$ & $3.0795 E+05$ & .0 & \\
\hline 4 & EEBII & $1.1901 E+08$ & DEEBI. & 612.06 & 221028 & $1.1901 E+08$ & .0 & \\
\hline 5 & RRW & 8.7410 & DRRW & $-1.7271 E-04$ & 221031 & 8.7410 & .0 & \\
\hline 6 & QSB & $5.3776 E+05$ & DQSB & $7.7670 \mathrm{E}-02$ & 221033 & $5.3776 E+05$ & .0 & \\
\hline 7 & ESBT & $1.9504 E+08$ & DESST & -59.688 & 221035 & $1.9504 E+08$ & .0 & \\
\hline 0 & T3BO & 1640.3 & DTSEG & -2.4031 & 771037 & 1640.3 & .0 & \\
\hline 9 & TSEIIT & 1091.1 & DTSBHT & $7.8683 E-04$ & 221039 & 1091.1 & .0 & \\
\hline 10 & iis̄̄́ & $1 / 53.4$ & UHSB & .26010 & 221041 & 1453.2 & .0 & \\
\hline 11 & QRB & $2.6898 E+05$ & OQRB & $3.00] 5[-02$ & 221013 & $3.6888 E+05$ & .0 & \\
\hline 12 & ERBT & $9.7154 E+07$ & DERBT & -40.250 & $Z Z 1045$ & $9.7154 E+07$ & .0 & \\
\hline 13 & ERBG & $1.5371 E+05$ & DERBG & -148.82 & 221047 & $1.5371 E+05$ & .0 & \\
\hline 14 & TREI.1T & 1056.3 & DTRBHT & $5.0078 E-03$ & 221049 & 1056.3 & .0 & \\
\hline 15 & HRB & 1515.5 & DriRB & -.12981 & $Z 21051$ & 1515.5 & .0 & \\
\hline 16 & $\mathrm{FCB}$ & 24.200 & OFCB & $-4.2962 E-06$ & 221053 & 24.200 & .0 & \\
\hline 17 & QCB & 1. $2664 \varepsilon+05$ & DQCB & $-2.4152 \varepsilon-02$ & 221055 & $1.2864 E+05$ & .0 & \\
\hline 18 & ECB & $8.4730 E+07$ & $D E C B$ & -34.715 & $Z 21057$ & $8.4730 E+07$ & .0 & \\
\hline 1.9 & ECBG & 30822 & DECBG & -118.94 & $Z Z 1059$ & 30822 & .0 & \\
\hline 20 & $E C B W$ & $9.8803 E+07$ & DECBW & 118.38 & $z 21061$ & $9.8803 E+07$ & .0 & \\
\hline 21 & RSL & 3.3261 & DRSL & $-2.4889 E-04$ & 221063 & 3.3261 & .0 & \\
\hline 22 & HSL & 1454.0 & DHSL & $-0.0920 E-03$ & 221065 & 1454.0 & .0 & \\
\hline 23 & TSLN & 995.02 & DTSLM & $4.0230 E-04$ & 221067 & 995.02 & .0 & \\
\hline 24 & RRT & .65040 & DRRT & $4.1837 E-07$ & 221069 & .65040 & .0 & \\
\hline 25 & RPS & 5.2623 & DRPS & $2.0518 E-04$ & 221071 & 5.2623 & .0 & \\
\hline 26 & TPSG & 1047.9 & DTPSG & $7.9631 E-02$ & 221073 & 1047.9 & .0 & \\
\hline 27 & HPS & 1255.5 & DHPS & $5.4265 E-03$ & 221075 & 1255.5 & .0 & \\
\hline 28 & TPSH & 925.98 & DTPSM & $-3.7113 E-04$. & 221077 & 925.98 & .0 & \\
\hline 29 & TRHG & 675.28 & DTRHG & $-1.1205 E-03$ & 221079 & 675.28 & .0 & \\
\hline 30 & TRHII & 816.30 & DTRHII & $5.2937 E-04$ & 221081 & 816.30 & .0 & \\
\hline 31 & HRHS & 1387.6 & DHRHS & $-1.2252 E-02$ & 221083 & 1387.6 & .0 & \\
\hline 32 & TECH & 552.94 & DTECH & $1.4271 E-03$ & $Z 21085$ & 552.94 & .0 & \\
\hline 33 & TEC & 539.25 & DTEC & $-1.3727 E-03$ & 221007 & 539.25 & .0 & \\
\hline 34 & TECG & 720.26 & DTECG & $-4.5345 E-04$ & 221009 & 720.26 & .0 & \\
\hline 35 & TAHII & 438.12 & DTAHH & $-1.0343 E-04$ & 221091 & 438.12 & .0 & \\
\hline 36 & TGP & $135 \% .7$ & OTEP & $\because 2.4606 E-02$ & 221093 & 1.352 .7 & .0 & \\
\hline 37 & TGPH & 747.68 & DTGPM & $2.1733 E-03$ & 221095 & 747.68 & .0 & \\
\hline 38 & HGPS & 1188.3 & DHGPS & $-1.8236 E-02$ & 221097 & 1188.3 & .0 & \\
\hline 39 & TGP 1 & 923.71 & DTGP 1 & $-3.5470 \mathrm{E}-03$ & $2 Z 1099$ & 923.71 & .0 & \\
\hline 40 & TGP2 & 720.25 & DTGP2 & $-.7 .2440 E-04$ & 221101 & 720.25 & .0 & \\
\hline
\end{tabular}

$\begin{array}{lc}\text { ABSERR } & \text { RELERR } \\ 1.0000 E-04 & 1.0000 E-04 \\ 1.0000 E-04 & 1.0000 E-04 \\ 1.0000 E-04 & 1.0000 E-04 \\ 1.0000 E-04 & 1.0000 E-04 \\ 1.0000 E-04 & 1.0000 E-04 \\ 1.0000 E-04 & 1.0000 E-04 \\ 1.0000 E-04 & 1.0000 E-04 \\ 1.0000 E-04 & 1.0000 E-04 \\ 1.0000 E-04 & 1.0000 E-04 \\ 1.0 n N O E-04 & 1.0000 E-04 \\ 1.0000 E-04 & 1.0000 E-04 \\ 1.0000 E-04 & 1.0000 E-04 \\ 1.0000 E-04 & 1.0000 E-04 \\ 1.0000 E-04 & 1.0000 E-04 \\ 1.0000 E-04 & 1.0000 E-04 \\ 1.0000 E-04 & 1.0000 E-04 \\ 1.0000 E-04 & 1.0000 E-04 \\ 1.0000 E-04 & 1.0000 E-04 \\ 1.0000 E-04 & 1.0000 E-04 \\ 1.0000 E-04 & 1.0000 E-04 \\ 1.0000 E-04 & 1.0000 E-04 \\ 1.0000 E-04 & 1.0000 E-04 \\ 1.0000 E-04 & 1.0000 E-04 \\ 1.0000 E-04 & 1.0000 E-04 \\ 1.0000 E-04 & 1.0000 E-04 \\ 1.0000 E-04 & 1.0000 E-04 \\ 1.0000 E-04 & 1.0000 E-04 \\ 1.0000 E-04 & 1.0000 E-01 \\ 1.0000 E-04 & 1.0000 E-04 \\ 1.0000 E-04 & 1.0000 E-04 \\ 1.0000 E-04 & 1.0000 E-04 \\ 1.0000 E-04 & 1.0000 E-04 \\ 1.0000 E-04 & 1.0000 E-04 \\ 1.0000 E-04 & 1.0000 E-04 \\ 1.0000 E-04 & 1.0000 E-04 \\ 1.0000 E-04 & 1.0000 E-04 \\ 1.0000 E-04 & 1.0000 E-04 \\ 1.0000 E-04 & 1.0000 E-04 \\ 1.0000 E-04 & 1.0000 E-04 \\ 1.0000 E-04 & 1.0000 E-04 \\ & \end{array}$

OUTPUT VARIABLES

\begin{tabular}{|c|c|c|c|c|c|c|c|c|c|}
\hline AAH & 1379.3 & AAHI & 1465.4 & AAHO & 1293.2 & AAL & 172.13 & $A C B$ & 145.06 \\
\hline$A E B$ & 483.76 & AGV & 40.074 & AGVF & 40.074 & ARAHP & $3.3333 E-04$ & ARB & 241.88 \\
\hline$\Delta R T$ & 182.51 & ASB . & 483.76 & $B C B$ & 3.1632 & $B E B$ & 7.5180 & BRB & 3.7590 \\
\hline ESB & 7.5180 & DXEBWF & .0 & DXEBWS & .0 & FCBI & 24.200 & PEB & 94.320 \\
\hline FRO & 27.160 & FSB & $54.320^{\circ}$ & GAK & 1567.5 & GAHO & 1653.5 & GCB & 172.42 \\
\hline GCBC & 128.80 & GEC & 1352.6 & GGP & 1352.6 & GGPI & 1352.6 & GGP2 & 1481.4 \\
\hline GPS & 901.74 & GRH & 450.87 & HEEDIF & 442.27 & HEBİ & 650.99 & HEBS & 1093.3 \\
\hline HEEST & 2097.1 & IIInWS & $785 ،$ 亿11 & HEEISSD & 253.49 & HGP & 1190.0 & $\mathrm{HHP}$ & 1304.3 \\
\hline HPSI & 1258.0 & HRH & 1387.6 & HRHI & 1391.0 & HRT & 1515.5 & HKII & 1519.0 \\
\hline $\mathrm{HRW}$ & 1093.3 & HSLI & 1456.0 & IPRRBB & 550.70 & IRGPS & 6.0605 & IRGPSI & 5.0000 \\
\hline IRPS & 5.2455 & IRPSI & 5.0000 & IRRBS & .64906 & IRRH & .81529 & IRRHI & .00000 \\
\hline IRRT & .64906 & IRRTI & .60000 & IRRW & 8.7247 & IRSB & 4.2830 & IRSL & 3.3206 \\
\hline
\end{tabular}




\begin{tabular}{|c|c|c|c|c|c|c|c|c|c|}
\hline IRSLI & 3.3000 & KAHTA & 6676.1 & KAHTG & 2174.4 & KGP & .10000 & KGVI & $2.0555 E-03$ \\
\hline KHPFR & I. 7423E-05 & KPS & .10000 & KPSHG & 867.28 & KRH & .10000 & KRT & .10000 \\
\hline KRHFR & $7.9355 E-04$ & KSBF & .10000 & KSBHV & 11000 . & KSBRR & 1.0610 & KSHFR & $7.2522 \varepsilon-04$ \\
\hline KSL & .10000 & LEB & 10.480 & LRB̈ * & 5.2400 & LSB & 10.480 & HEC & 29582 \\
\hline HGP 2 & 1380.5 & MHP & $1.4930 E+08$ & MPS & 13729. & HRBS & 1622.1 & $\mathrm{MRH}$ & 2249.6 \\
\hline MRHG & 32352 . & HRT & $4.1649 E+0 \theta$ & MSBO & 8468.2 & MSL & 15791. & PASS & .0 \\
\hline PGP I & 2717.7 & PGVN & $1.8120 \mathrm{E}-03$ & PGVSS & 2530.7 & PHP & 589.67 & PHPISS & -50.474 \\
\hline PHP 1 & 891.47 & PHPISS & 1800.0 & PPS & 2735.8 & PPSI & 2740.7 & PRH . & 568.78 \\
\hline PRHI & 564.70 & PRT & 549.11 & PRTI & 550.70 & PRTN & $1.9073 E-04$ & PRTSS & 549.11 \\
\hline PRW & 2894.8 & PSL & 2530.7 & PSLI & 2534.7 & QAHA & $2.0966 E+05$ & QAHG & $2.0966 \mathrm{E}+05$ \\
\hline QCBEC2 & 50330 & QCBGWE & 68756 & QCBGHR & 18426 & QCBT & 57098 & QEBGWR & 90445 \\
\hline QEBT & $2.6251 E+05$ & QEBTB & $4.8844 E+05$ & QECC & 84125 . & QECH & 84076. & QEH & $1.0478 E+05$ \\
\hline QGPISS & $1.0456 E+05$ & QPSA & 74196 & QPSHA & 74231 & QRBGWR & 44972 & QRBT & $1.2654 E+05$ \\
\hline QRBTS & $1.2638 E+05$ & QSBGIR & 90511 & QSBT & $2.1878 E+05$ & QSBTS & $2.1875 E+05$ & QSLA & .0 \\
\hline QSLHA & -17.494 & .RCEG & $1.6923 E-02$ & REBG & $1.9752 E-02$ & RGP & $2.1901 E-02$ & RGPS & 6.0774 \\
\hline RGP 1 & $2.8691 E-02$ & RGP2 & $3.3637 E-02$ & RRBB & .64907 & RRBG & $1.9832 E-02$ & RPBS & .65040 \\
\hline SRT & 989.71 & SRH & 1103.5 & S58 & 1101.8 & SSL & 1101.8 & TAHA & 367.44 \\
\hline TAHAO & 638.87 & TAHG & 501.89 & TAHGO & 263.53 & TAHO & 630.87 & TCB & 1885.9 \\
\hline TCBG & 720.14 & TCBGA & 1303.0 & TCBGPI & 720.00 & TCBGPY & $1.9455 E-02$ & TCBI & 1900.0 \\
\hline TCBI & 621.82 & TCBNI & 623.30 & TCBWY & -.23726 & TCBY & -.74178 & TEB & 1550.0 \\
\hline TEBGP & 1850.0 & TEGGPI & 1850.0 & TEBGPY & $-1.3123 E-03$ & TEBI & 1550.0 & TEBSAT & 689.74 \\
\hline TEBY & $-2.9144 E-03$ & TGPHAR & 1207.7 & TGPR & 1812.7 & THRS & 735.04 & TEV & 495.06 \\
\hline TR,NIN & 005.06 & tovs & 064.82 & T̄GVSH & 325.23 & TGVT & $-1.2517 E-04$ & TGVV & 998.13 \\
\hline TGVUS & 670.06 & THP & 620.57 & TIYAEM & .0 & TPRIN & .0 & TPS & 778.31 \\
\hline TPSA & 756.77 & TPSGA & 1200.3 & TRB & 1541.8 & TREBS & 385.11 & TRBGP & 1845.2 \\
\hline TRBGPI & 1850.0 & TRBGPY & -.25861 & TRBI & 1550.0 & TRBS & 994.85 & TRBSI & 1005.0 \\
\hline TRBSY & -1.0200 & TRBY & -.52612 & TRHGA & 1014.0 & TRHS & 760.10 & TRHSA & 690.34 \\
\hline TRT & 994.85 & TRTO & $-2.9802 E-05$ & TRTS & 304.55 & TRTSH & 610.30 & TRTSS & 994.85 \\
\hline TRHS & 698.24 & TRWSI & 700.00 & TRWSY & -.25127 & TSB & 1547.7 & TSBGP & 1847.6 \\
\hline TSBGPI & 1850.0 & TSBGPY & -.12770 & TSBI & 1550.0 & TSBS & 1001.0 & TSBSI & 1005.0 \\
\hline TSBSY & -.32045 & TSBY & -.15138 & HCB & 1103.0 & HEB & 1103.0 & WEBA & 1103.0 \\
\hline WEBW & .0 & WEBWS & .0 & HEC & 1103.0 & WECSS & 1103.0 & WFW & 1103.0 \\
\hline XSB & .62607 & XSBH & 3.9979 & XUNA & 1.0000 & XUNB & 1.0000 & XUtiE & 1.0000 \\
\hline XUNF & 1.0000 & XUIVGV & 1.0000 & XUNL & 1.0000 & XUNW & 1.0000 & 221000 & 2534.7 \\
\hline 221001 & 3.3208 & 221002 & .0 & 221003 & 2740.6 & 221004 & 5.6515 & $Z Z 1005$ & .0 \\
\hline 221006 & 550.70 & ZZ1007. & .64921 & $Z Z 1008$ & .0 & 221009 & 2716.4 & 221010 & 6.1912 \\
\hline 221011 & .0 & 221012 & 550.70 & 221013 & .64880 & 221014 & .0 & 221015 & 2900.0 \\
\hline 221016 & 8.7247 & 221017 & .0 & 221018 & 550.70 & ZZ1019 & .64906 & 221020 & .0 \\
\hline 221029 & .0 & $2 Z 1102$ & .0 & & & & & & \\
\hline
\end{tabular}




\section{THIS PAGE}

WAS INTENTIONALLY

LEFT BLANK 
APPENDIX V-B5

STEP IN COMBUSTION RATE

This section presents the detailed results in CSMP plot format for a $5 \%$ step increase in combustion rate. 
THIS PAGE

\section{WAS INTENTIONALLY \\ LEFT BLANK}



5 PERCENT STEP CHANGE IN COMBUSTION RATE
CALCOHP PLOT VARIABLES

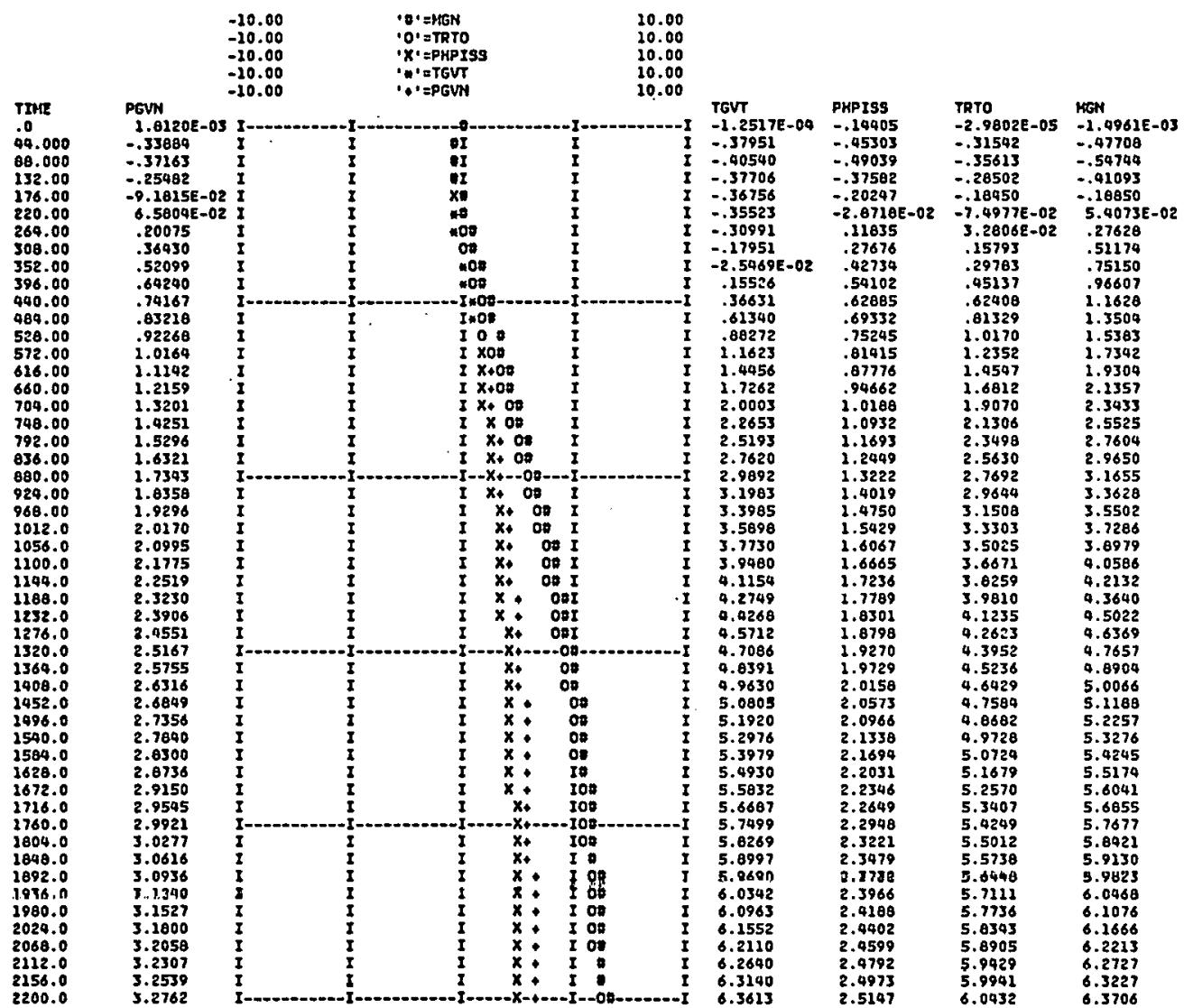

5 PERCENT STEP CHANGE IN CONBUSTION RATE

\begin{tabular}{|c|c|}
\hline 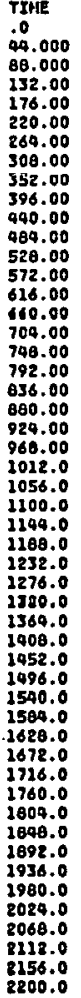 & 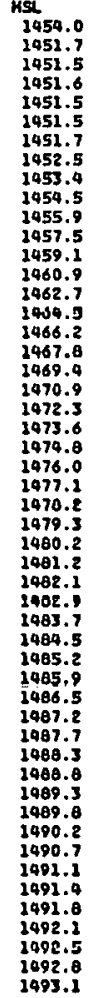 \\
\hline
\end{tabular}
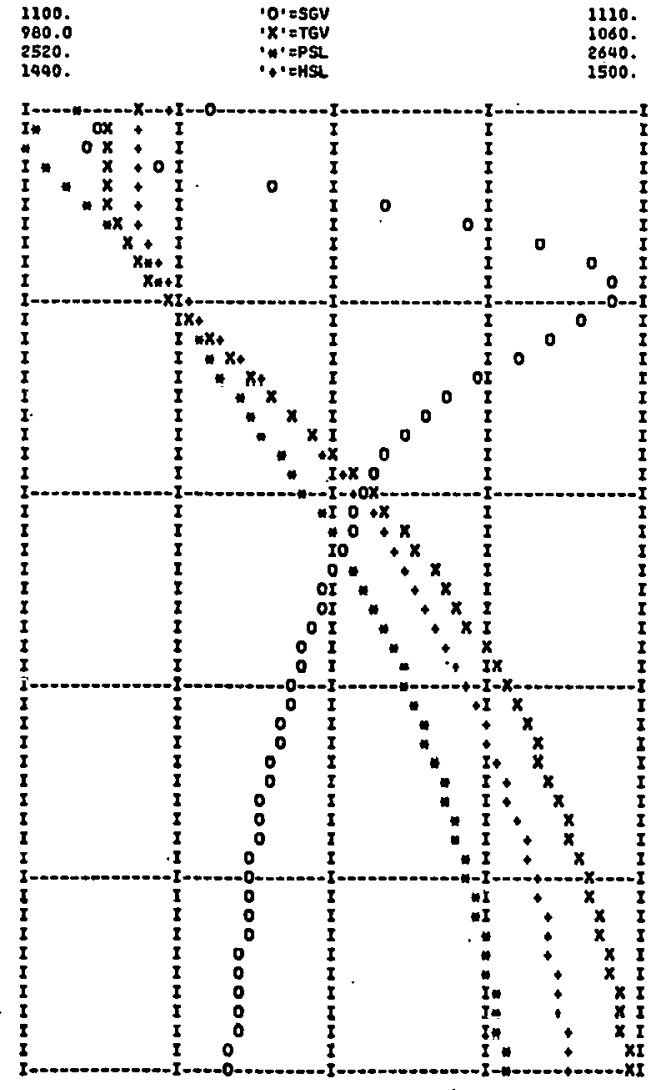

\begin{tabular}{|c|c|c|}
\hline 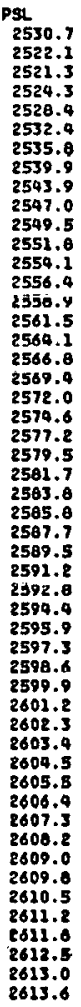 & 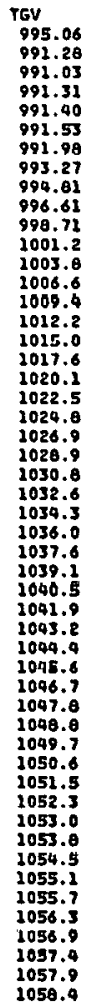 & 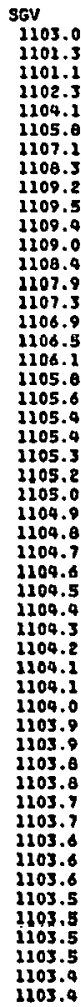 \\
\hline
\end{tabular}


3 PERCENT STEP CHANGE IN COHBUSTION RATE

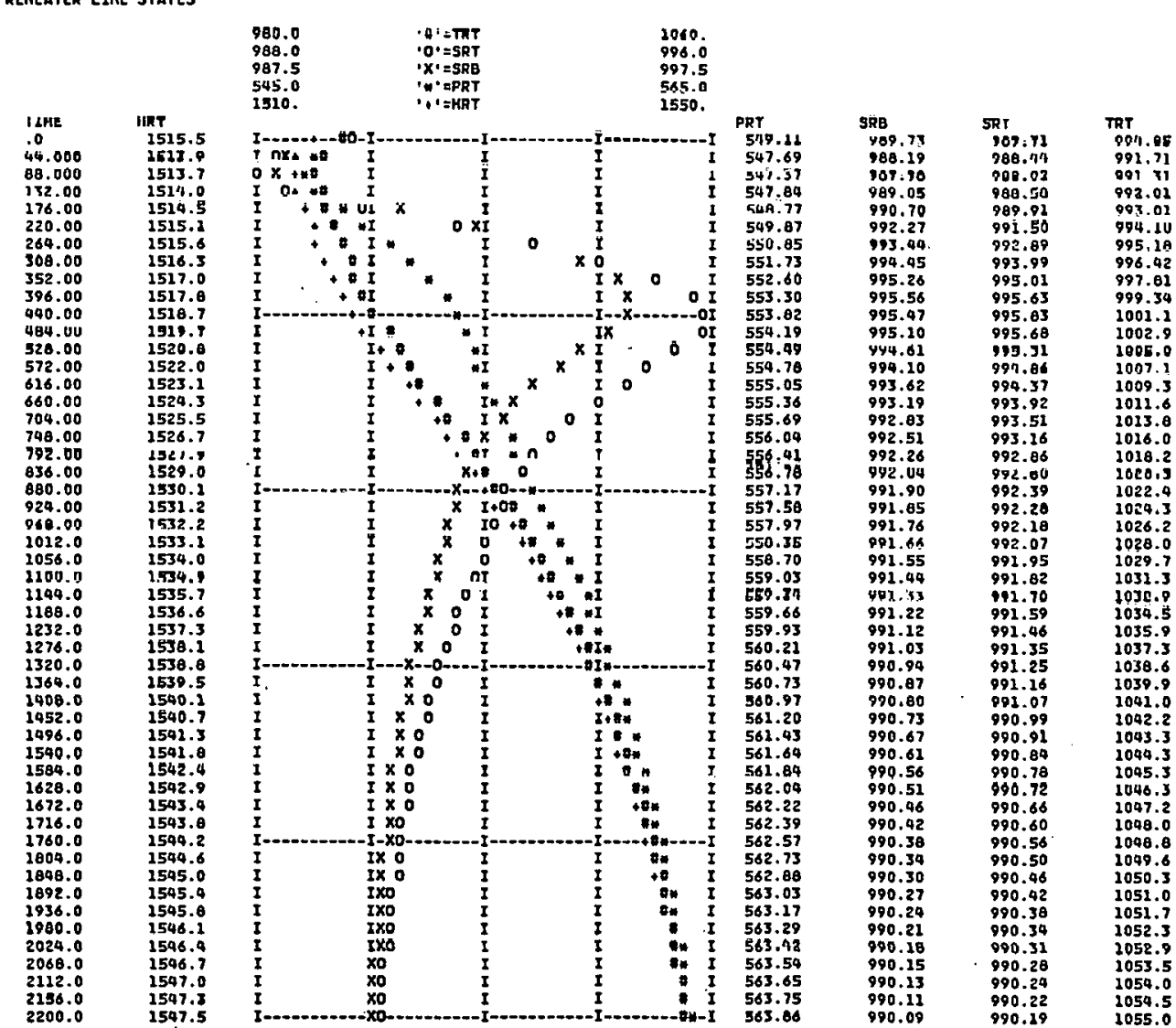


5 PERCENT STEP CHANGE IN COHBUSTION RATE

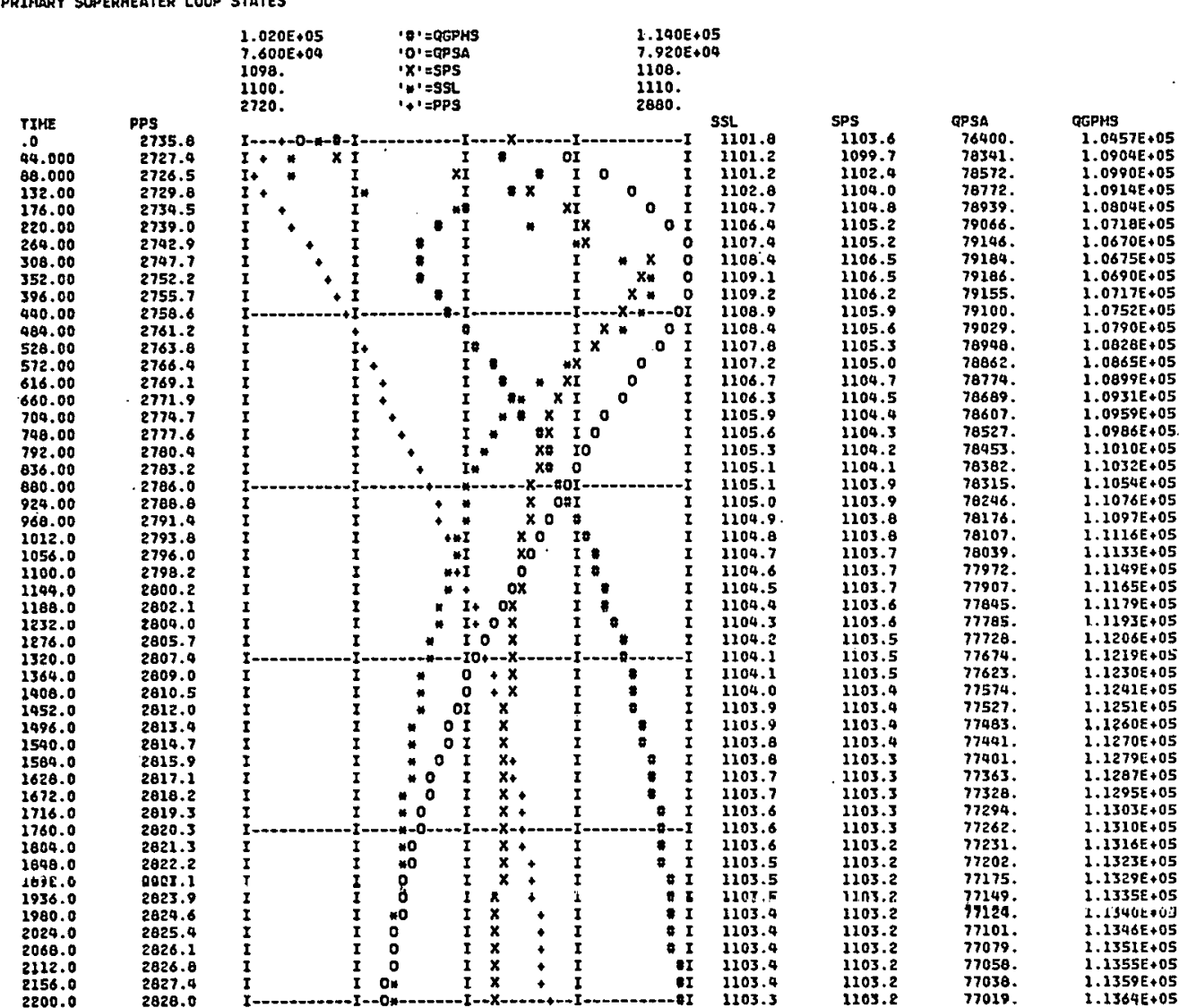

5 PERCENT STEP CHANGE IN COHGUSTION RATE

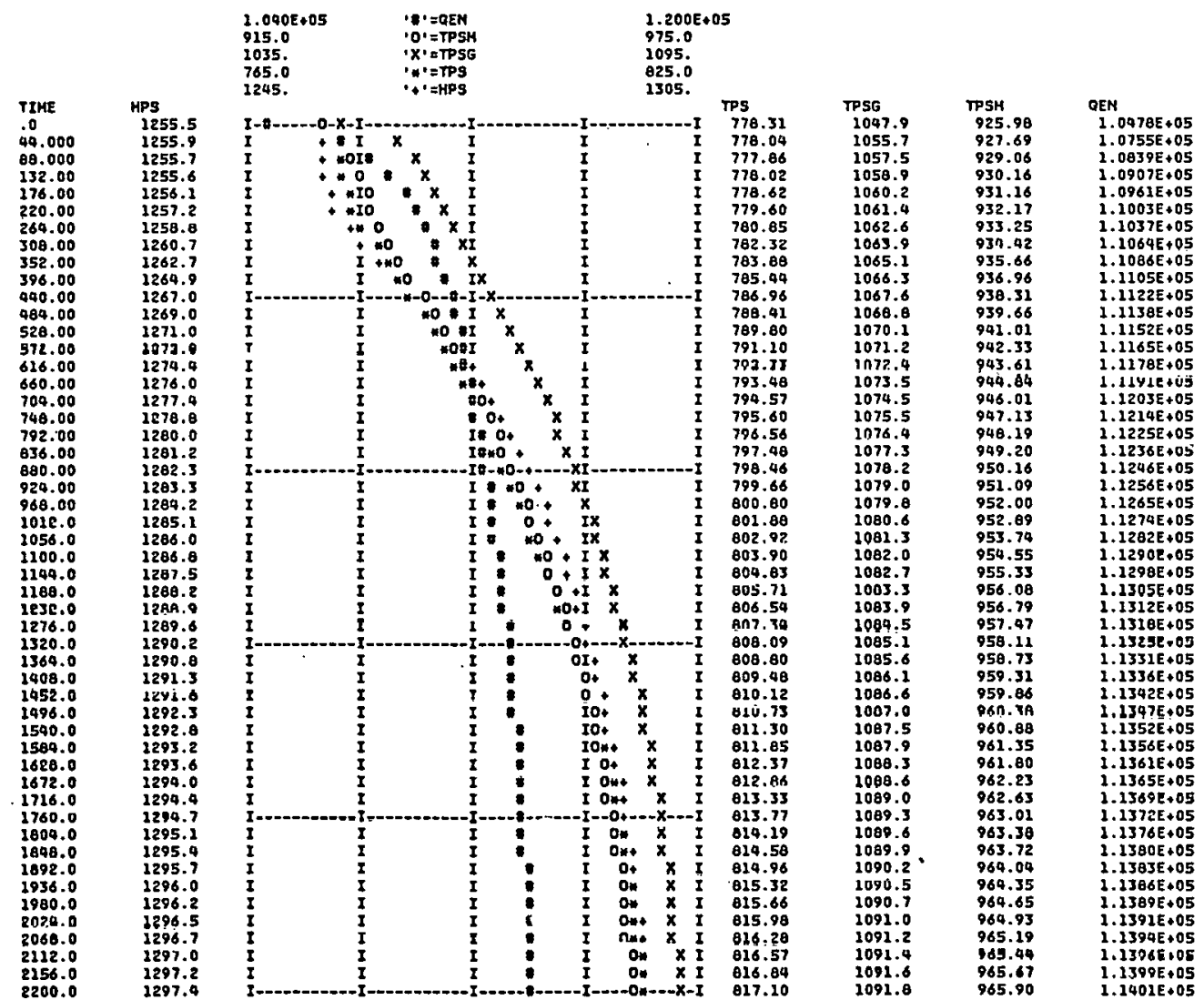


5 PERCENT STEP Change in corbustion Rate

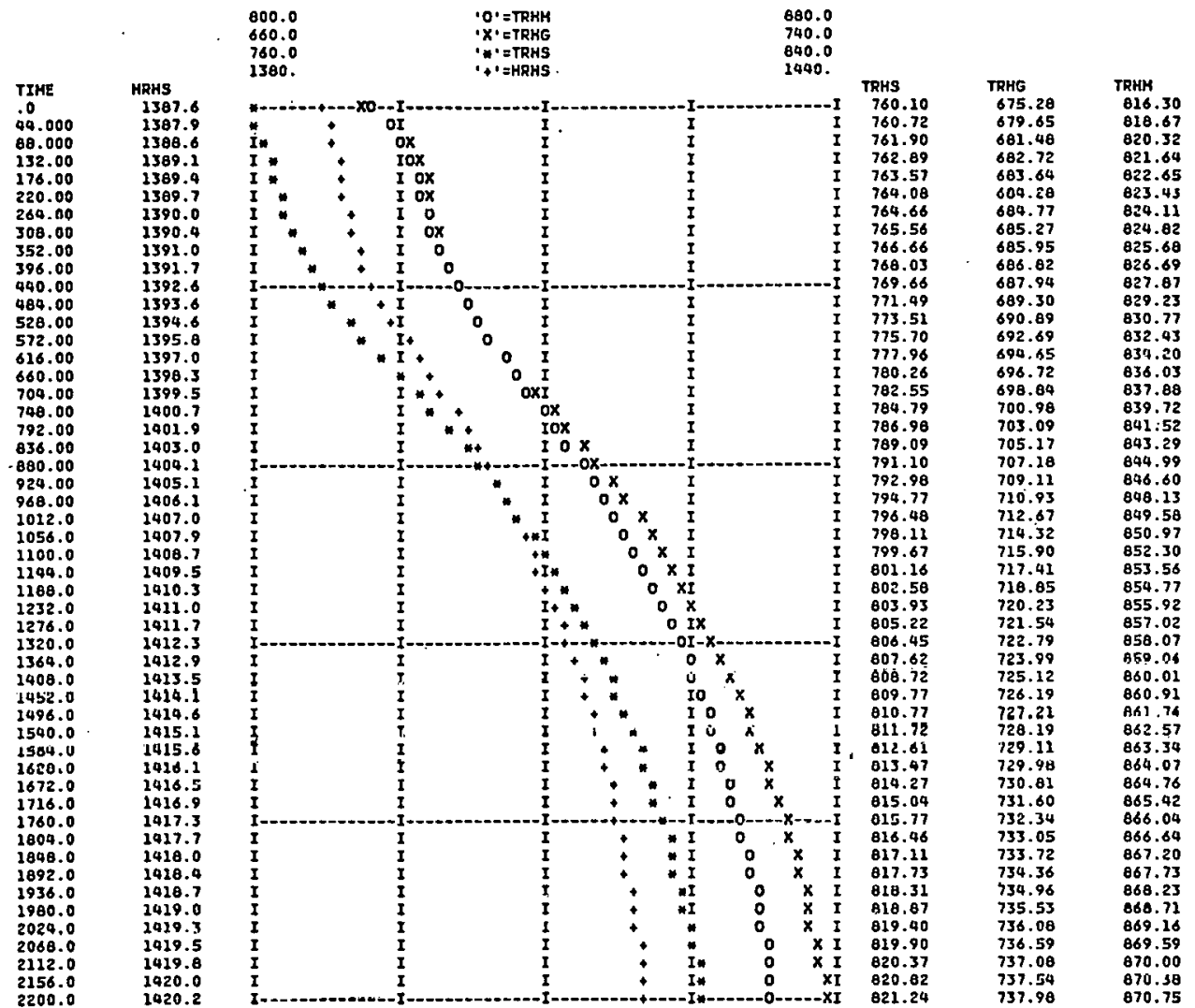

5 PERCENT STEP CHANGE IN CORBUSTION RATE

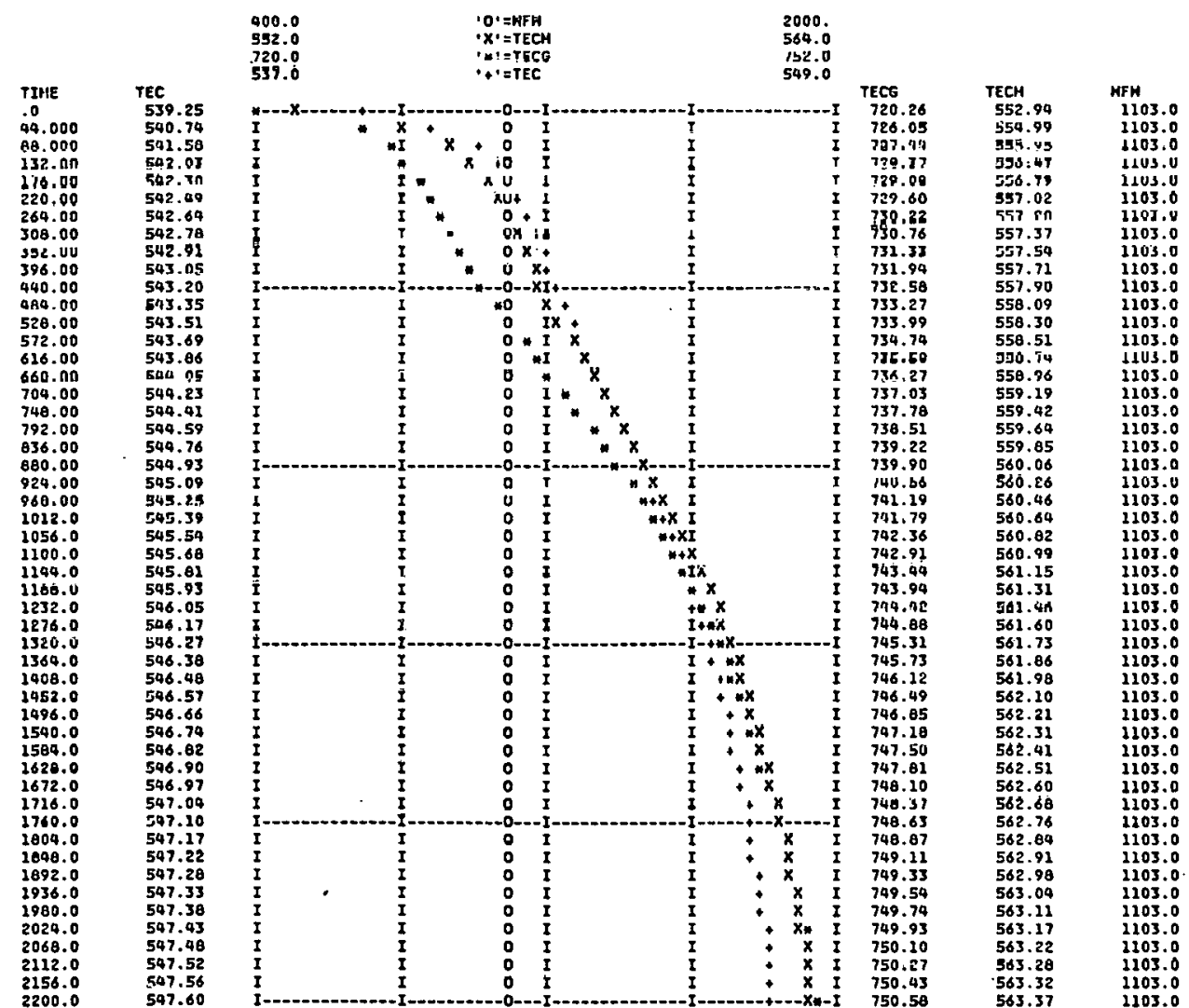


5 PERCENT STEP CHANGE IN COABUSTION RATE

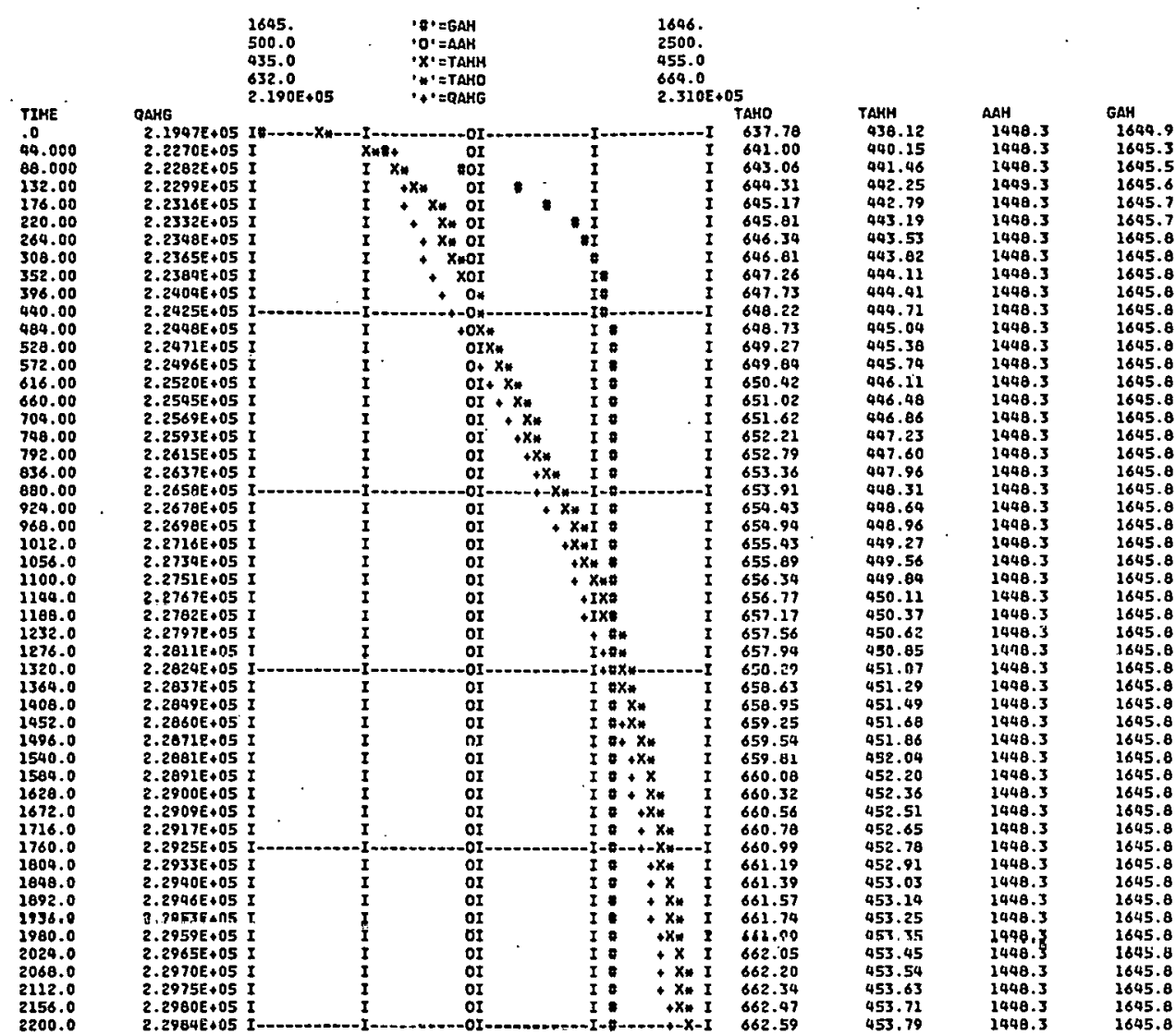

5 PERCENT STEP CHANGE IN COMBUSTION RATE GAS PATH STATES

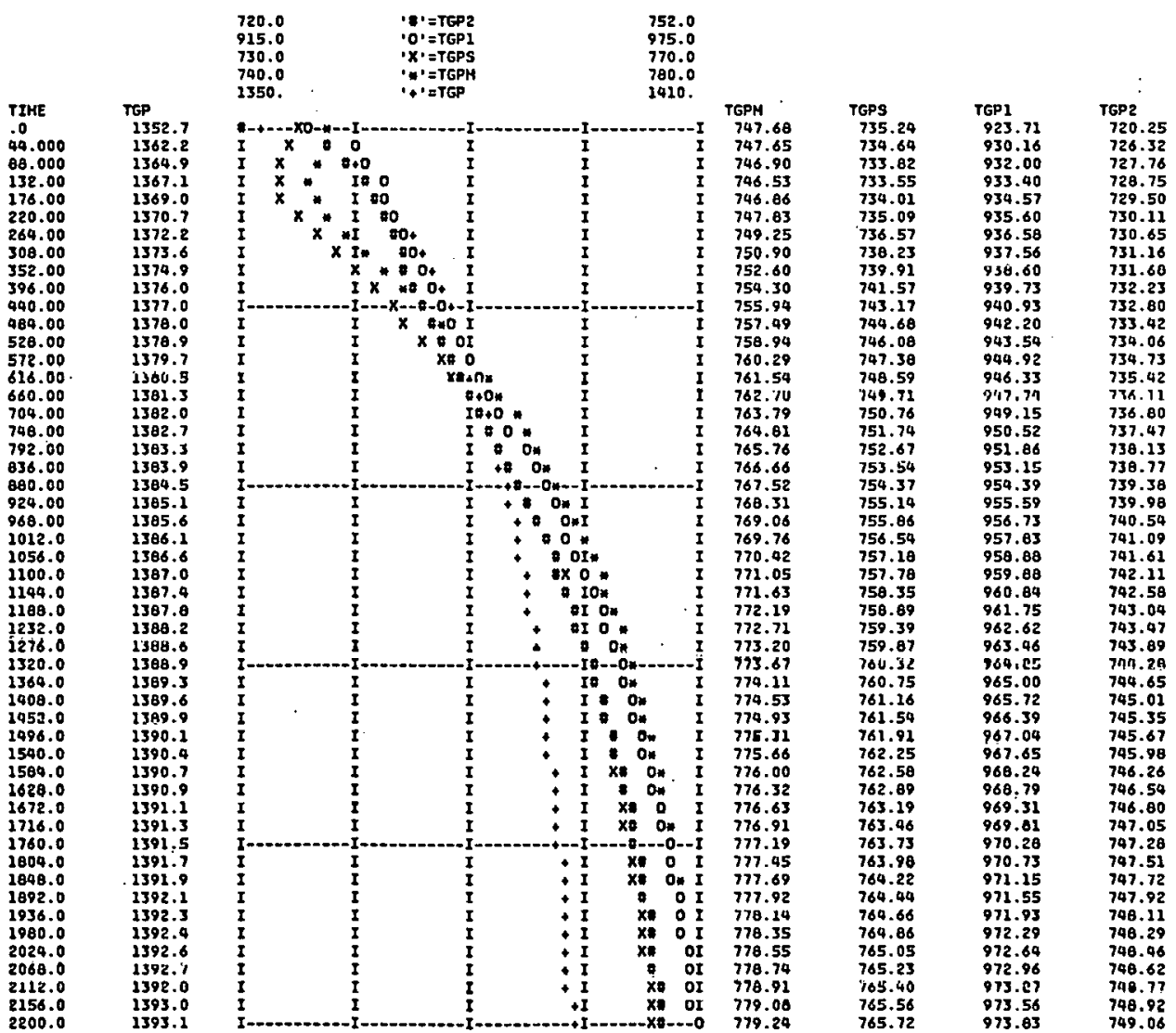


5 PERCENT STEP CHANGE IN COHBUSTION RATE

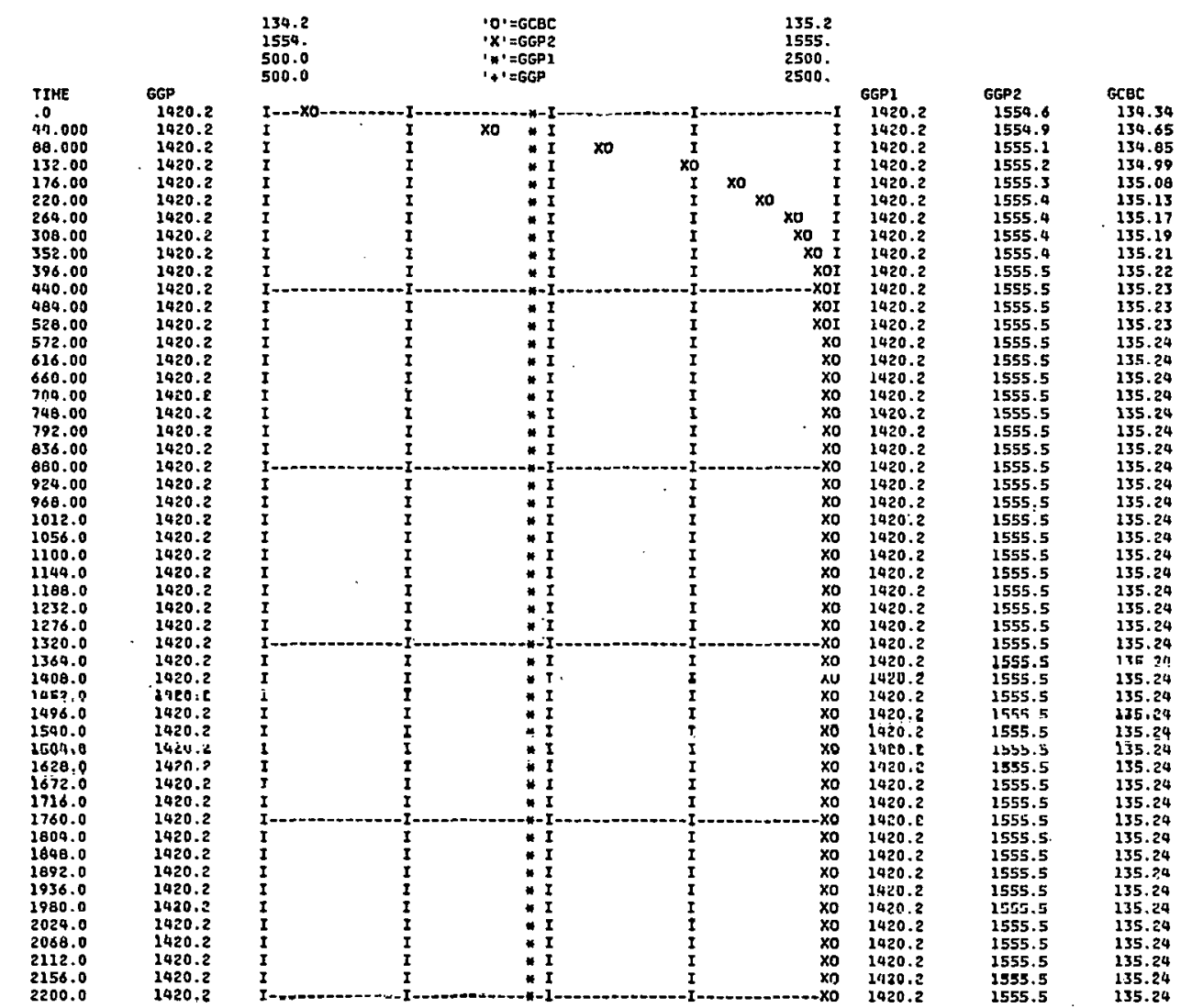

5 PERCENT STEP CHANGE IN COMBUSTION RATE

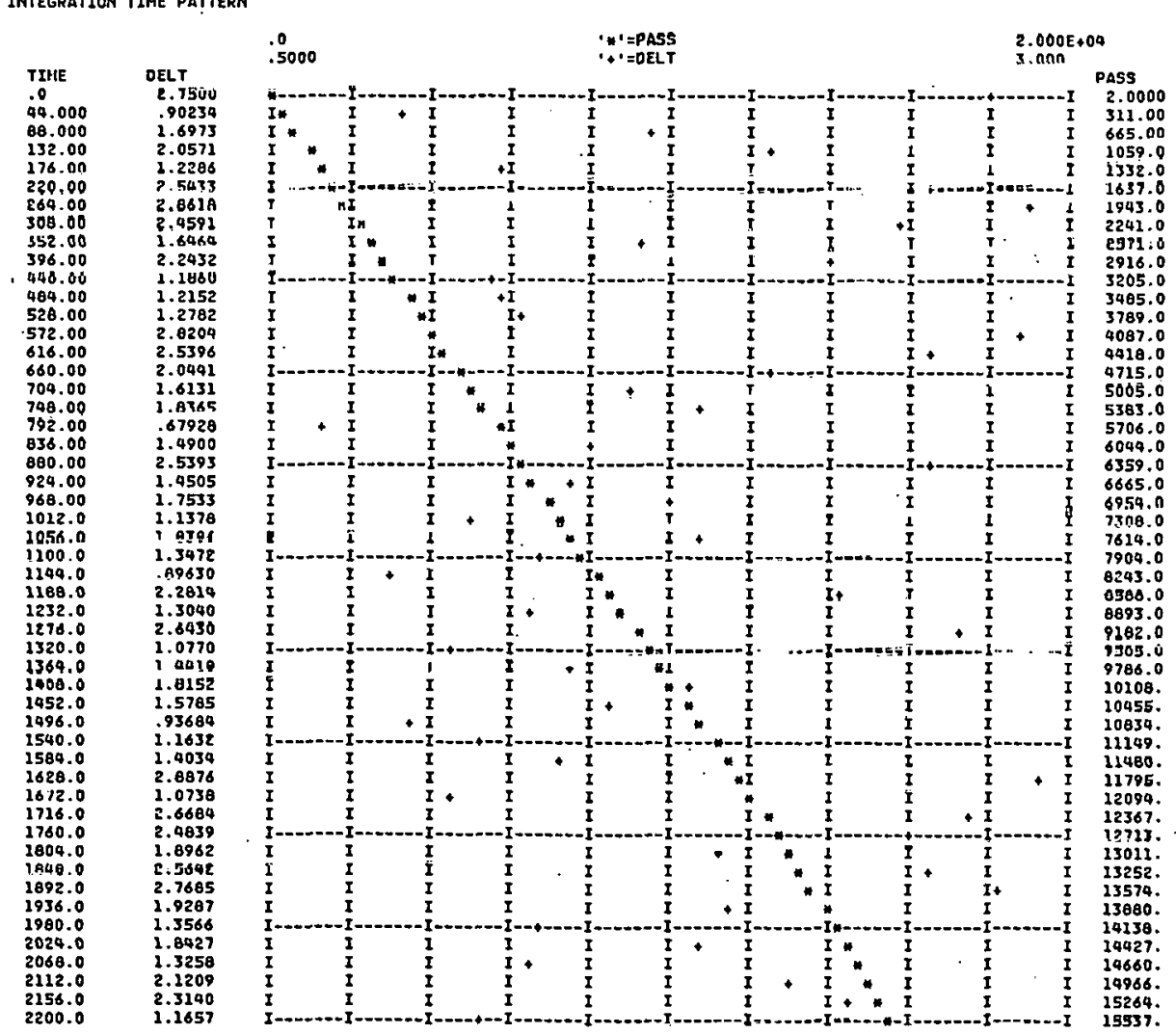


5 PERCent step change in cohbustion rate

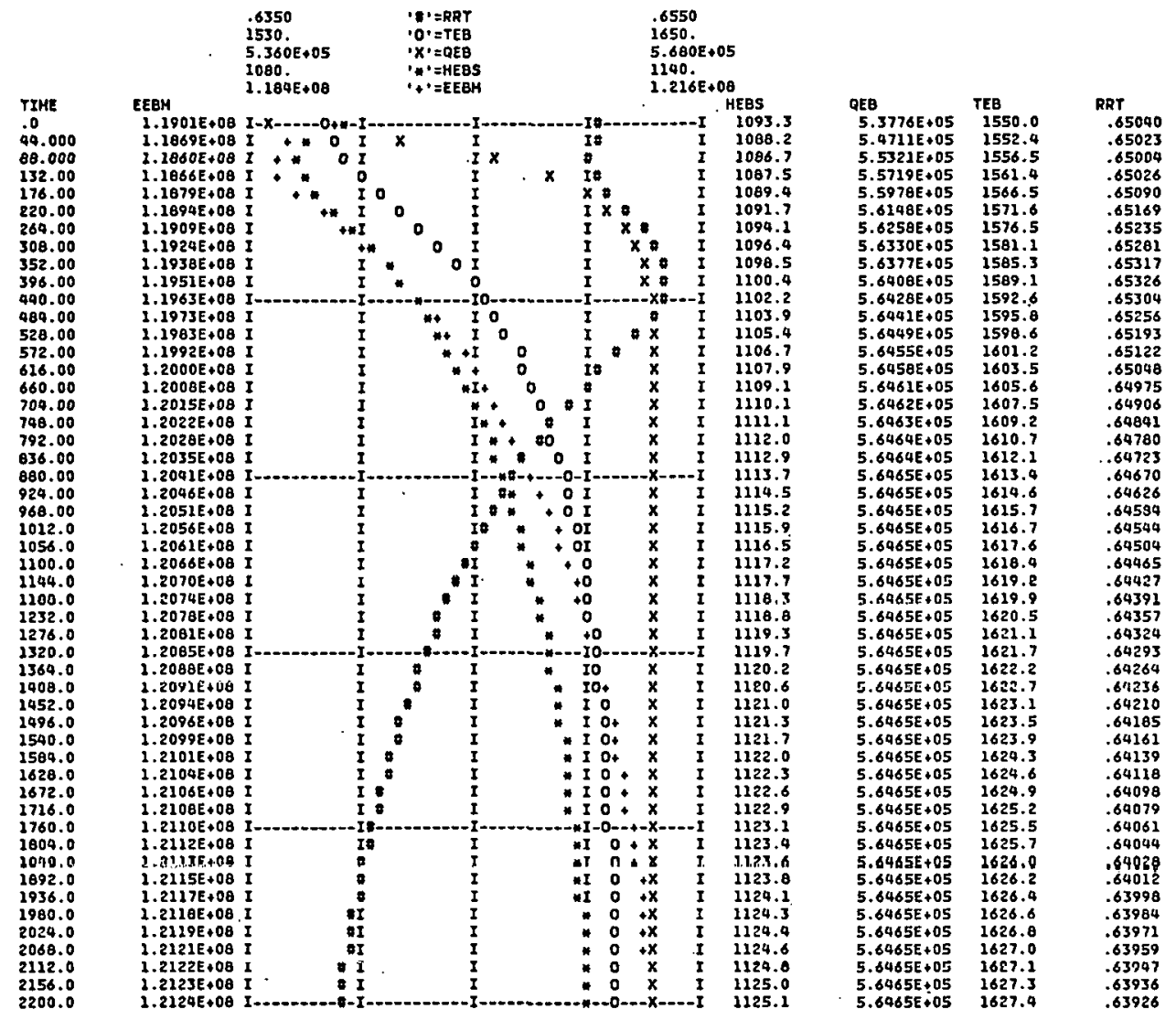

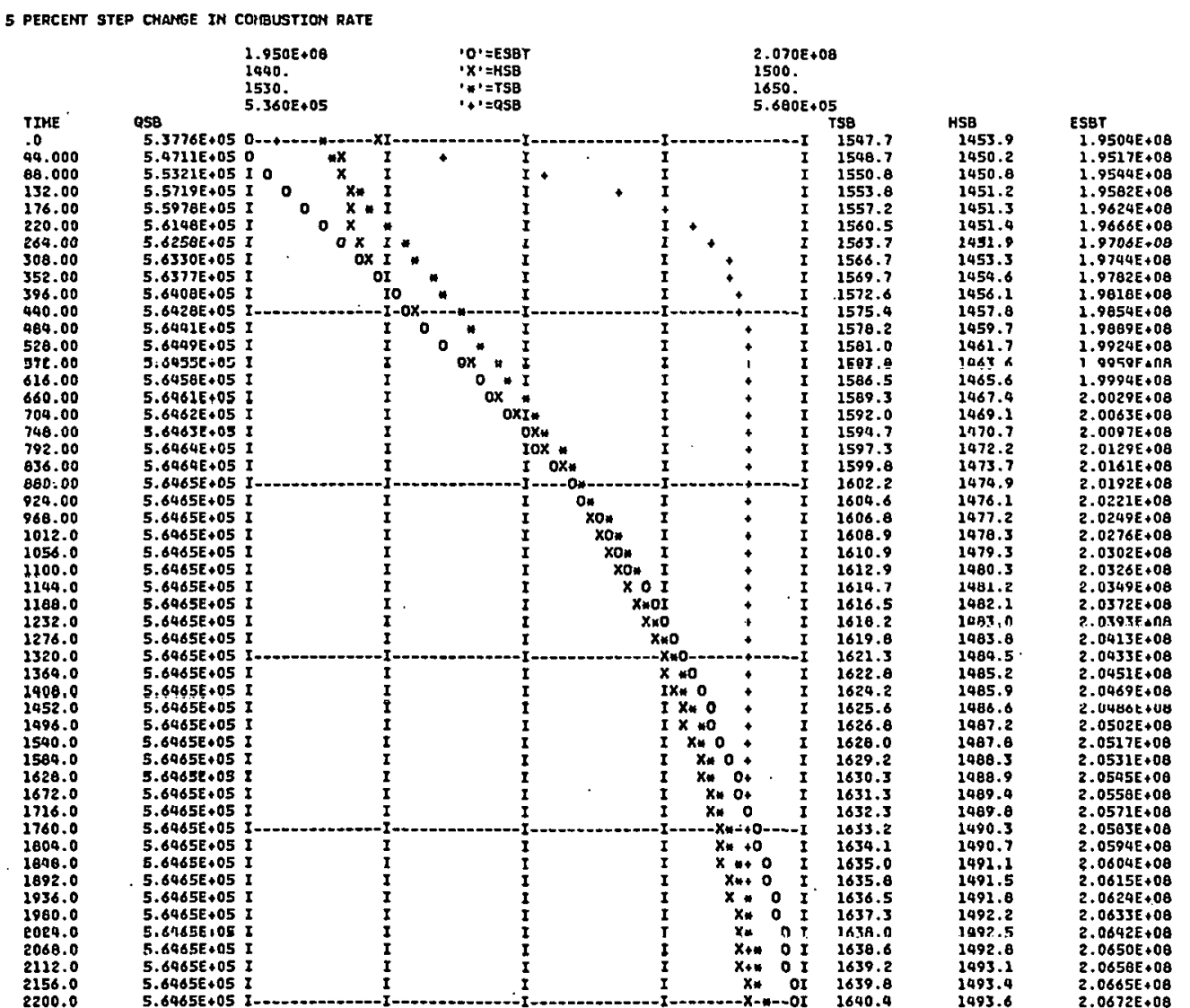




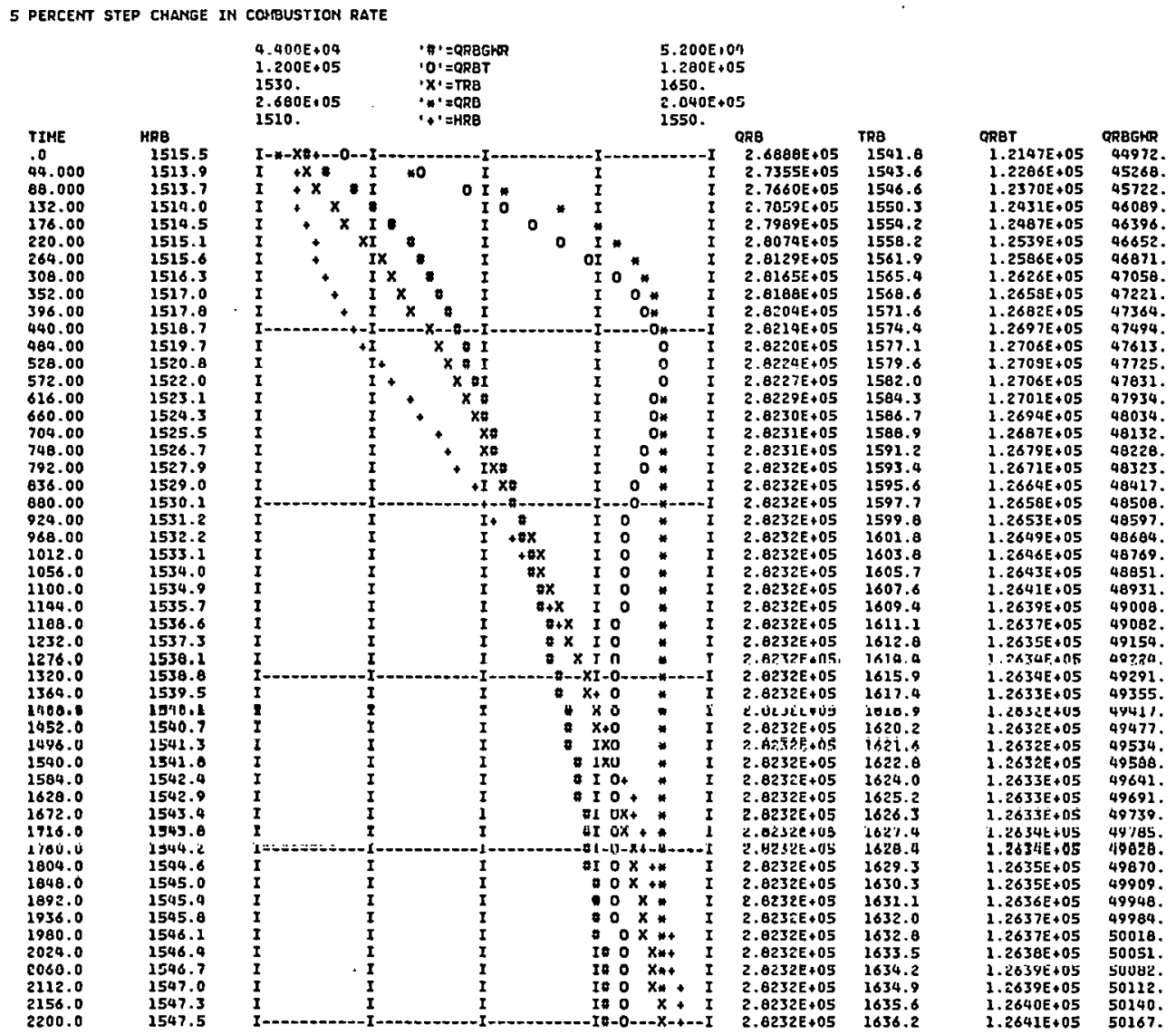

5 PERGENT STEP change ih corbustion rate

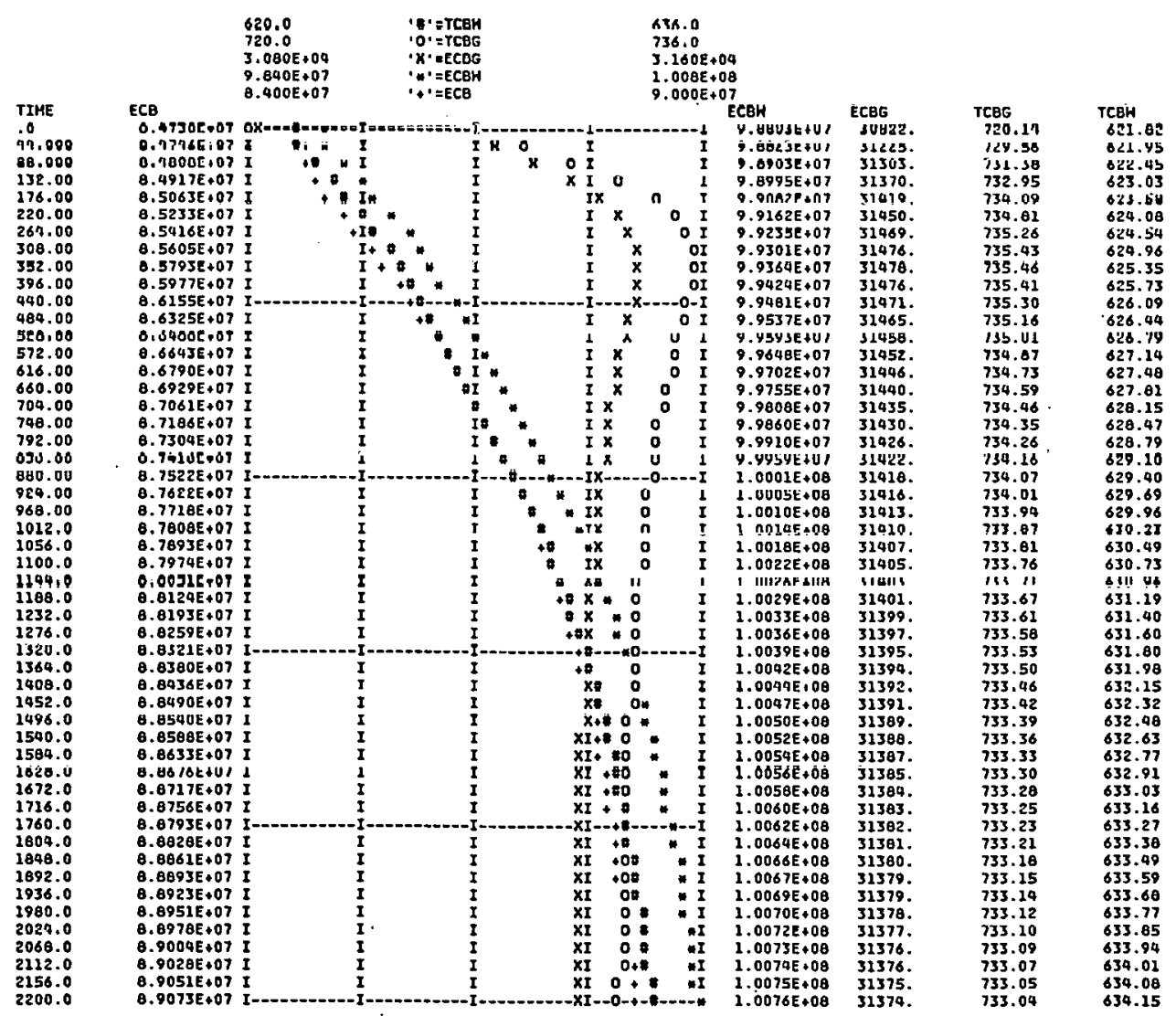


5 PERCENT STEP CHANGE in COHBUSTION RATE
FLUIDIZED CELL BEO HEIGHTS (FT)

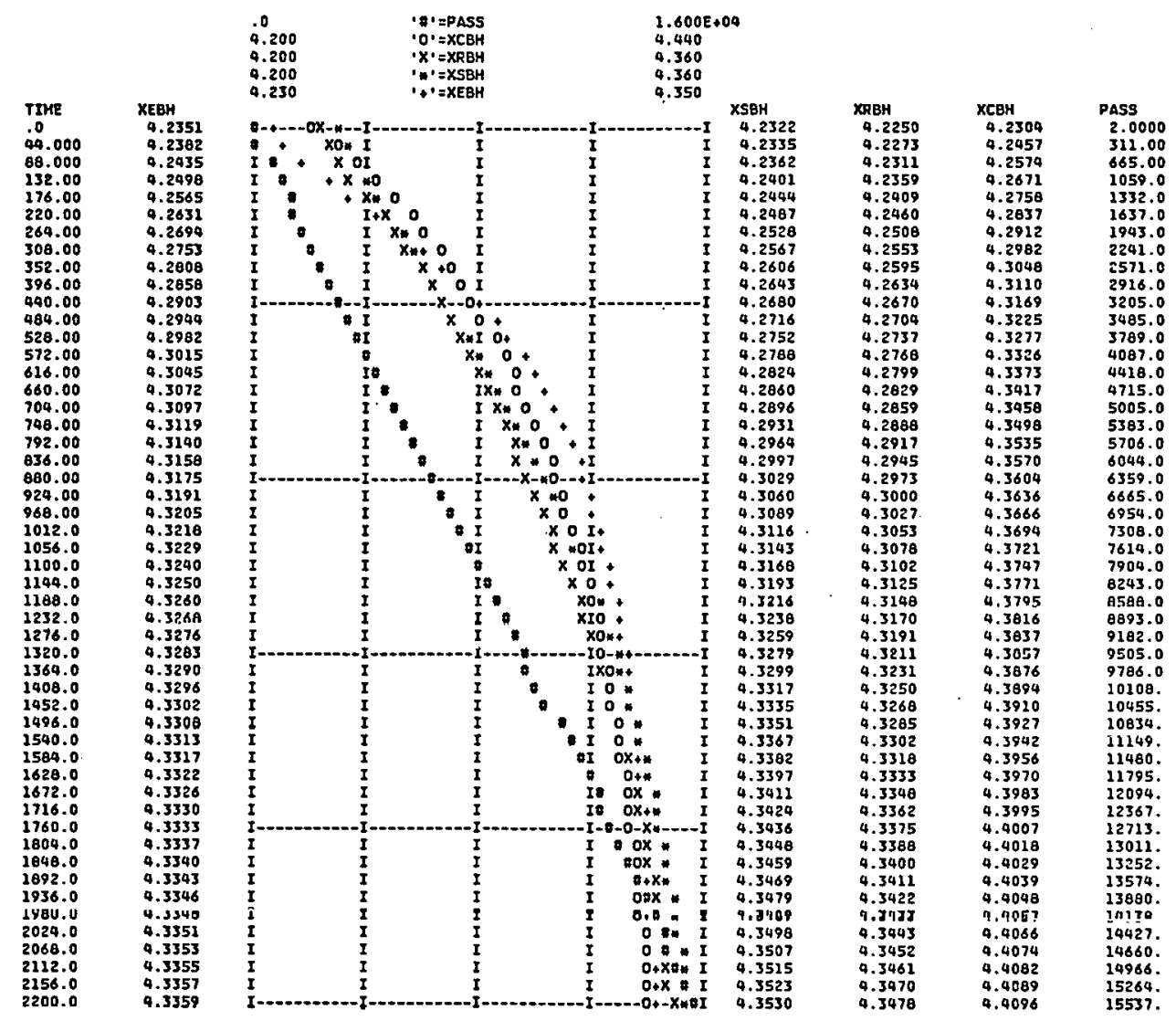

5 PERCENT STEP CHANGE IN CONBUSTION RATE

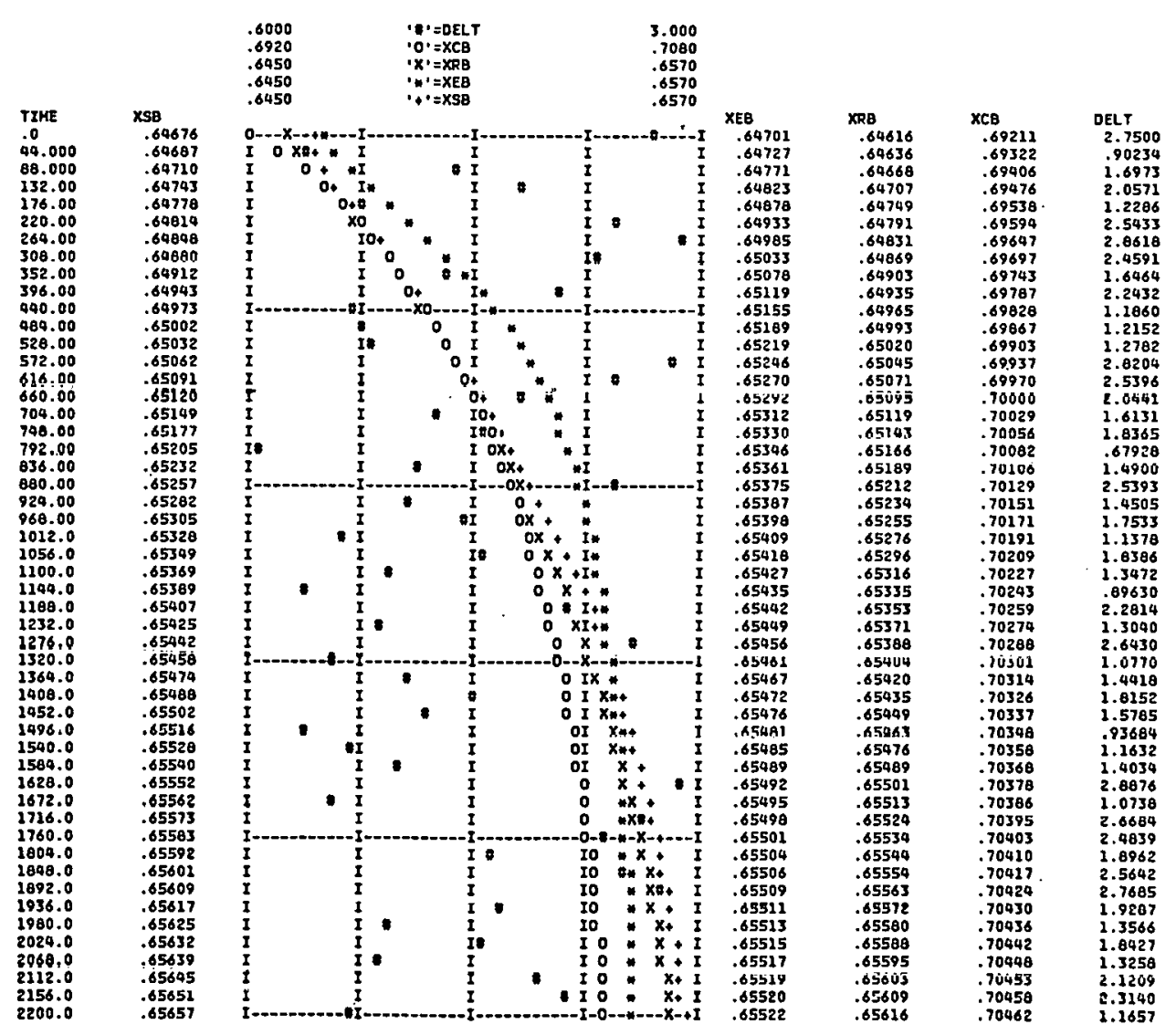


5 PERCENT STEP CHANGE IN COMBUSTION RATE

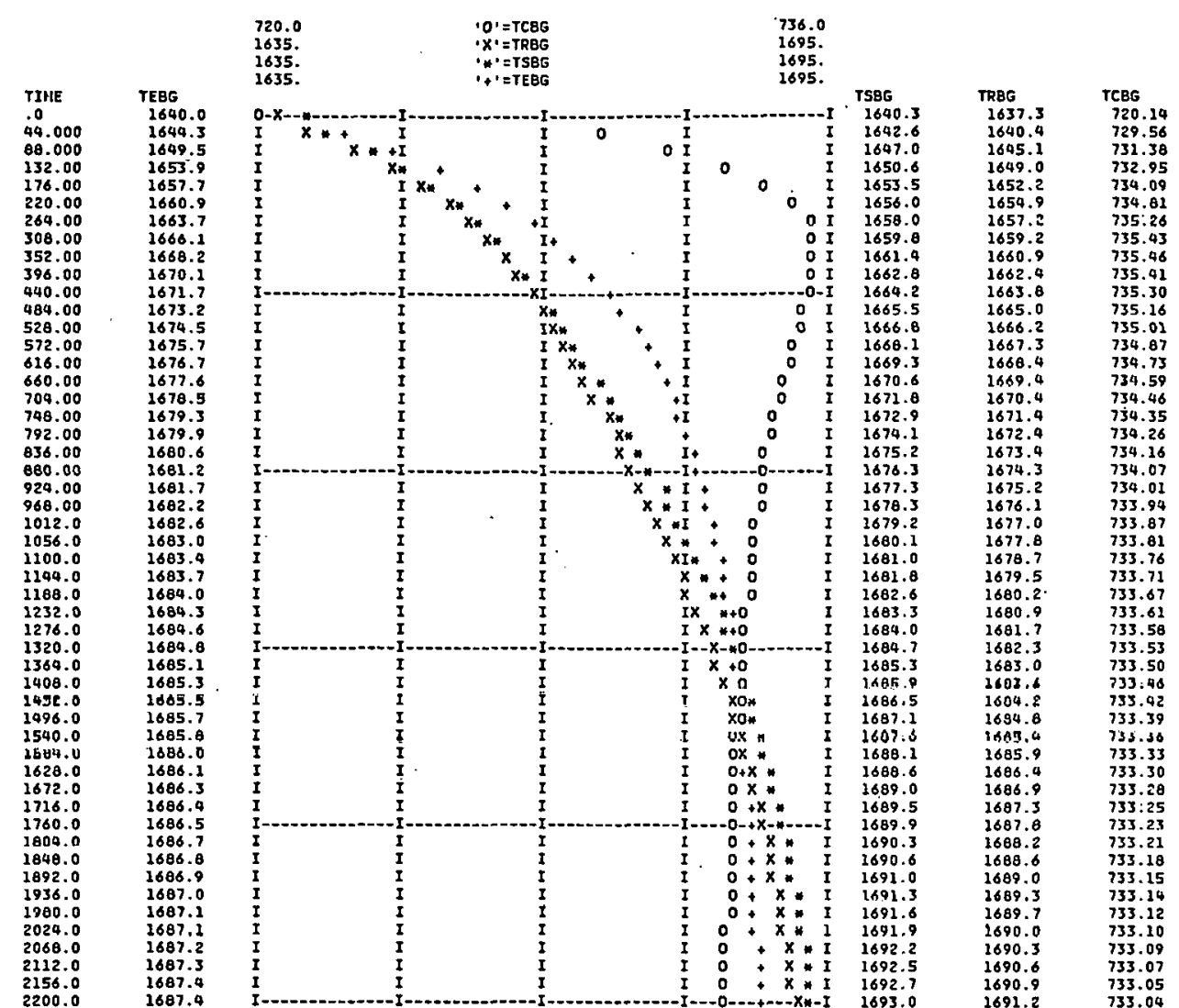

5 PERCENT STEP CHANGE IN COHBUSTION RATE

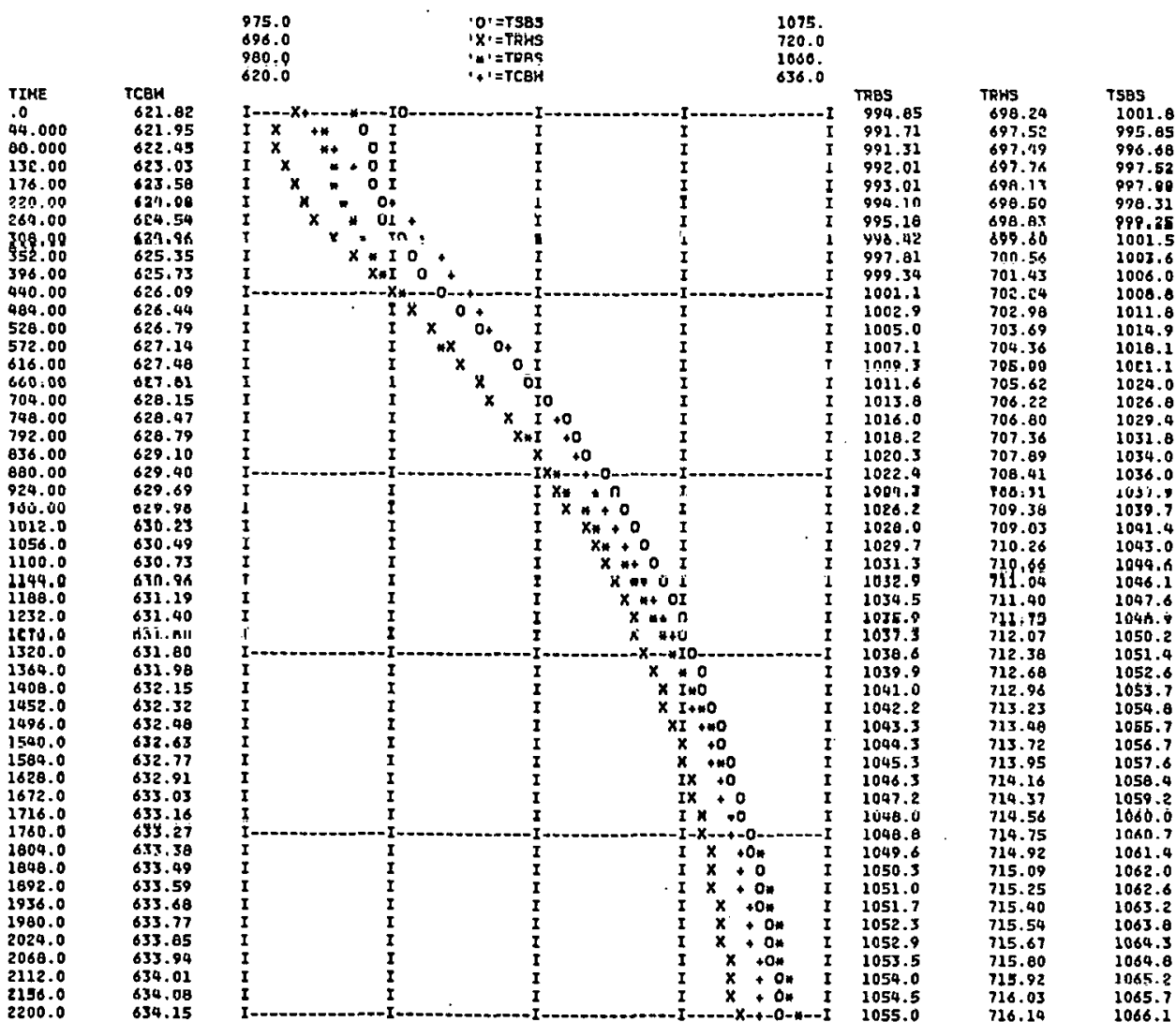


5 PERCENT STEP CHANGE IN CORBUSTION RATE

DEO TEHIPERATURES

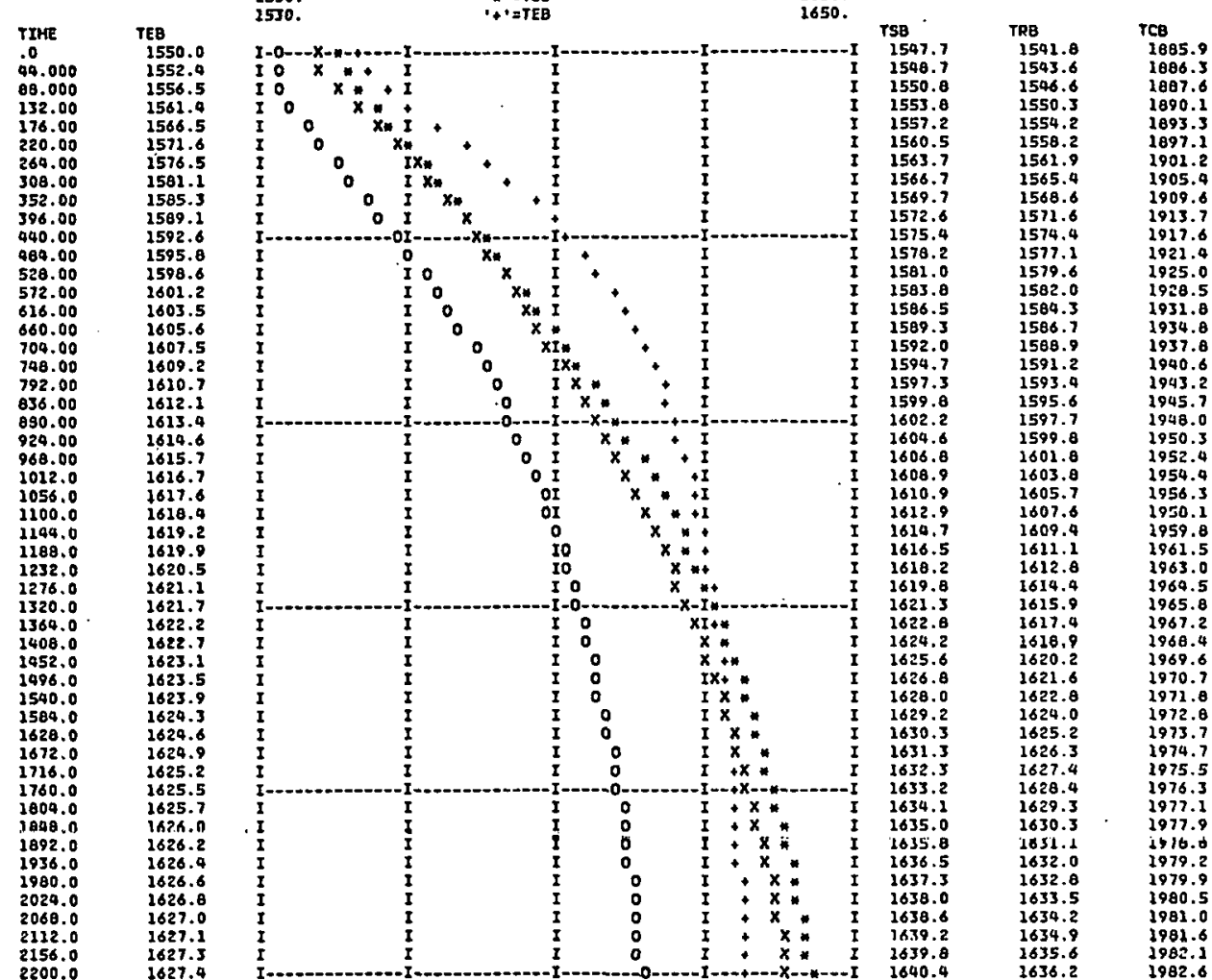

5 PERCENT STEP CHANGE IM COMGUSTION RATE

FRACTIOY OF MATER THO PHASE STEAH BOTTME BED IMET TO AM OMTL

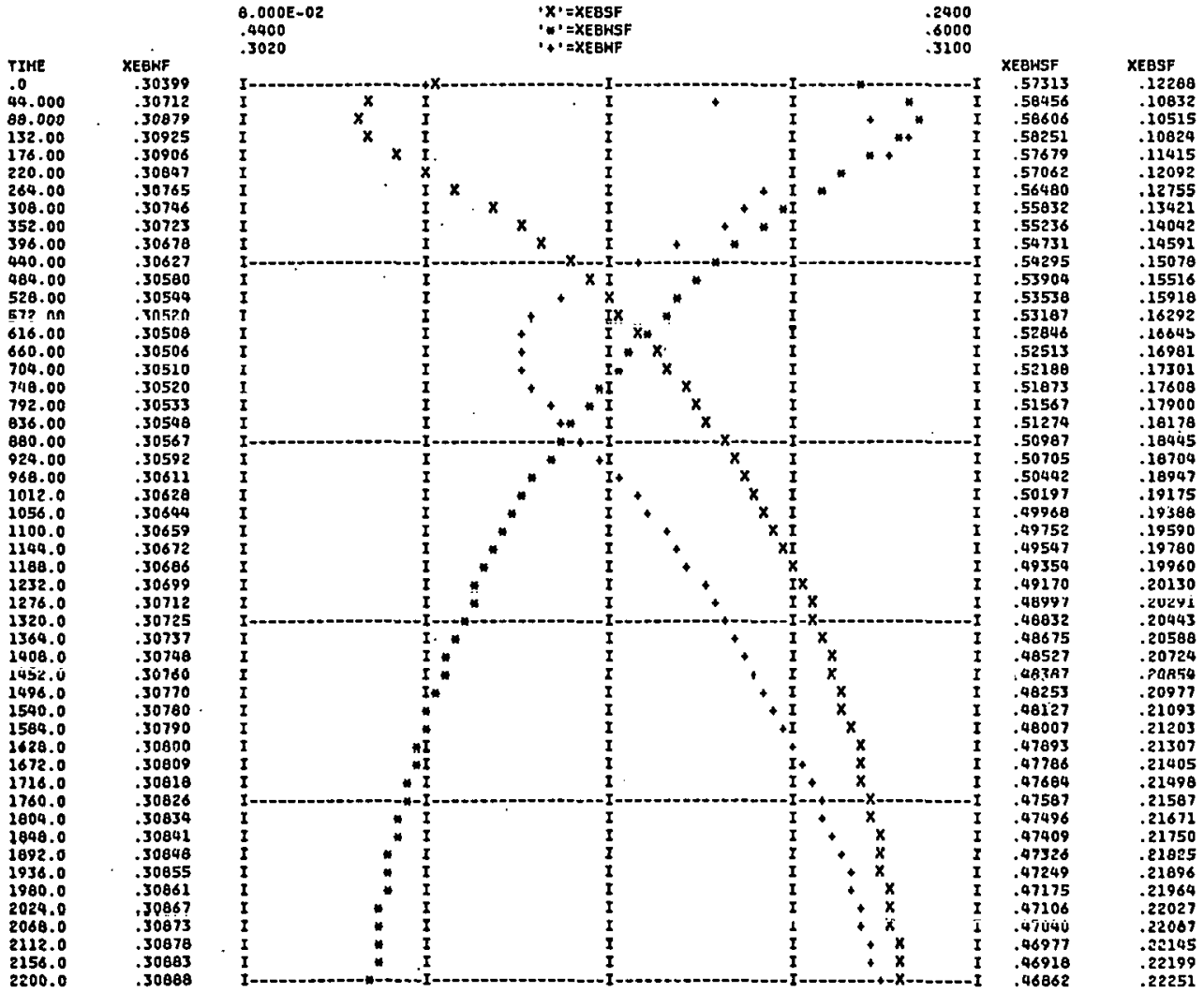


5 PERCENT STEP CHANGE IN COHBUSIION RATE

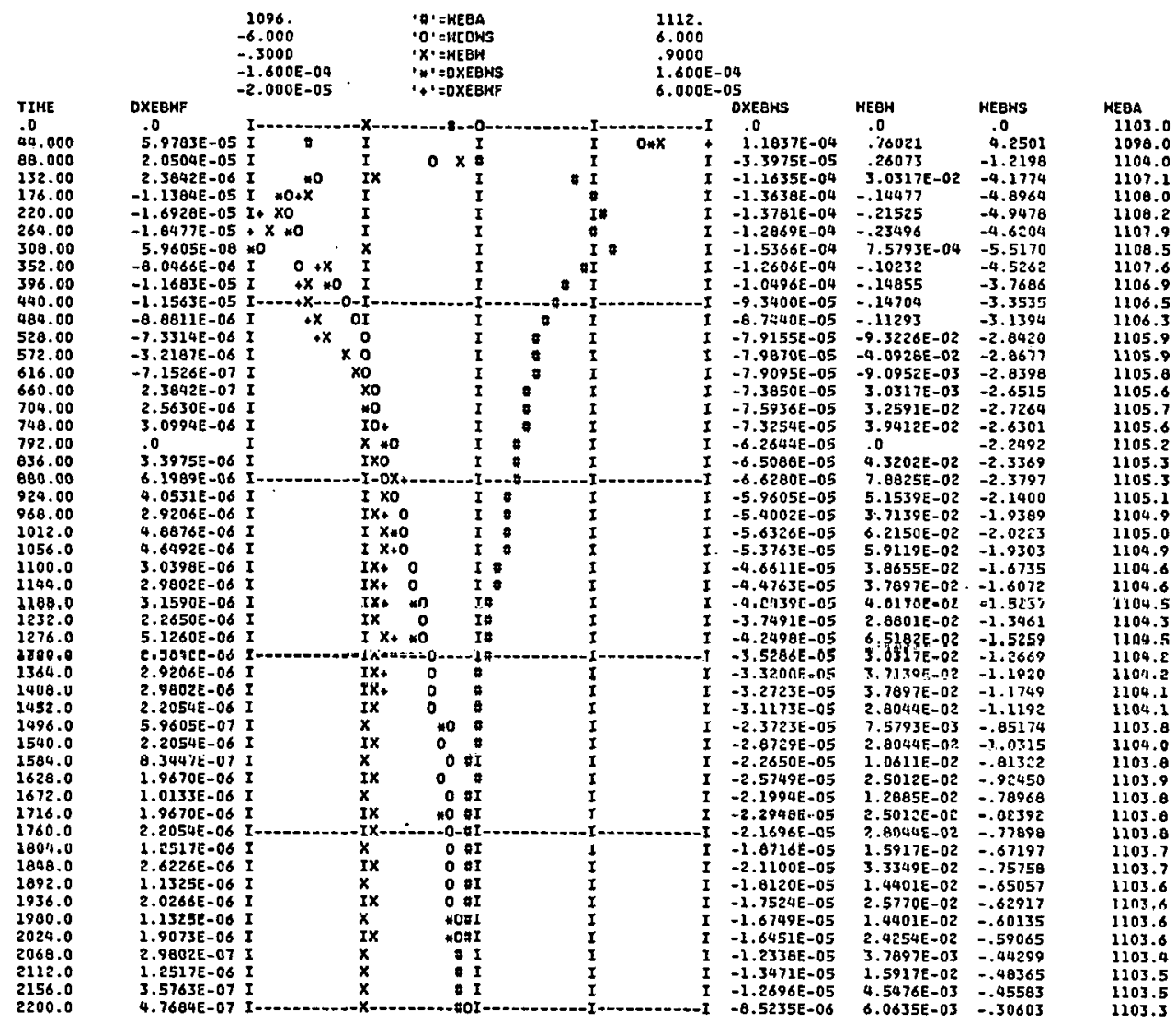

5 PERCENT STEP CHANGE IN COMBUSTION RATE
PRESSURES IN BOILIMG, SUPERHEAT AND REHFAT BEO

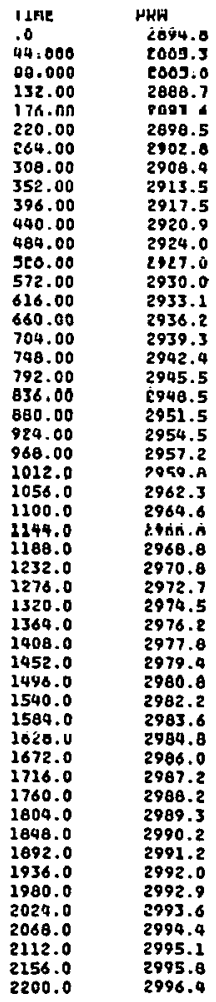

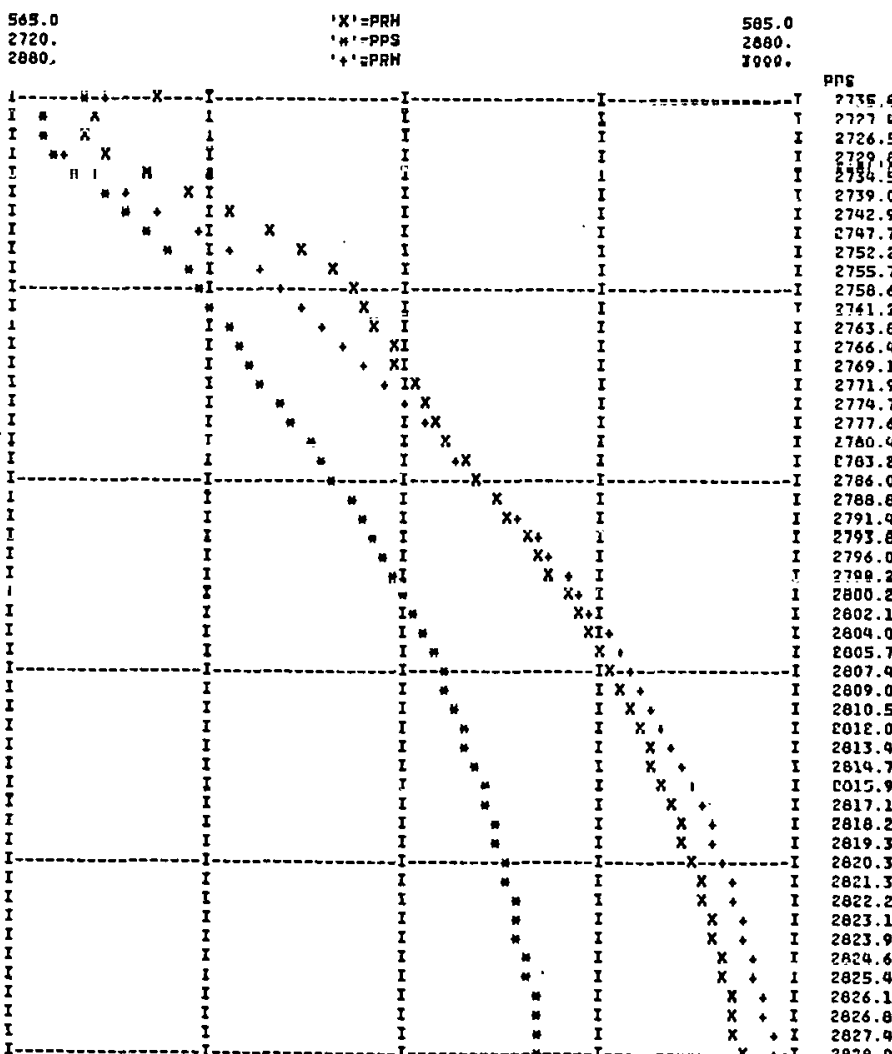




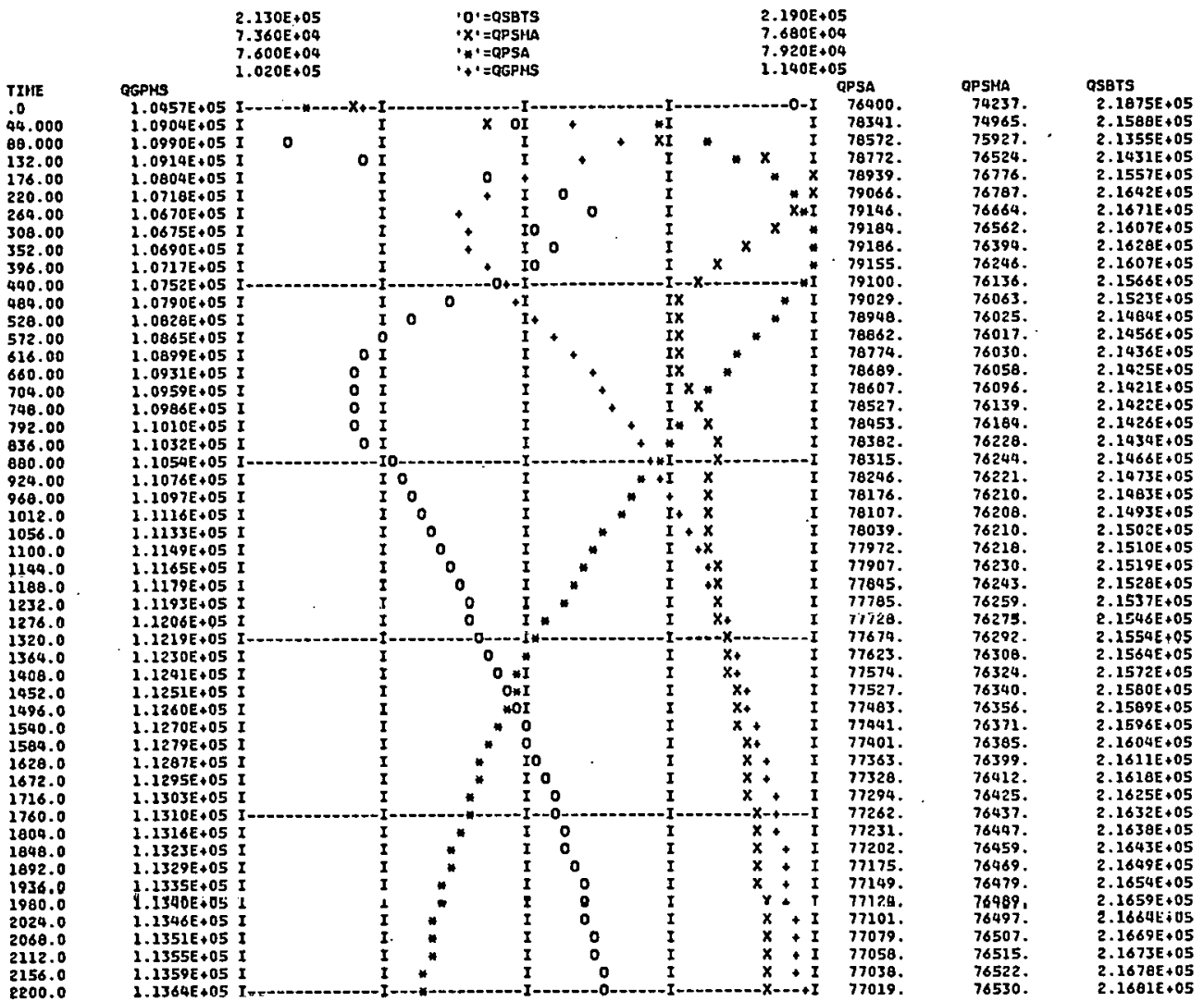

5 PERCENT STEP CHANGE IN COHBUSTION RATE

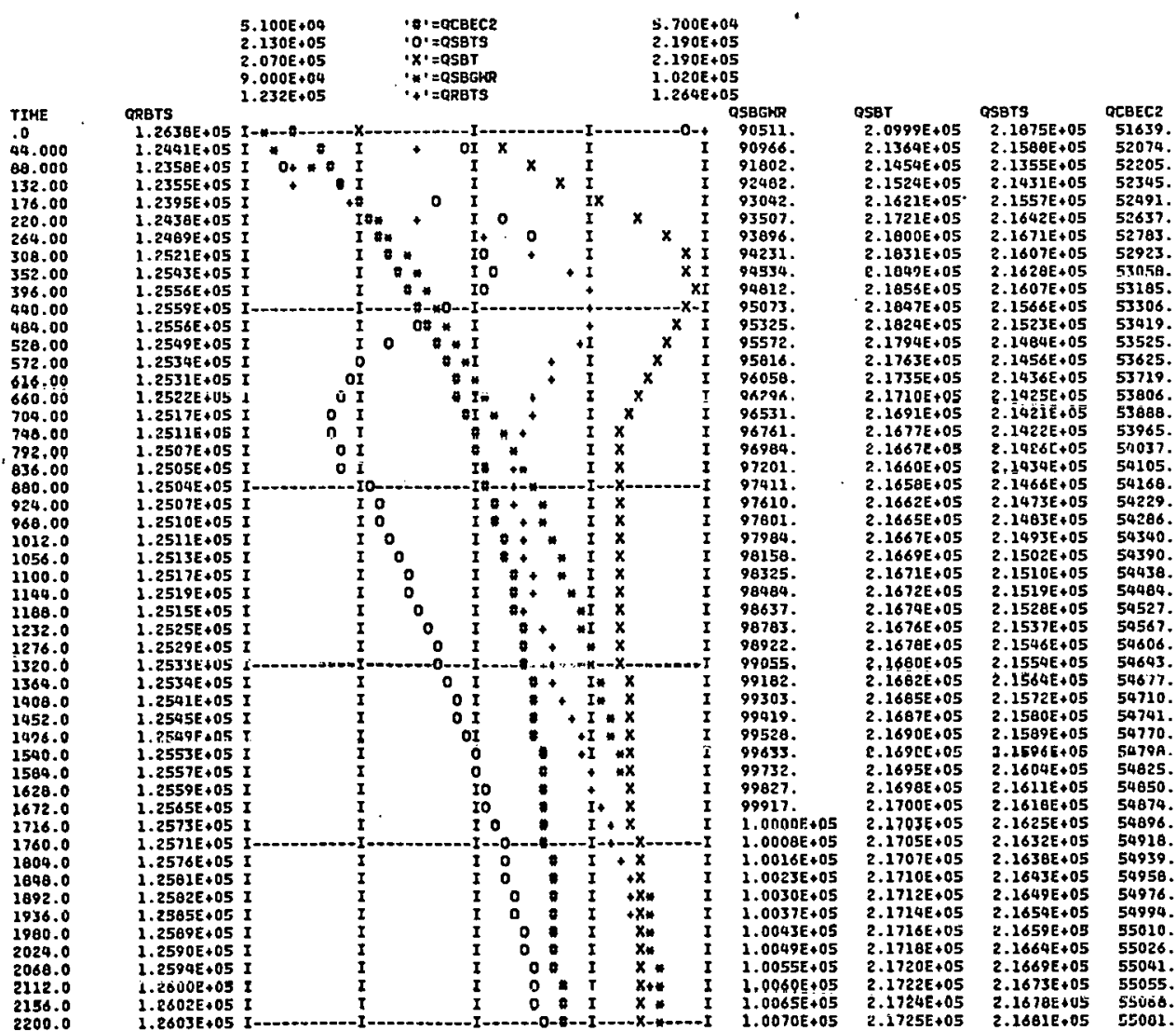




\section{THIS PAGE}

WAS INTENTIONALLY

LEFT BLANK 


\section{APPENDIX V-B6 \\ STEP IN FEEDWATER FLOW}

This section presents the detailed results in CSMP plot format for a $5 \%$ step increase in feedwater flow rate. 


\section{THIS PAGE}

\section{WAS INTENTIONALLY \\ LEFT BLANK}




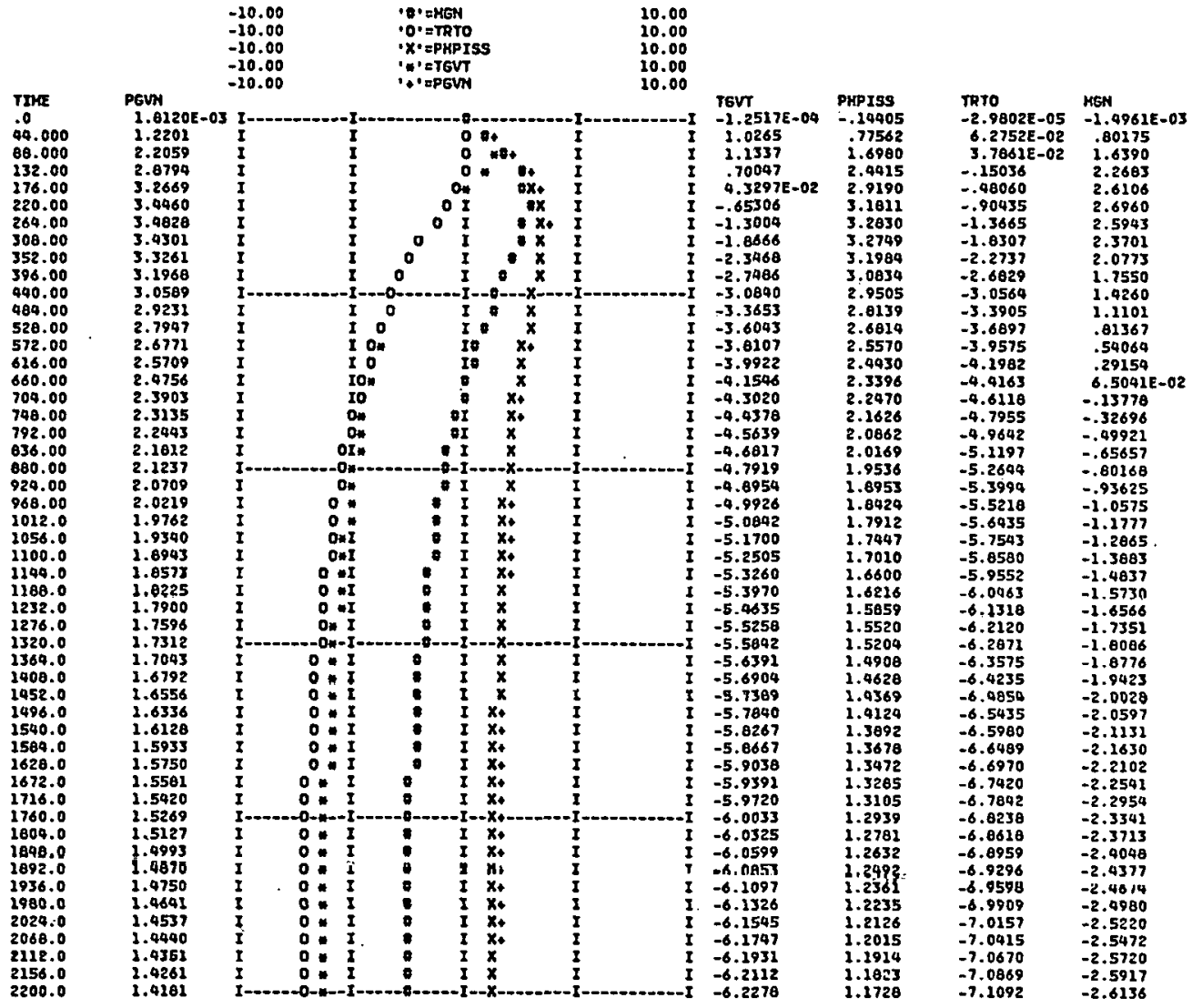

S PERCENT STEP CHANGE IN FEEOMATER FLON DEMANO

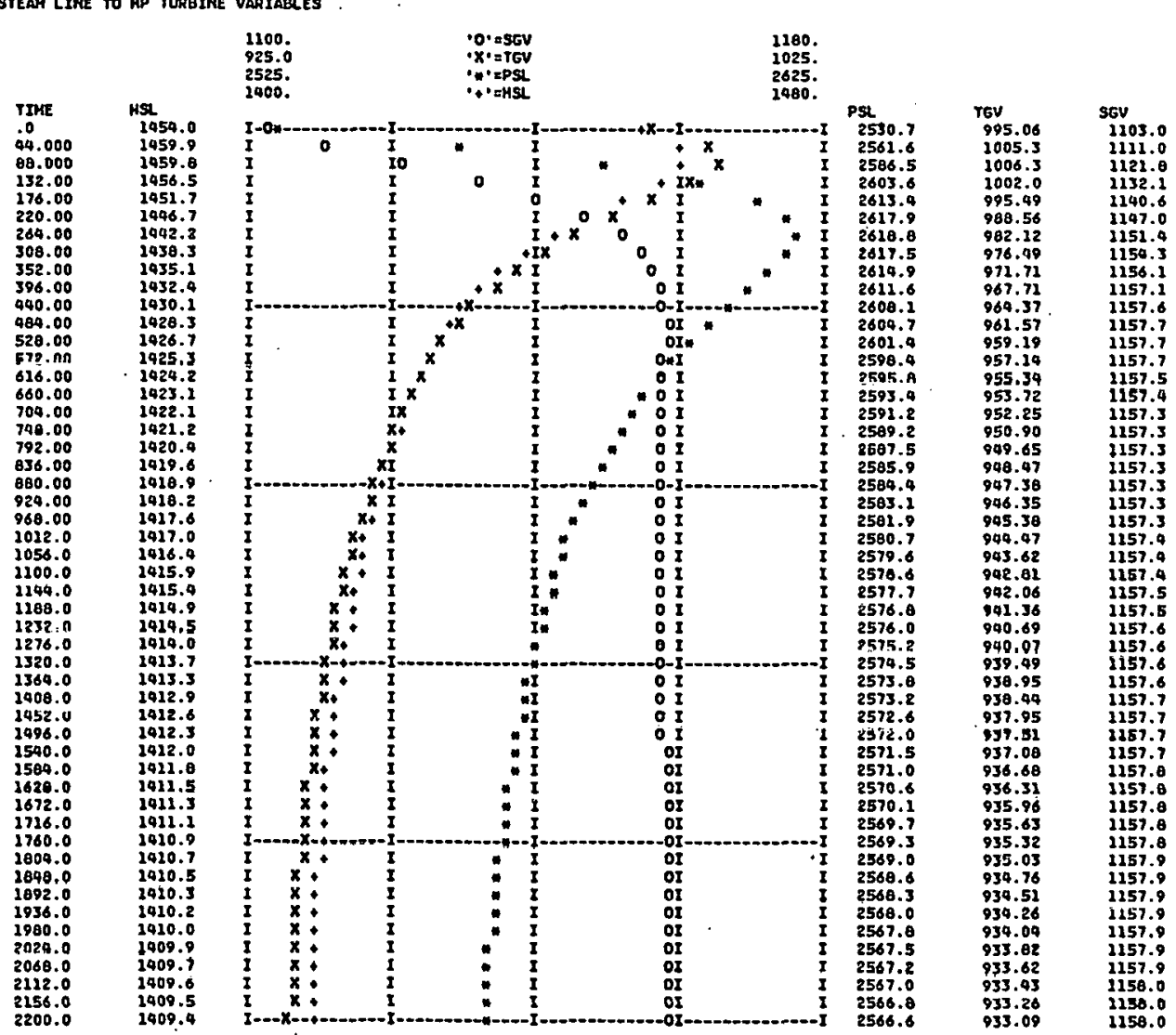




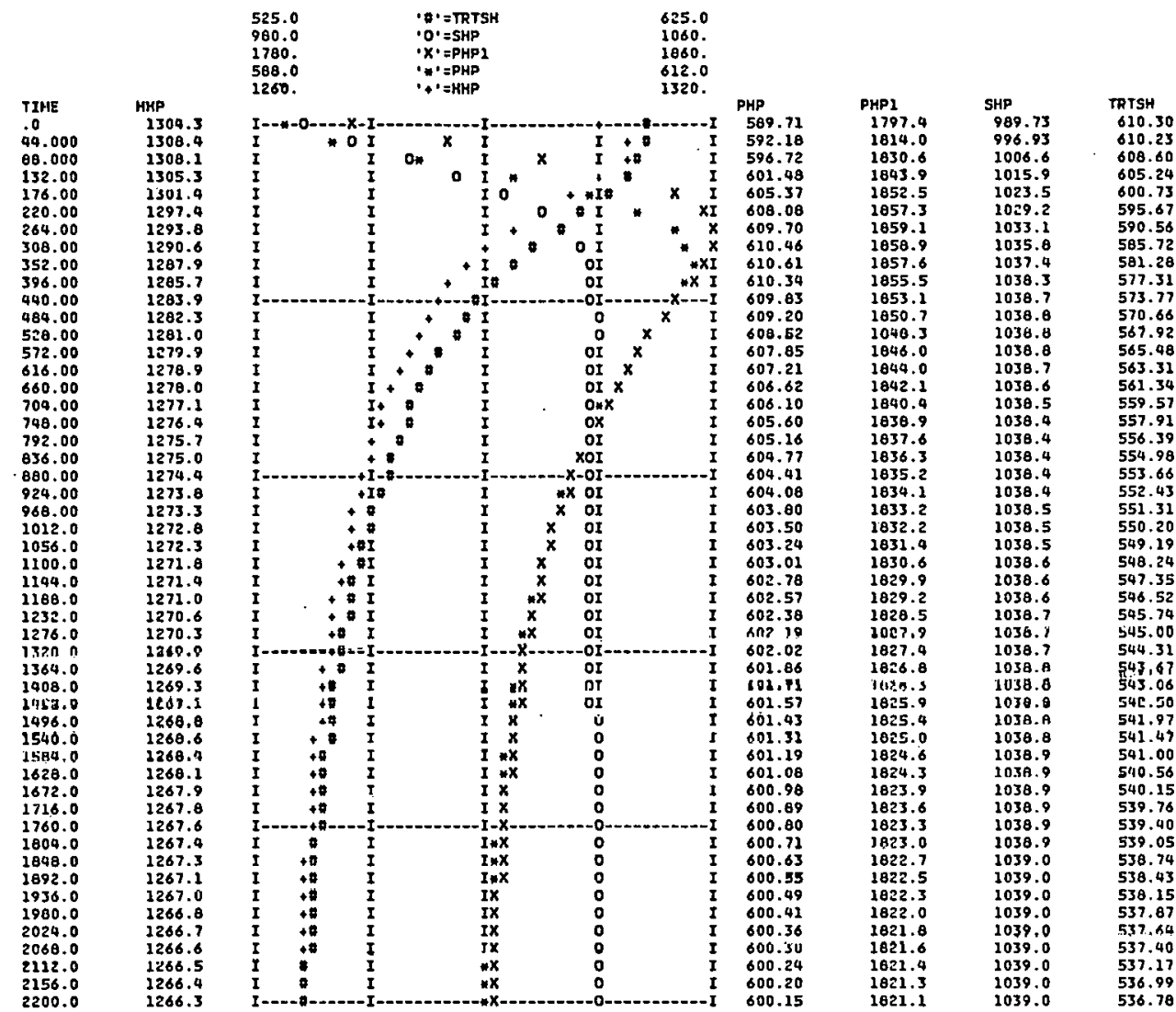

5 PERCENT STEP CHANGE IN FEedhater FLOM DEMAND

REHEATER LIRE gTates

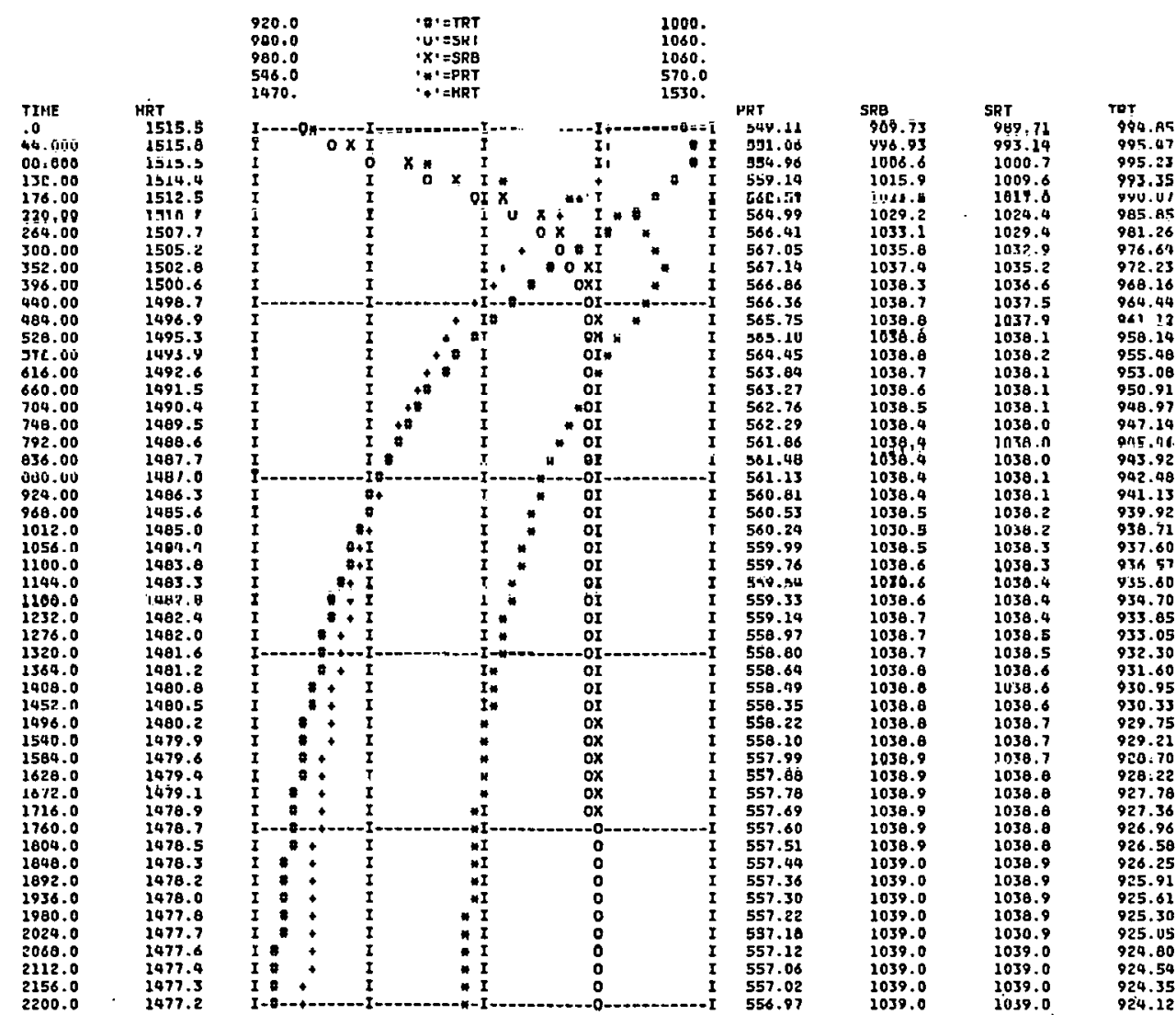




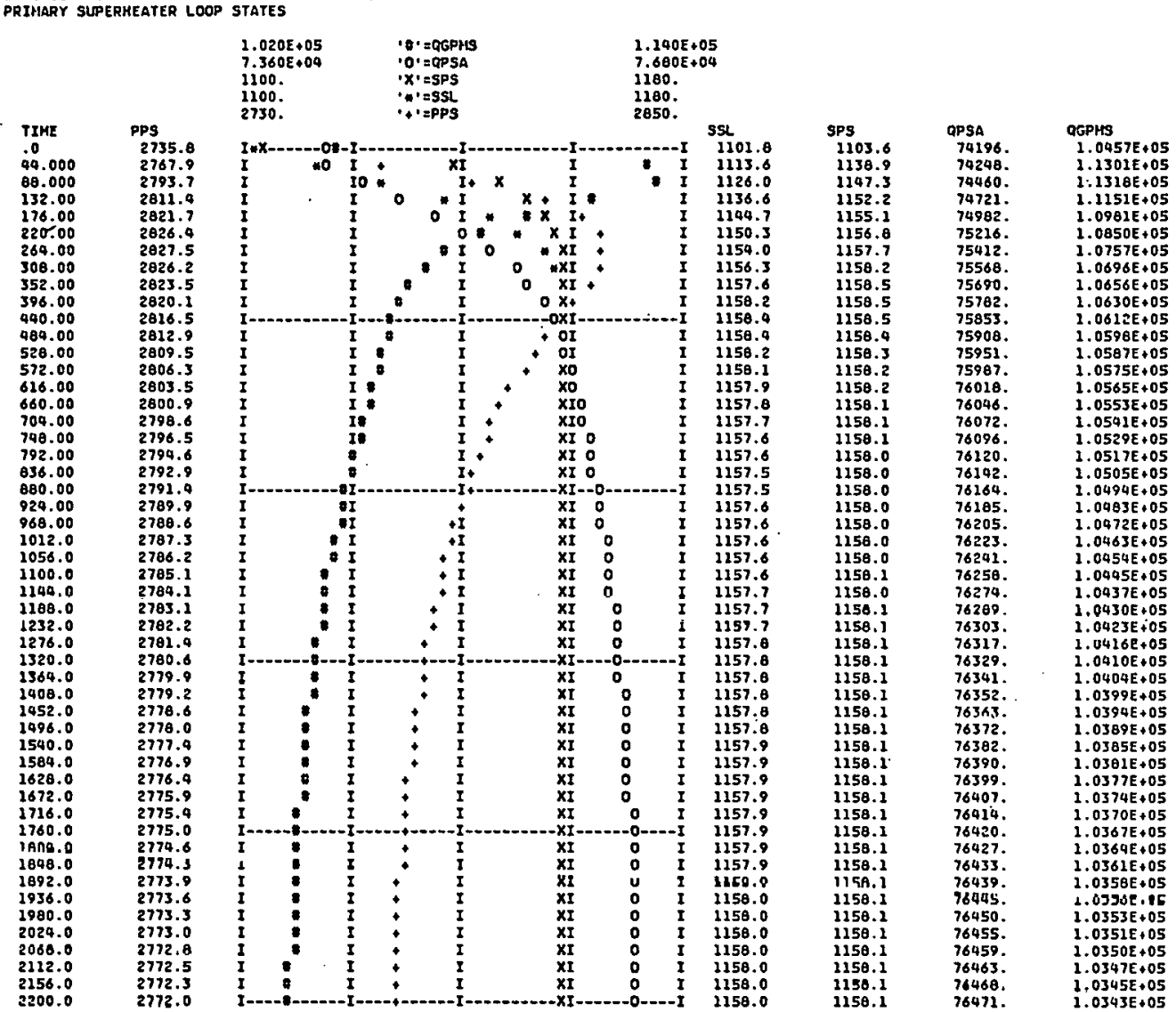

5 PERCENT STEP CHANGE IN FEEDHATER FLON DEMENO

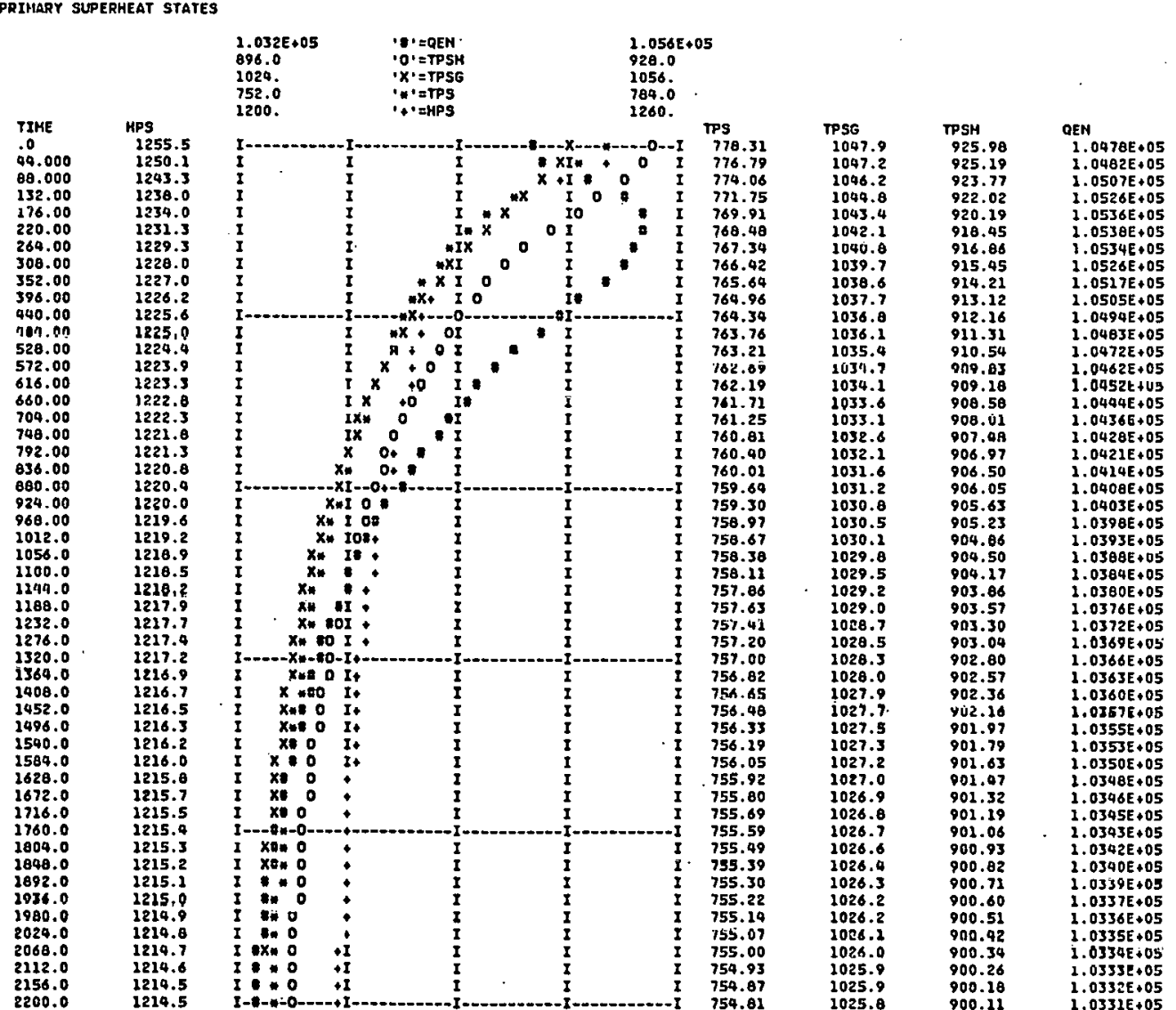




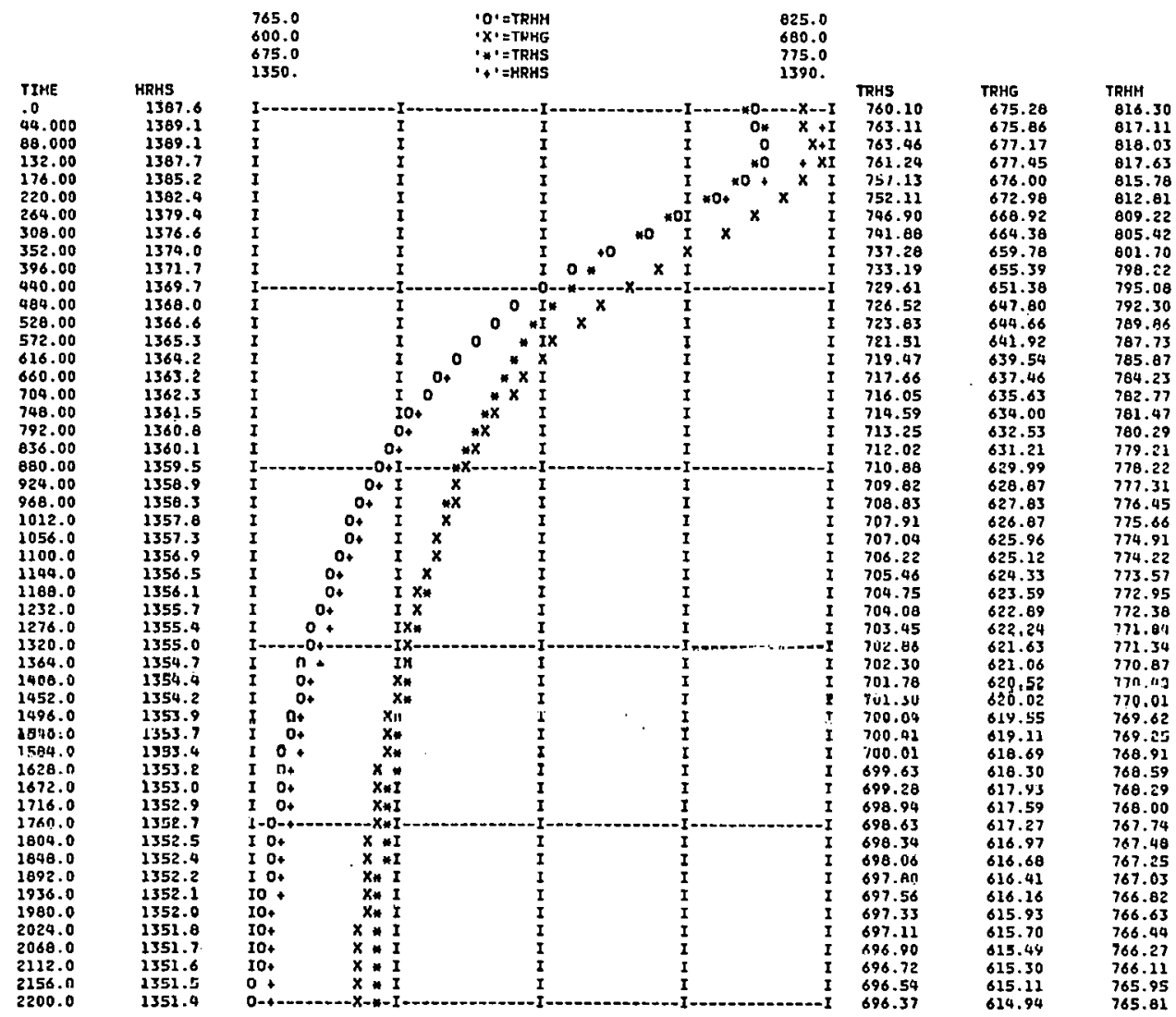

5 PERCENT STEP CHANGE IN FEEDHATER FLOH DEMAND

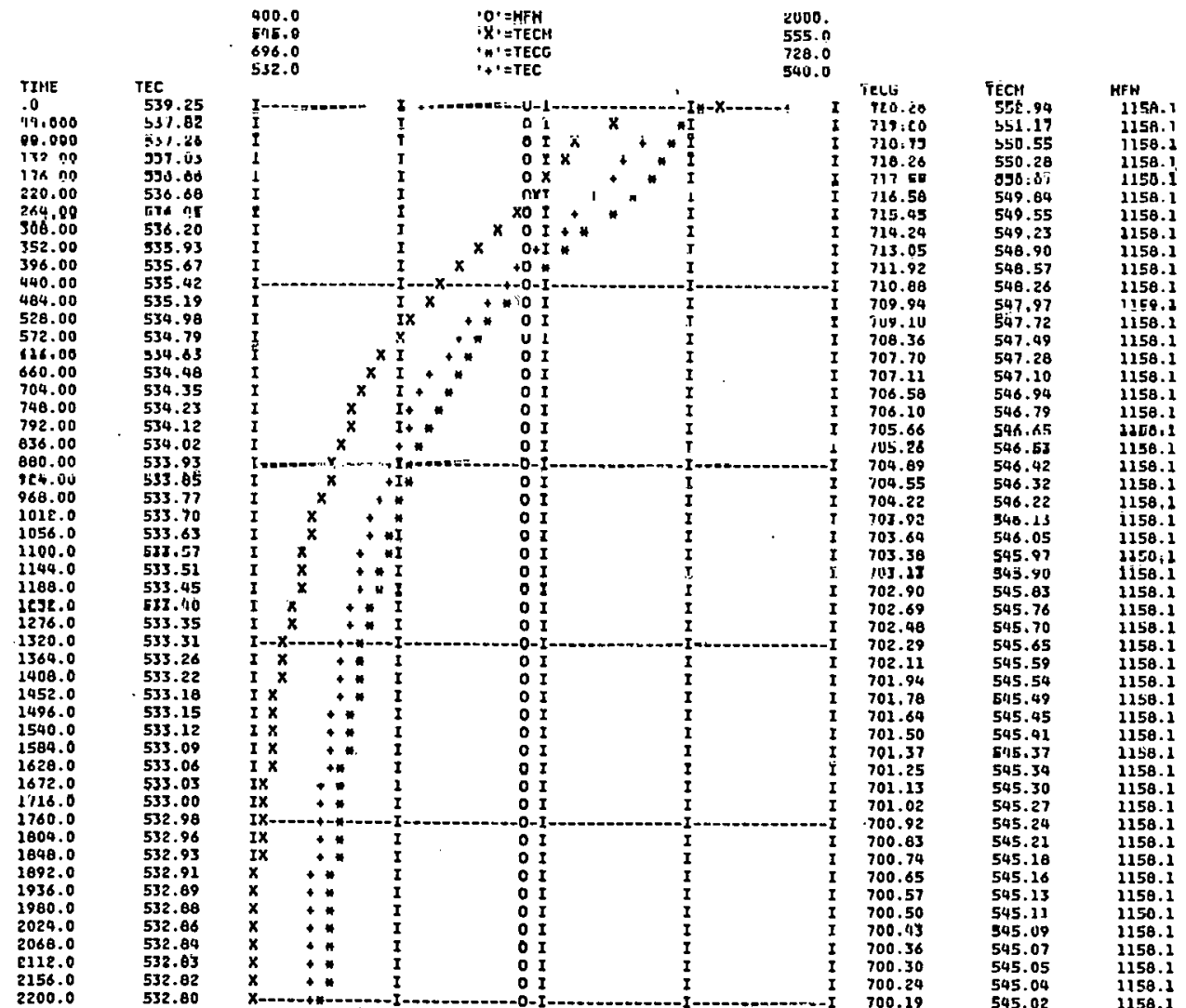


5 PERCENT STEP CHANGE IN FEEDHATER FLOH DEMAND
AIR HEATER STATES

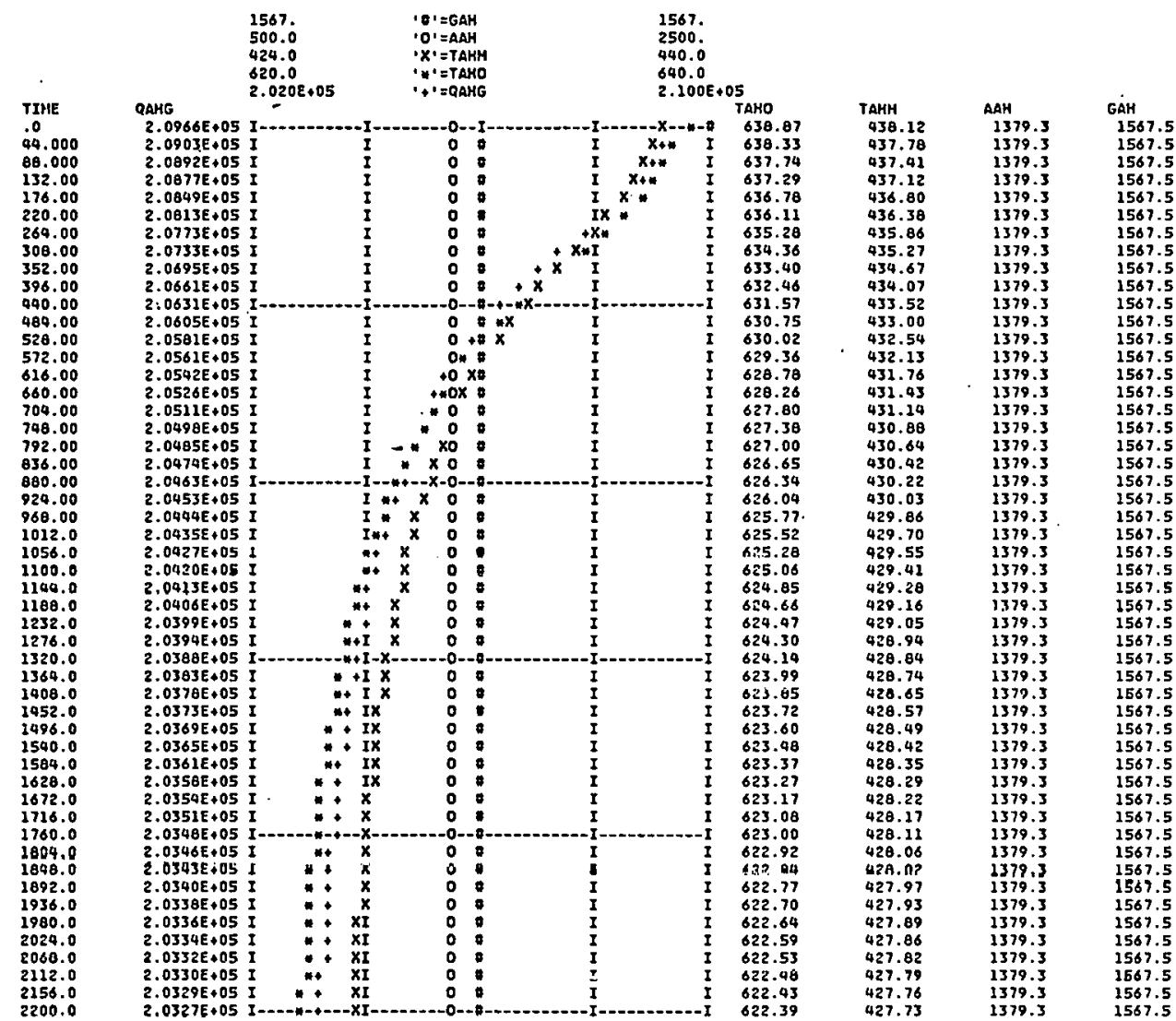

5 PERCENT STEP CHANGe IN fEeOHATER floh DEmaND Gas PaTH STATES

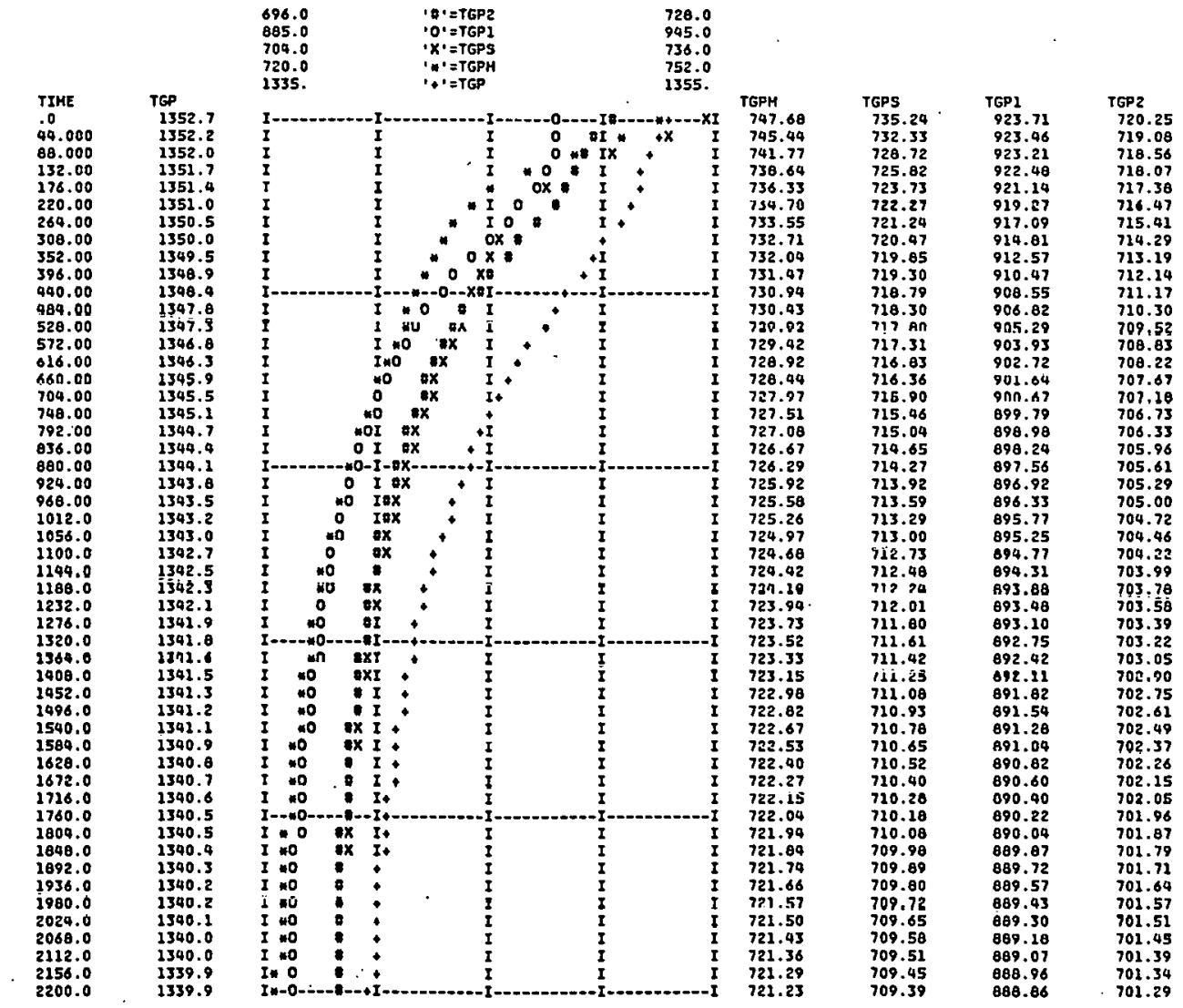




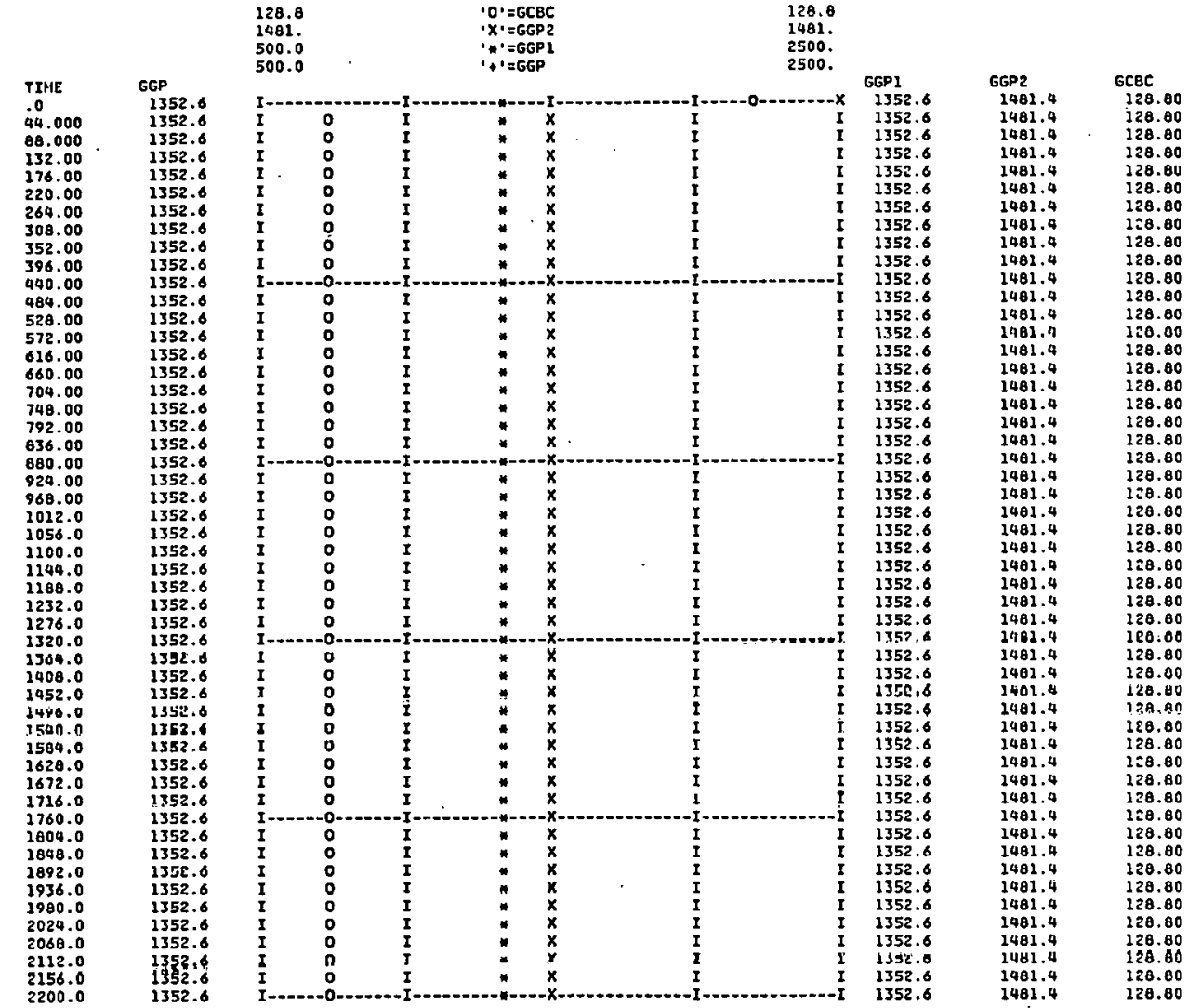

5 PERCENT STEP CHANGE IN FEEDHATER FLOH DEHANO INTEGRATION TIHE PATTER

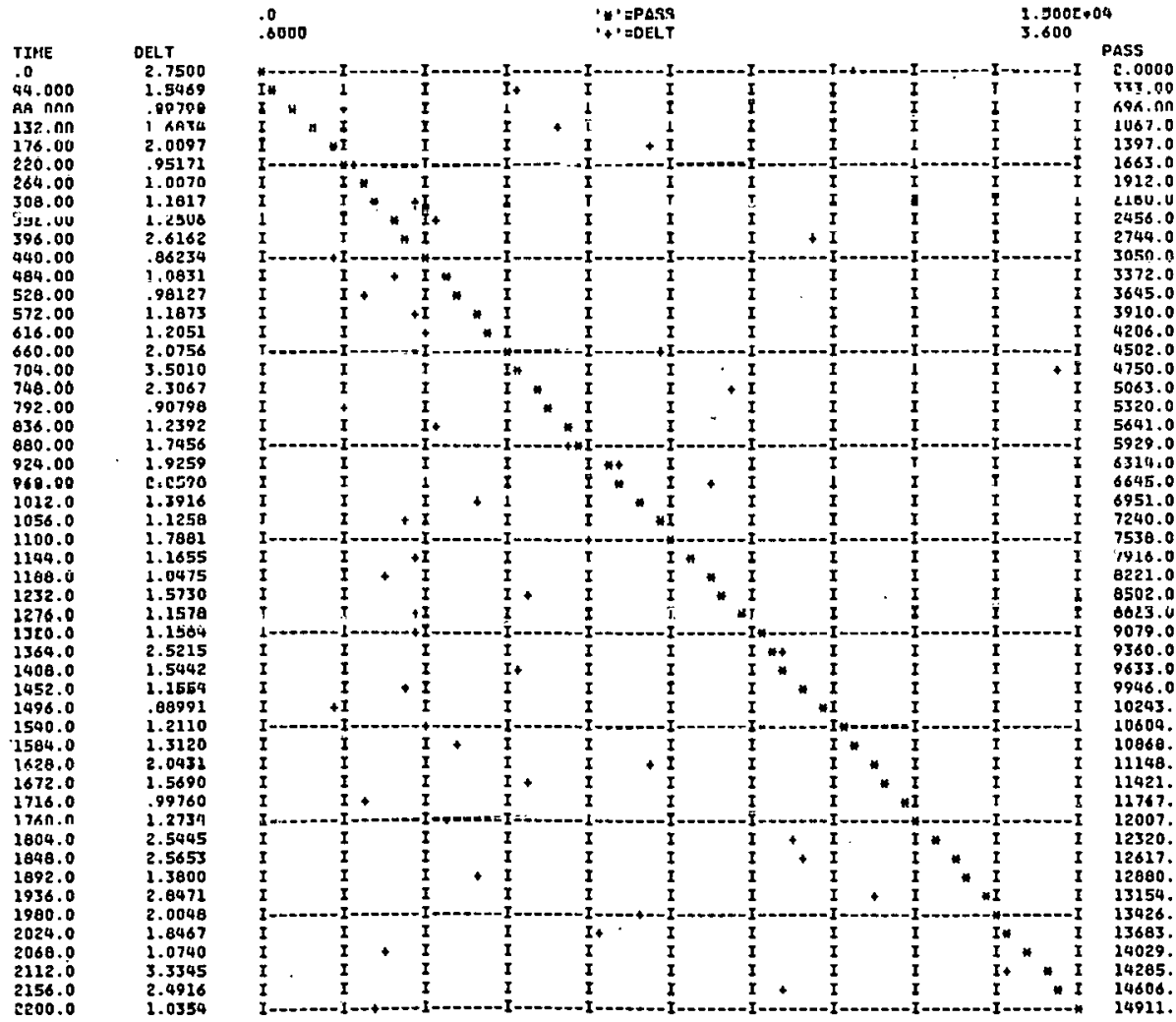


5 PERCENT STEP CHANGE IN FEedMater FLOM DEMANO

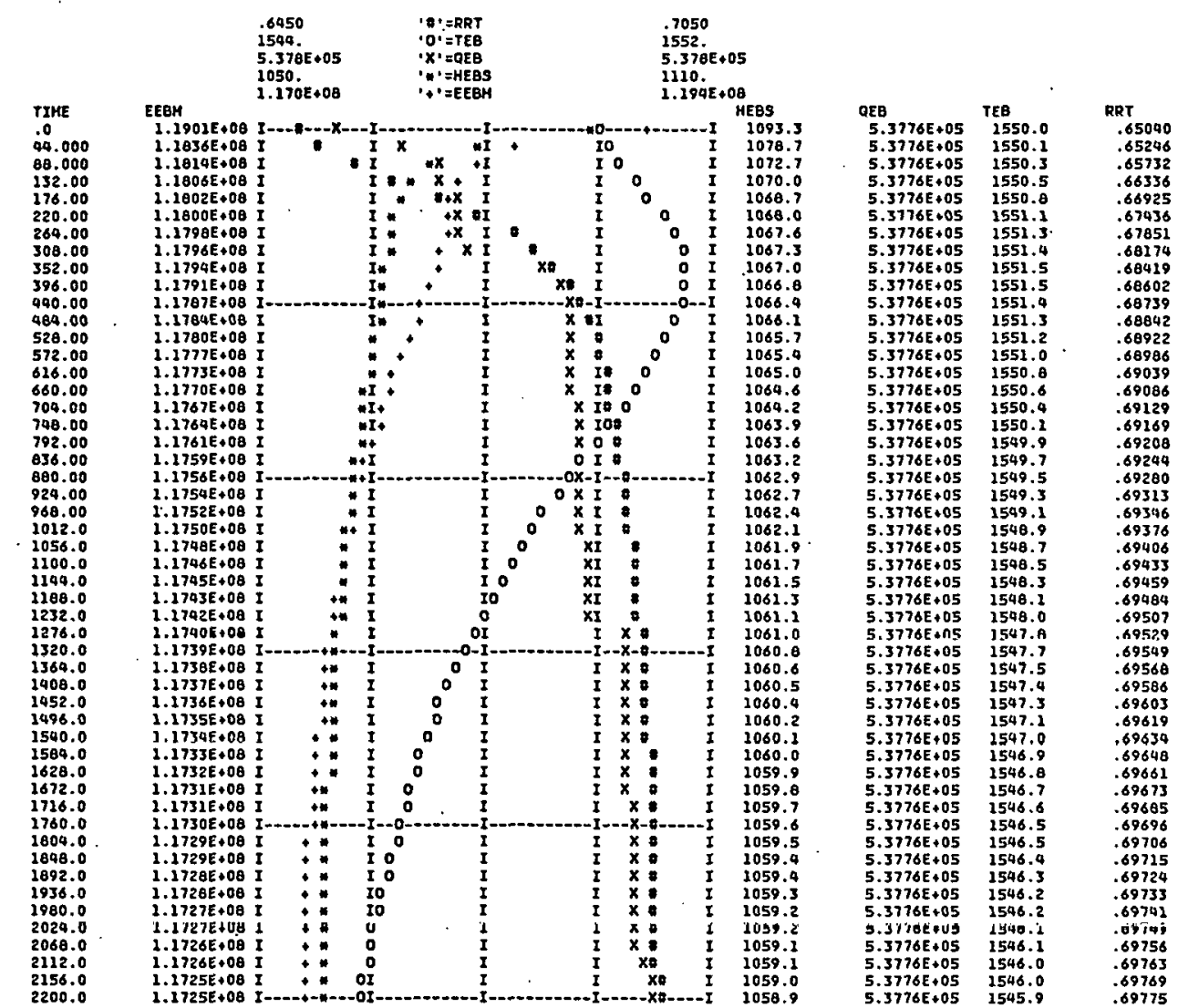

S PERCENT STEP CHANGE IN FEEOMATER FLOH DEHANO

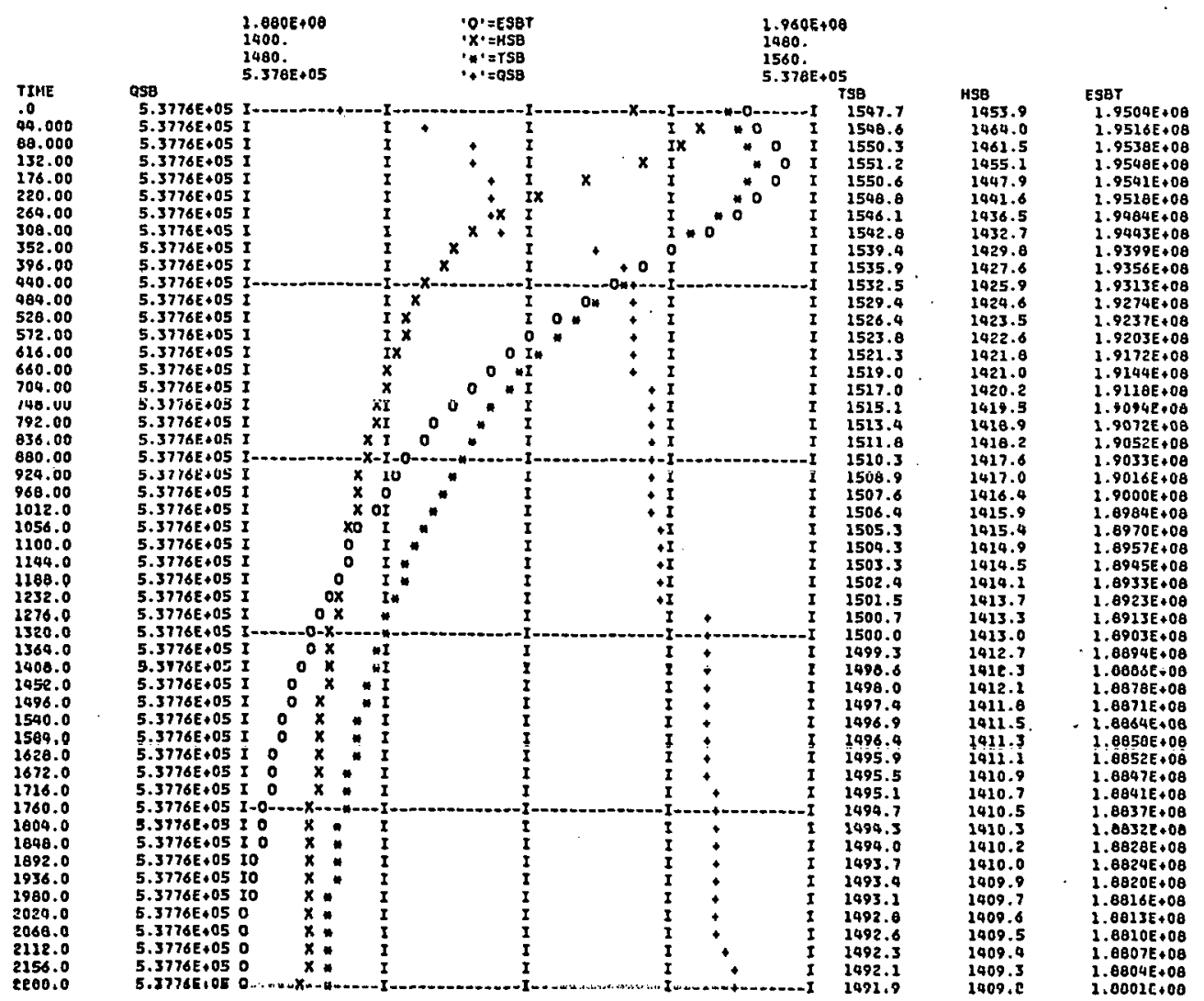


5 PERCENT STEP CHANGe IN FEedhater flow OEMAND

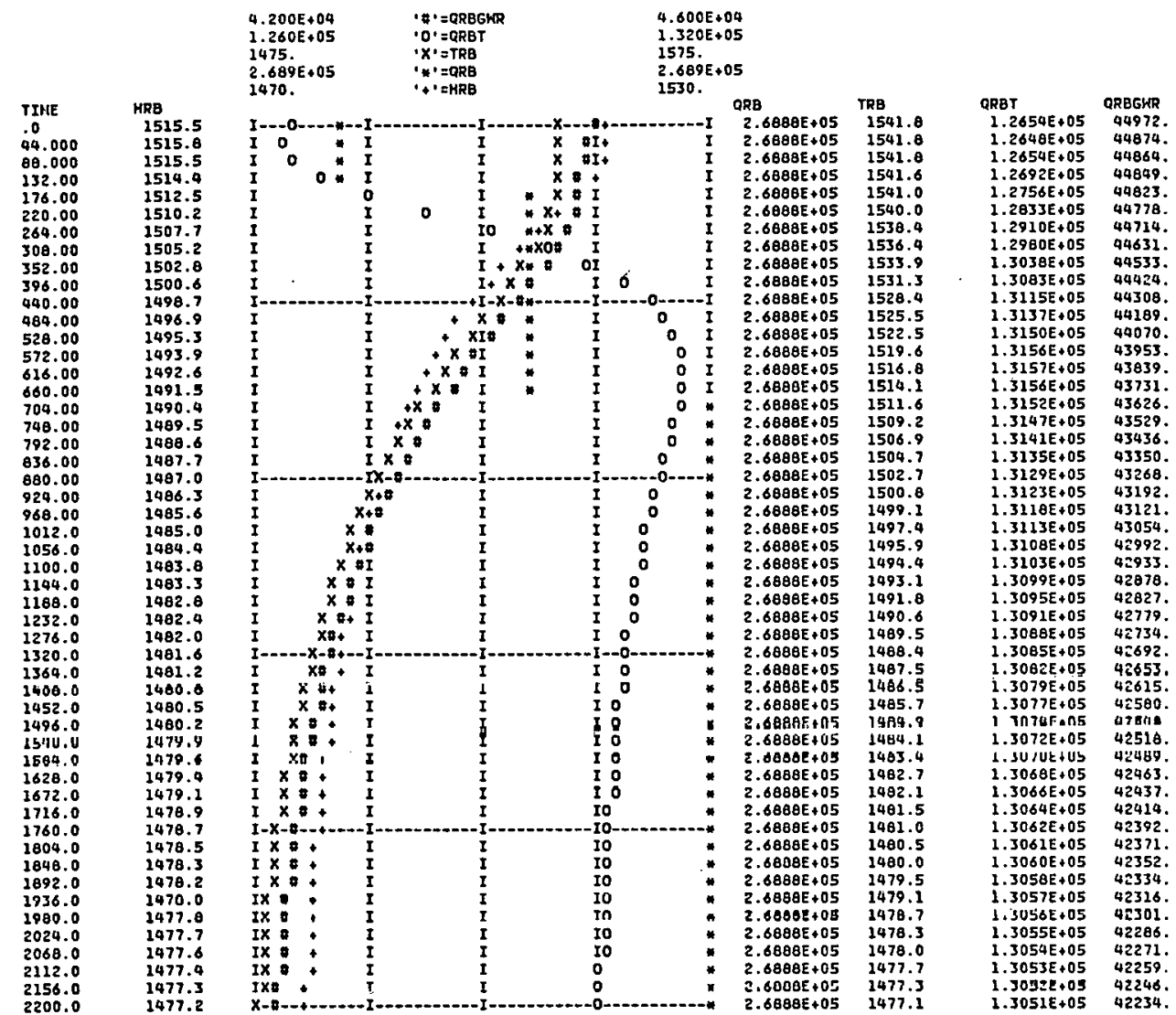

5 PERCENT STEP CHANGE IN fEedhater FLom DemaNo

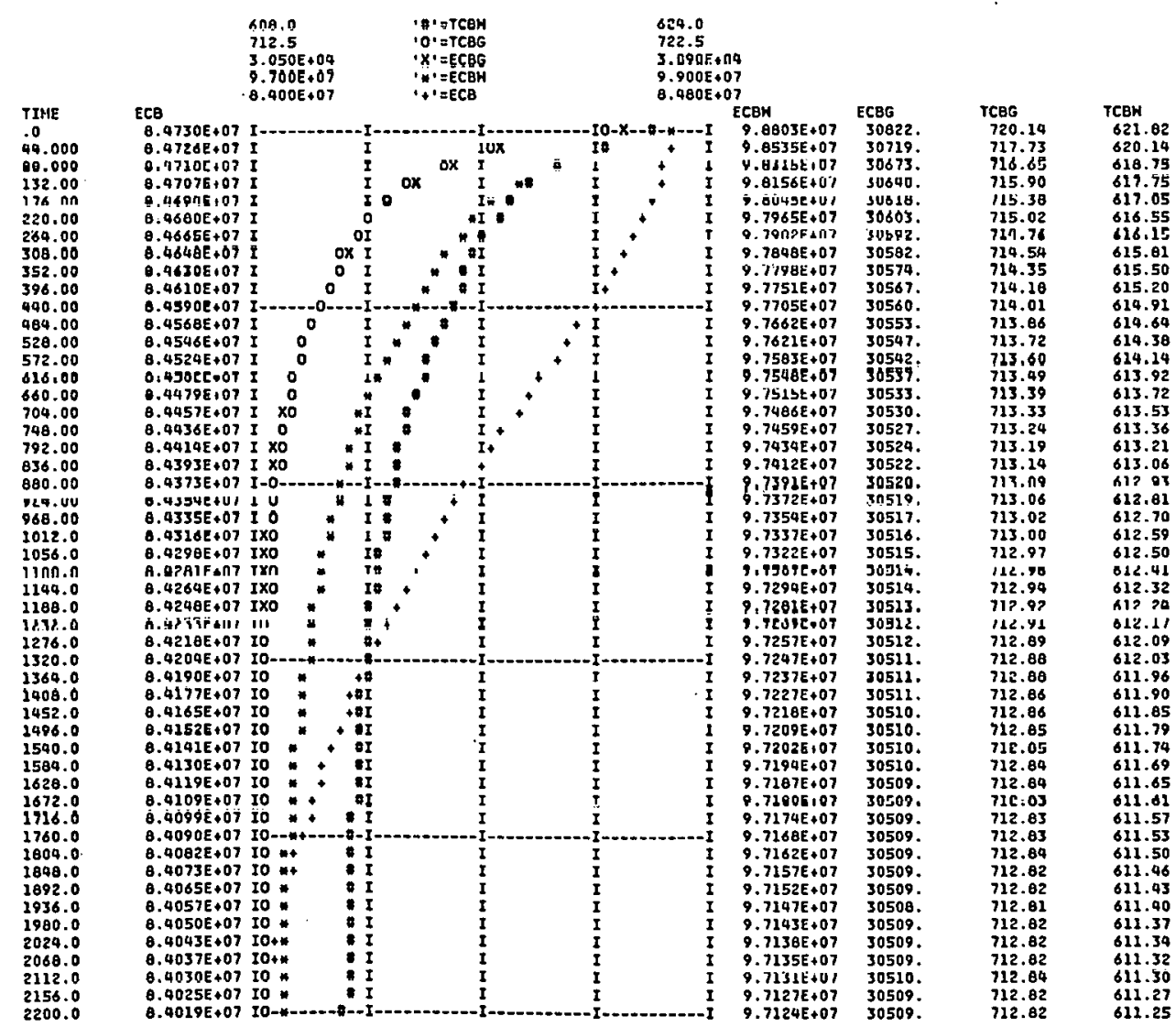


5 PERCENT STEP CHANGE IN FEEOHATER FLON OEMANO

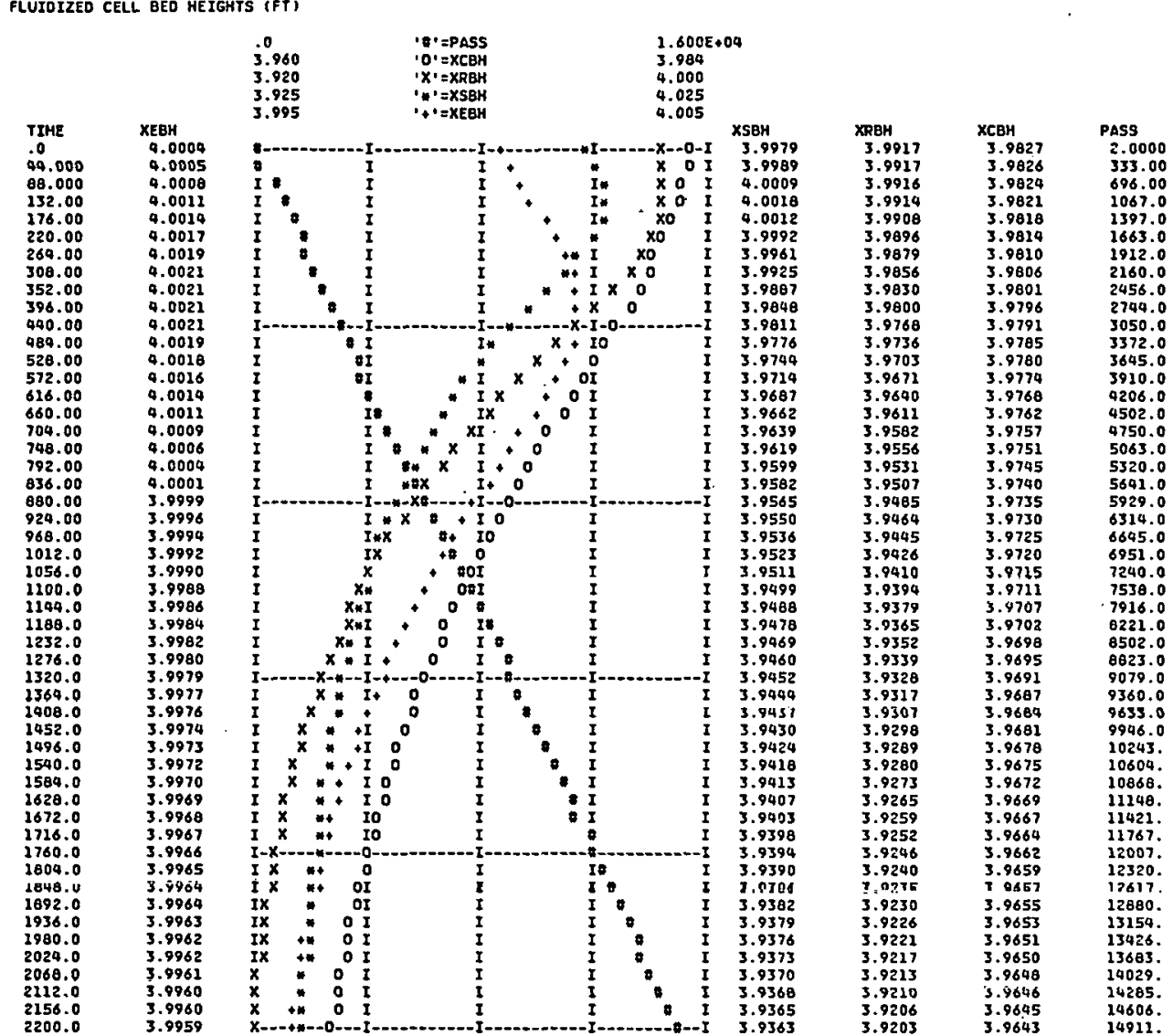

5 PERCENT STEP CHANGE IN FEEDHATER FLOH DEMANG

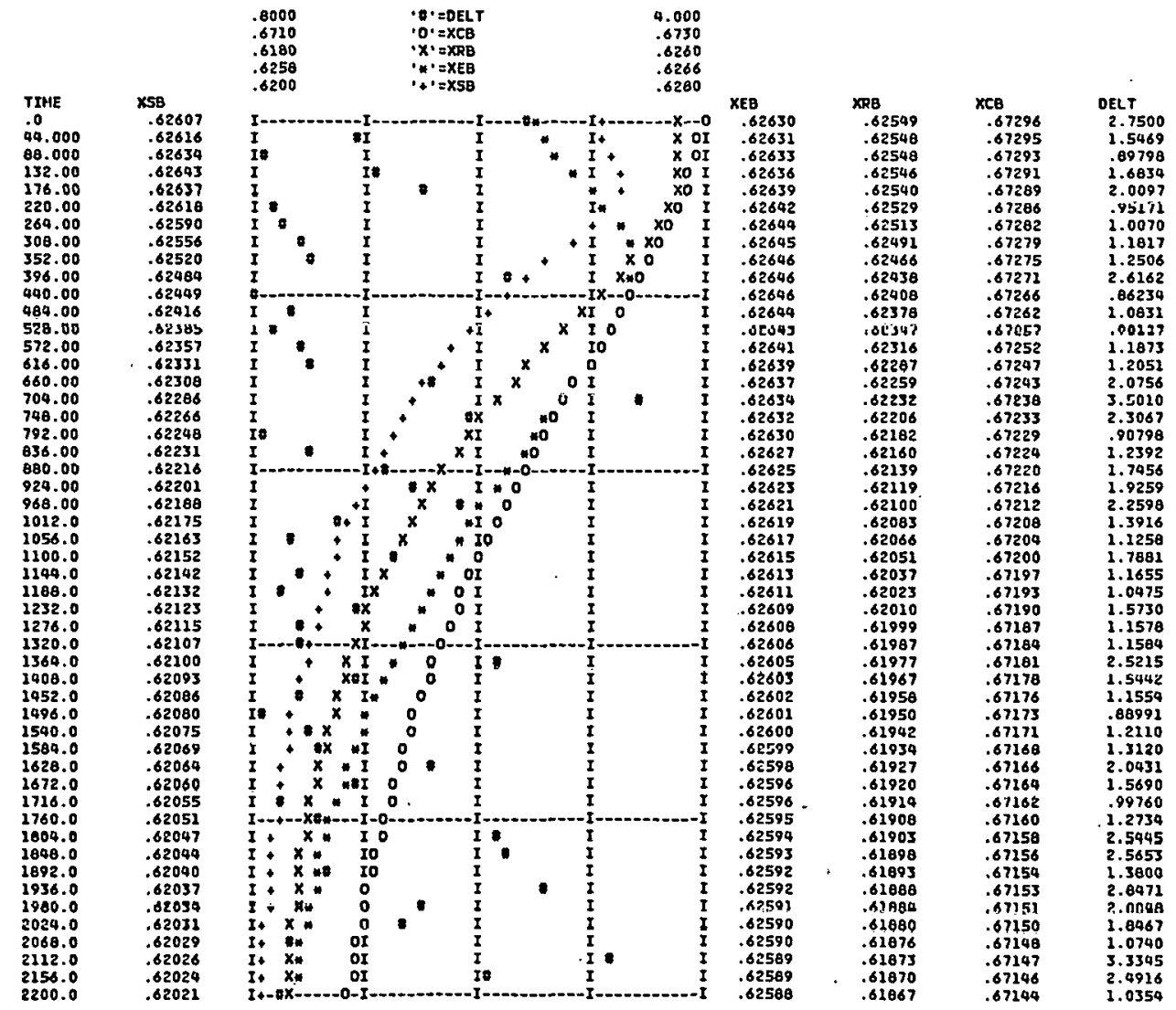


5 PERCENT STEP Change IN feedhater flow demand

PERT GAS TEMPERATURES

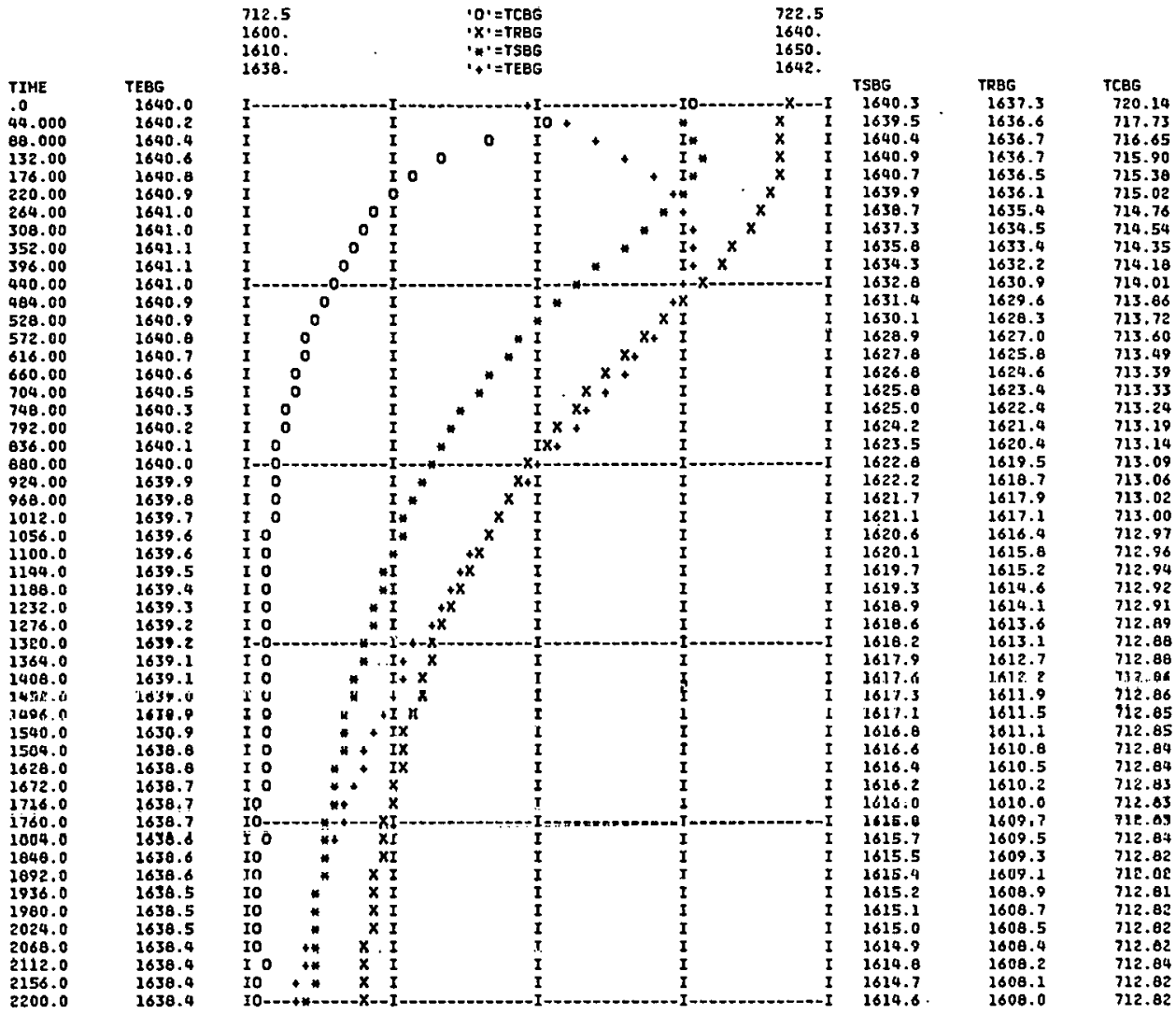

5 PERCENT STEP CHANGE IM FEEDHATER FLON DEHANO

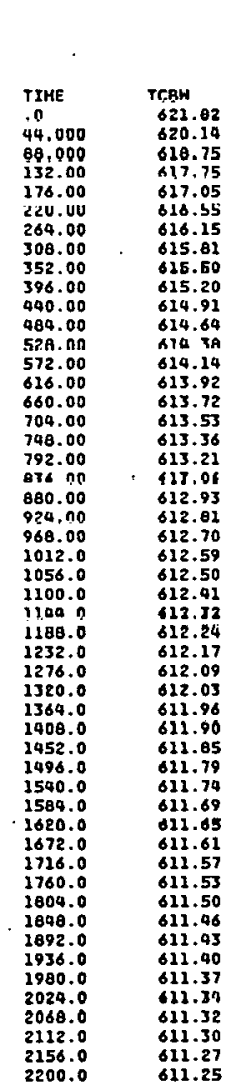

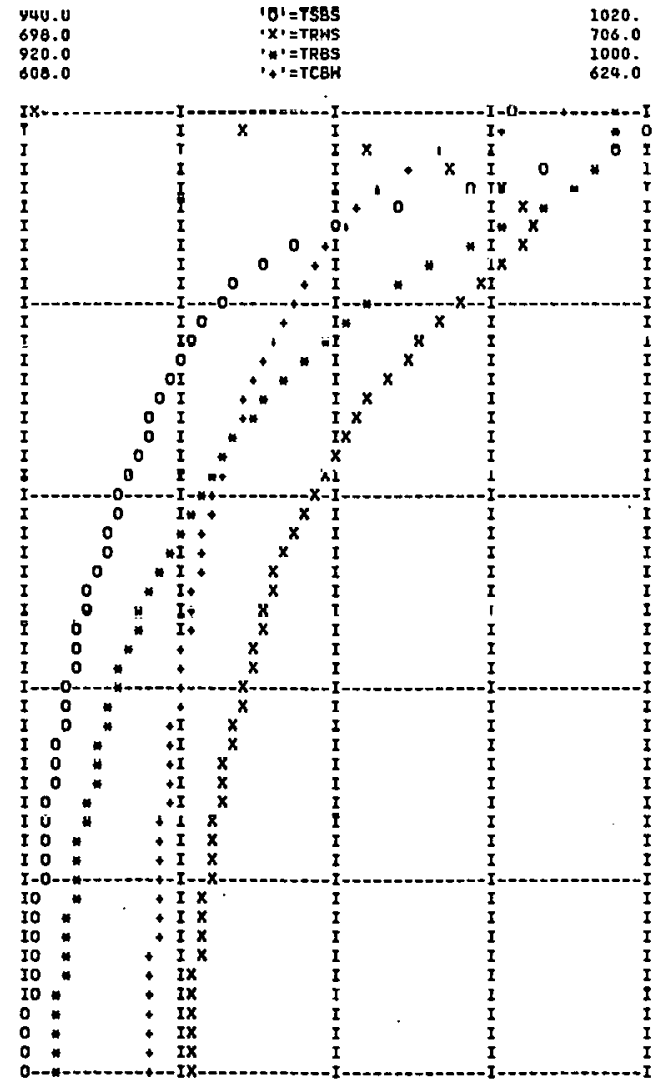

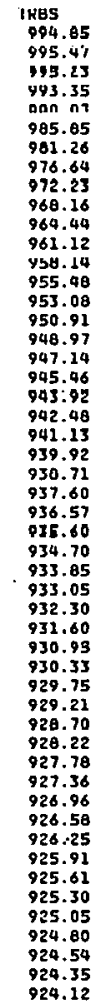

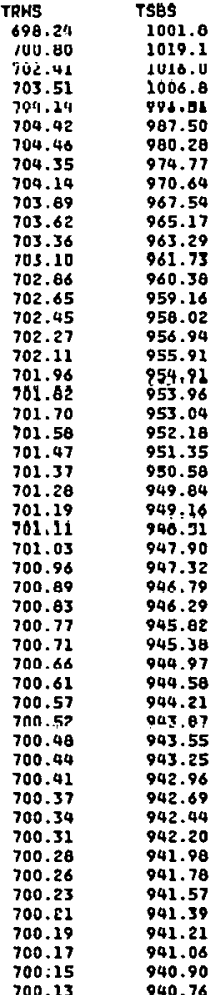



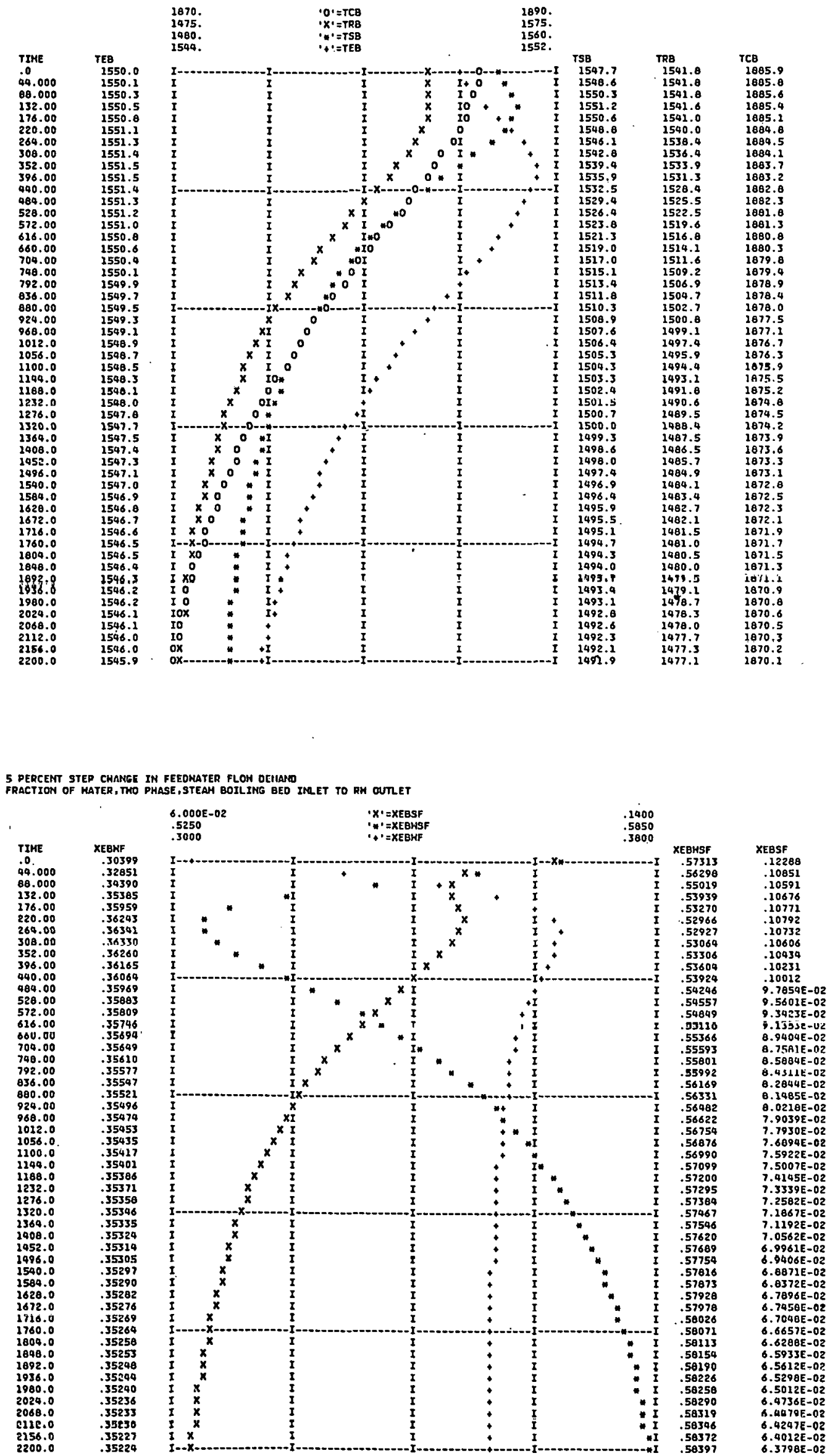
5 PERCENT STEP CHANGE IN FEEDHATER FLOW DEMANO

NET WATER AND TNO PHASE FLOW INVENTORIES

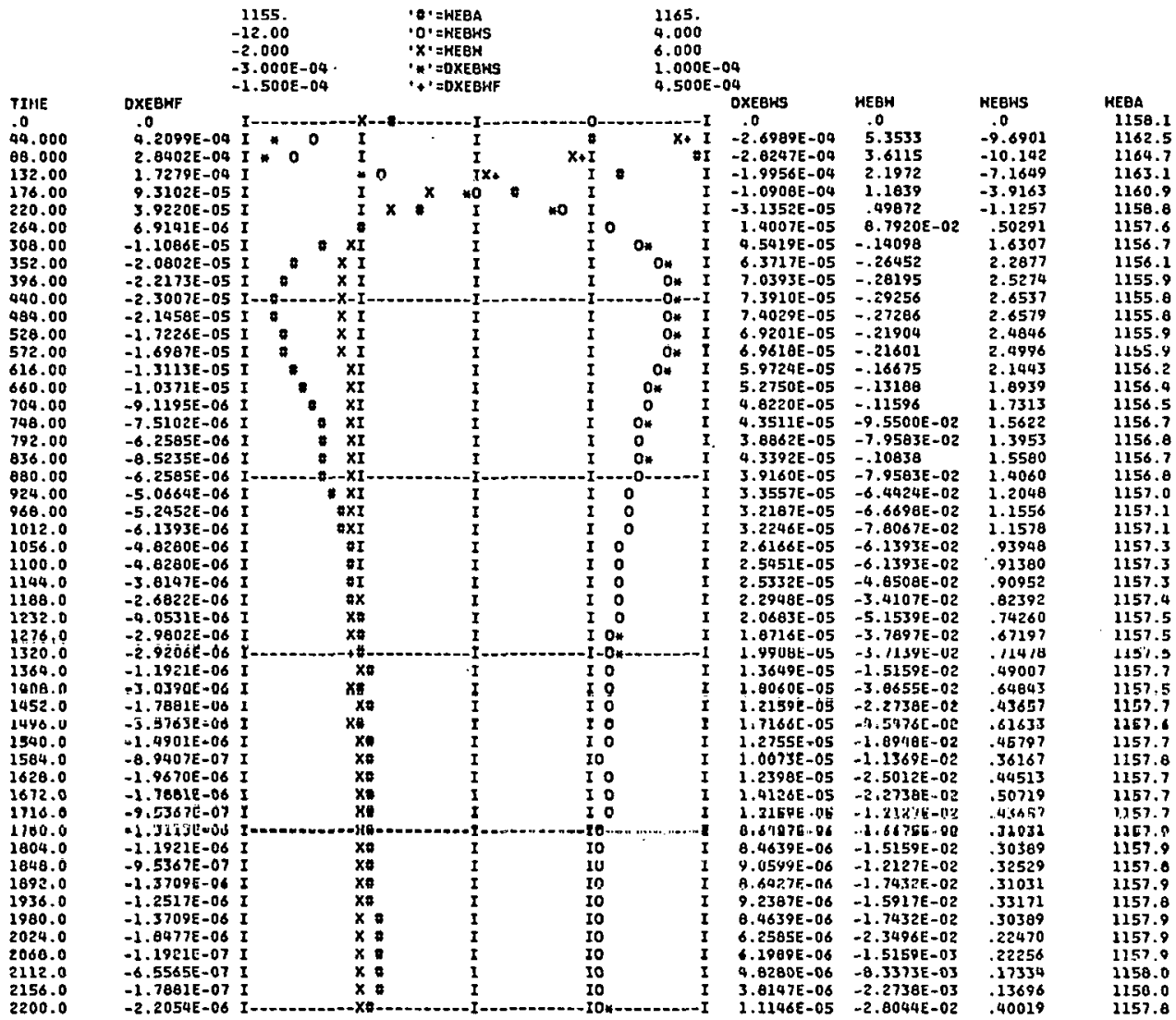

5 PERCENT gTer chance in fEeohater flok ofmand

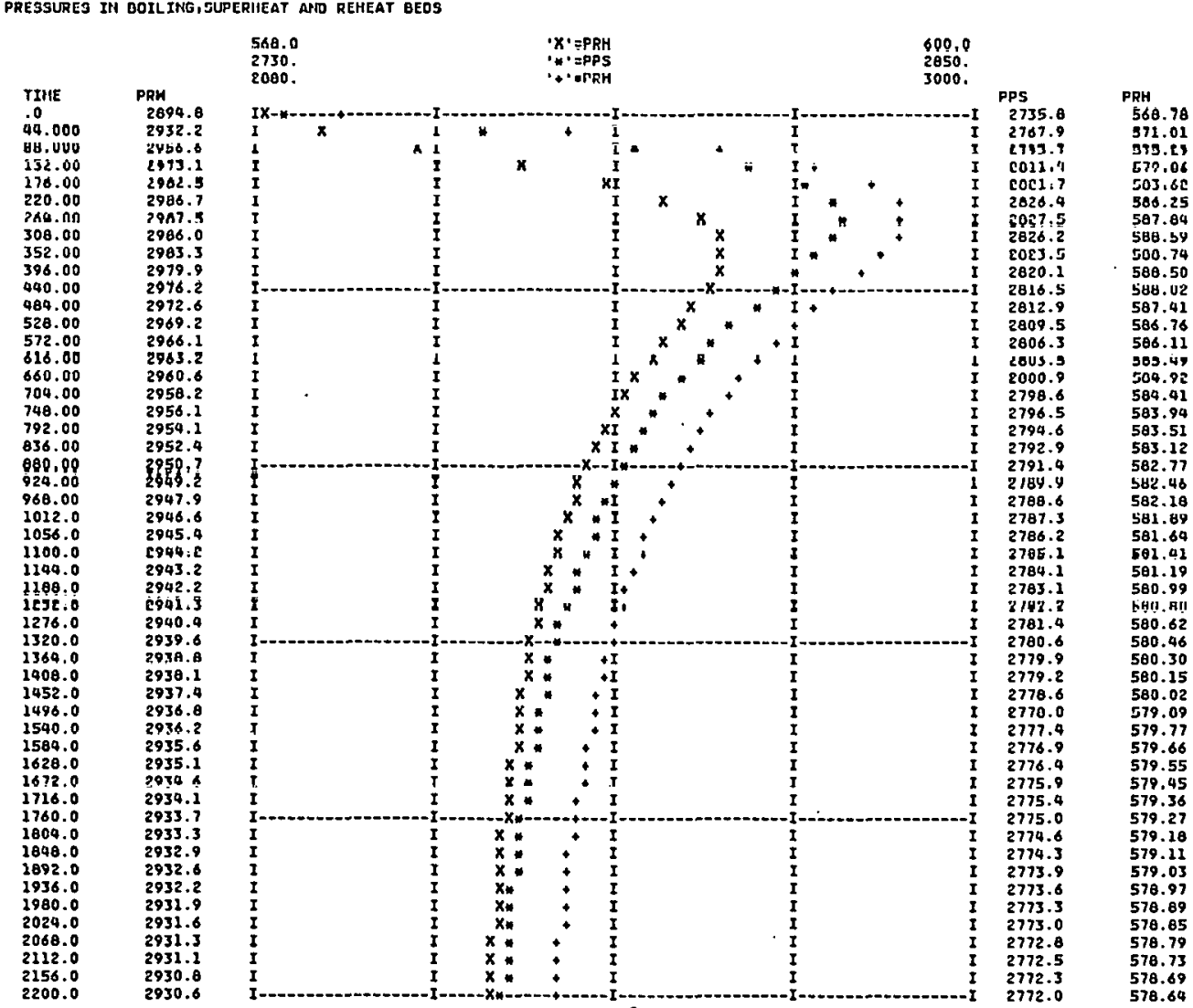




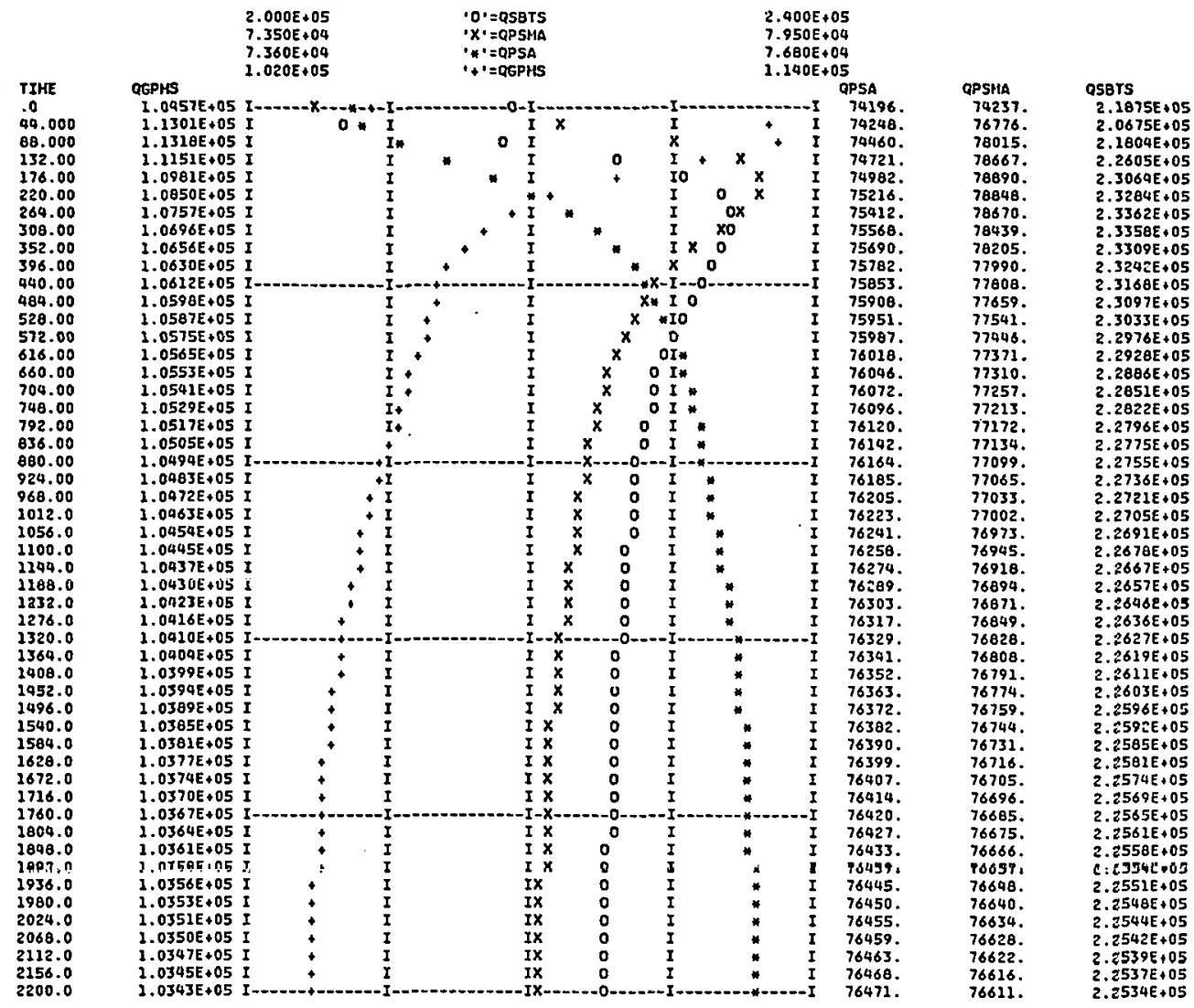

5 PERCENT STEP CHANGe IN fEedhater flon derand

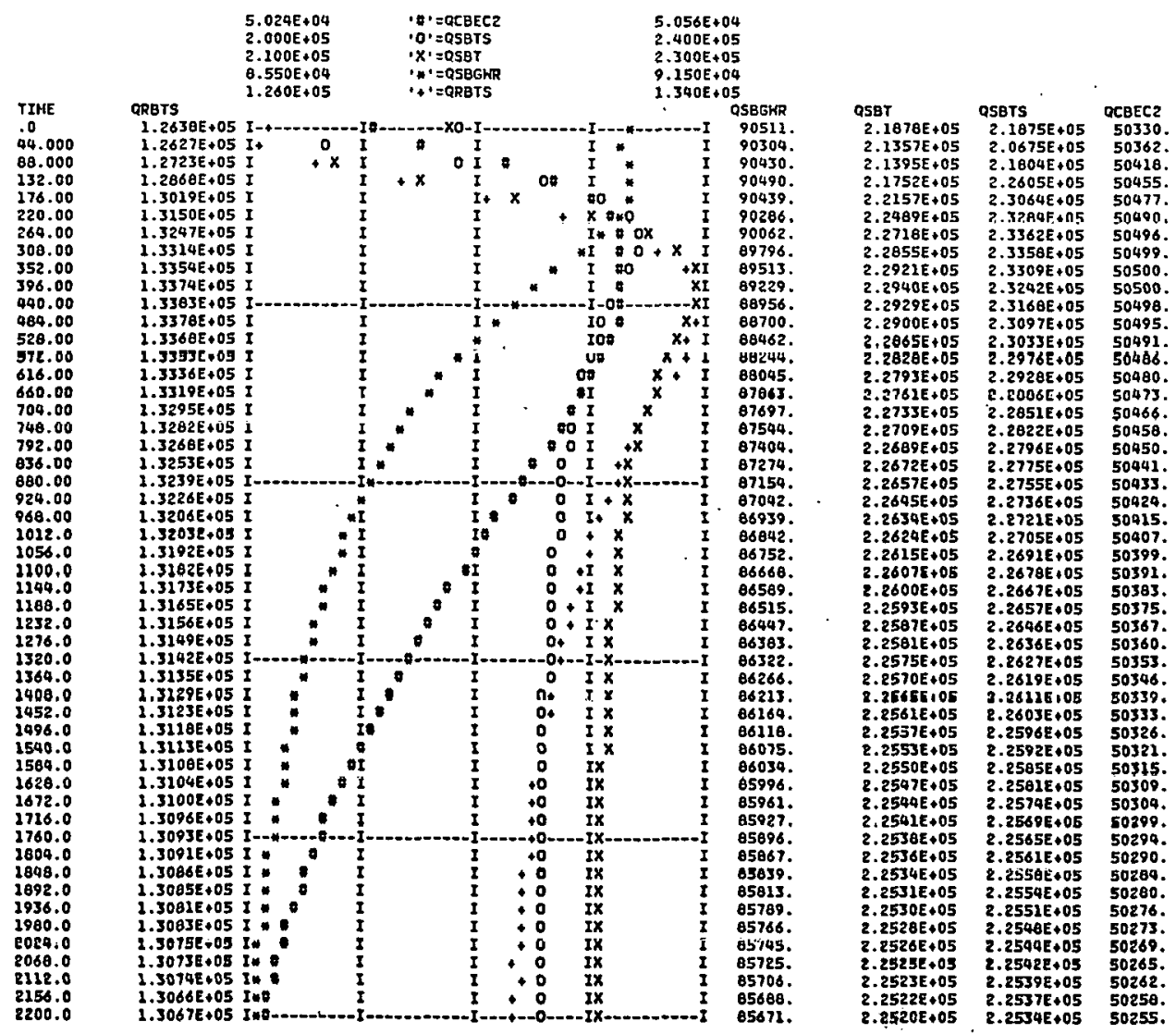




\section{THIS PAGE}

\section{WAS INTENTIONALLY LEFT BLANK}




\section{APPENDIX $\quad \mathrm{V}-\mathrm{B} 7$ \\ STEP IN THROTTLE VALVE POSITION}

This section presents the detailed results in CSMP plot format for a $5 \%$ step increase in throttle valve position. 


\section{THIS PAGE}

\section{WAS INTENTIONALLY}

LEFT BLANK 


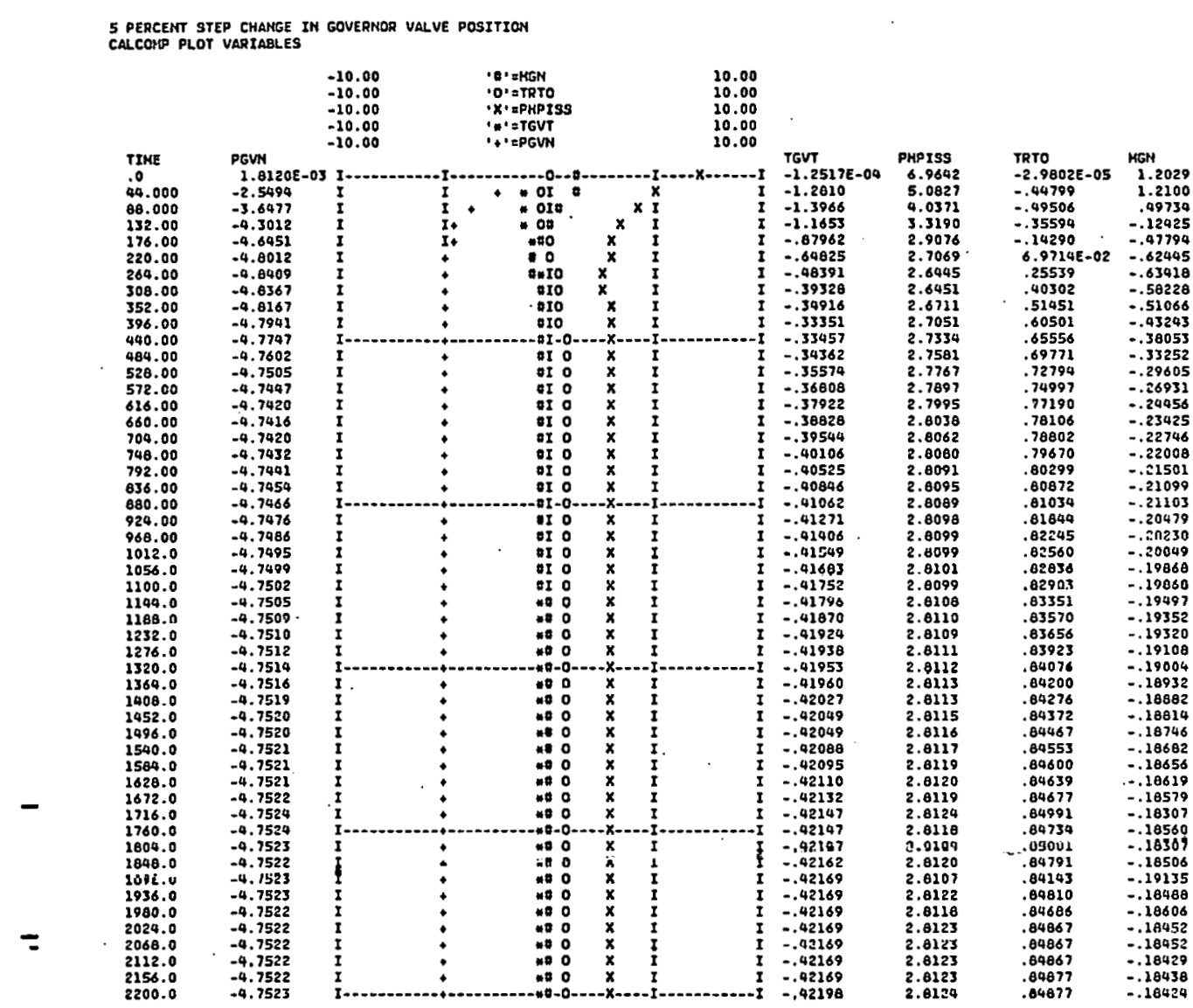

II

3 PERCENT STEP CHANGE IN GOVERNOR VALVE POSITIOA STCAH LINE TO HP TURBINE VARIABLES

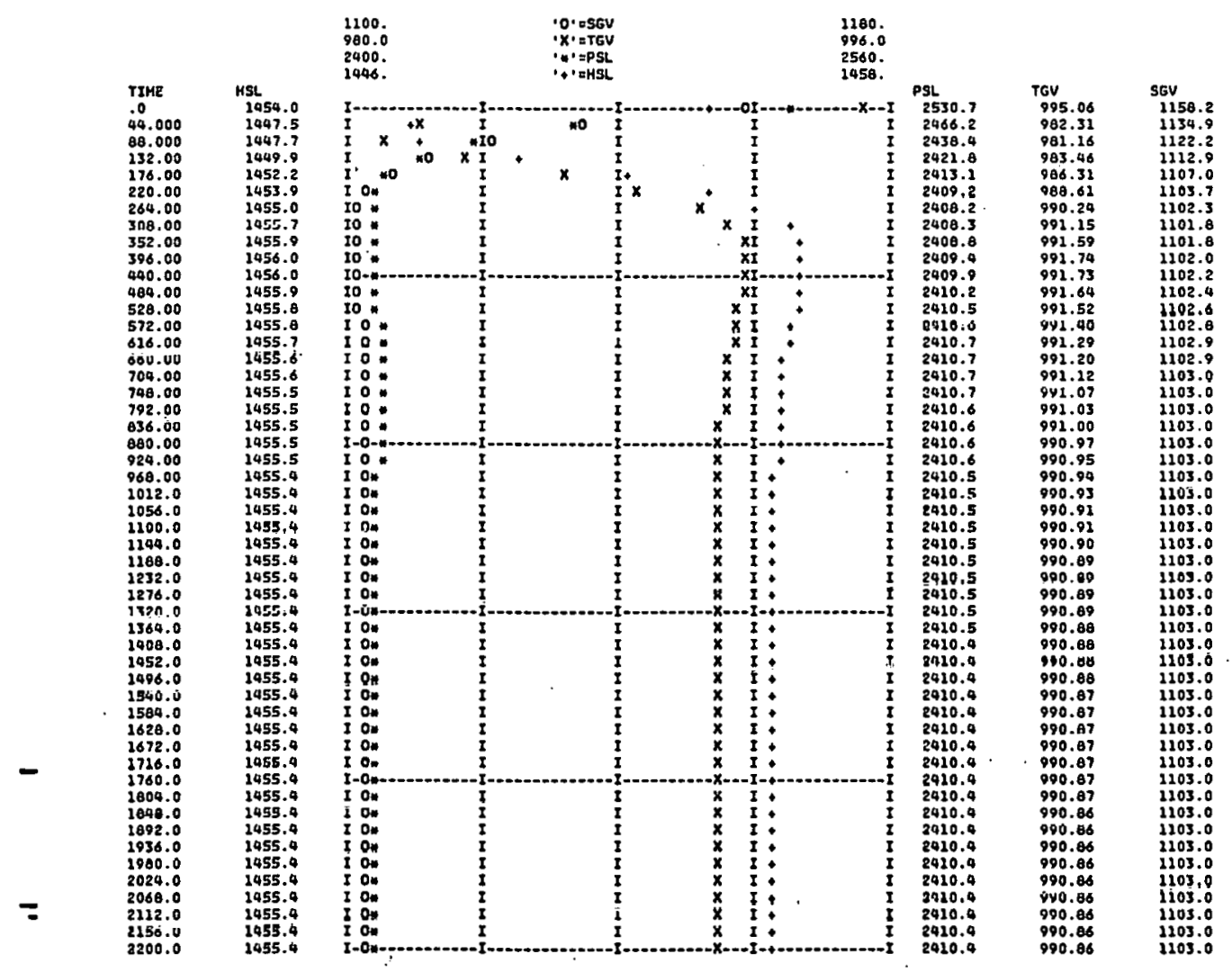

103 


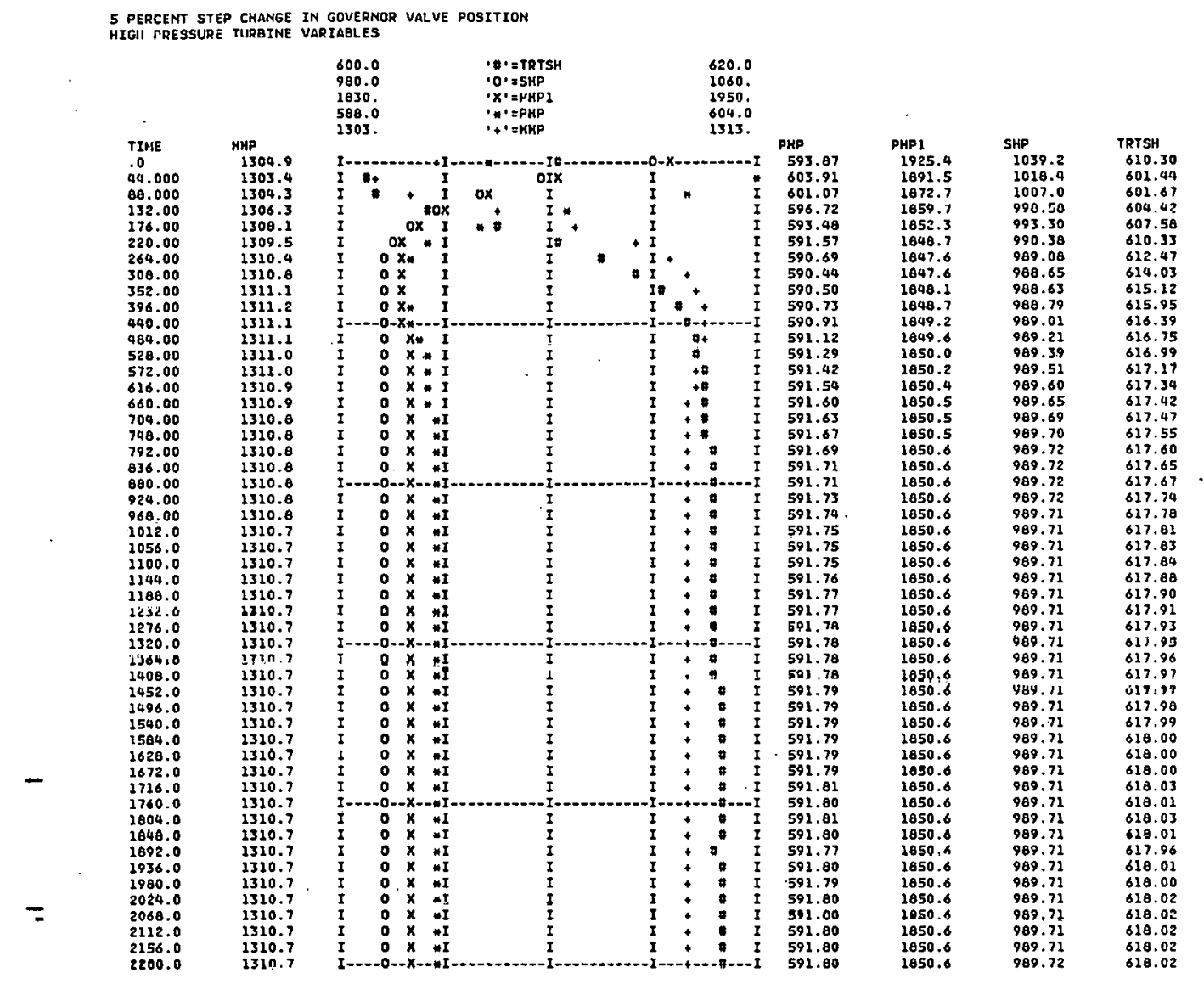

II

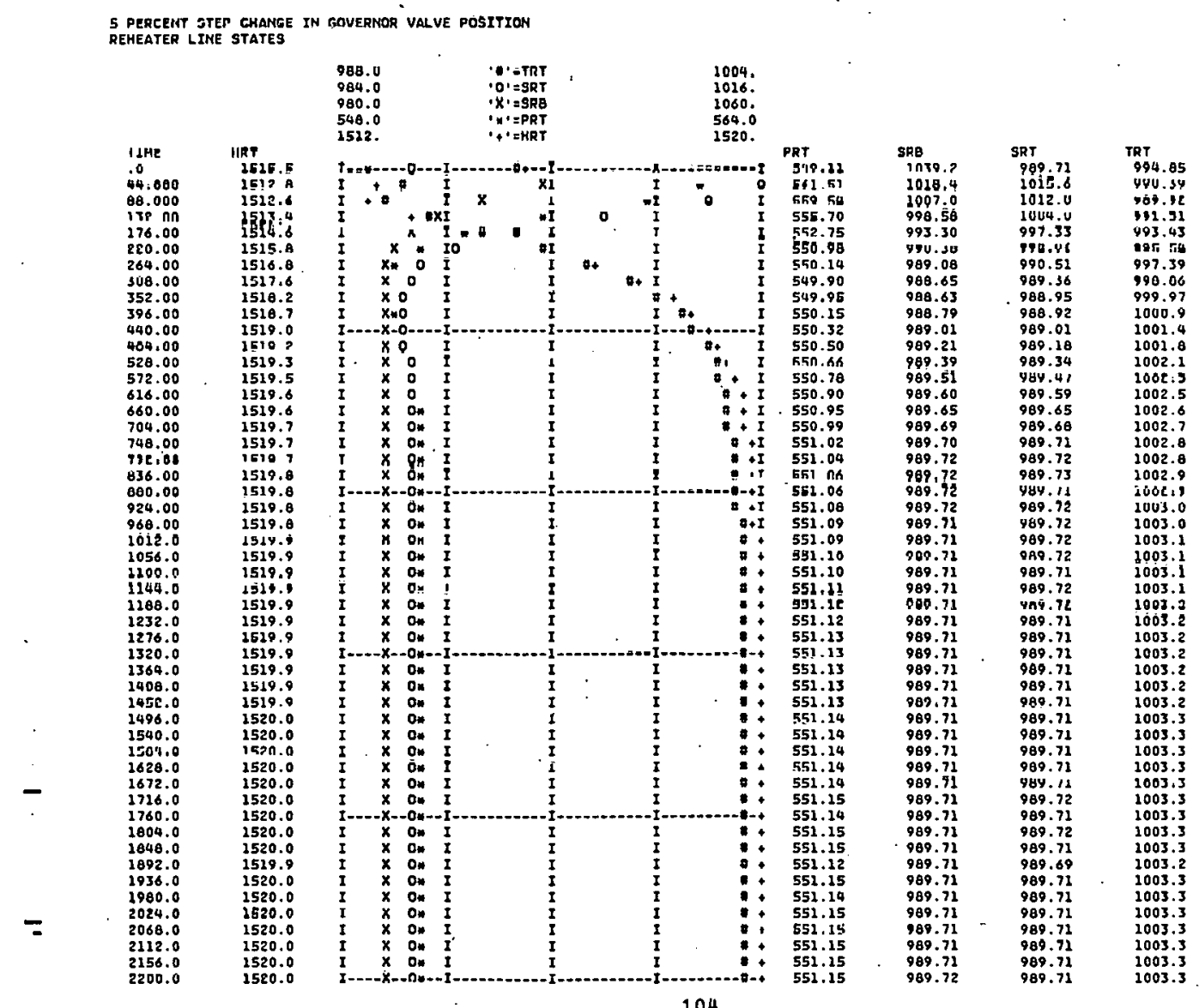




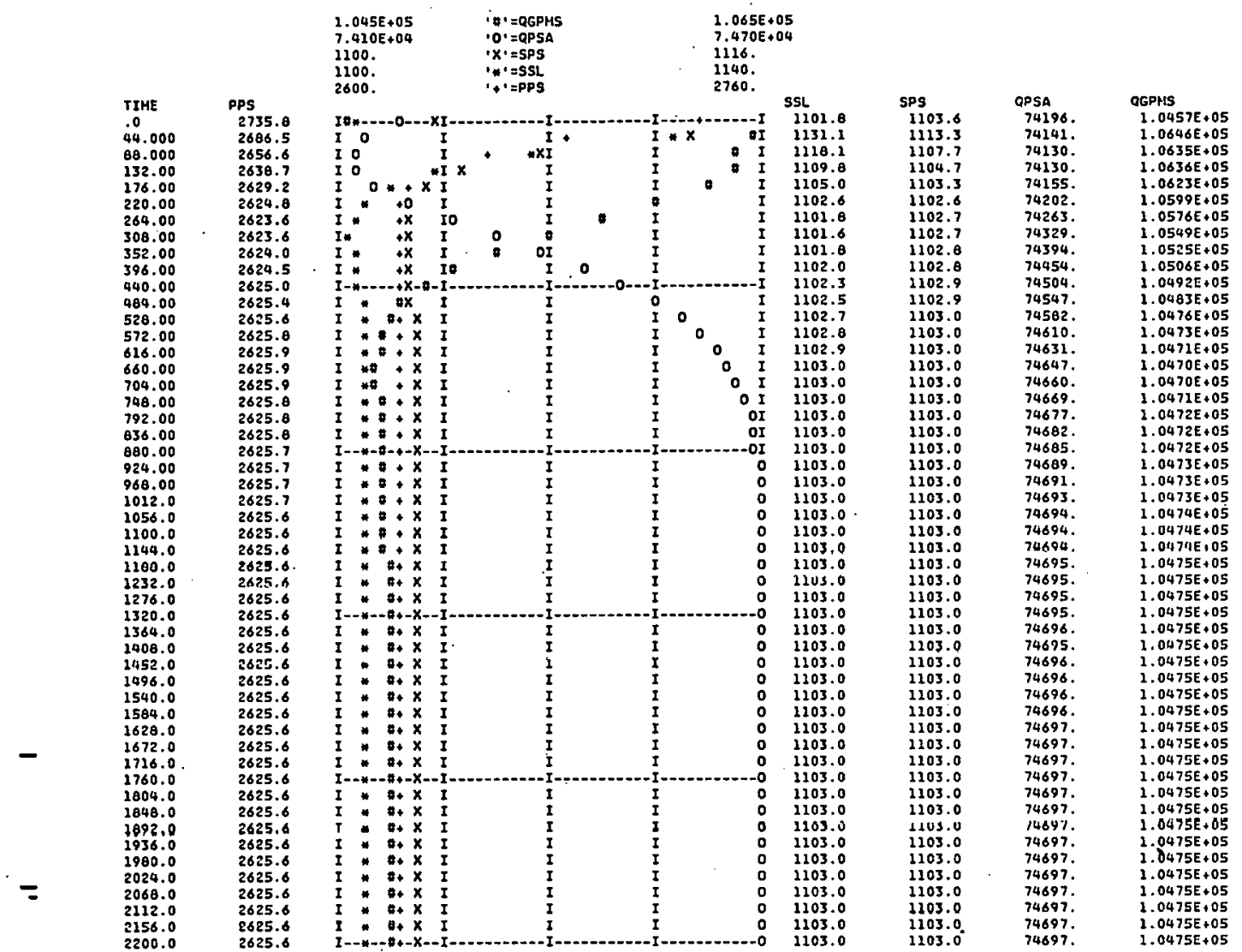

5 PERCENT STEP CHANGe IN GOVERNOR VALVE POSITION

PRIHARY SUPERHEAT STATES

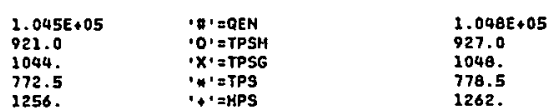

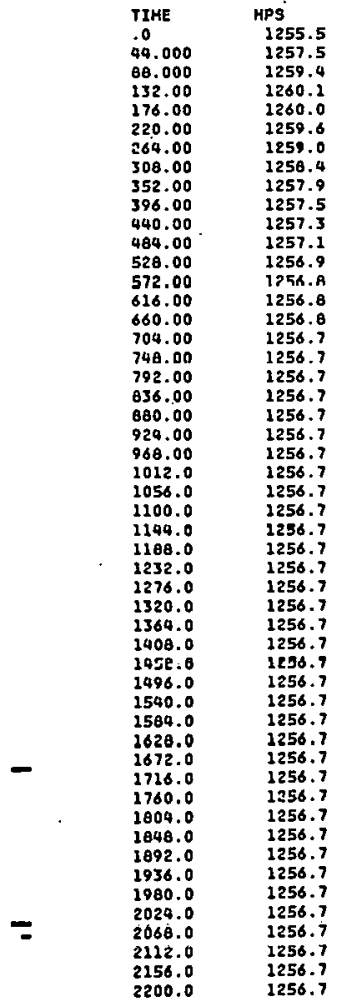

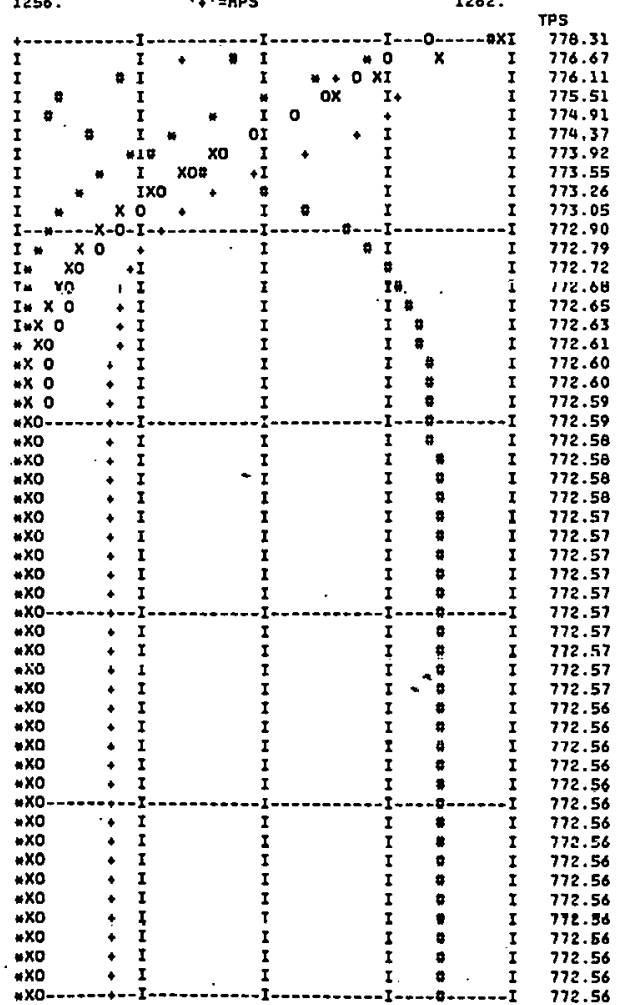

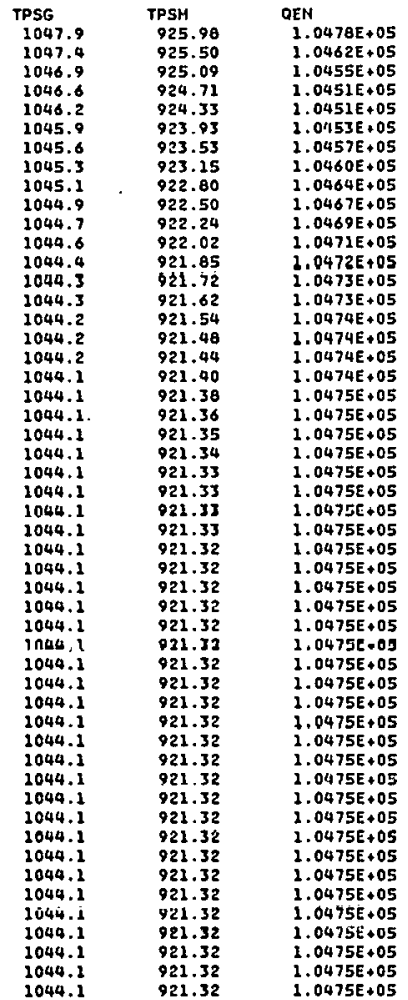



5 PERCENT STEP CHANGE IN GOVERNOR VALVE POSITION
REHEATER STATES

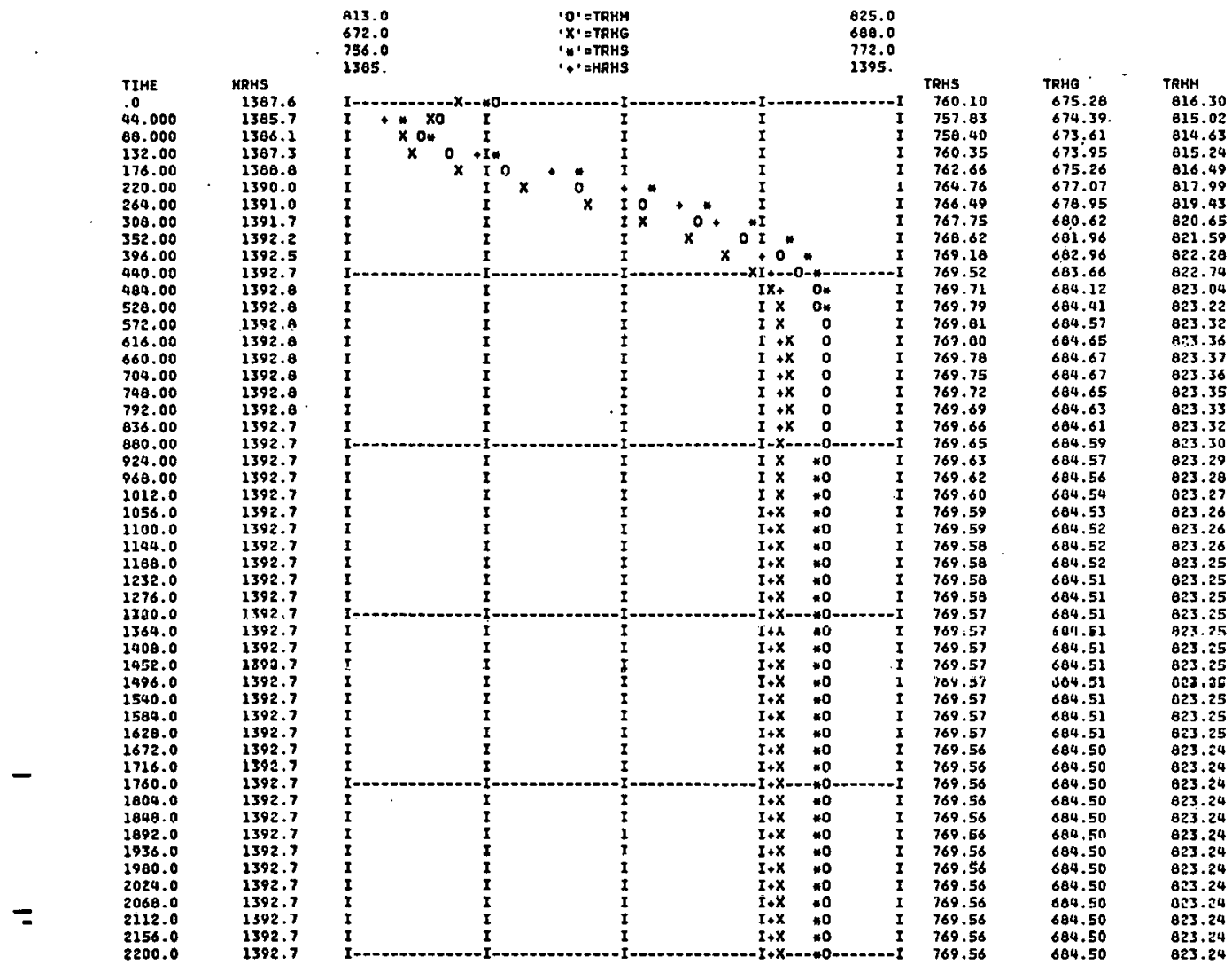

II

5 PERCENT STEP CHANGE IN GOVERNOR VALVE POSITION

\begin{tabular}{|c|c|}
\hline 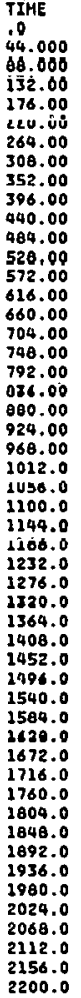 & 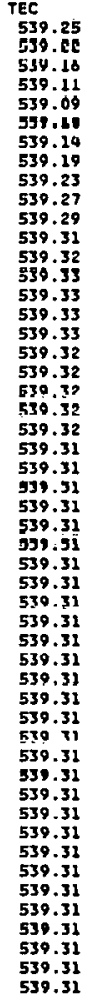 \\
\hline
\end{tabular}

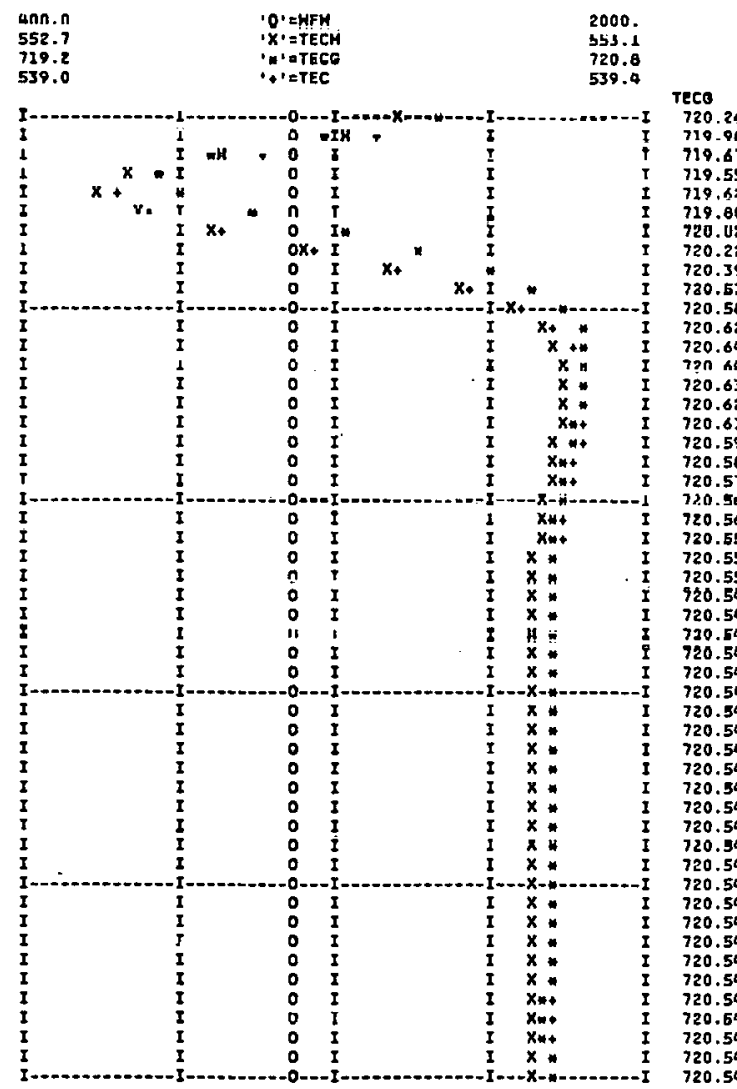

$\begin{array}{ll}\text { TECH } & \text { HFH } \\ 552.94 & 1103.0 \\ 552.91 & 1103.0 \\ 552.45 & 1103.0 \\ 552.77 & 1103.0 \\ 552.75 & 1103.0 \\ 552.77 & 1103.0 \\ 532.02 & 1105.8 \\ 552.08 & 1103.0 \\ 552.93 & 1103.0 \\ 552.08 & 1103.0 \\ 553.01 & 1103.0 \\ 553.03 & 1103.0 \\ 553.04 & 1103.0 \\ 553.05 & 1103.0 \\ 553.05 & 1103.0 \\ 553.04 & 1103.0 \\ 553.04 & 1103.0 \\ 553.04 & 1103.0 \\ 553.04 & 1103.0 \\ 553.03 & 1103.0 \\ 553.03 & 1103.0 \\ 553.03 & 1103.0 \\ 553.03 & 1103.0 \\ 553.03 & 1103.0 \\ 553.03 & 1103.0 \\ 553.03 & 1103.0 \\ 553.03 & 1103.0 \\ 553.03 & 1103.0 \\ 553.03 & 1103.0 \\ 553.03 & 1103.0 \\ 553.03 & 1103.0 \\ 553.03 & 1103.0 \\ 553.03 & 1103.0 \\ 553.03 & 1103.0 \\ 553.03 & 1103.0 \\ 553.02 & 1103.0 \\ 553.02 & 1103.0 \\ 553.02 & 1103.0 \\ 553.02 & 1103.0 \\ 553.02 & 1103.0 \\ 553.02 & 1103.0 \\ 553.02 & 1103.0 \\ 553.02 & 1103.0 \\ 553.02 & 1103.0 \\ 553.02 & 1103.0 \\ 553.02 & 1103.0 \\ 553.02 & 1103.0 \\ 553.02 & 1103.0 \\ 553.02 & 1103.0 \\ 553.02 & 1103.0 \\ 553.02 & 1103.0 \\ & \\ & \end{array}$ 
5 PERCENT STEP CHANGe IN GOVERNOR VALVE POSITION

AIR HEATER STATES

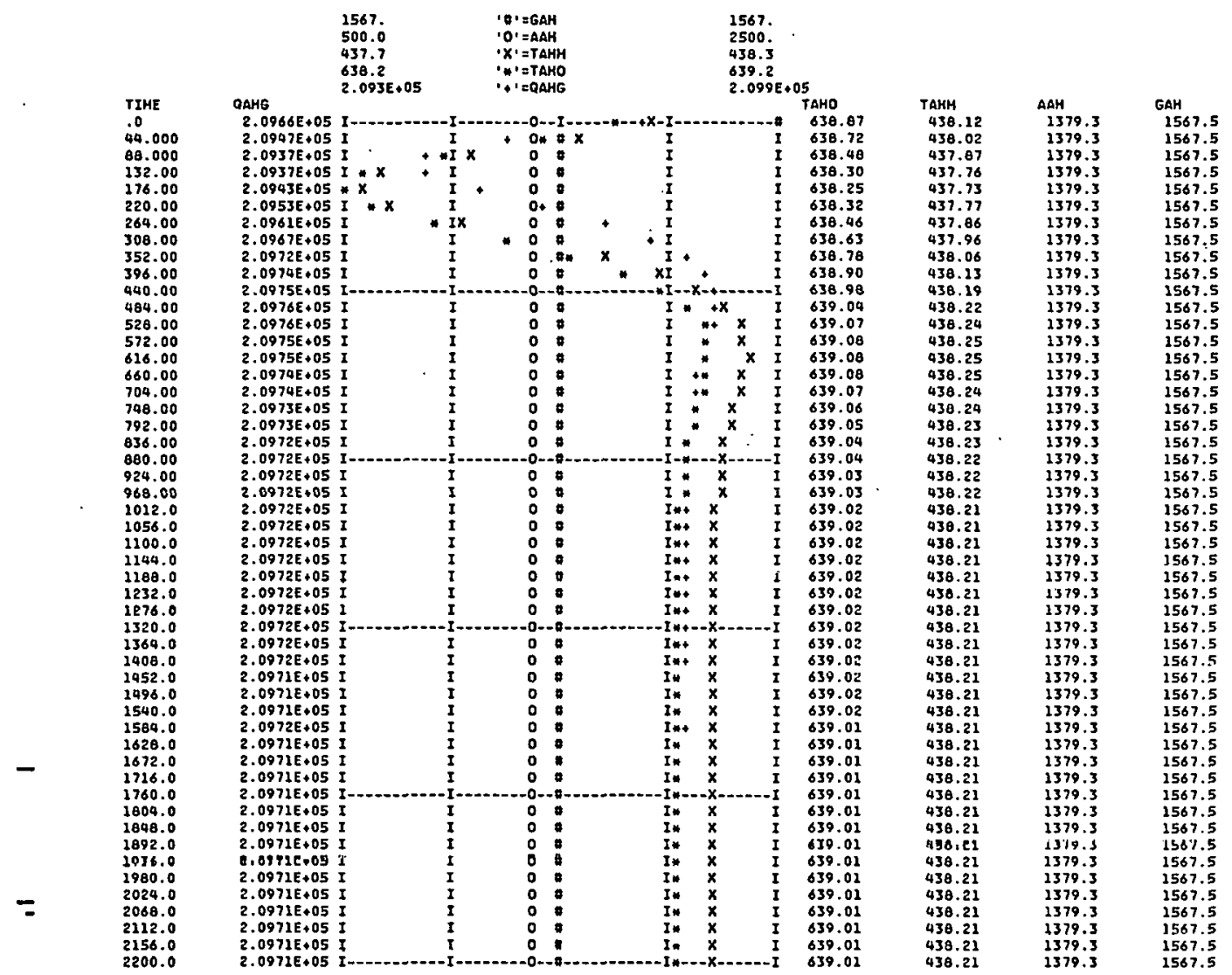

II

5 PERCENT STEP CHANGe in govermor Valve position

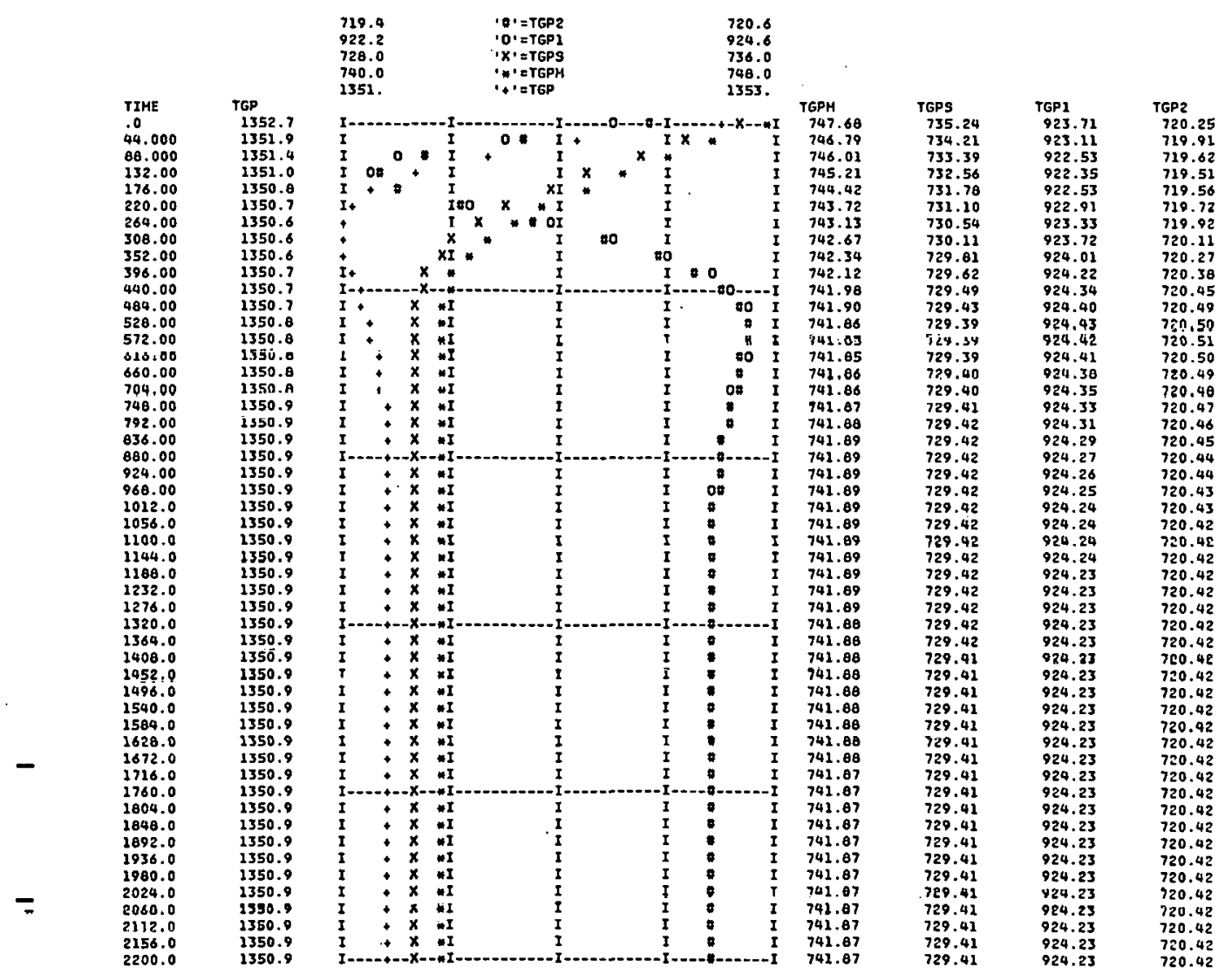




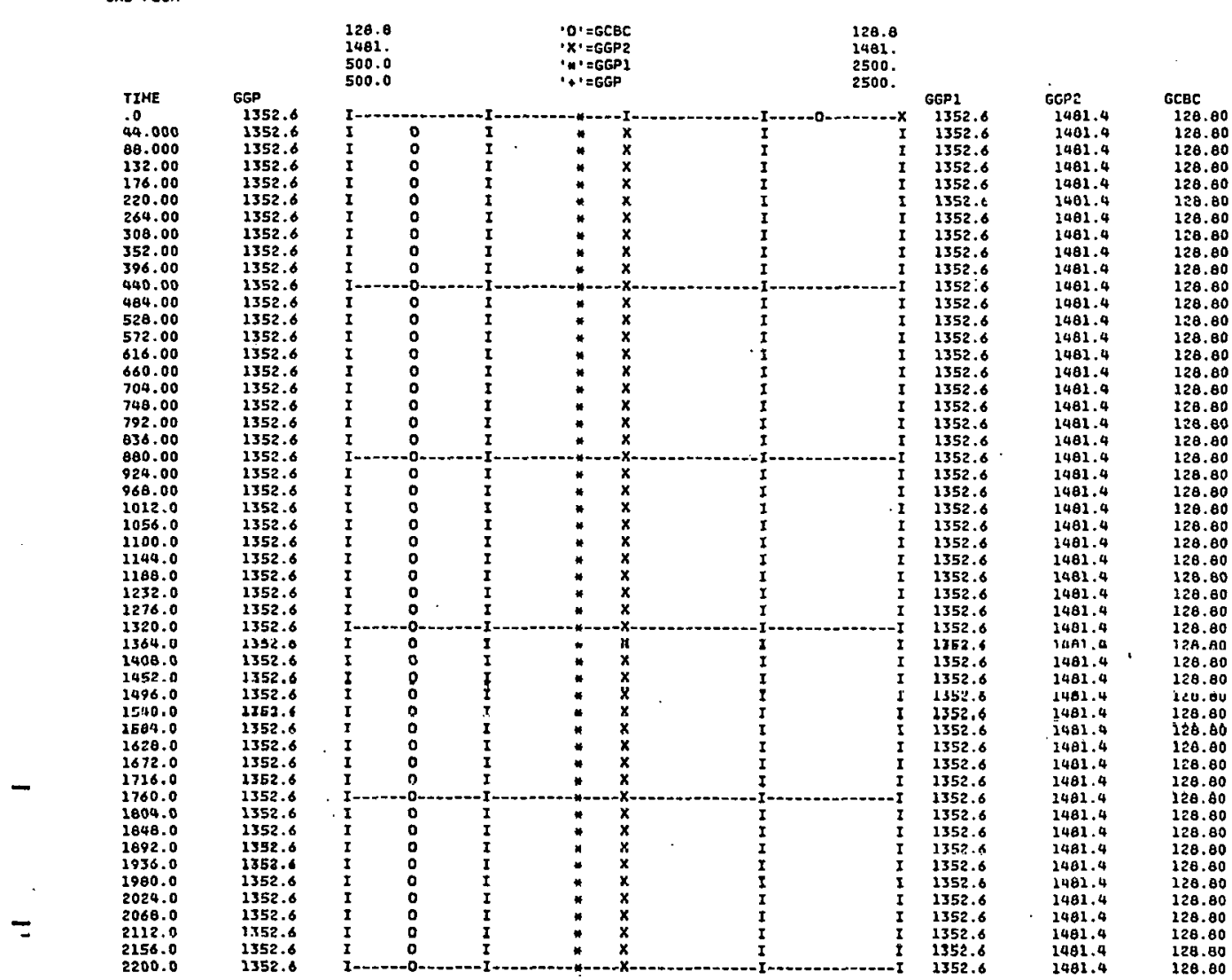

II

5 PERCENT STEP CHANGE IN GOVERNOR VALVE POSITION

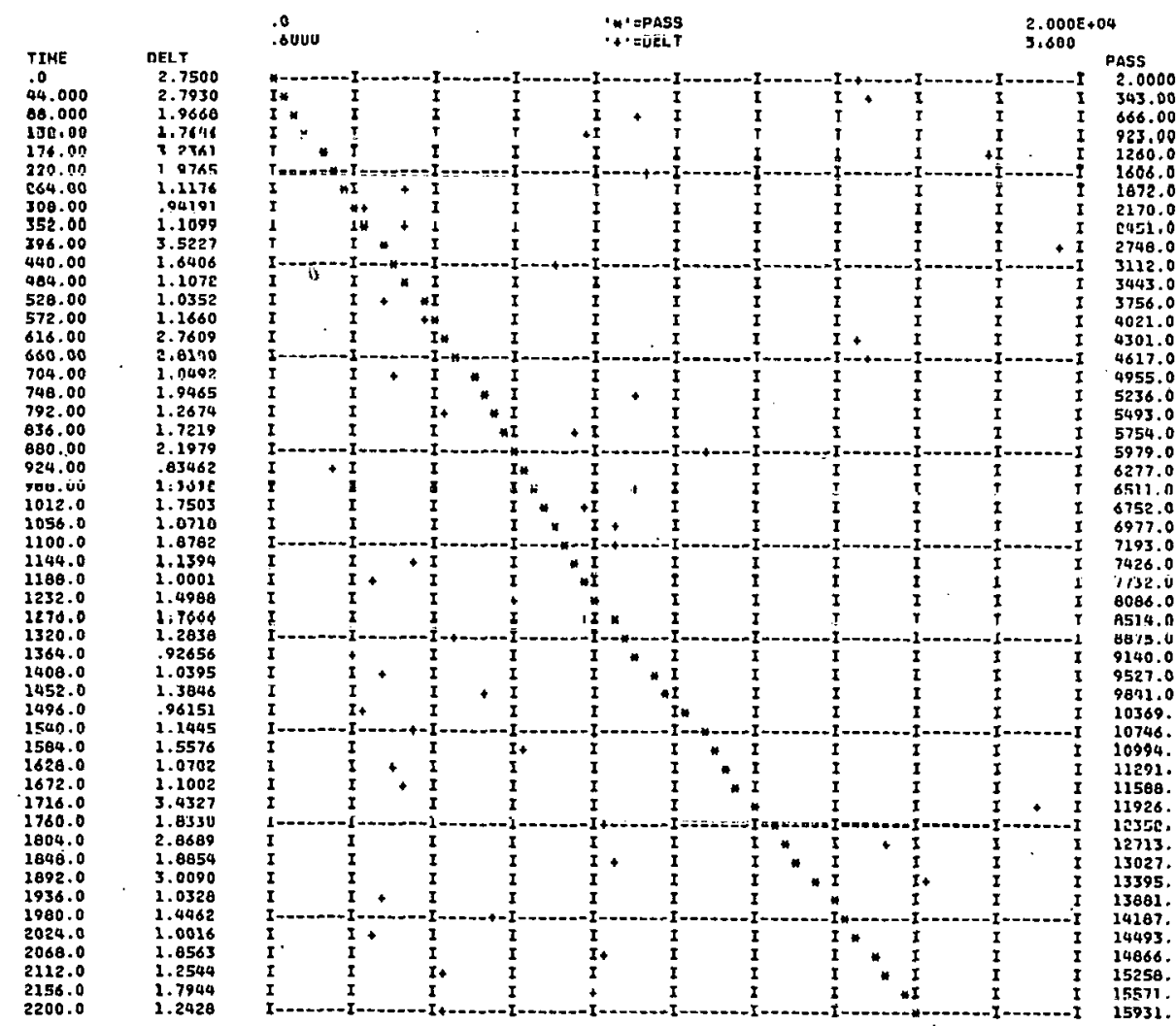


5 PERCENT STEP CHANGe IN GOVERNOR VALVE POSITION

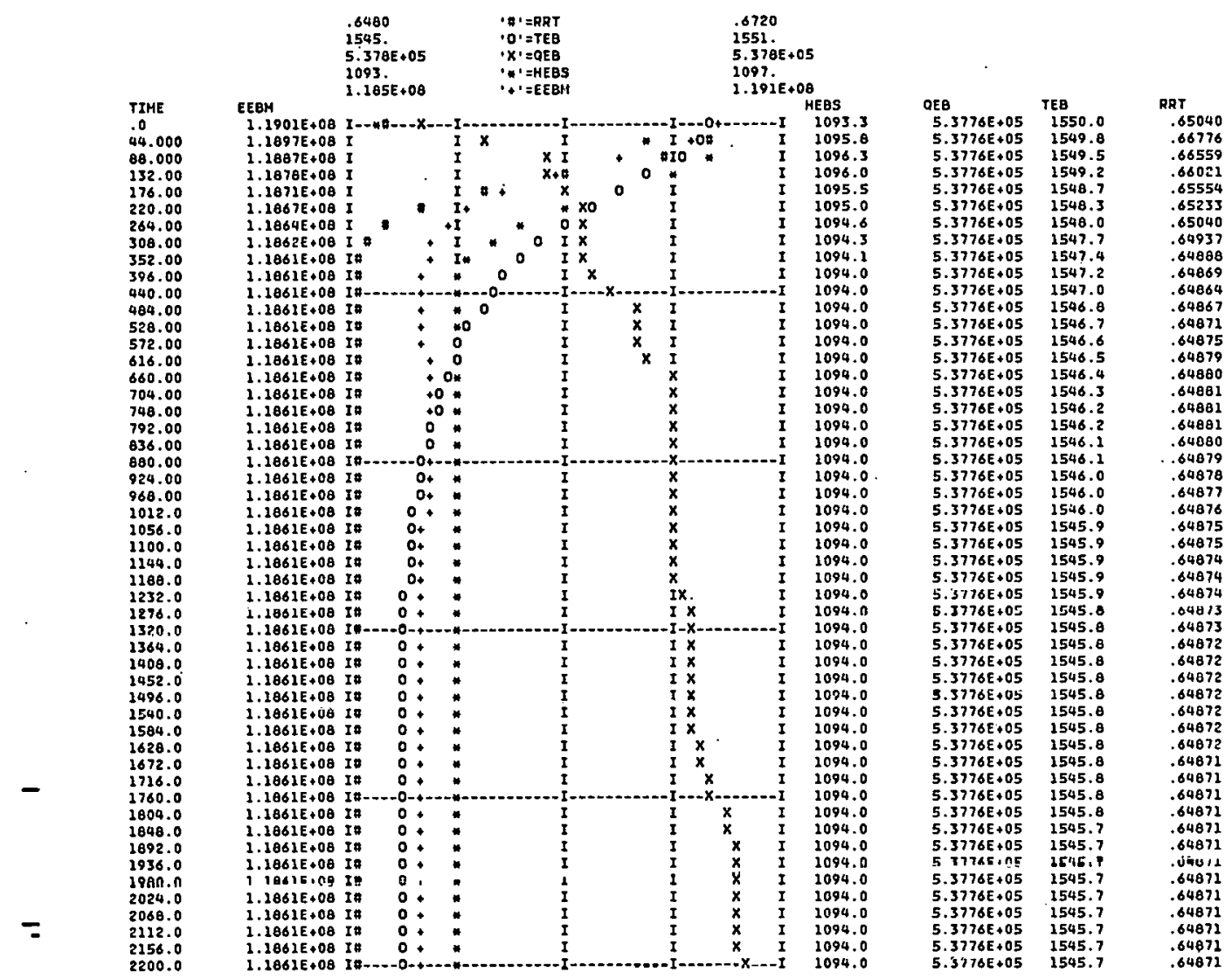

II

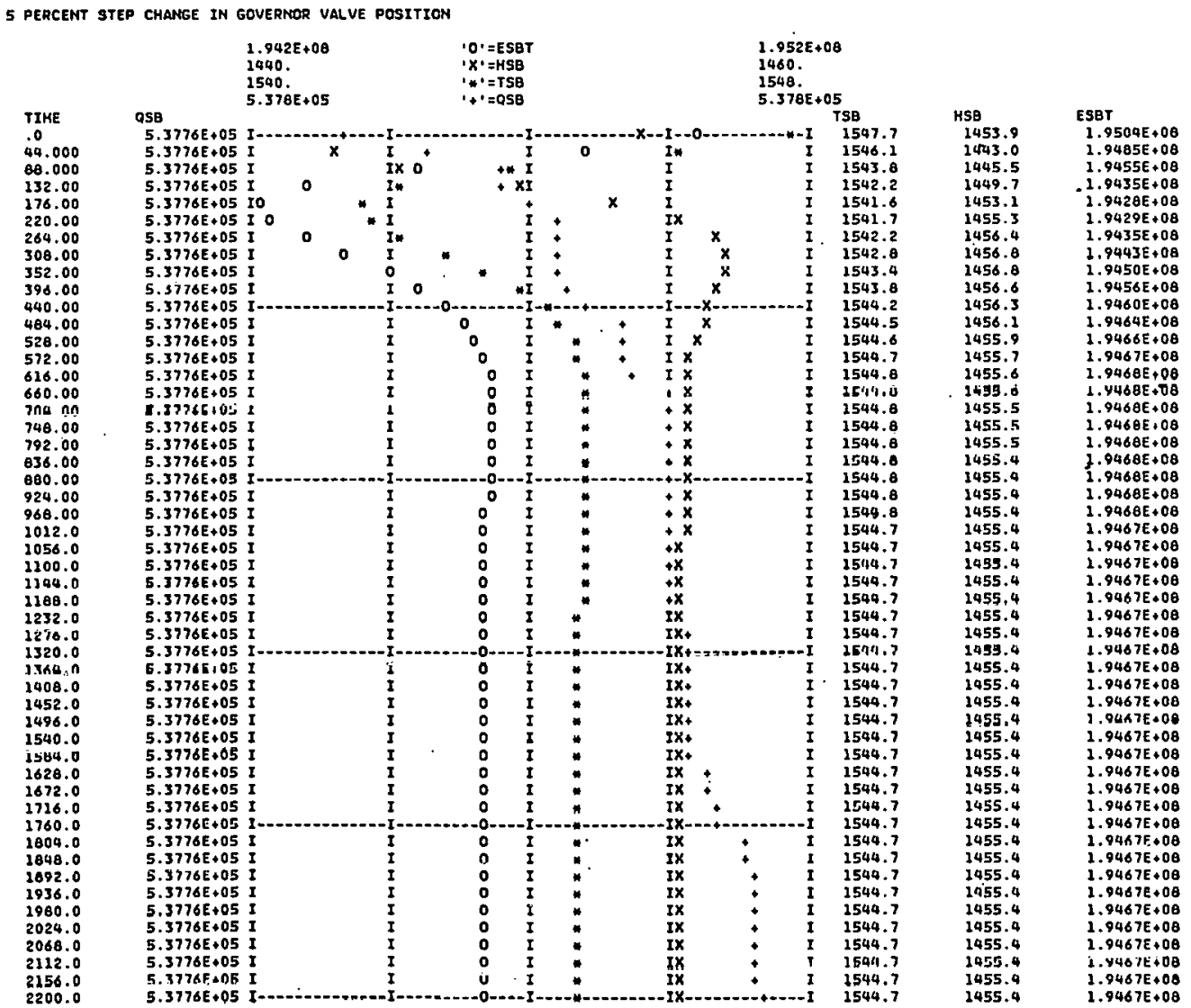


5 PERCENT SteP change in governor Valve position

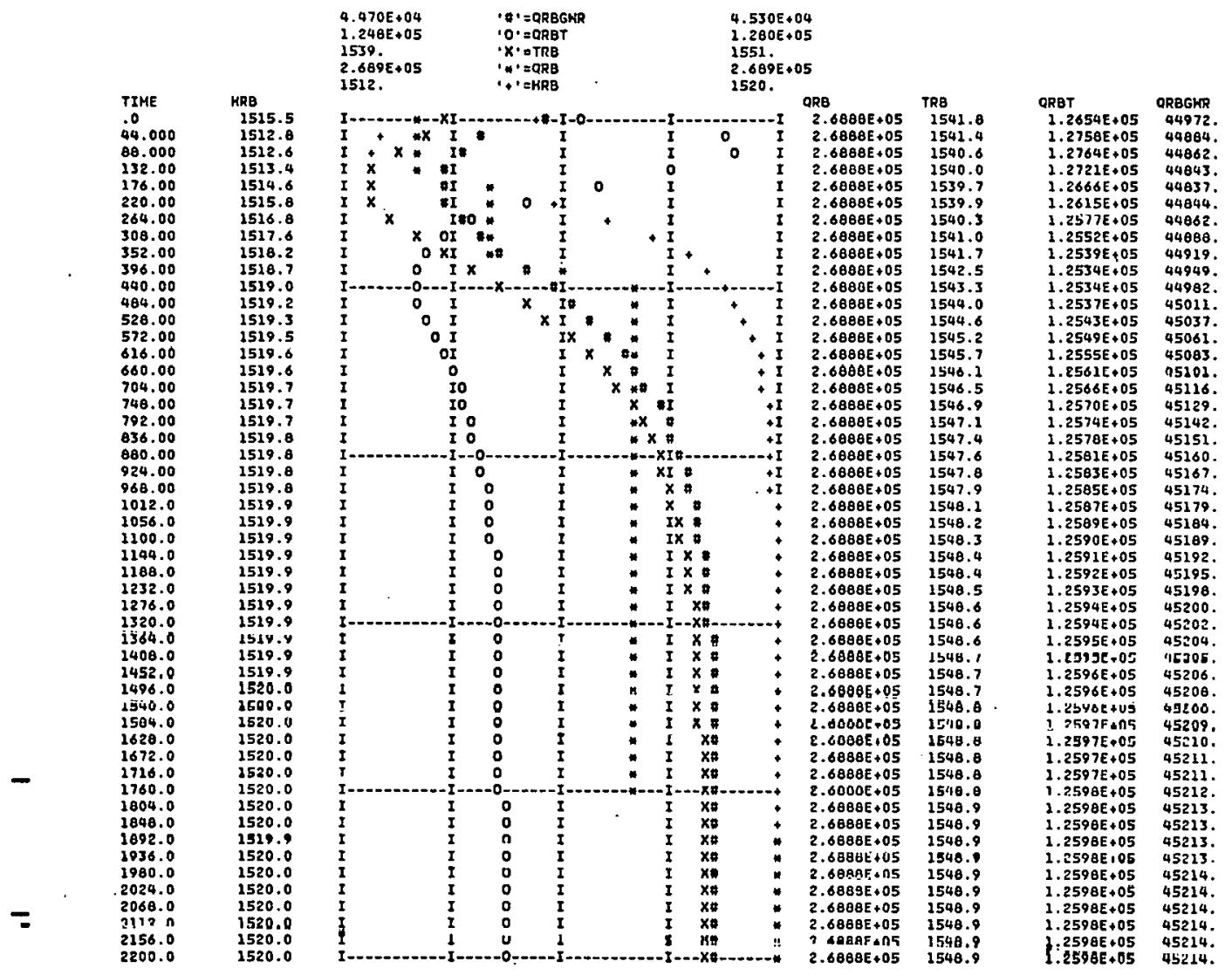

ii

- percent step change in governor valve position

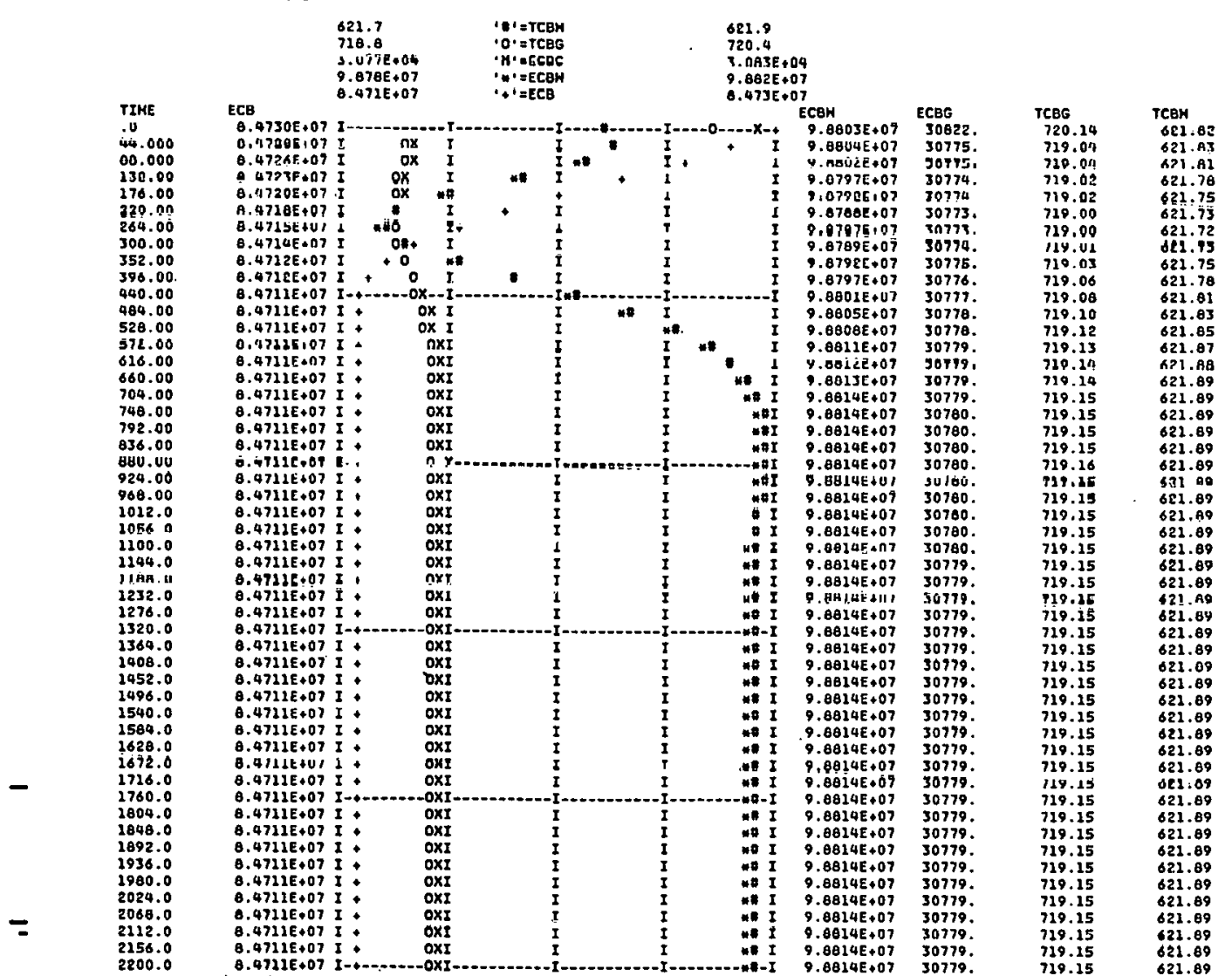


5 PERCENT STEP CHANGE IN GOVERNOR VALVE POSITION

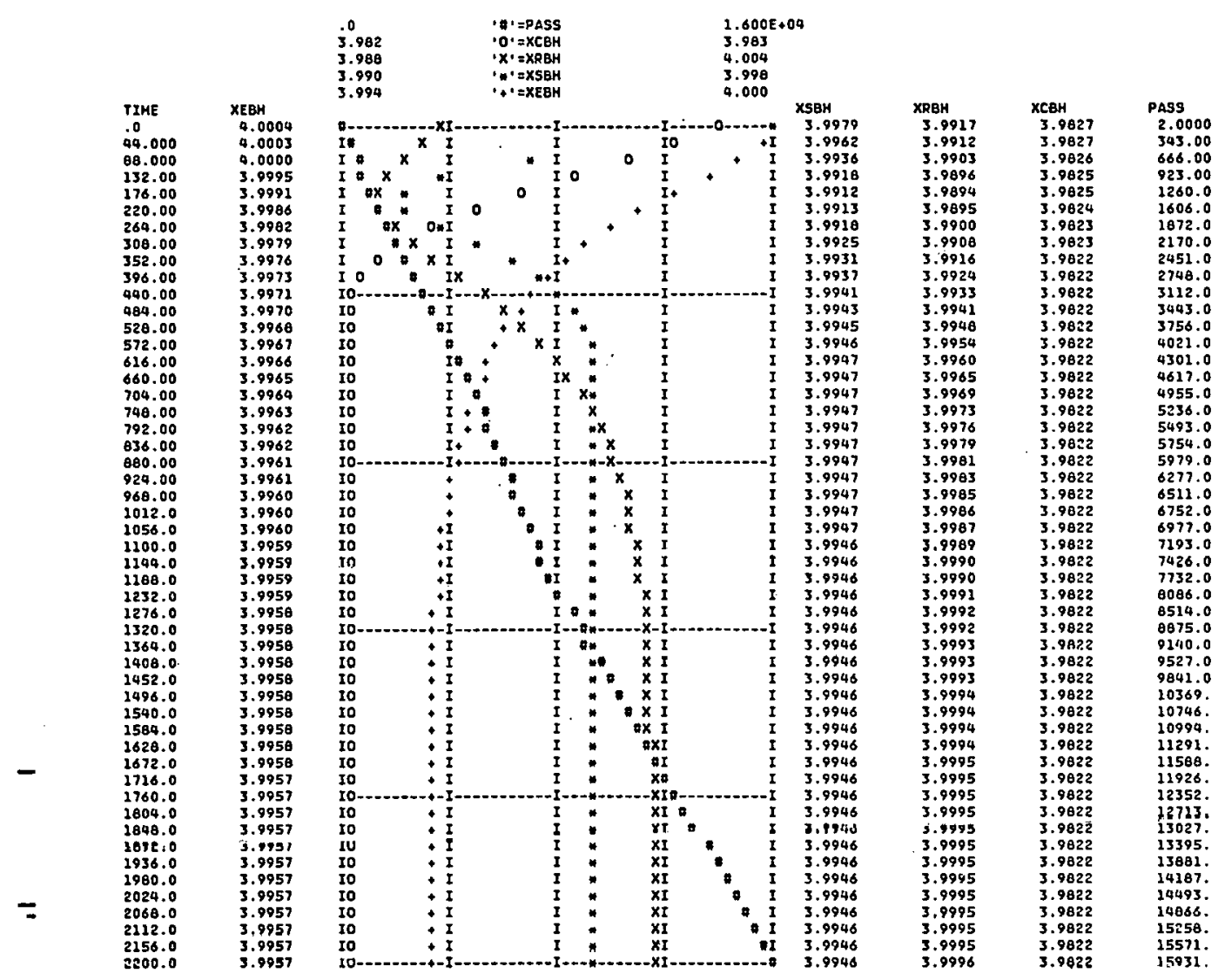

II

5 PERCENT STEP CHANGE IM GOVERMOR VALVE POSITION

PLIOZO BED VOID FRACTIOY

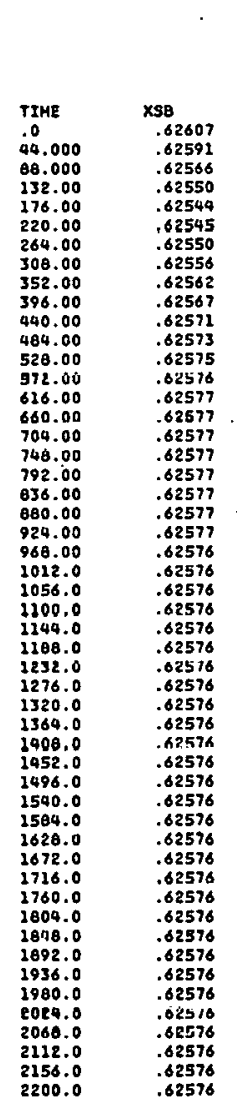
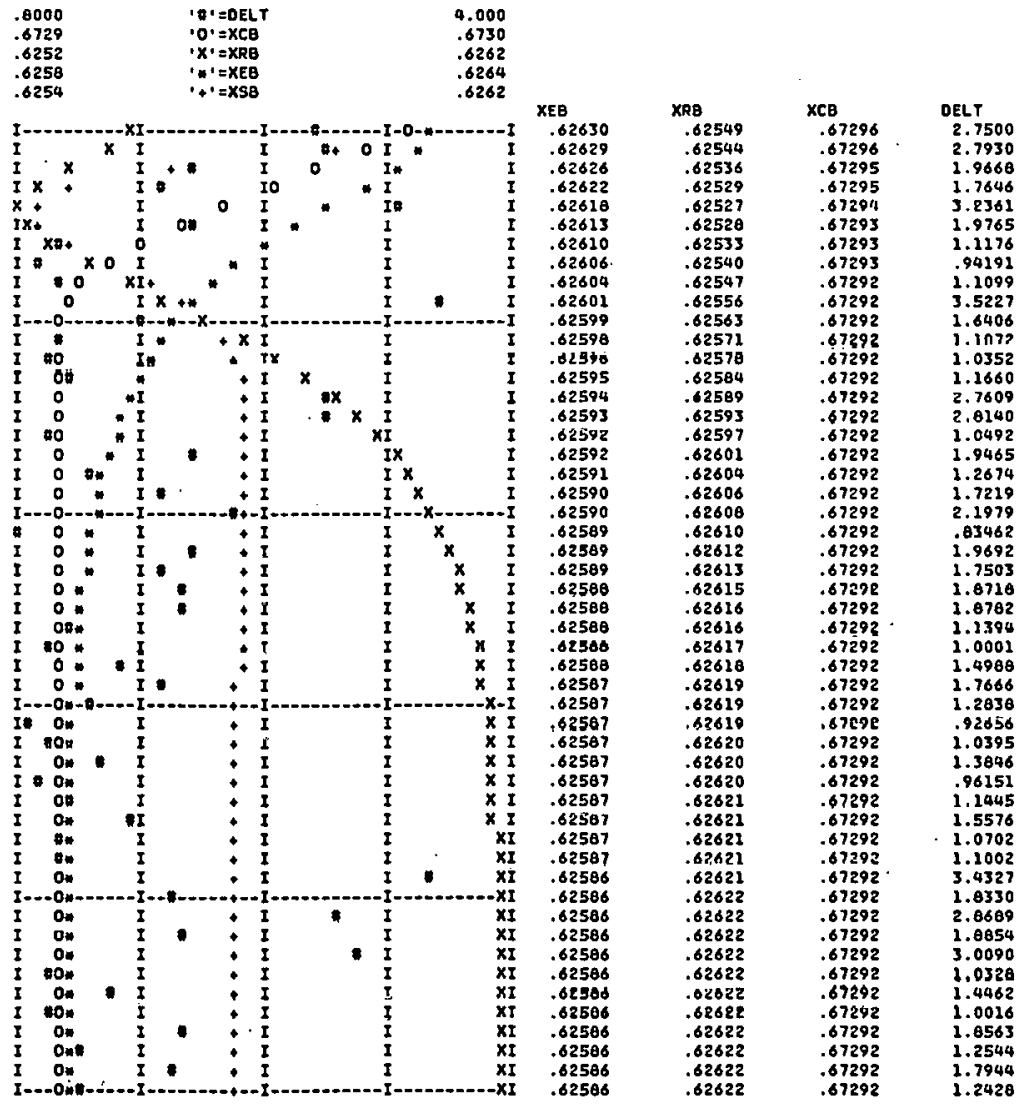
5 PERCENT STEP CHANGE IN GOVERNOR VALVE POSITION

CELL EXIT GAS TEMPERATURES

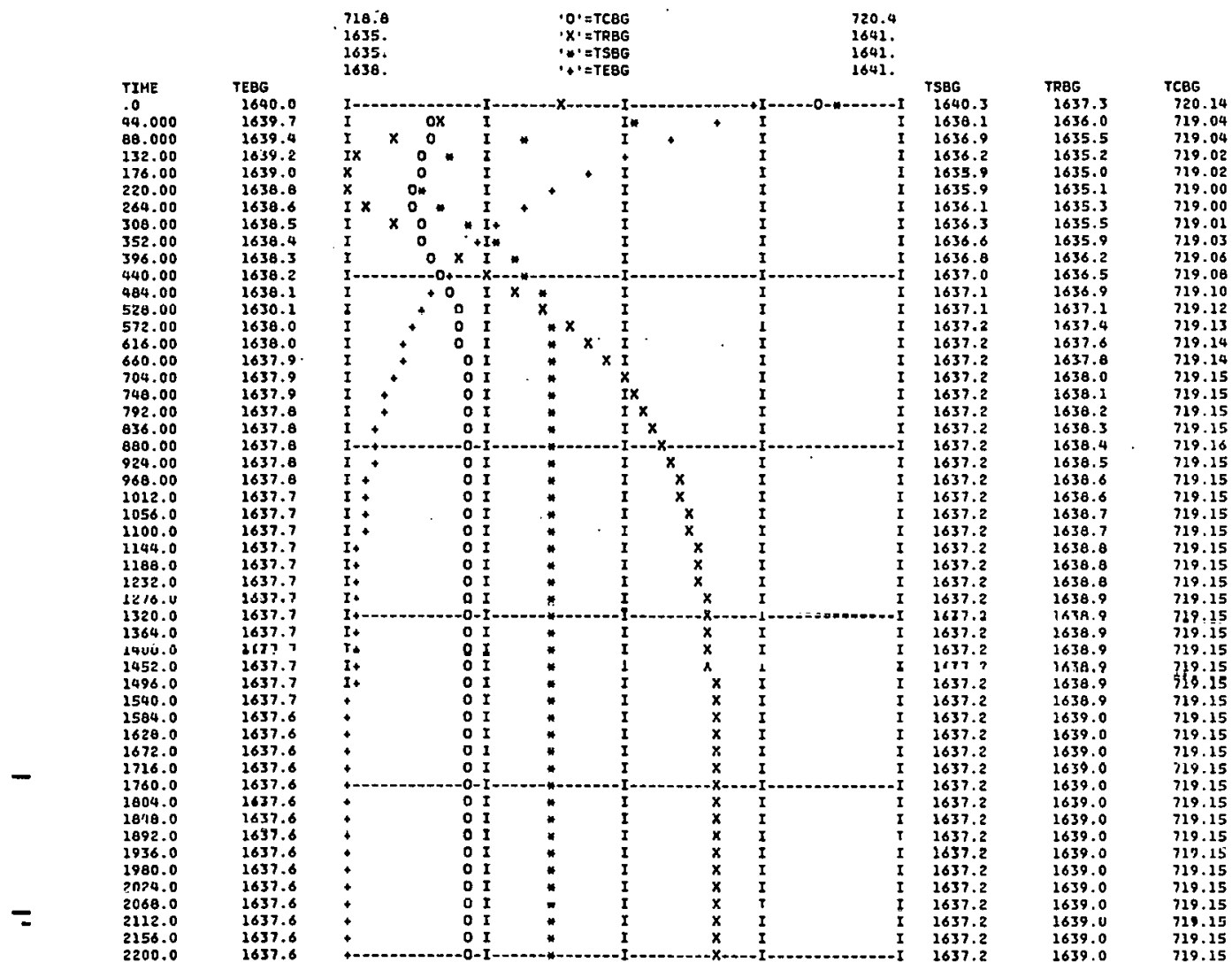

5 PERCeNt Step change in governor val ve position

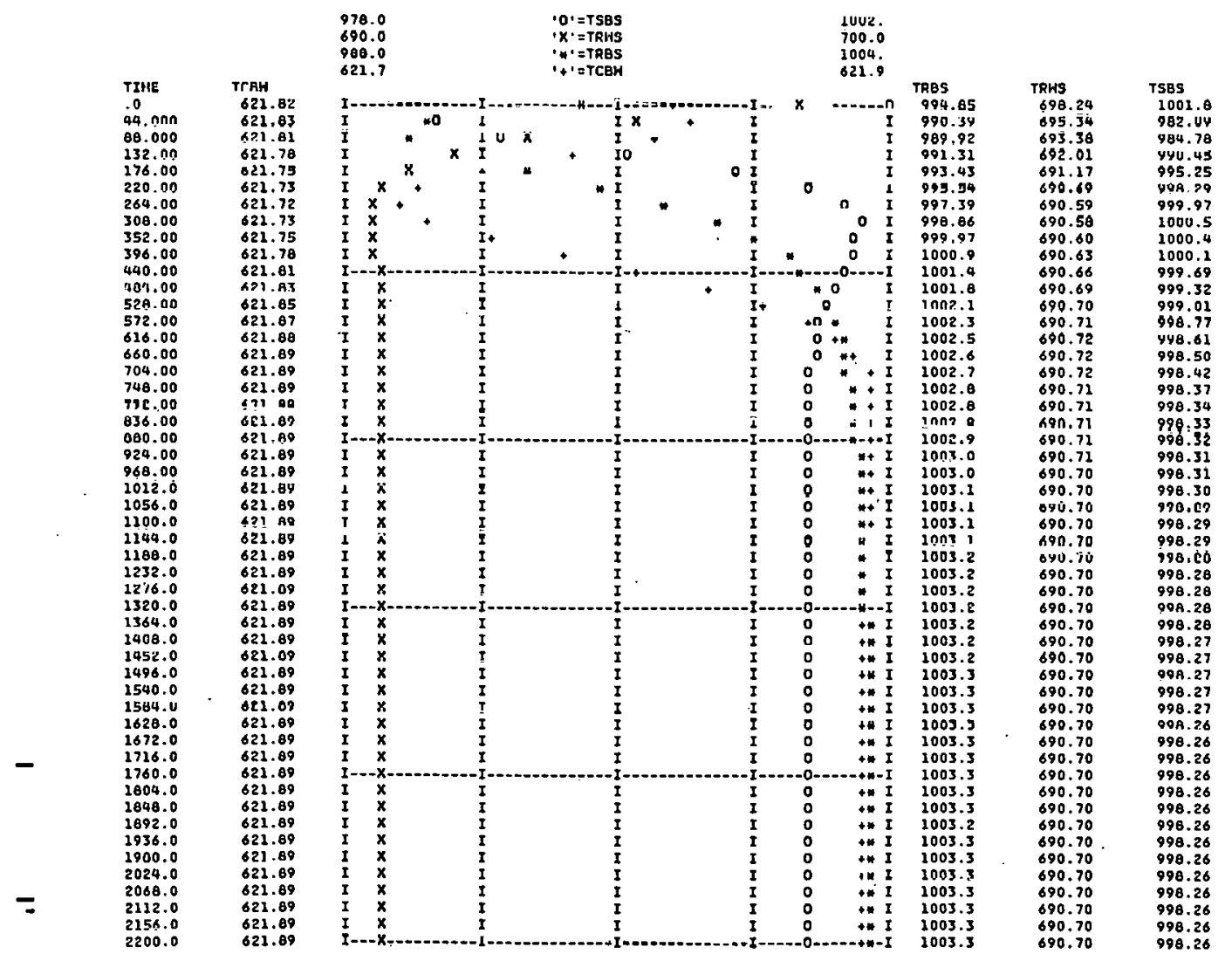




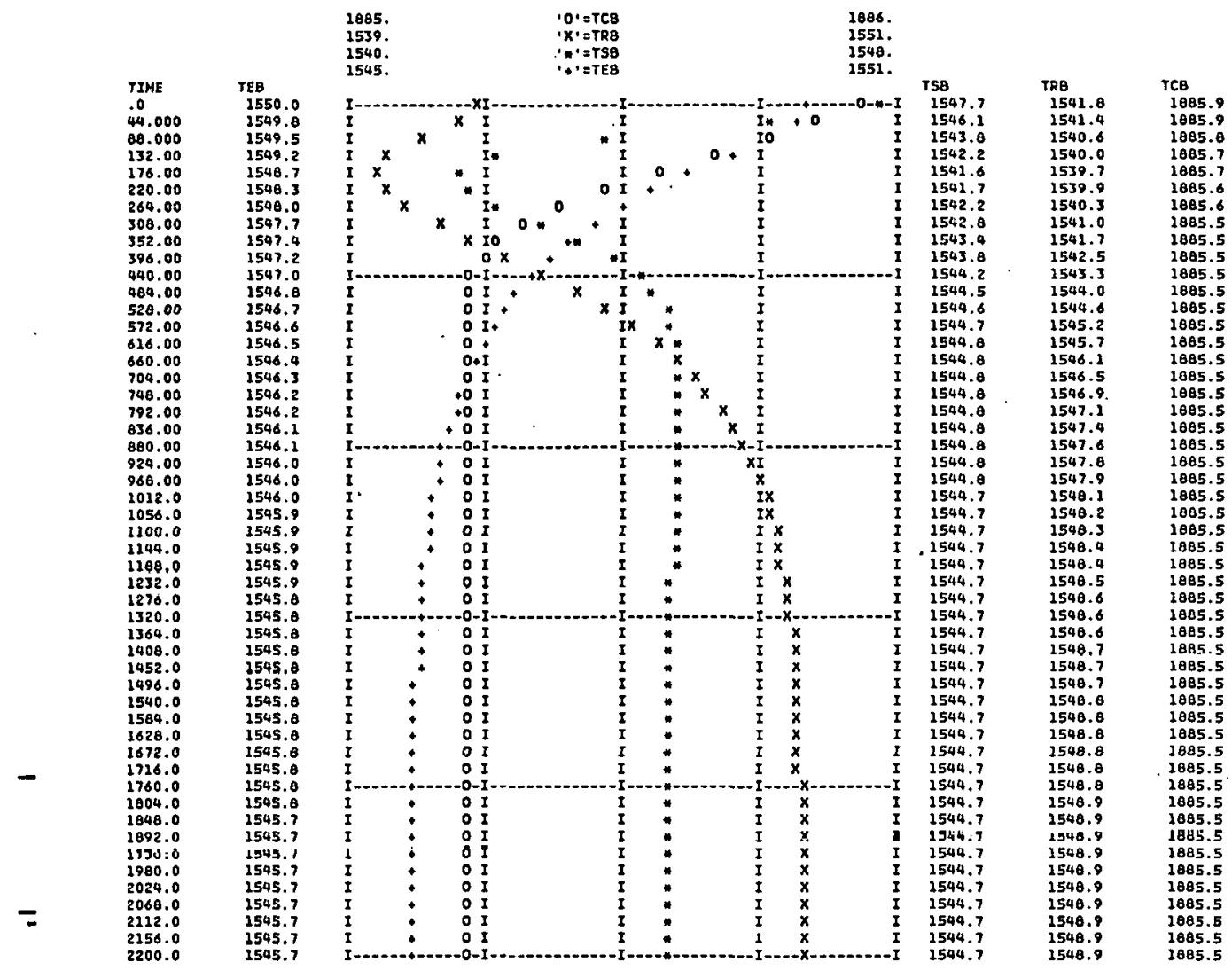

II

5 PERCENT STEP CHANGE IN GOVERNB VALVE POSITION

FRACTION OF MATER, TKD PHASE, STEAM BOILING BED INLET TO RM OUTLET

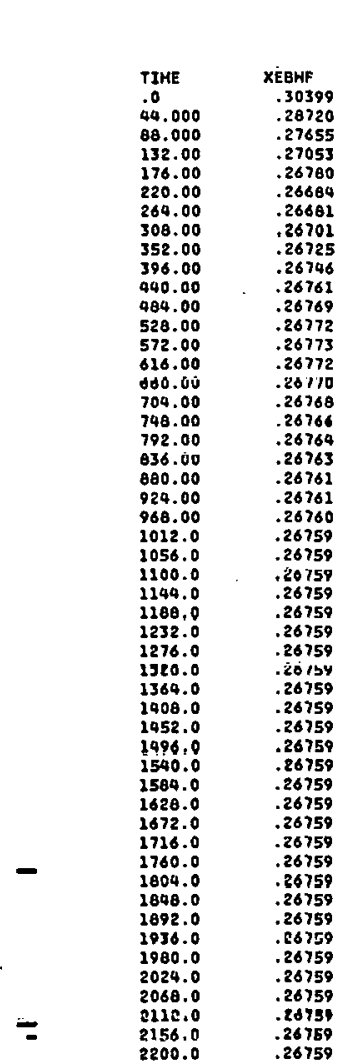

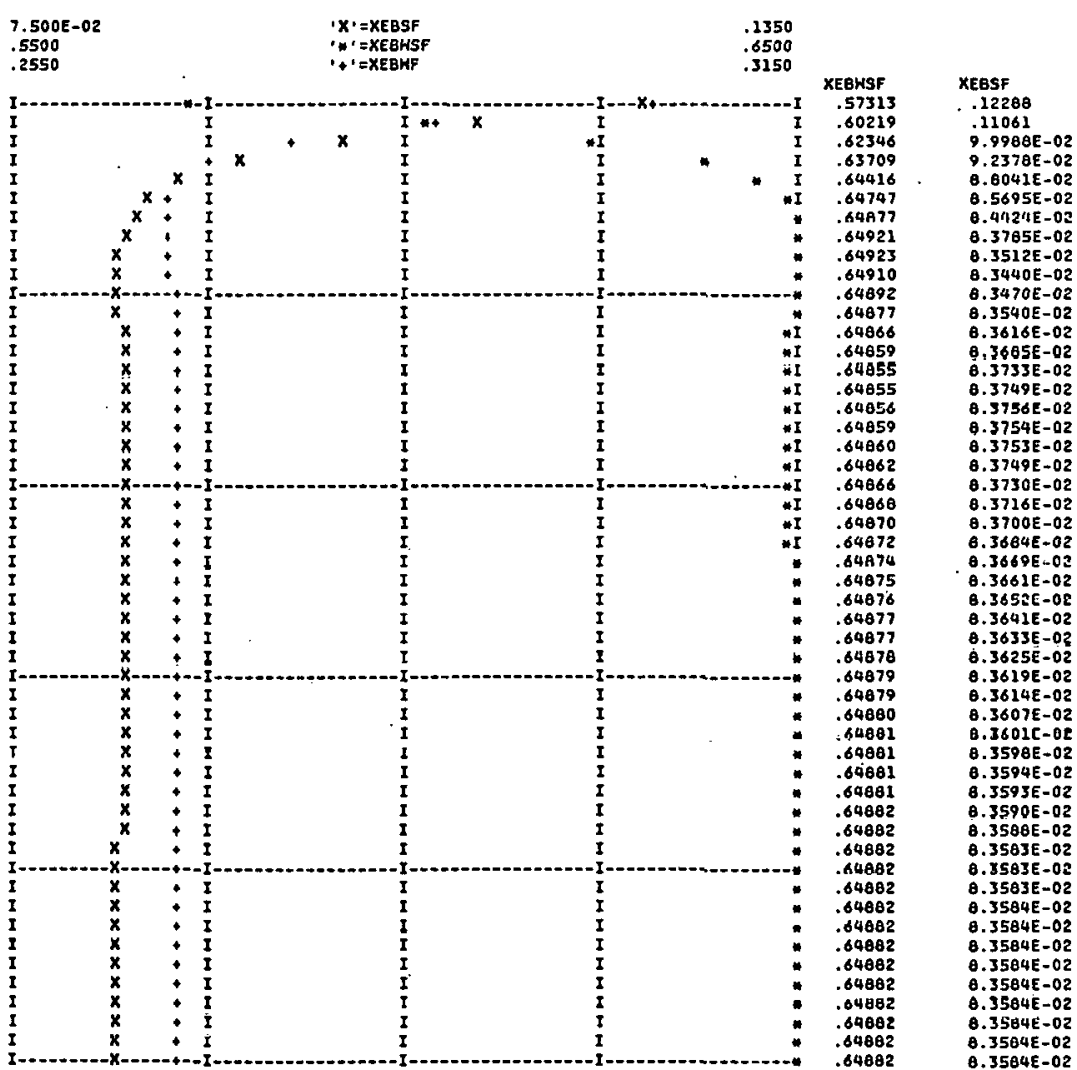



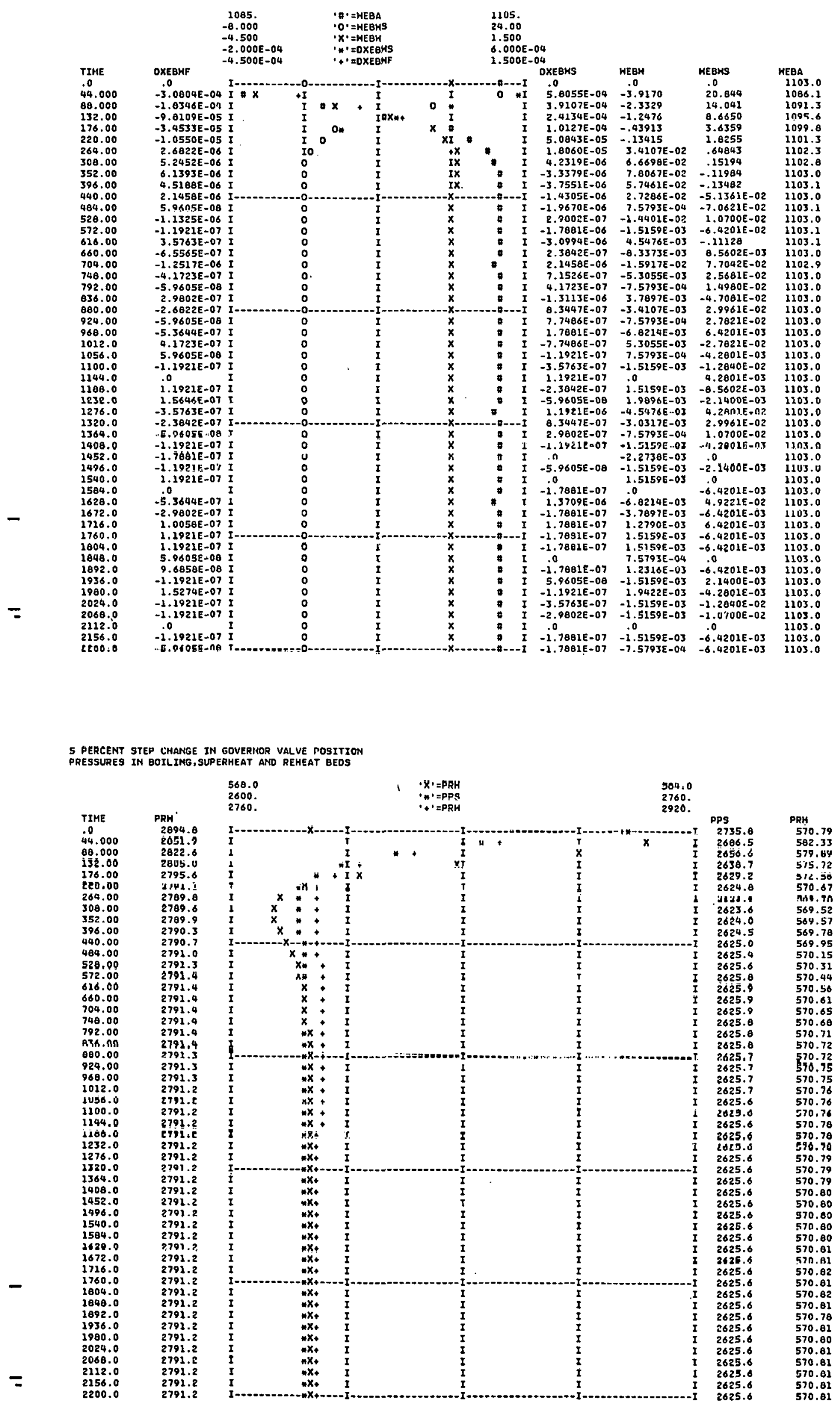
5 PERCENT STEP change in GOVERNor Valve positrom

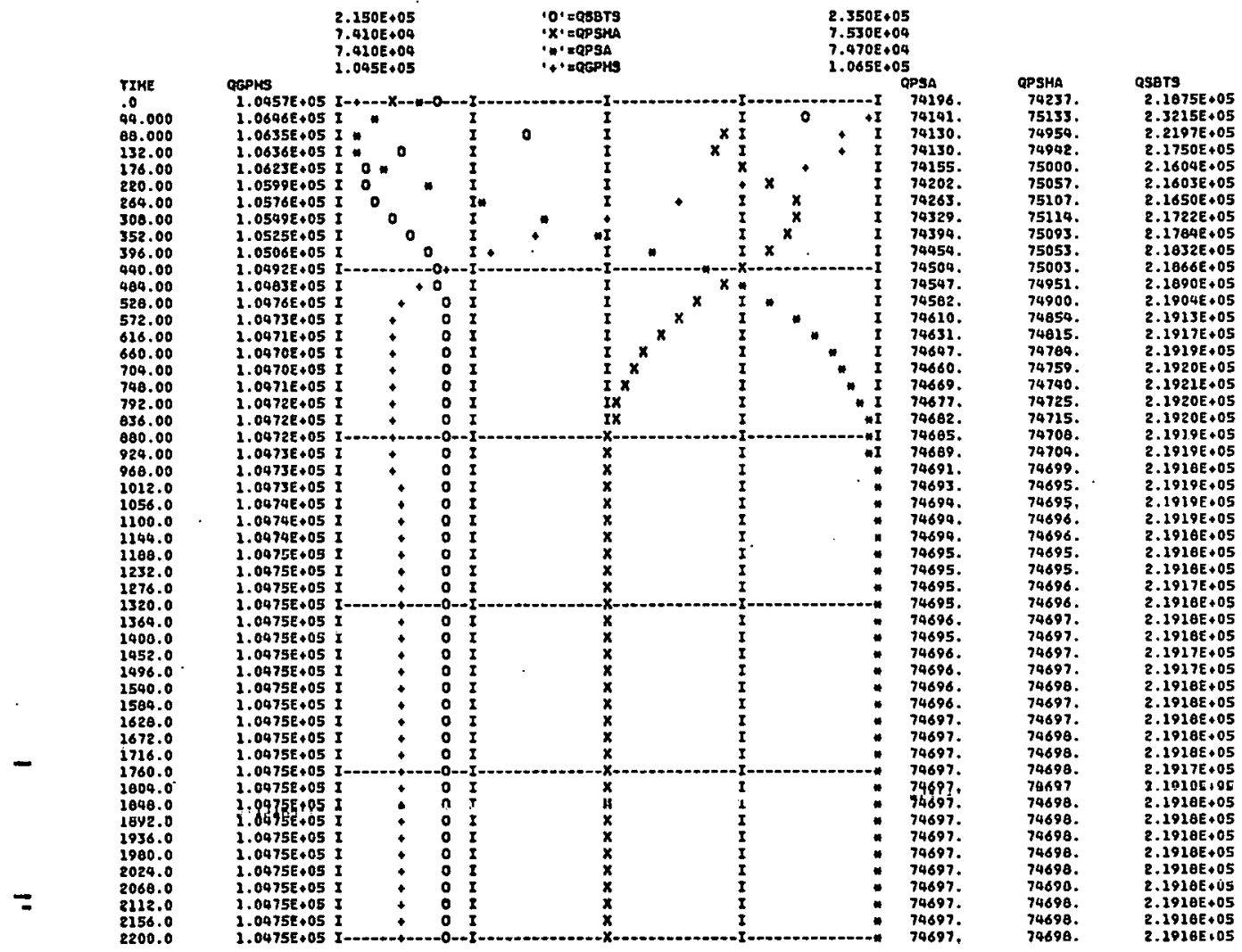

5 PERCENT STEP CHANGE IN GOVERNOR VALVE POSITION

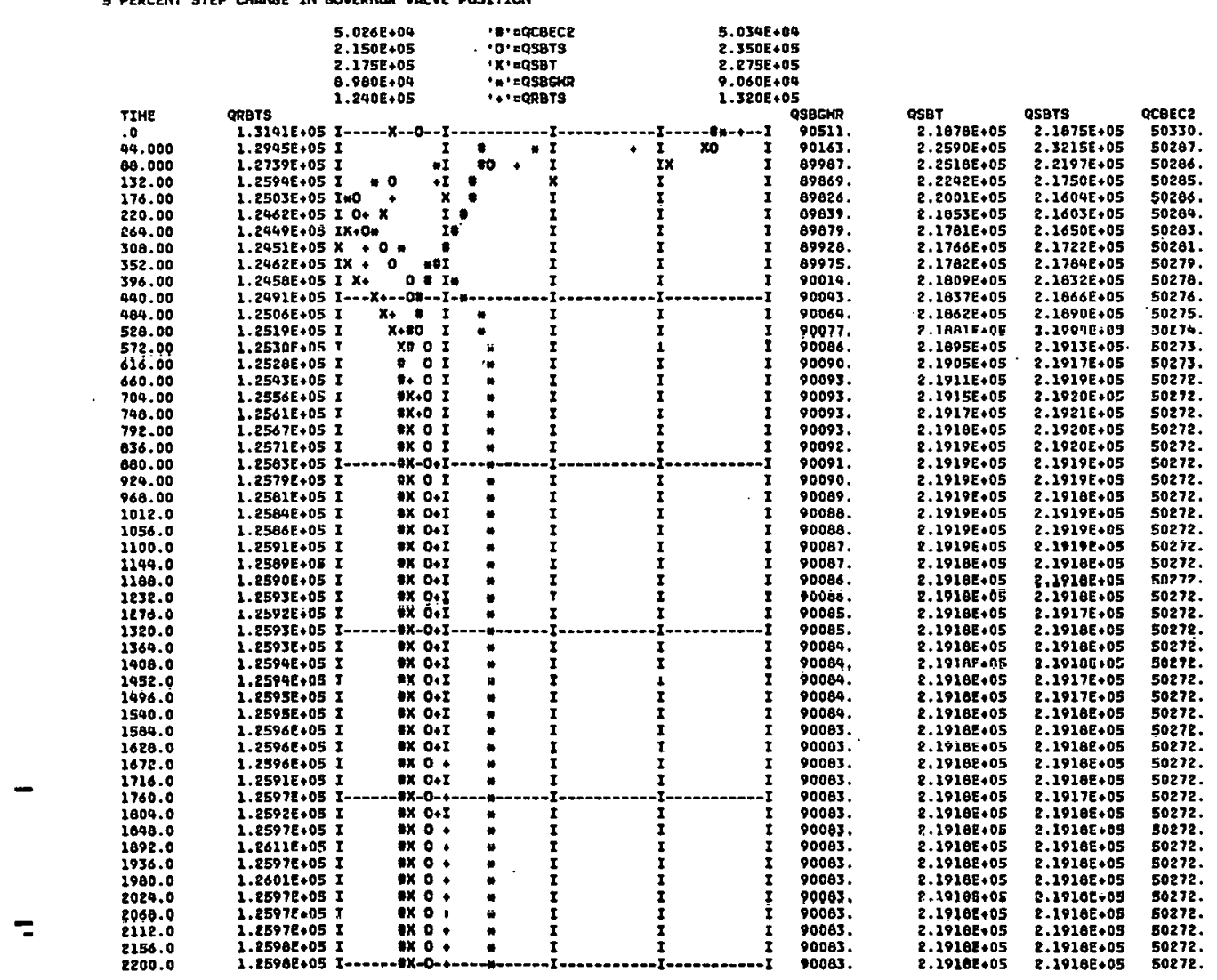




\section{THIS PAGE}

WAS INTENTIONALLY

LEFT BLANK 


\section{APPENDIX $V-B 8$ \\ STEP IN UNIT LOAD}

This section presents the detailed results in CSMP plot format for a $5 \%$ step change in unit load. 


\section{THIS PAGE}

WAS INTENTIONALLY

LEFT BLANK 


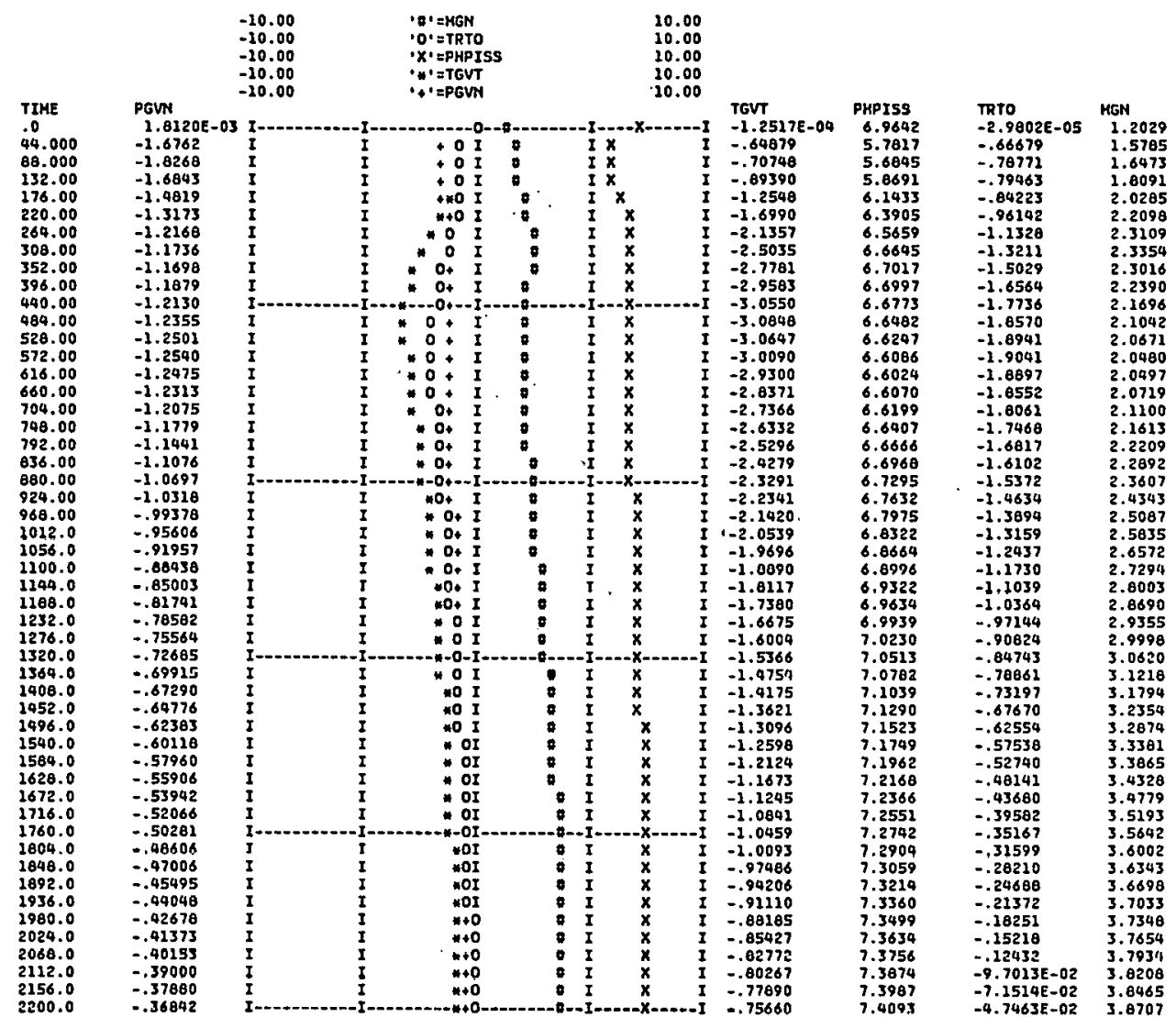

5 PERCENT STEP CHANGE IN UNIT LOAD

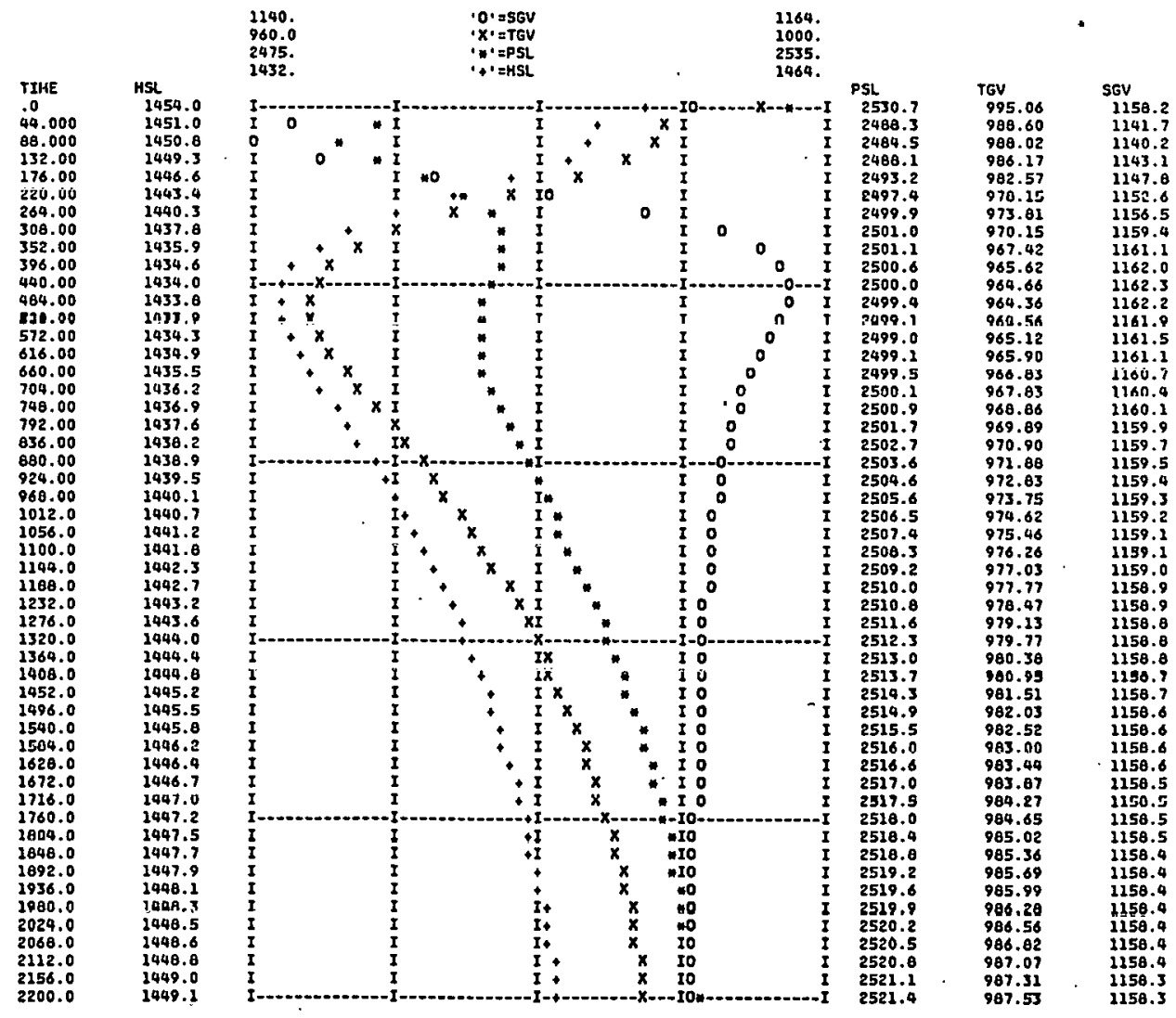




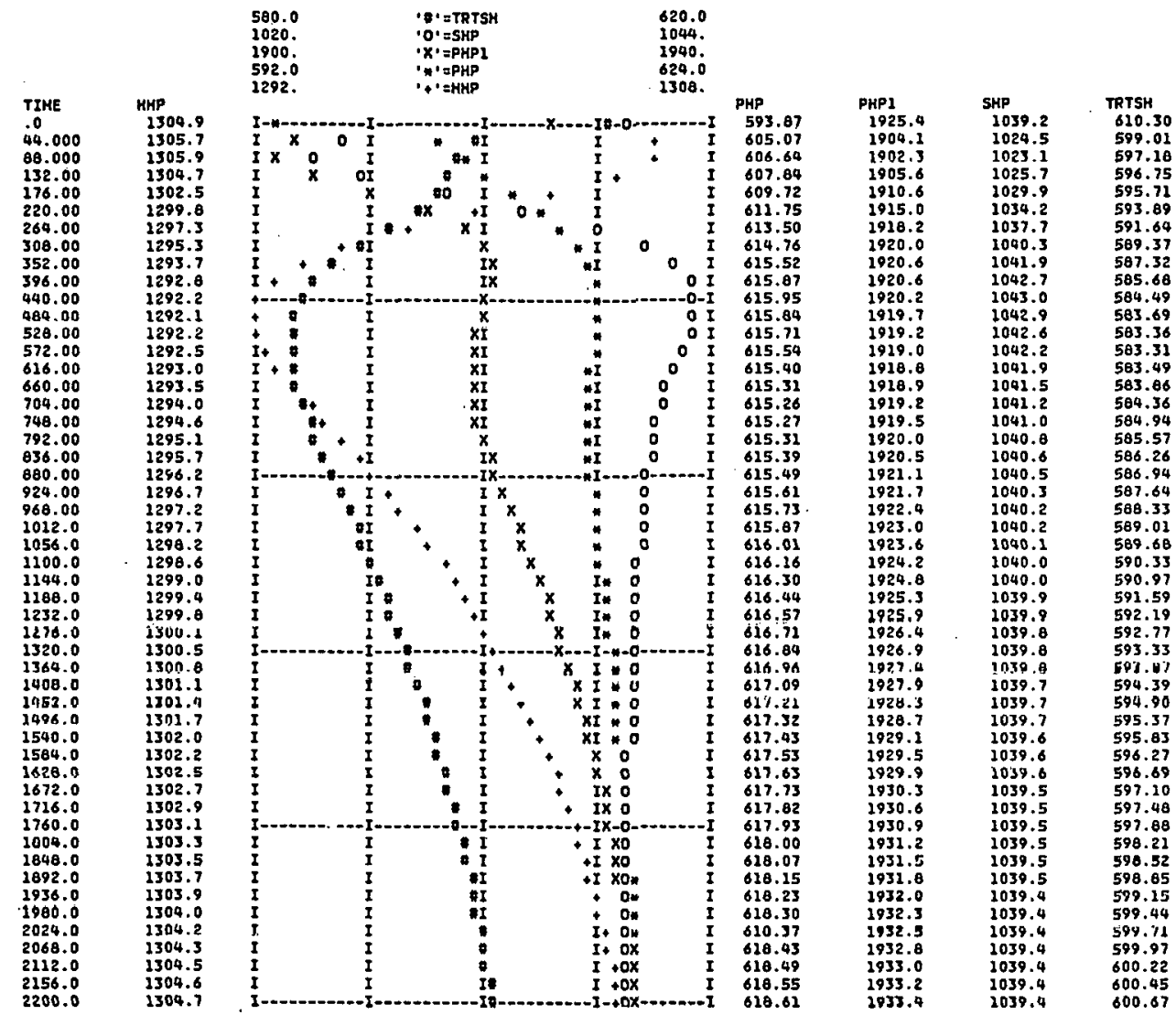

5 PERCENt Step change in untt lanad R LINE STATES

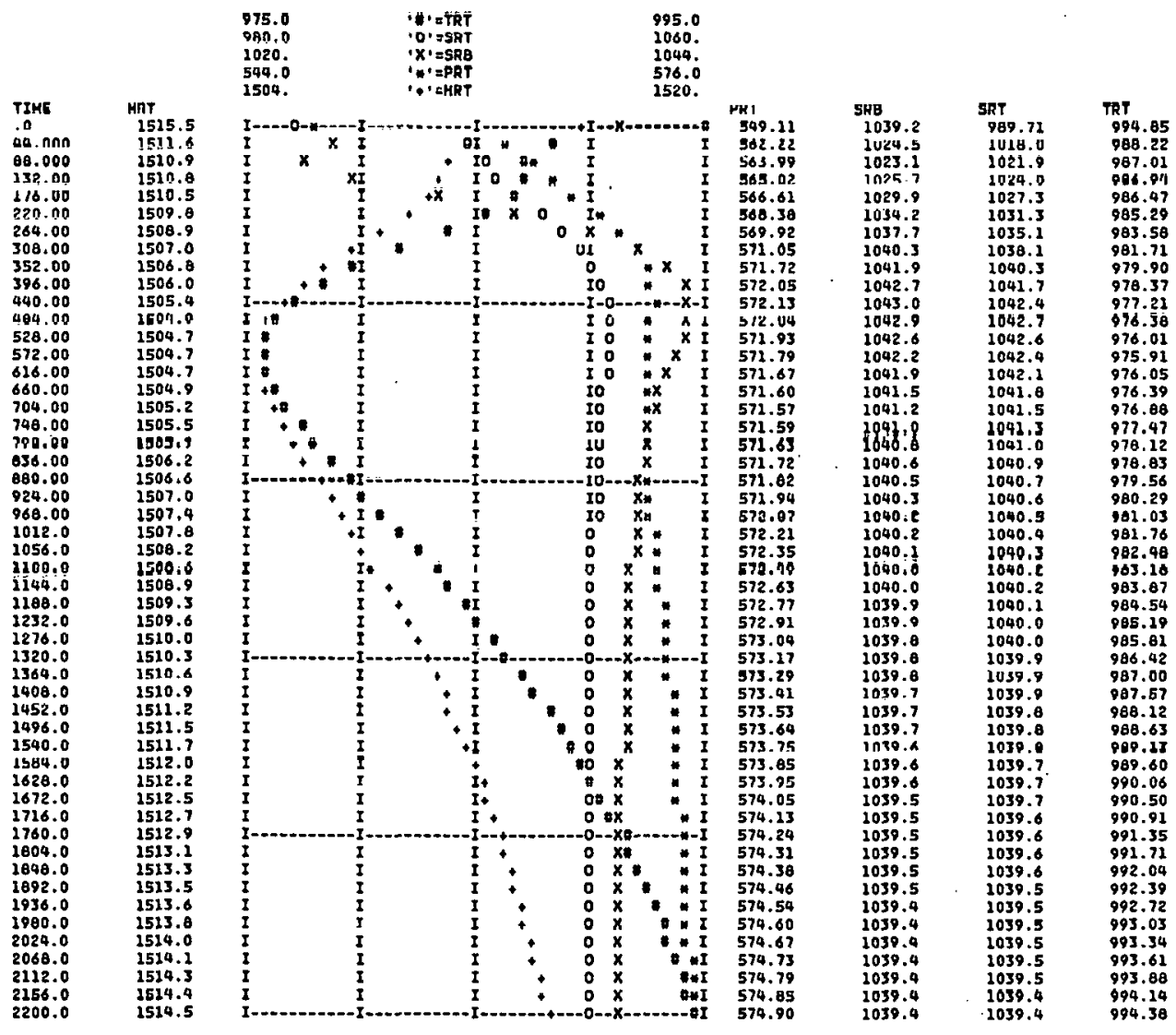




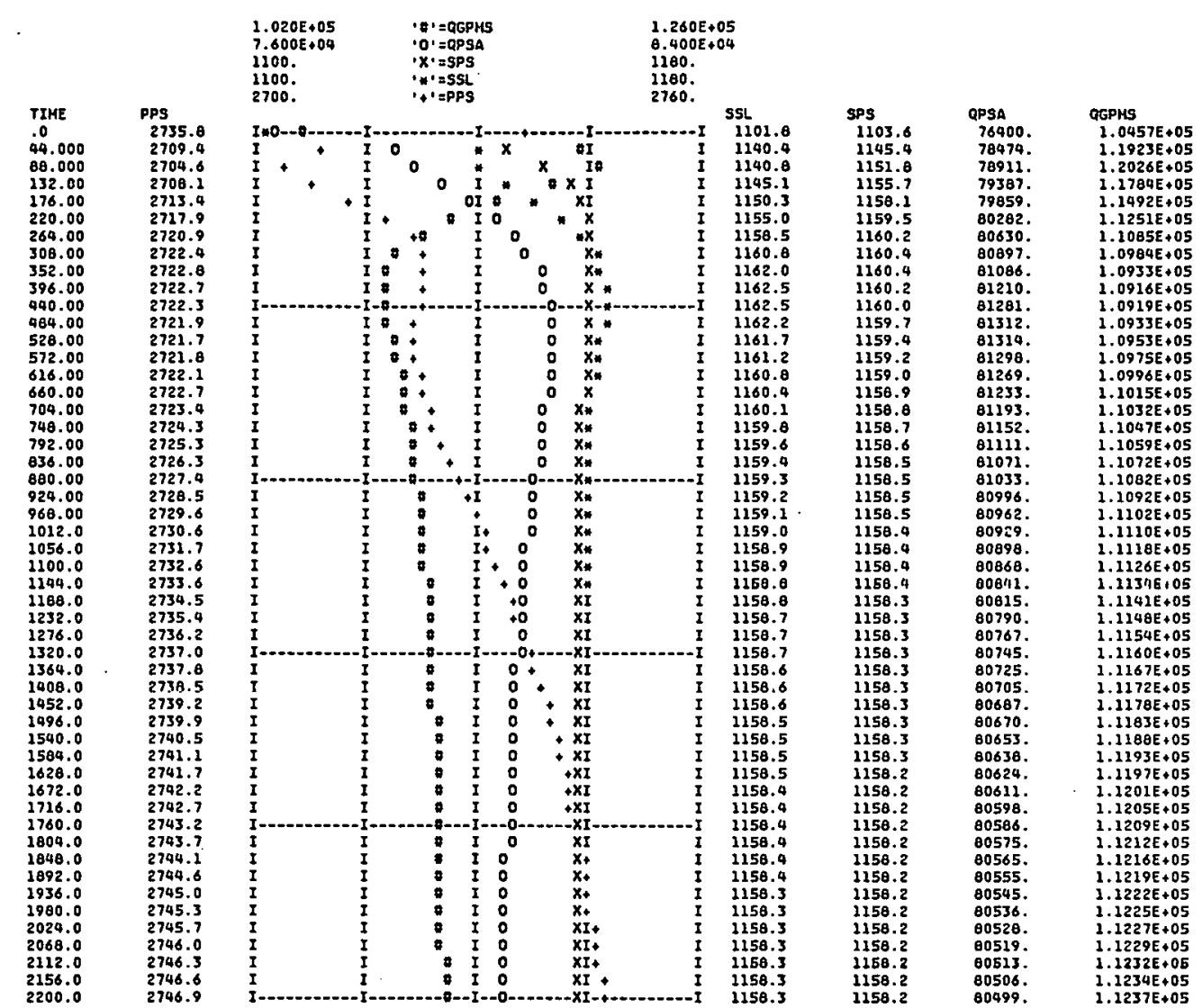

5 PERCENT STEP CHANGE IN UNIT LOAD

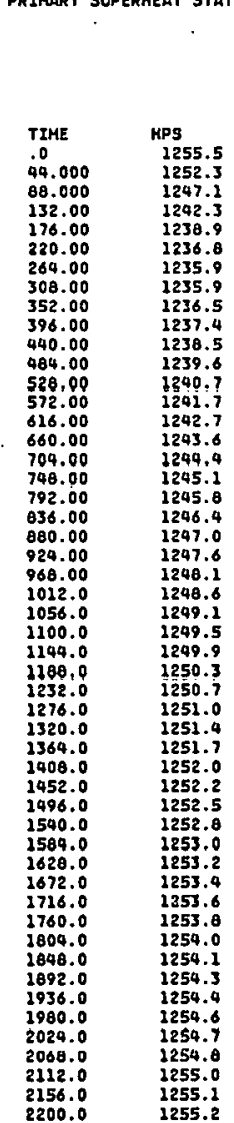
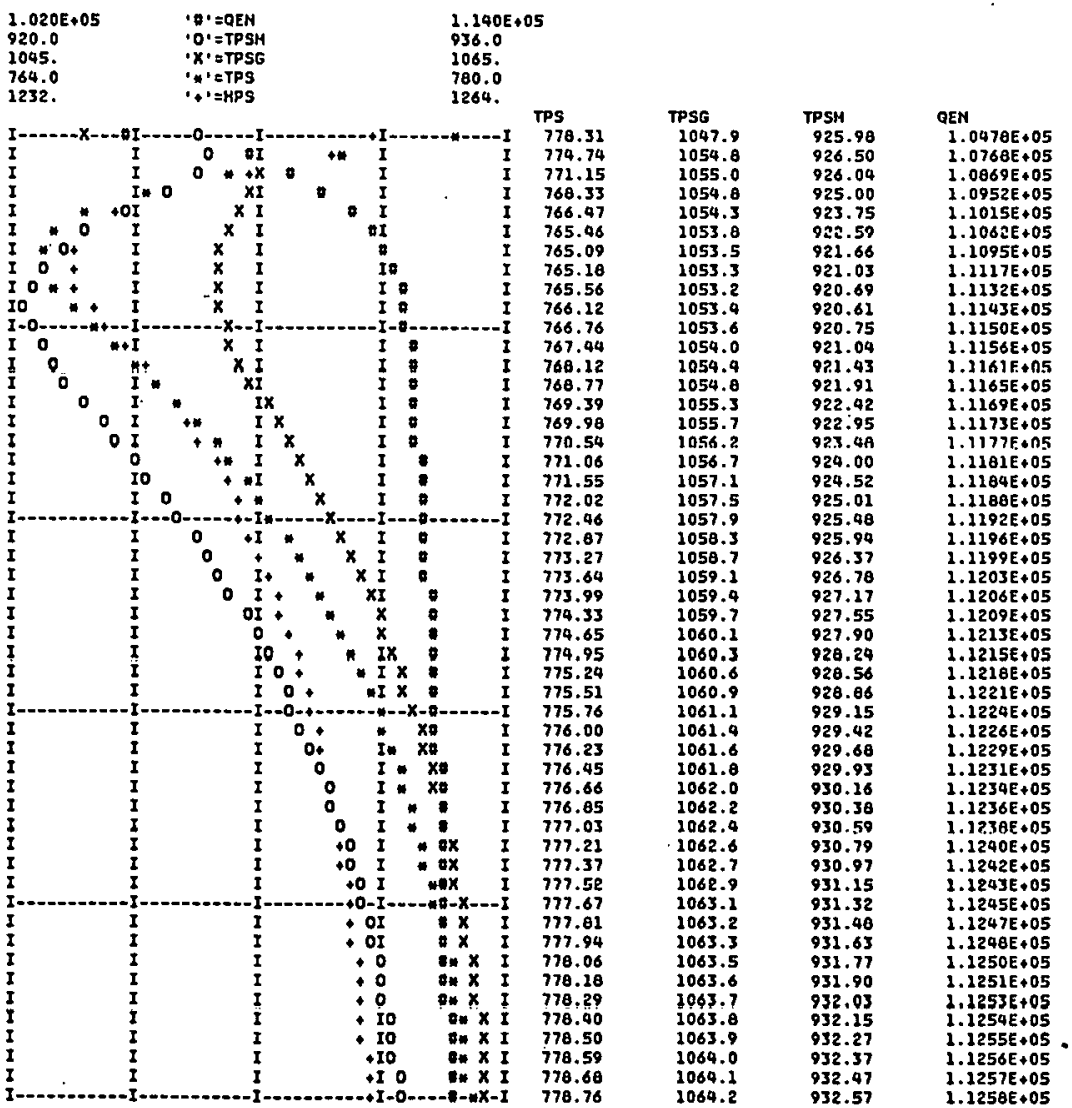
5 PERCENT STEP CHANGE IN UNIT LOAO

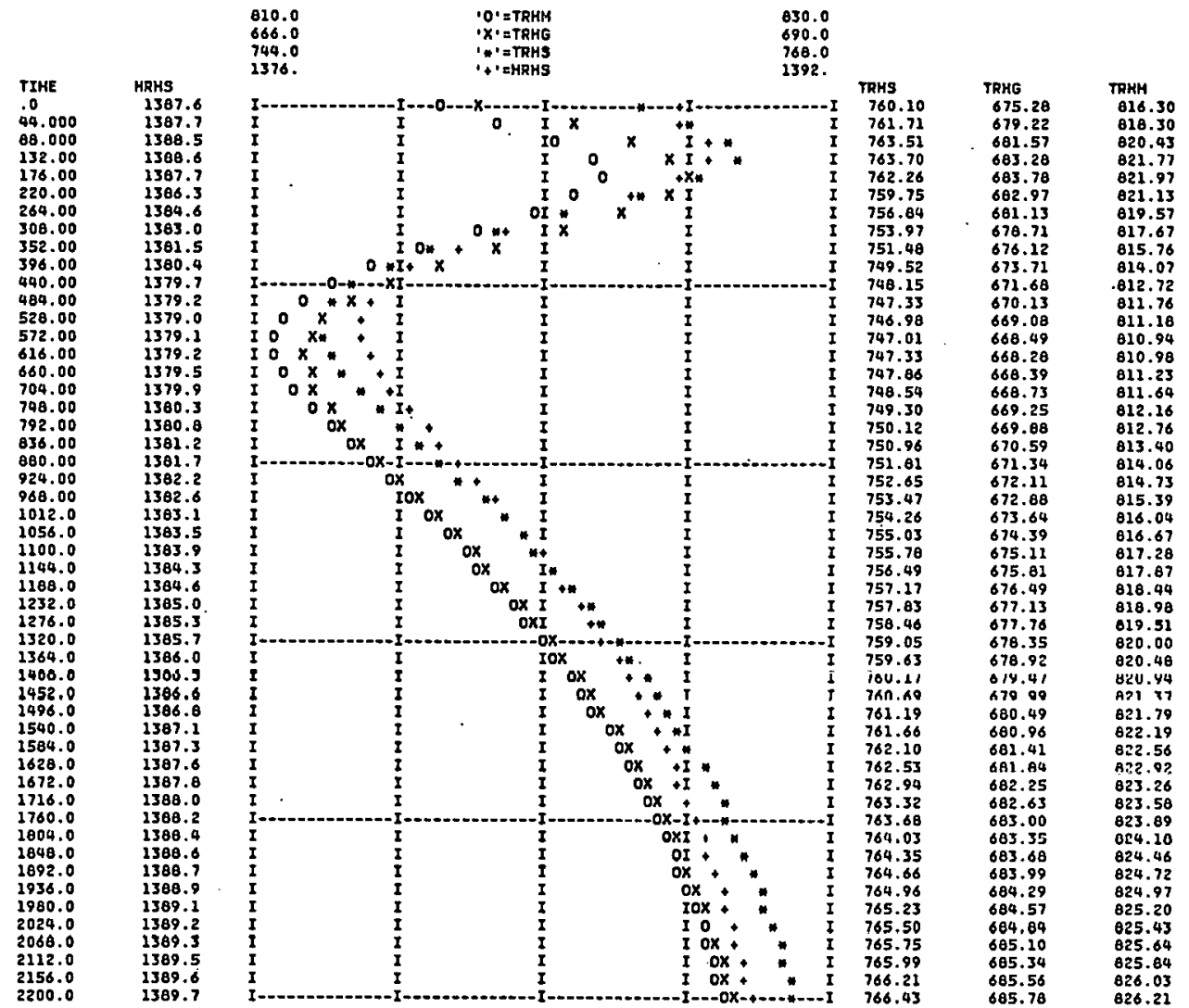

5 PERCENT STEP CHANEE IN UNIT LOAD ECONOMIZER STATES

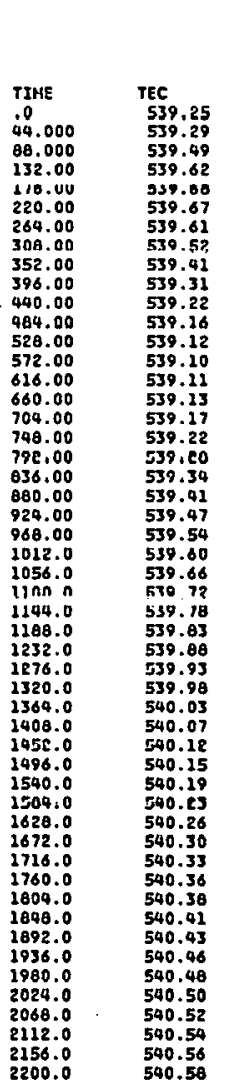
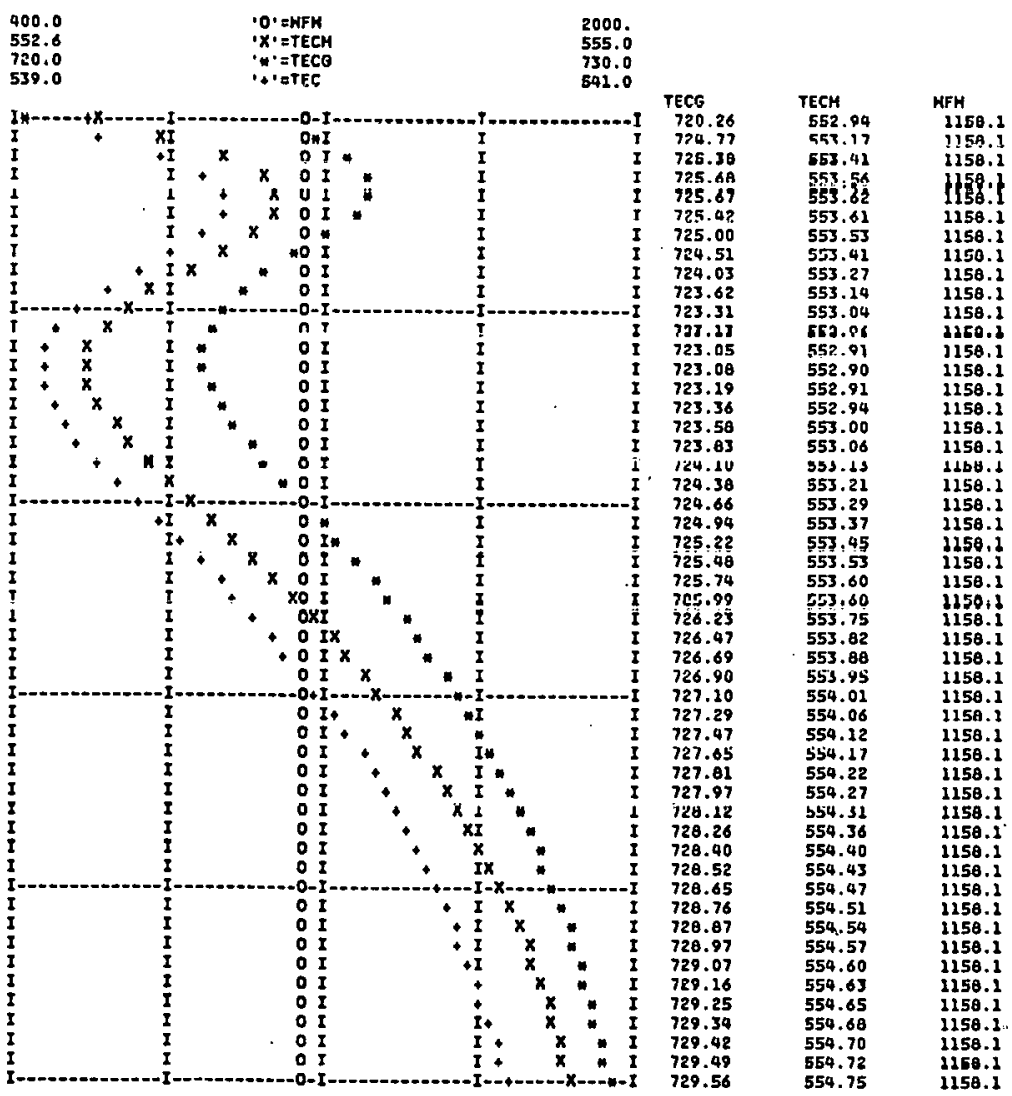


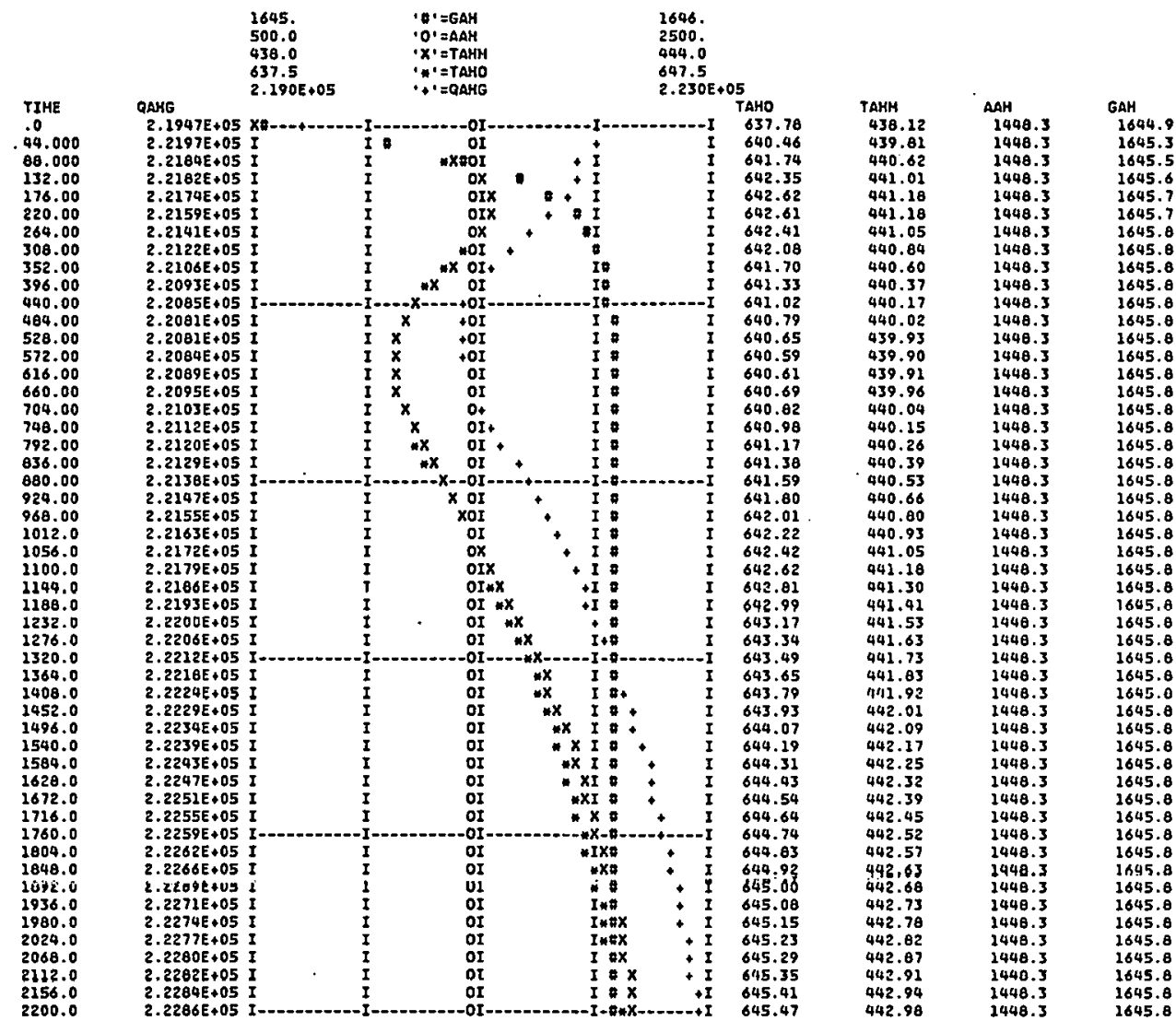

5 PERCENT STEP CHANGE IN UNIT LOAD

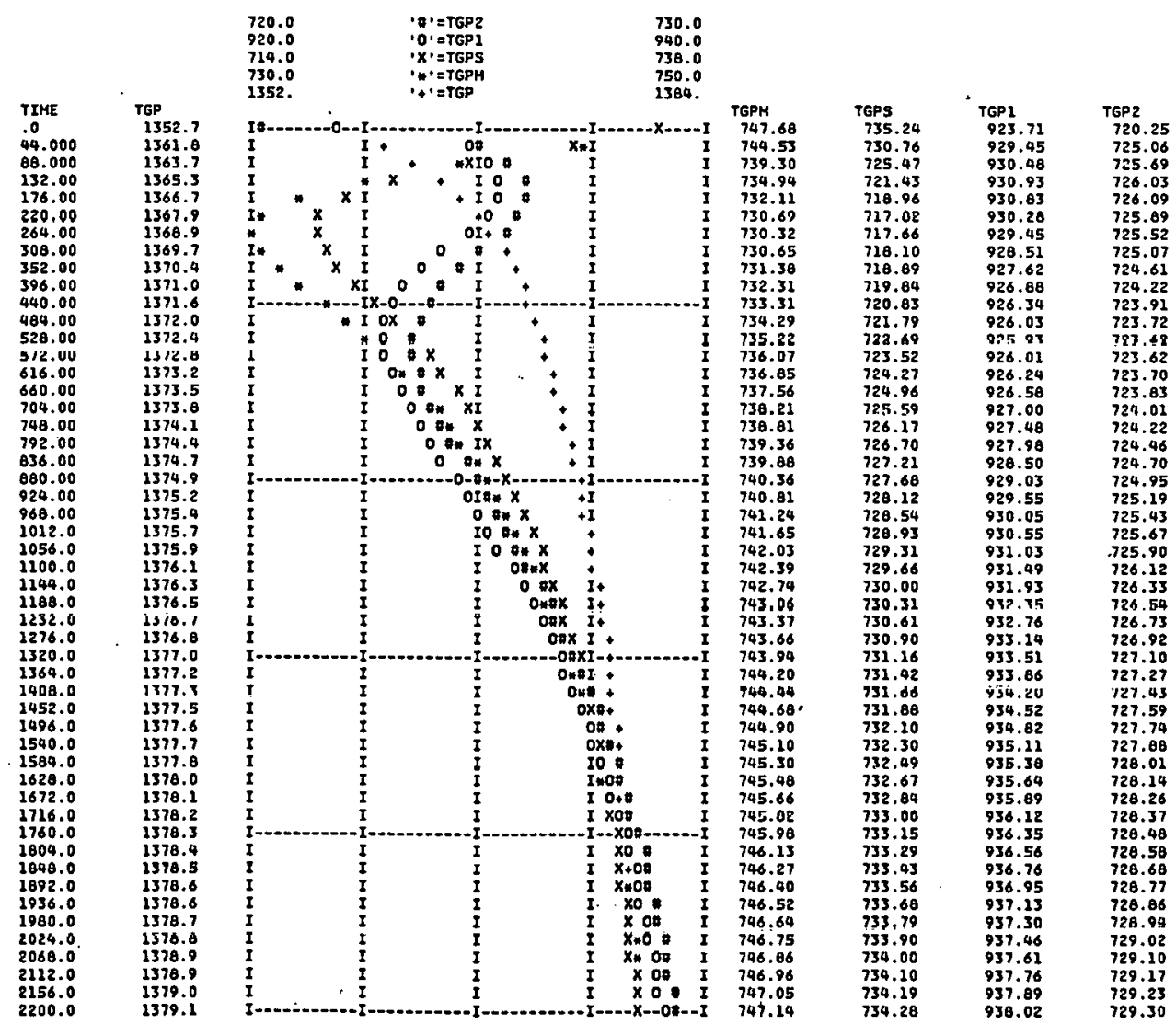


5 PERCENT STEP CHANGe IN UNIT LCAD

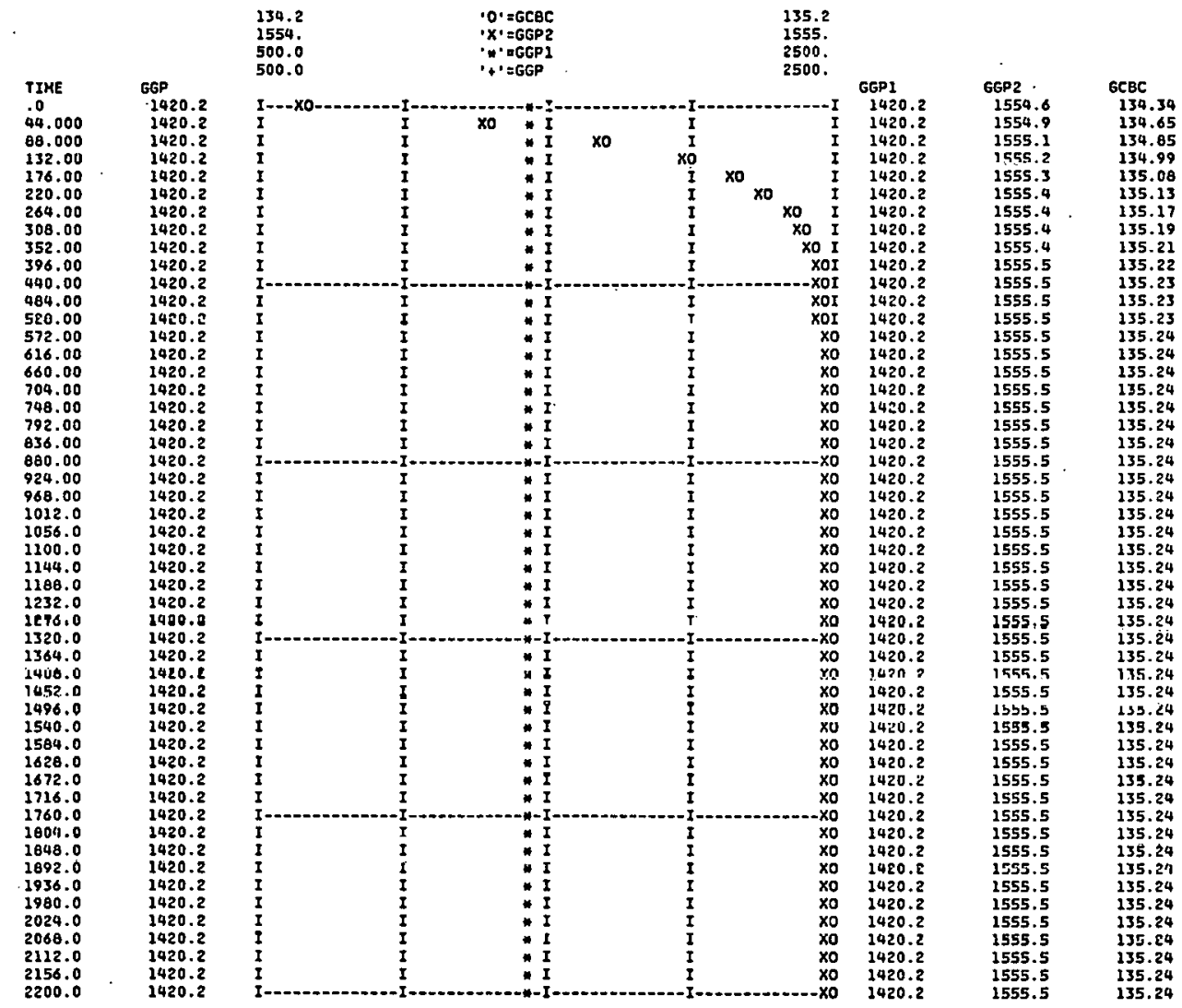

5 PERCENT STEP CHANGEE IN UNIT LOAD INTEGPATION TIHE PATTERH

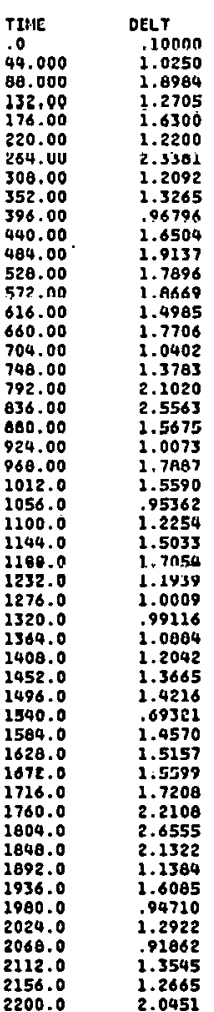

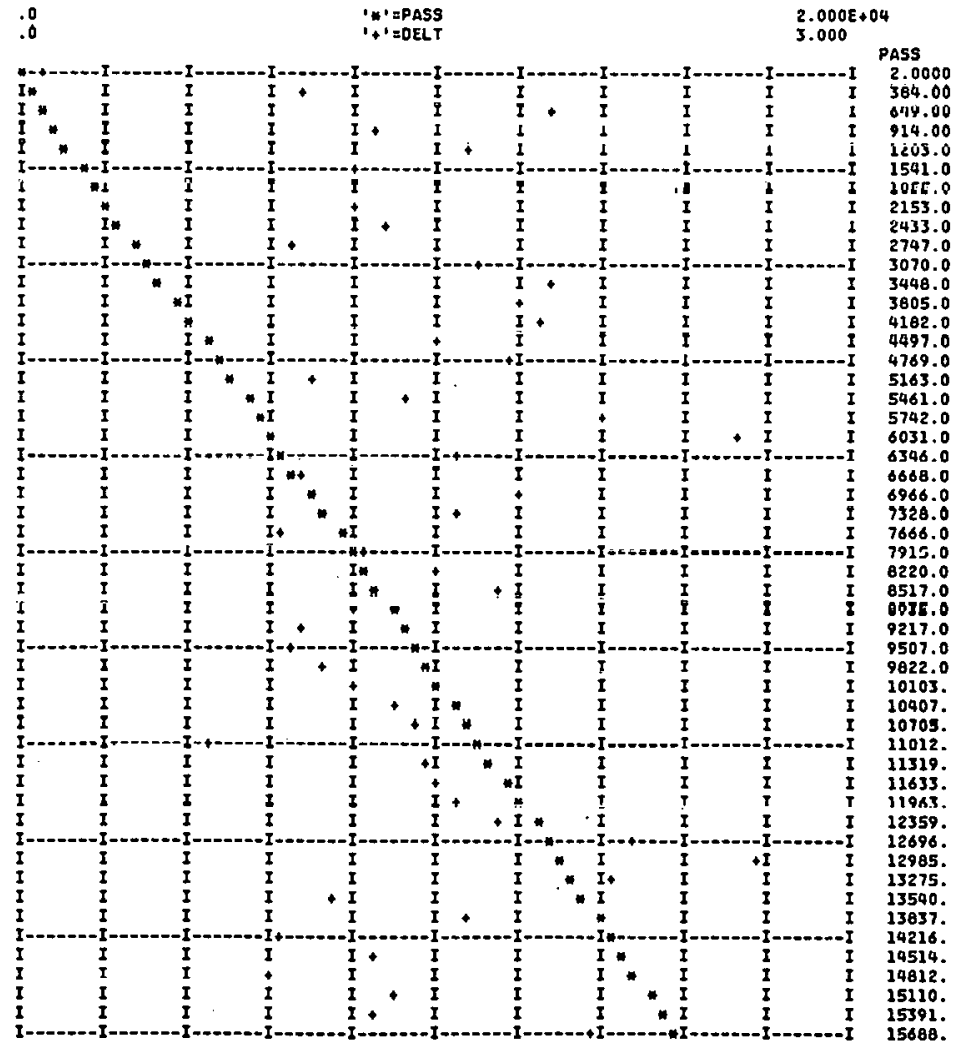


5 PERCENT STEP CHANGE IN UNIT LOAD

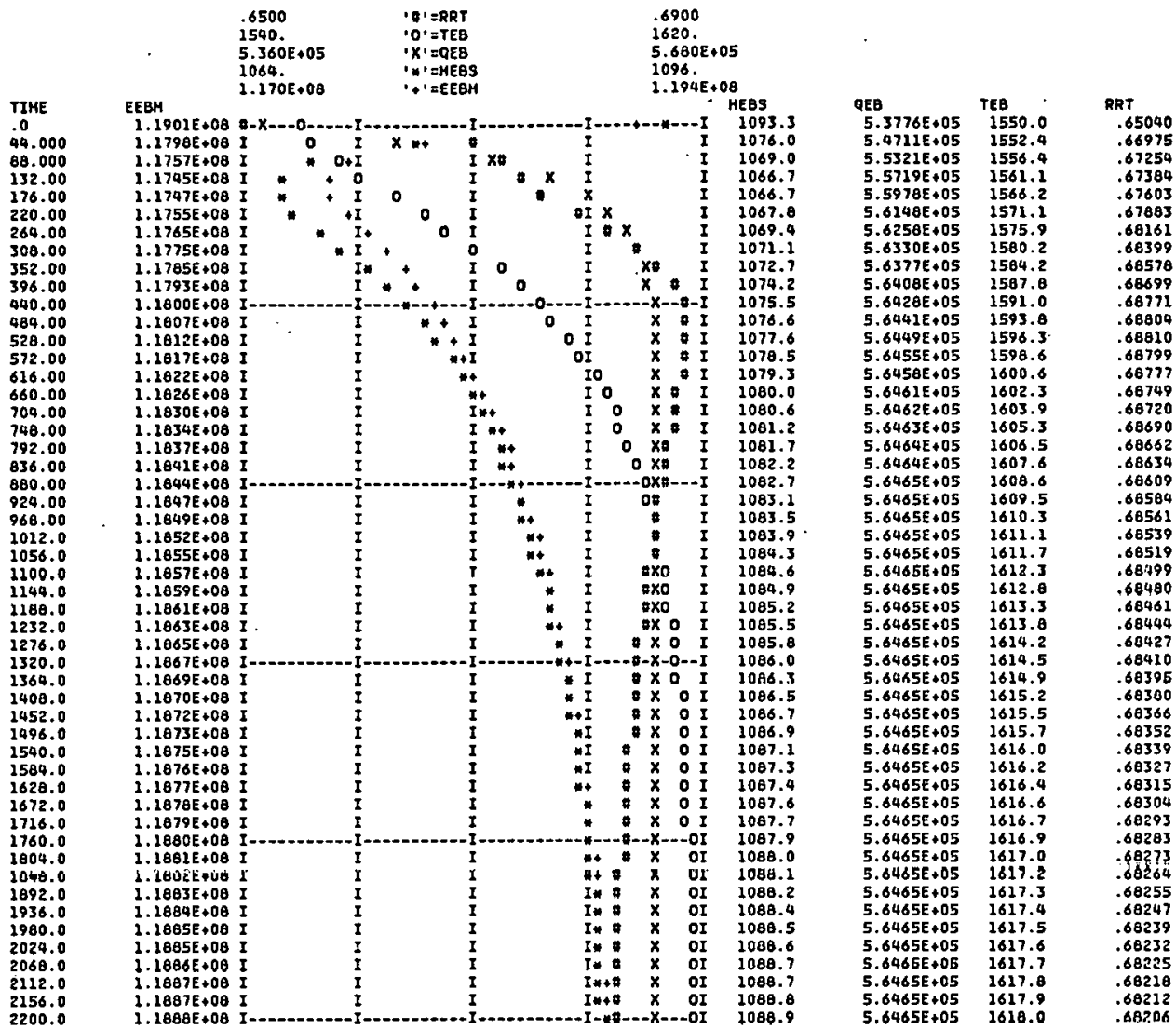

5 Percent step change in UNIT Load

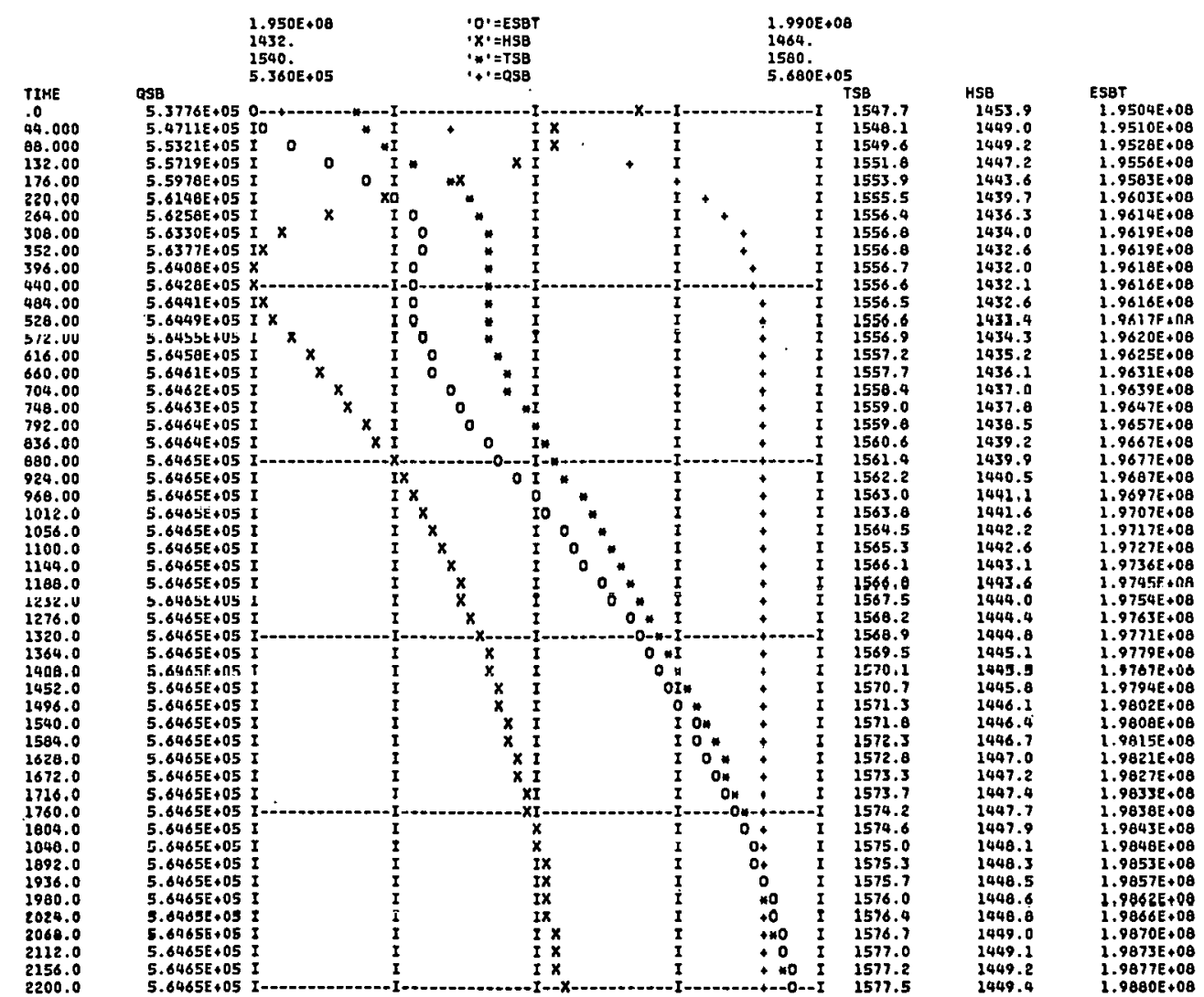




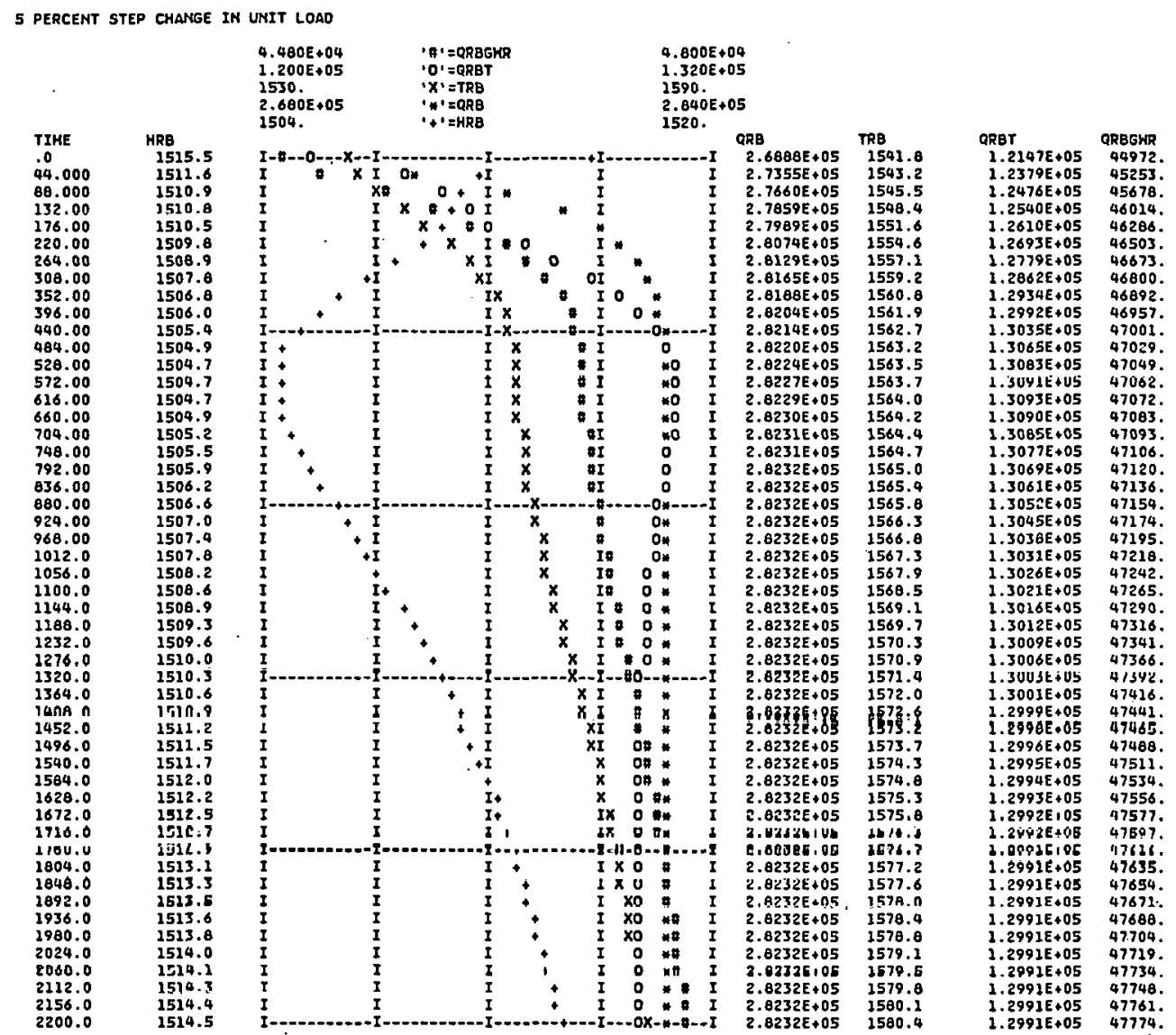

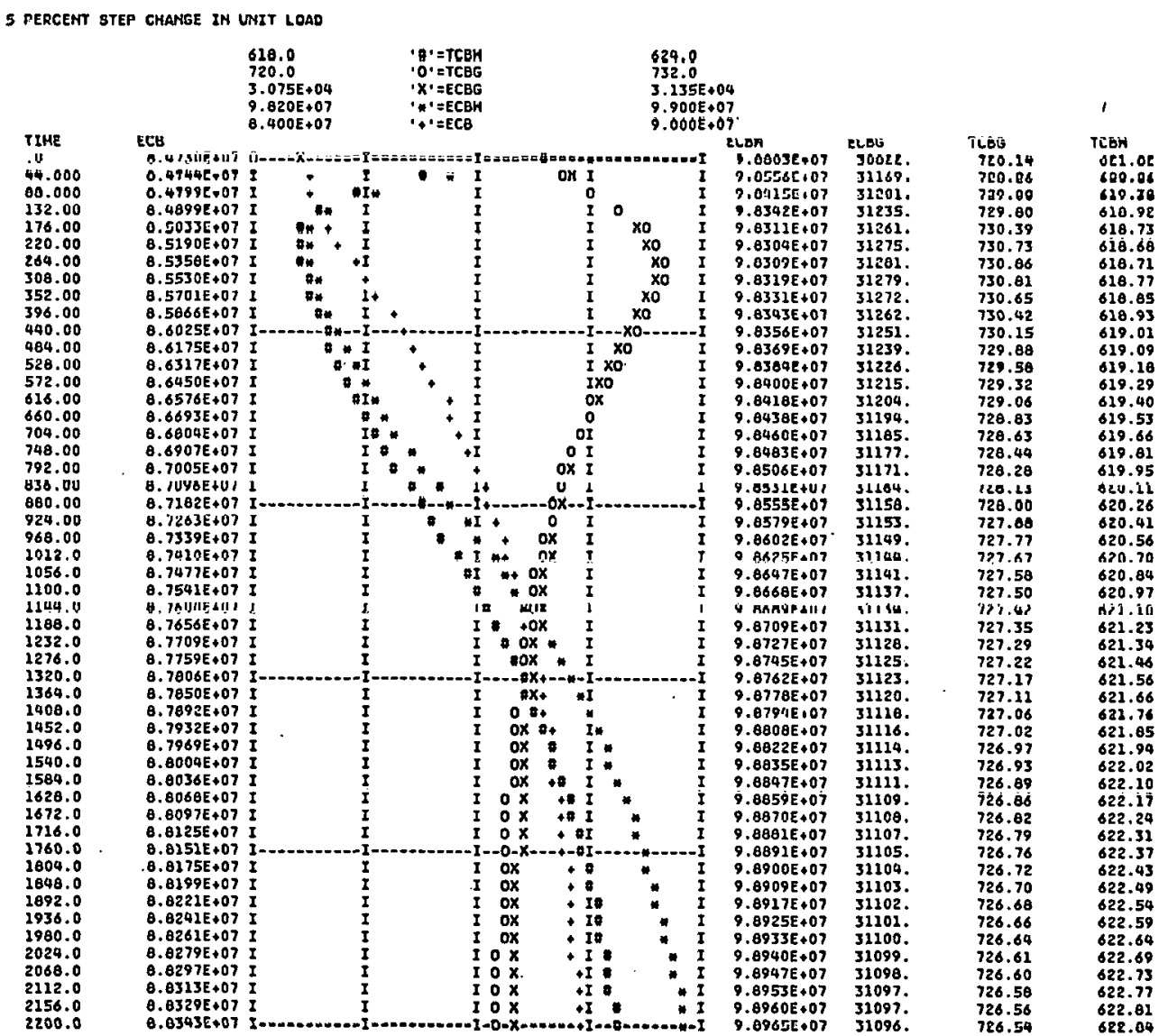


5 PERCENT STEP CHANGE IN UNIT LOAD

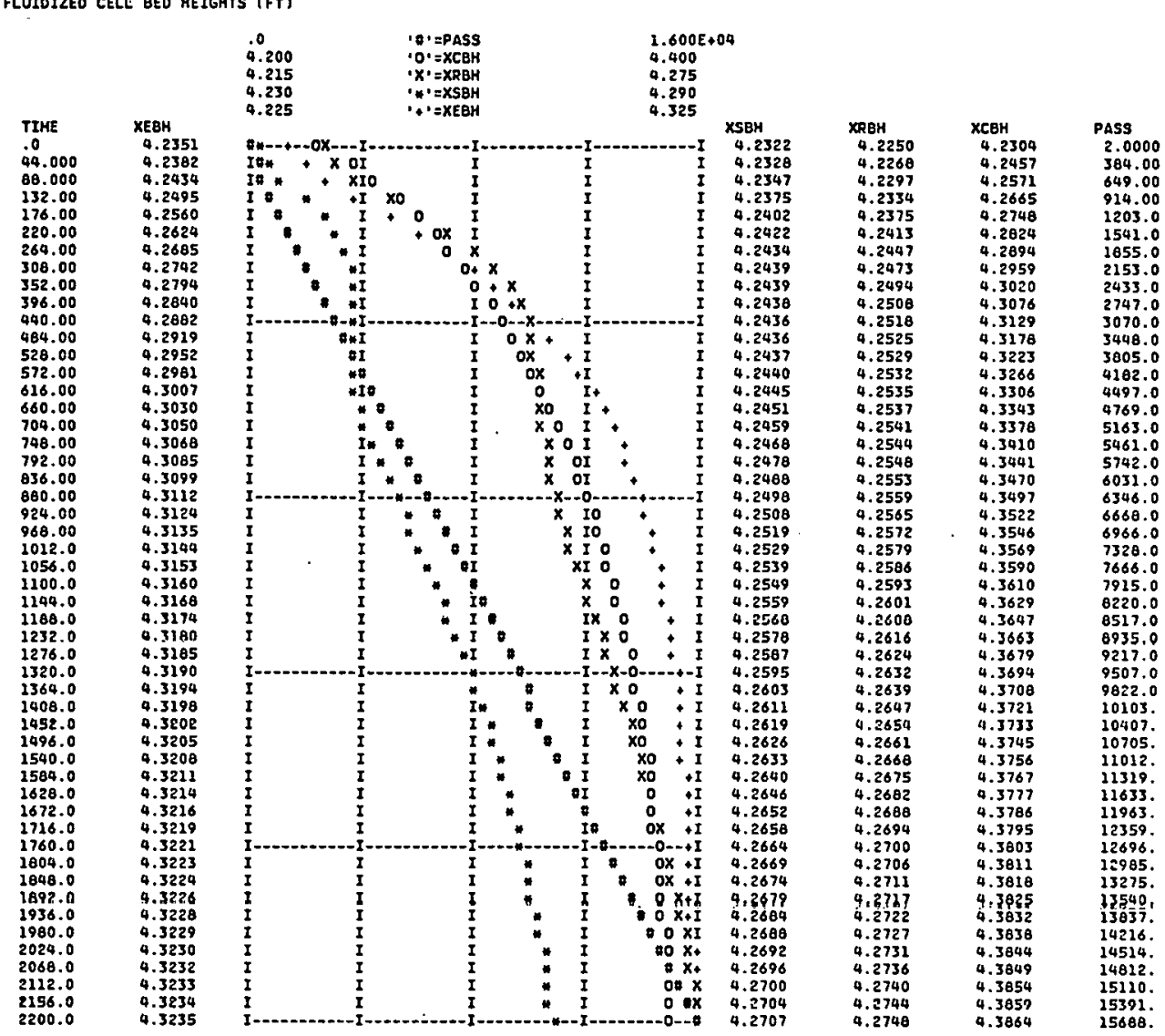

5 PERCENT STEP CHANGE IN UNIT LOAD

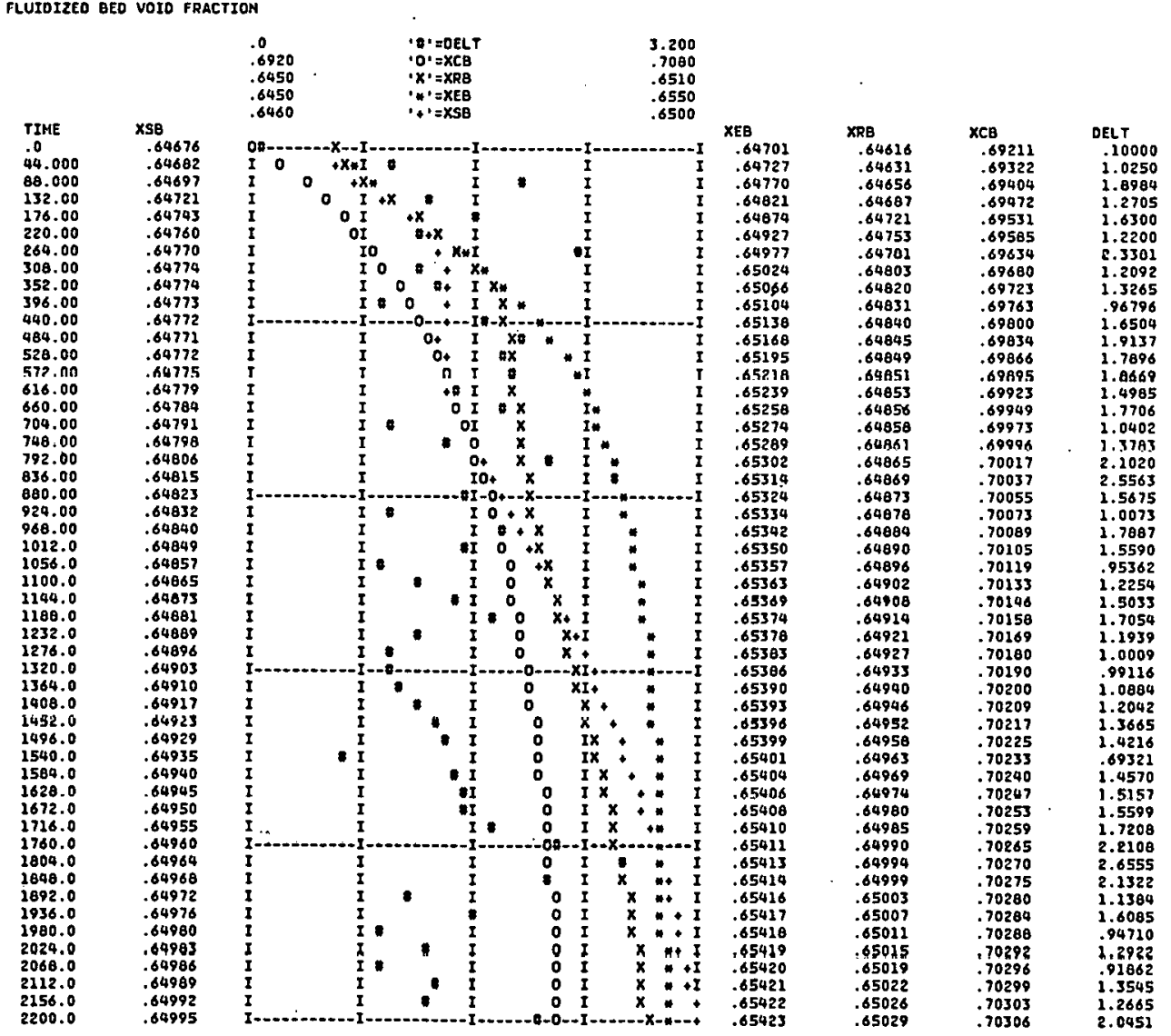




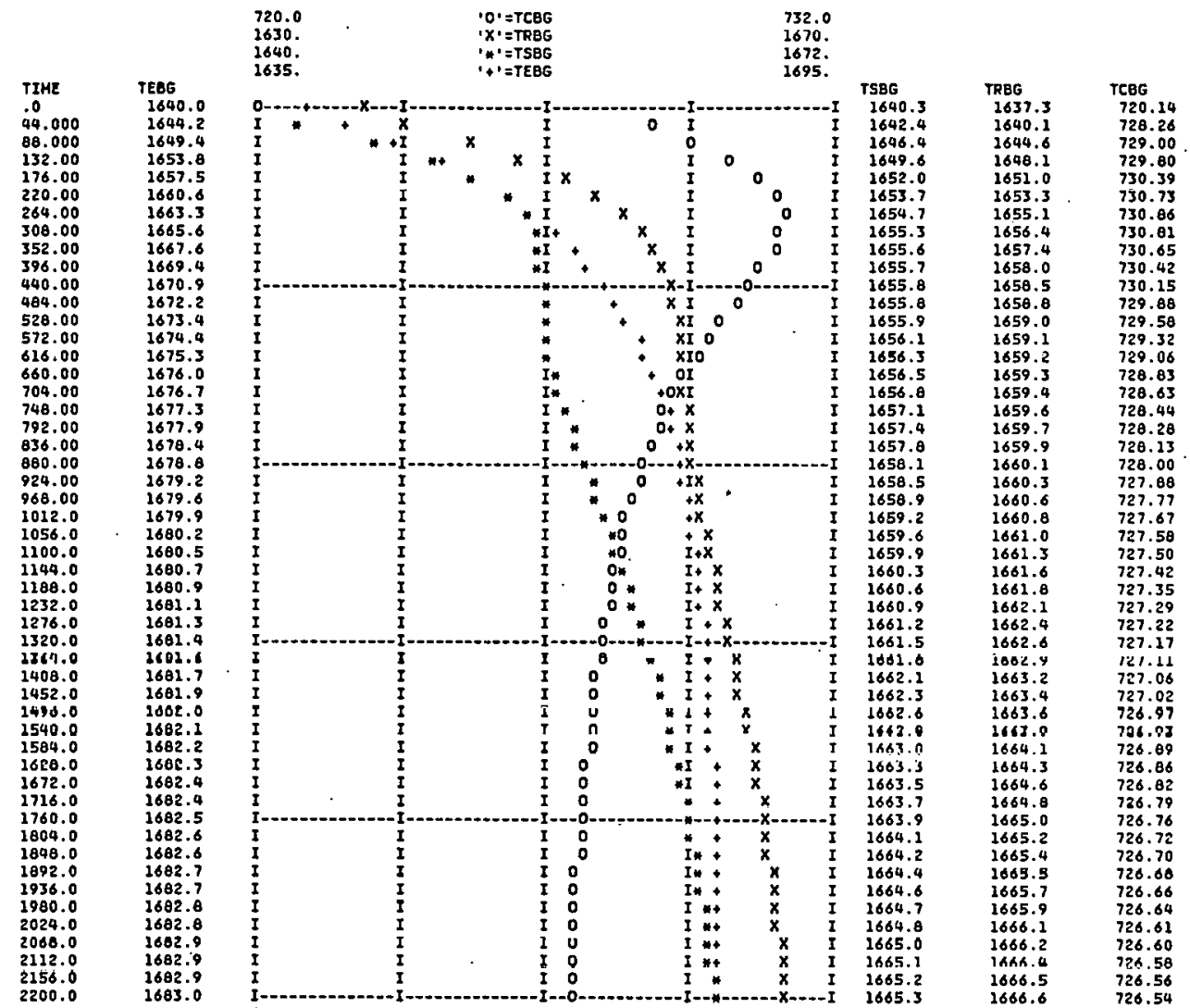

5 PERCENT STEP CHAKGE IN UNIT LOAO

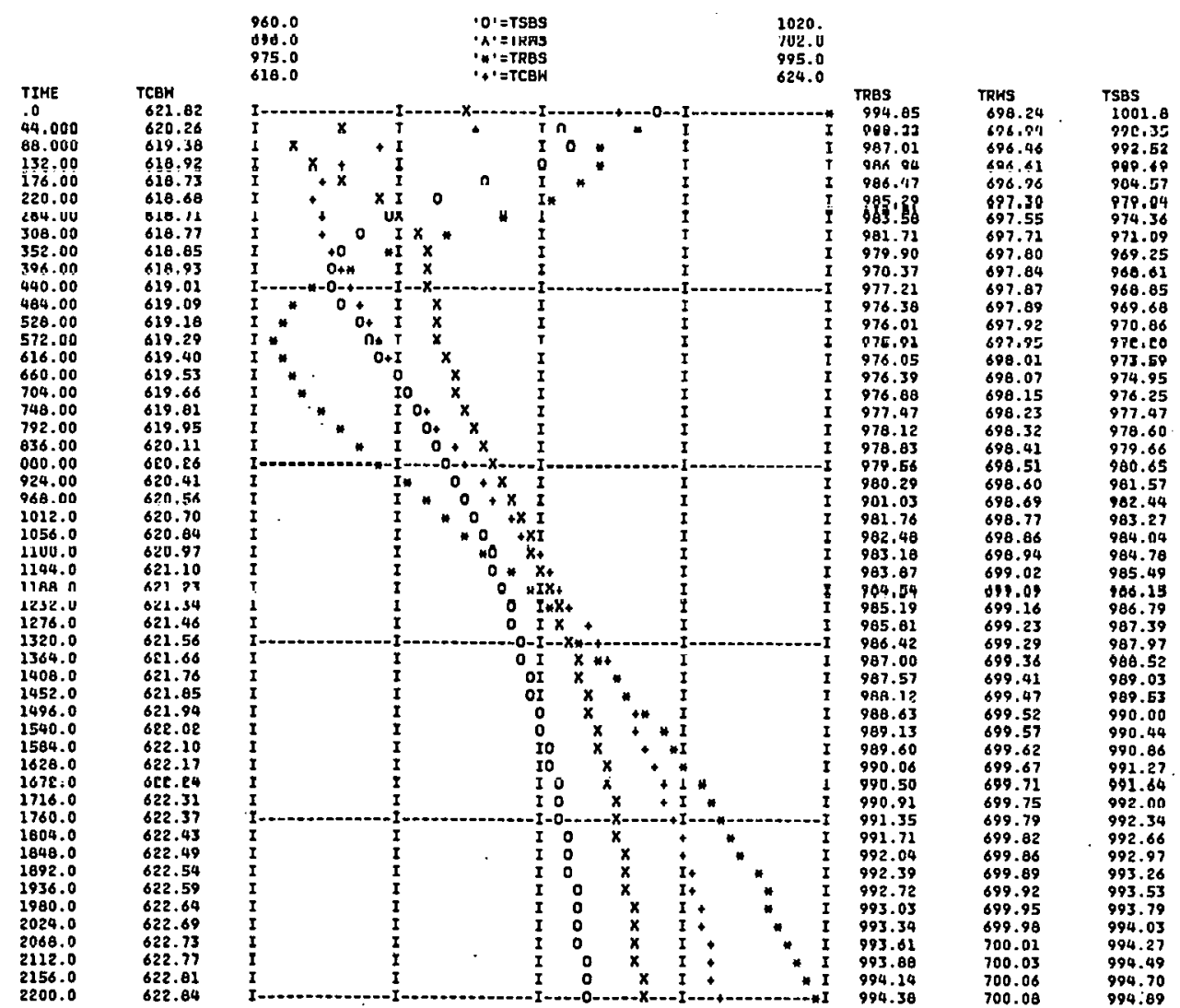


5 PERCENT STEP CHANGE IN UNIT LOAD

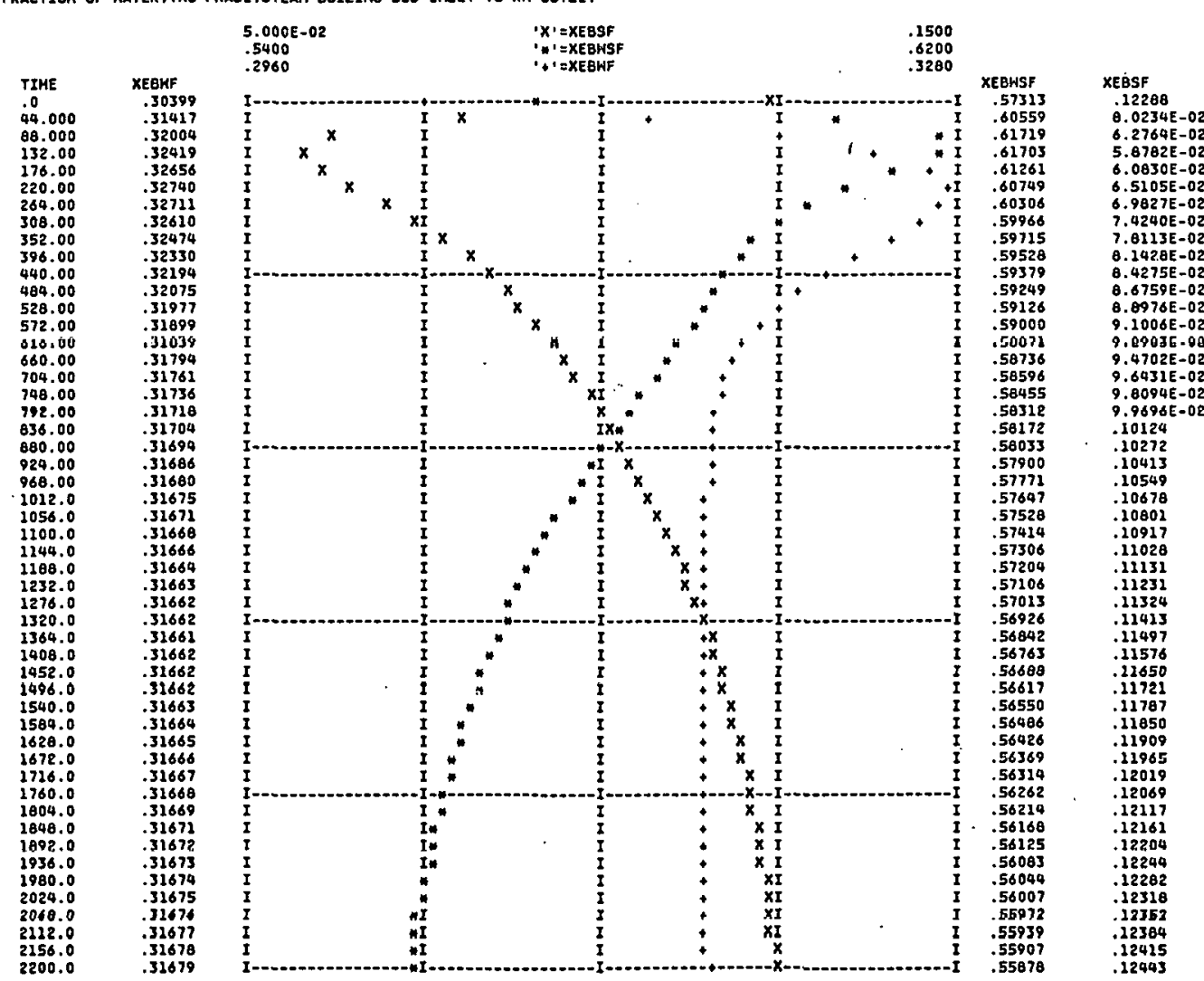




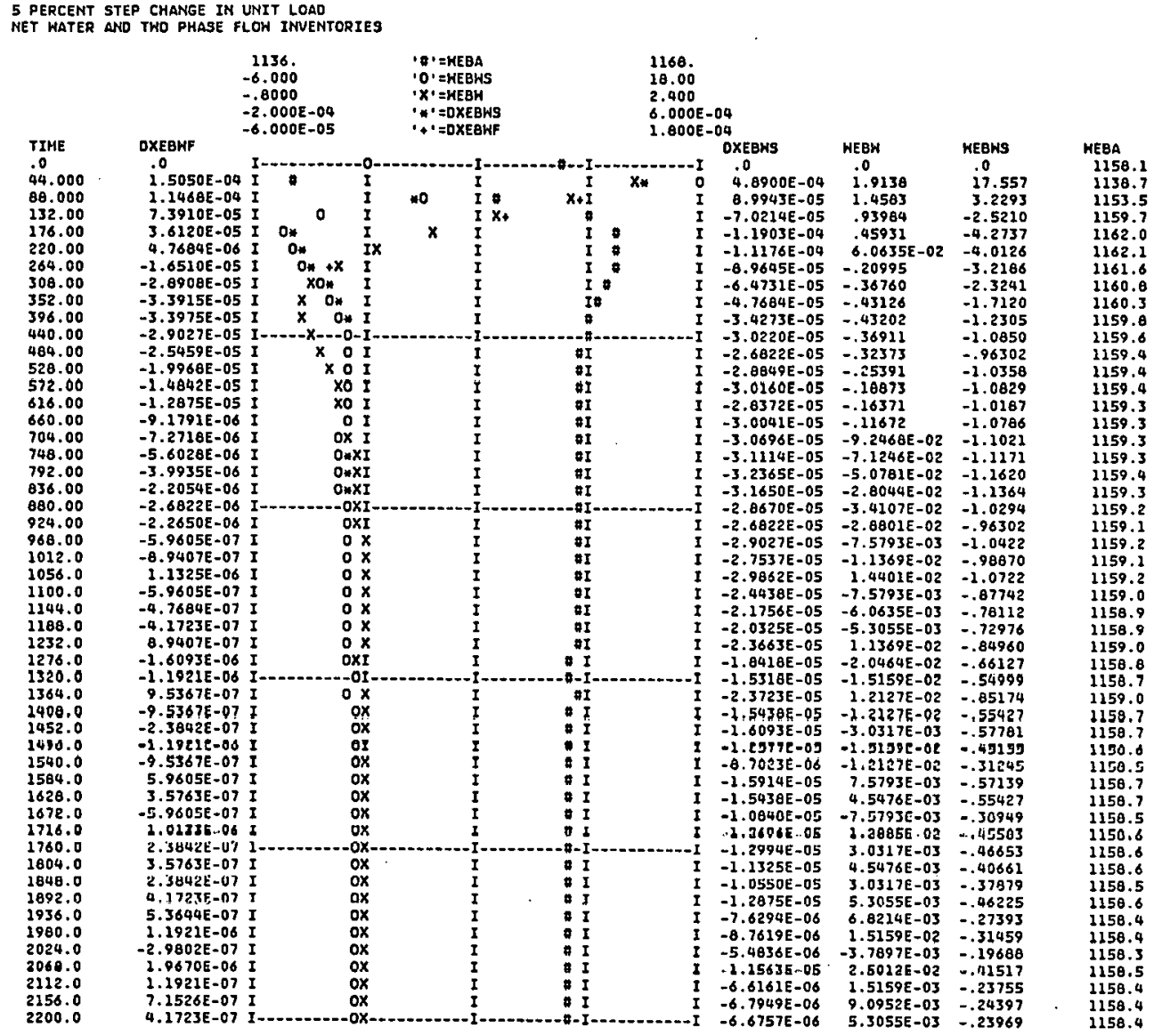

5 PERTERT STFP THANGF IN UNTT I RAO

PRESSURES IM BOILINE, SUPEPHEAT AND REMEAT OEOS

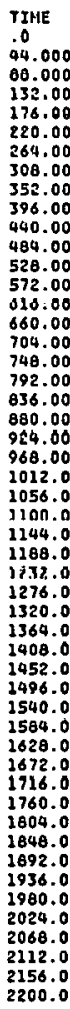
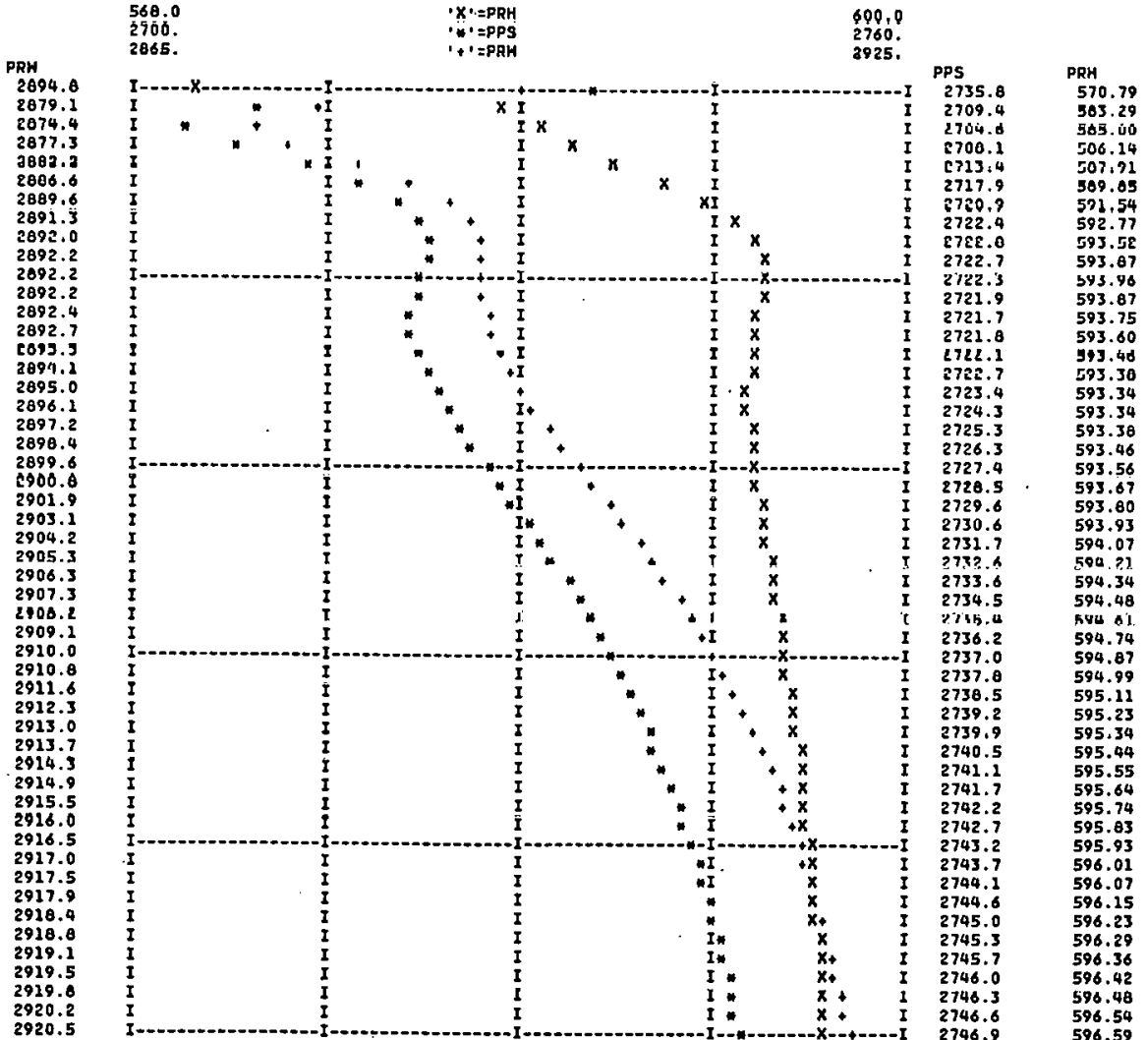


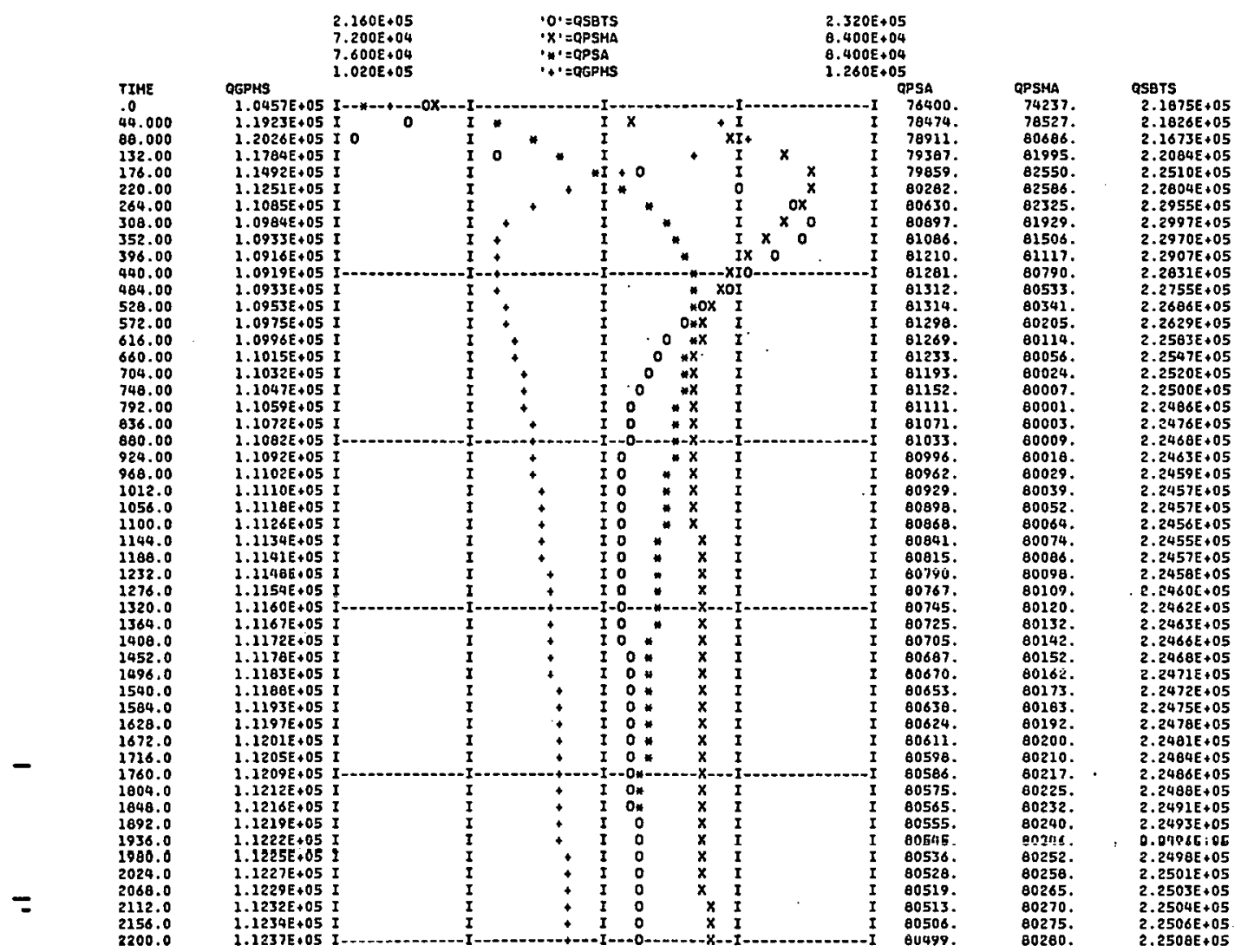

5 Percent step change in UNIT Load

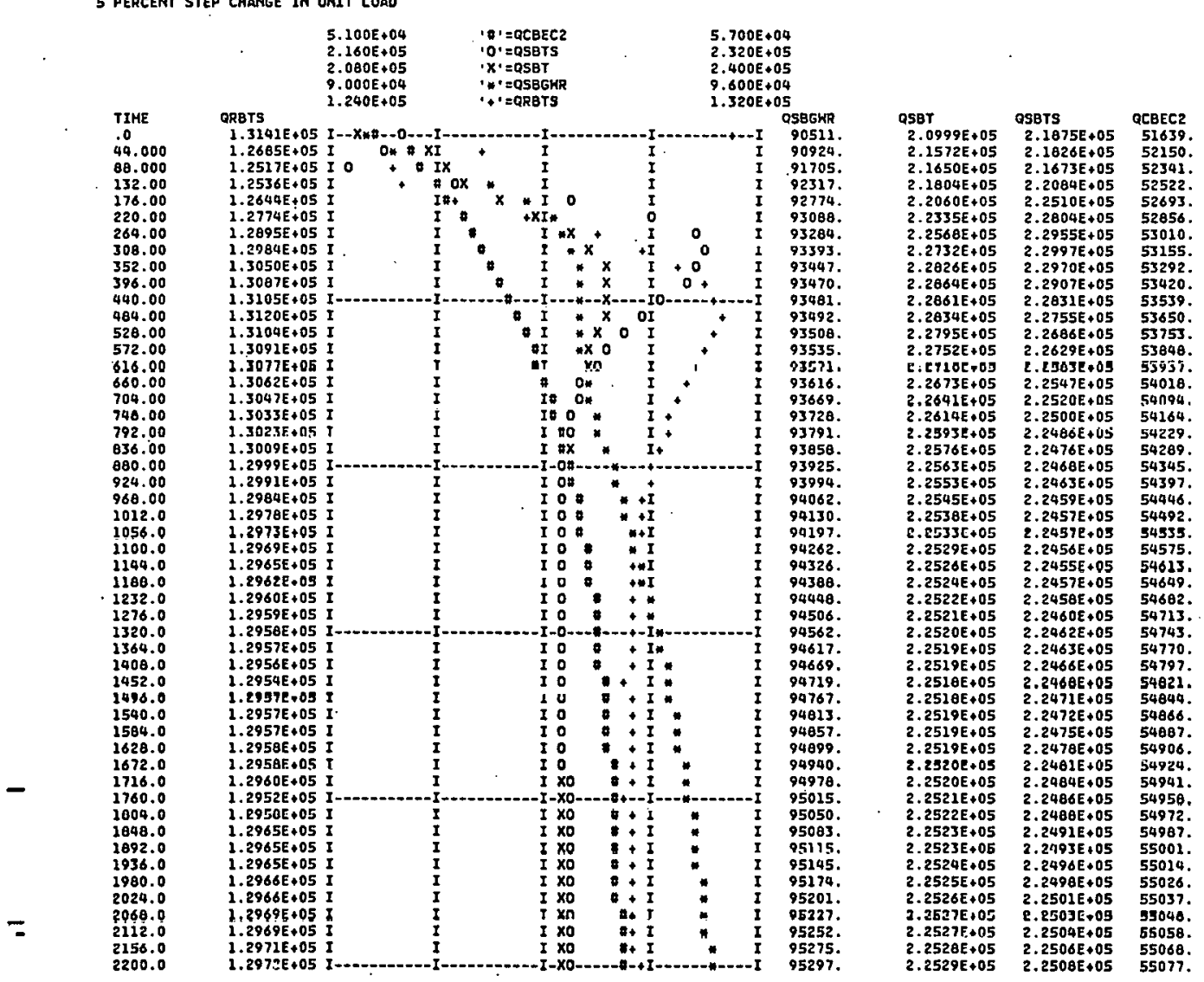

